OAK

RIDGE

NATIONAL

LABORATORY

UNION

CARBIDE

\section{An Evaluation of the Long-Term Energy Analysis Program Used for the 1978 EIA Administrator's Report to Congress}

\author{
R. W. Peelle \\ C. R. Weisbin \\ R. G. Alsmiller, Jr.
}

ORNL --5741

DE82 013361
OPERATED BY

UNION CARBIDE CORPORATION FOR THE UNITED STATES DEPARTMENT OF ENERGY 


\section{DISCLAIMER}

This report was prepared as an account of work sponsored by an agency of the United States Government. Neither the United States Government nor any agency Thereof, nor any of their employees, makes any warranty, express or implied, or assumes any legal liability or responsibility for the accuracy, completeness, or usefulness of any information, apparatus, product, or process disclosed, or represents that its use would not infringe privately owned rights. Reference herein to any specific commercial product, process, or service by trade name, trademark, manufacturer, or otherwise does not necessarily constitute or imply its endorsement, recommendation, or favoring by the United States Government or any agency thereof. The views and opinions of authors expressed herein do not necessarily state or reflect those of the United States Government or any agency thereof. 


\section{DISCLAIMER}

Portions of this document may be illegible in electronic image products. Images are produced from the best available original document. 


\section{Printed in the United States of America. Available from National Technical Information Service \\ U.S. Department of Commerce 5285 Port Royal Road, Springfield, Virginia 22161 NTIS price codes-Printed Copy: A13 Microfiche A01}

This report was prepared as an account of work sponsored by an agency of the United States Government. Neither the U nited States Government nor any agency thereof, nor any of their employees, makes any warranty, express or implied, or assumes any legal liability or responsibility for the accuracy, completeness, or usefulness of any information, apparatus, product, or process disclosed, or represents that its use would not infringe privately owned rights. Reference herein to any specific commercial product, process, or service by trade name, trademark, manufacturer, or otherwise, does not necessarily constitute or imply its endorsement, recommendation, or favoring by the United States Government or any agency thereof. The views and opinions of authors expressed herein do not necessarily state or reflect those of the United States Government or any agency thereof. 
Protide

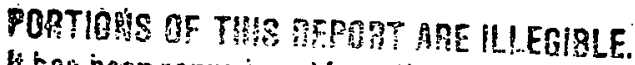

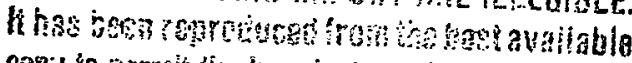

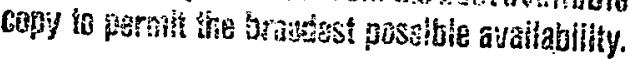

ORNL-5741

Special

Contract No. W-7405-eng $=26$

Engineering Physics Division

Energy Division

Computer Sciences Division

\section{AN EVALdATION OP THB LONG-TERX ENBBgY ANALYSIS PBOGRA}

USED FOR THE 1978 BIA ADIINISTRATOR'S REPORT TO CONGRESS
R. W. Pee11e*
C. R. Weisbin

R. G. Alsmiller, Jr.

Including Contributions by:

J. Barish

M. Becker**

J. Drischler

W. E. Ford, III

M. Goldstein

J. Hansen***

L. Hi11
J. Horwede 1

J. Lucius

B. F. Maskewitz

J. McAdoo

E. Oblow

L. Stewart

J. Trimble

Date Published: October 1981

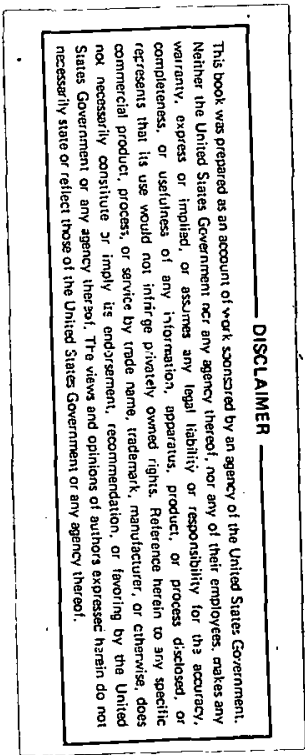

This Work Sponsored by

Department of Energy

Office of Energy Information Validation

OAK RIDGE NATIONAL LABORATORY

Oak Ridge, Tennessee $\mathbf{3 7 8 3 0}$

Operated by

UNION CARBIDE CORPORATION

for the

DEPARTMENT OF ENERGY

*The principal authors are responsible for the selection

of conclusions and recommendations in this report

** Rensse1aer Polytechnic Institute, Troy, New York

*** Charles River Associates, Boston, Massachusetts 
THIS PAGE ,

WAS INTENTIONALLY
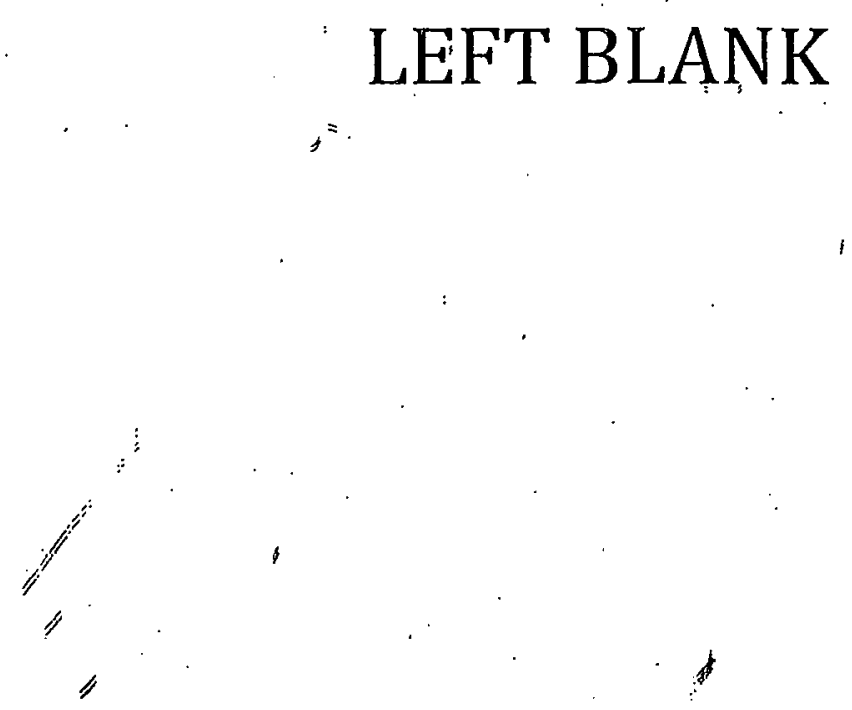


\section{TABLE OF CONTENTS}

Executive Summary

$\underline{\text { Page }}$

Abstract

vii

I. Introduction I-1

II. An Overview of the 1978 LEAP Mode1 II-1

A. The Conceptual Framework of ErA's Long-Term Energy Analysis Program (LEAP)

B. The 1978 ARC Version of EIA's Long-Term Energy Analysis Program

Definition of Mode1 22C

xxiii

The Network

The Process Submodels

The Parameter Input Data

II-1

II-5

II-5

II-6

II-9

II-12

III. Mode1 Results of Interest to Users of LEAP Mode1 22C III-1

A. Information Sources Used in Response Definition III-1

Statements of Statutory Goals III-2

Emphasis in the EIA Annual Report to Congress III-3

Interviews with Specific Users Outside EIA III-4

Insight of the Modeler

III-6

B. Selected Responses and Accuracy Targets III-7

IV. Documentation and Its Adequacy IV-1

A. Documentation by LEAP Modelers IV-1

B. Documentation Aids from the Evaluation Effort IV-4

C. Documentation of the Evolving LEAP System IV-5

D. Conclusions and Recommendations on Documentation IV-9

v. Operating Experience from the Computer Analyst's Perspective

A. Precise Definition of the Model

B. Mode1 Access and Assessment of Mode1 Transportability

C. Generation of Sample Problems

D. Cost, Computer Time, and Learning Investment to Operate LEAP-78

$\mathrm{V}-1$

$\mathrm{V}-1$

$\mathrm{V}-2$

$\mathrm{V}-2$

$\mathrm{V}-3$

E. Review of Plan for Continued Maintenance V-4

F. Experience in Obtaining Solutions and Replicating Results

$v-5$

G. Conclusions

$\mathrm{V}-7$

VI. Adequacy of Numerical Techniques VI-1

A. Introduction

VI-1

B. Convergence Tests VI-3

C. Relaxation VI-5

D. Uniqueness VI-6

E. Conc1usions VI-9 
VII. Economic Foundations VII-1

A. Major Assumptions and Basis of LEAP Mode1 22C VII-2

1. Conversion Process VII-2

a. As sumptions VII-2

b. Investment VII-5

c. Technical Change V.II-10

d. Illustrative Mode1 22C Conversion Process Numerical Values. VII-11

2. Resource Extraction Process VII-15

3. Allocation Process VII-17

4. Fina1 Demand Process VII-21

B. Comparison of Selected LEAP Model 22C Results with Independent Data

c. Comparison with Alternative Models and Consequent Domain of Applicability

D. Summary and Recommendations VII-33

VIII. LEAP-78 Computer Program Verification VIII-1

A. Consistency of the LEAP-78 Computer Program with
the Existing Documentation VIII-1

B. Communication of Input Parameter Values to the Process Submode1s vIII-3

C. Were Model 22C Output Data Compiled for Publication as Intended?

D. Conclusions on LEAP-78 Verification , VIII-7

IX. The Sensitivity of Important Mode1 22C Resilts to Input Parameter Changes

A. Sensitivities of Mode1 22C Responses to Some

Coupled Parameter Changes

Method

VII-23

Effects of Some Parameter Alterations Sensitivity Coeficients for Coupled Parameter Changes

Conclusions from Rerun Sensitivity'Studies

IX-1

IX-2

IX -2

$\mathrm{IX}-3$

IX-8

IX -25

B. First-Order Sensitivities Obtained Using Adjoint

Sensitivity Theory

IX -27

Me thodology

Results and Discussion. . IX-29

Response 1 IX-33

Response 2 IX -39

Response $3 \quad$ IX-46

Response 4 IX -50

Conc1usion from Adjoint Sensitivity Studies IX-55

X. The Mode1 Parameters for LEAP Mode1 22C . $X-1$

A. C1assification of the Mode1 22C Input Parameters X-1

B. Modeler's Method for Meeting Mode1 22C Input Data Requirements $\quad x-3$

C. Precision of Parameter Definition $X-5$

D. Traceability of Input Data to Its Original Source X-6 
E. Mode1 22C Data Qua1ity and Uncertainty X-8

Data Quality. $\quad X-8$

Data Uncertainty . X

F. Conclusions and Recommendations on Mode1 22C

XI. Conclusions and Recommendations XI-1

A. The Effect of Input Data Uncertainty on LEAP

B. Principal Strengths and Weaknesses of LEAP-78 and Mode1 22C XI-4

Usability . XI-4

Understandability XI-6

Realism XI-7

Credibility XI-8

C. Consolidated Summary of Recommendations XI-8

Acknow ledgments

Comments of Jimmie L. Peterson, EIA

References

Appendixes

A. The 1978 LEAP Mode1 22 Network and Its

Interpretation

A-1

B. Explicit Definition of Important Mode1 Results

C. Definition of Group Parameter Changes for Direct

Sensitivity Stadies

B-1

C-1 


\section{THIS PAGE ,}

\section{WAS INTENTIONALLY}
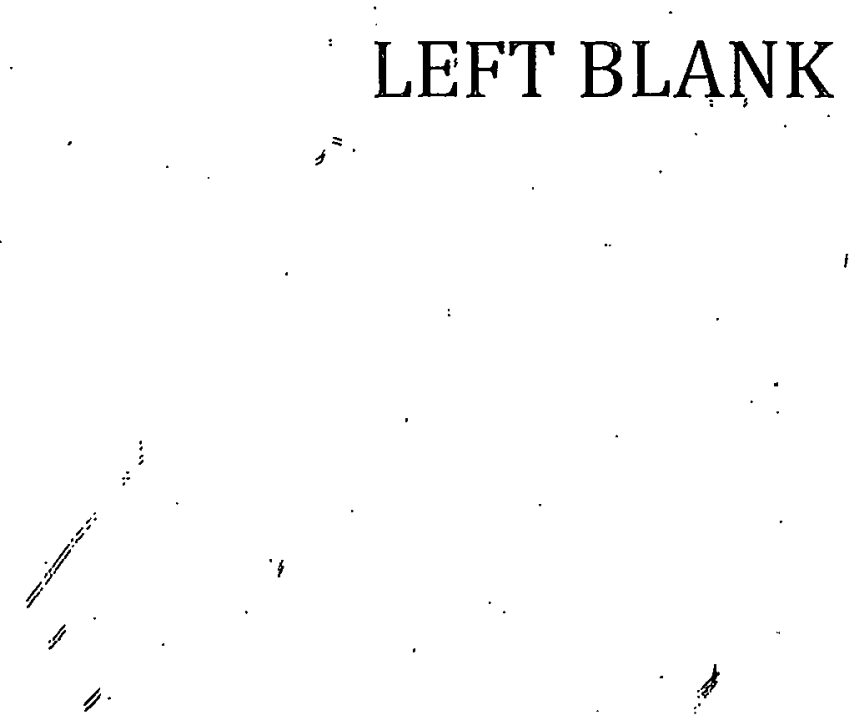


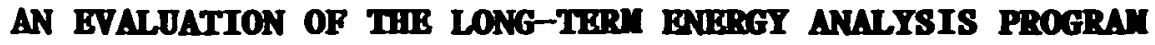 USED FOR THB 1978 BIA ADXINISTRATOR'S REPORT TO CONGRESS}

\section{EXRCUTIVE SUITART}

\section{A. Model Identification}

The Long-Term Energy Analysis Program (LEAP) is a computer modeling system that has been used by the Energy Information Administration (EIA) to develop the long-term (beyond 1995) projections of energy supply and demand that appear in the EIA Annual Report to Congress. The LEAP system consists of the LEAP computer code, including data editing and display systems, a data transfer system, and a data base storage system. The entire system was the responsibility of the Long-Term Energy Analysis Division (LTEAD) of the Integrative Analysis Office within the Office of Applied Analysis (OAA).* The particalar version of the model and data base used for the 1978 Annual Report to Congress (ARC-78) is known as Mode1 22C and was made available to Oak Ridge National Laboratory (ORNL) in June 1979. This model, representing the first published results using the LEAP system, was studied extensively at ORNL and forms the basis of our evaluation of LEAP. Through May 1981, the LEAP system has been maintained and used for projections in two more EIA Annual Reports to Congress (ARC-79 and ARC-80).

\section{B. Model Purpose}

\section{Statutory Requirenents}

The Department of Energy. (DOE) Organization Act (PL 95-91) designated the EIA to carry out some functions of predecessor agencies. Included therein is the Federal. Energy Administration (FEA) Act of 1974, as amended [PL 93-275, Sect. 57 (a)(2)], which states that an annual report must be submitted to Congress that includes (at 1east) projections of

\footnotetext{
*As this report is being written, EIA is in the process of reorganization.
} 
short-, medium-, and long-term energy consumption and supply trends and forecasts under various assumptions; and to the maximum extent practicable, a summary or schedule of the amounts of the mineral fuel resources, nonmineral energy resources and mineral fuels that can be brought to market at various prices and technologies and their relationship to forecasted demands.

Section 657 of the DOE Organization Act expands on this mandate with specific requirements for separate estimates of foreign and domestic energy supply and a breakdown of the energy supply provided by different sources.

\section{Role of LRAP}

LEAP was developed to meet the statutory requirements cited above with respect to energy supply and demand in the long term. The LEAP results are important because they reflect EIA's in-house capability to explicitly analyze long-run issues related to (1) depletion of resonrce bases and (2) the complete turnover of the capital stock of energy conversion industries with new technologies available.

LEAP is a member of a particular family of long-term modeling systems called "generalized equilibrium" process models. Essential concepts of this approach are (1) the market controls the long-term (50-year) behavior of investment and operating decisions in the energy sector, and (2) agents in the market sense and respond to the discounted stream of future net-dollar flows.

Mode1 22C is for the United States and represents explicitly nation-wide, time-dependent demands for energy in the industrial, residential, transportation, and commercial sectors. Energy supplies that deplete domestic fixed-resource bases inc1ude the coal, oil/gas, and uranium sectors. Additional energy is supplied by renewable resources and imports. Conversion processes are employed to represent transformations of energy form (e.g., electricity production). The various processes are linked together in a network 
that mode1s the flow of energy from primary resource to end-use demand.

\section{Modeling Process}

\section{Inputs}

In LEAP models, the relevant part of the economy is represented by a network of energy and dollar flows among generic energy-related activities. Each class of conceptaaly stmilar activities is modcled in LEAP using a general "process" submode1; however, a unique set of parameters can be supplied for each particular activity. Such parameter inputs for LEAP can be generally categorized according to whether they correspond to (1) major assumptions of scenario; (2) historical data on the national energy balance, facility costs, and trends in financing and tax accounting; (3) engineering estimates of values of cost, efficiency, and availability parameters for generic processes that are not yet "commercial"; or (4) parameterization of the departure of economic behavior from that expected under perfect competition.

Specifically, for each generic activity (e.g.. space heating) that represents conversion of energy form, Mode1 22C requires technical, historical, financial, and nonfuel cost data. These include process efficiencies, prices of material/labor, tax rates, etc. The electric ntility conversion activities require these data and the portions of electricity generation devoted to base, intermediate, and peak load service. In addition to the parameters required for basic conversion activities, the resources extraction activities require resource curves that quantify, as a function of cumulative resource commitments, the increasing effort required to recover energy commodities from depleting resource bases.

Each activity that represents the allocation of an energy demand among competing suppliers requires (1) the relative energy' flows 
(market shares) at the various inputs from competing suppliers for the initial model year (1975), (2) the market shares that would eventually apply if the prices from all suppliers were equal, and (3) the parameters used in modeling the price- and time-dependent market penetration dynamic. The "transport" activities require price increments and transport efficiency factors. The final demand activities require, for each class of demand, the parameters to determine an exogenous demand path and the price elasticity and lag parameters to modify the demand-path quantities in the later mode 1 years. The oil and gas import prices, hydroelectric production quantity, and metallurgical coal export quantity are required for each model time point. Altogether, a few thousand parameters were input to Mode1 22C.

\section{Computation}

An iterative algorithm is used to solve the coupled set of timedependent nonlinear equilibrium equations for the energy and dollar flows that link activities. The economic processes being simulated during iteration correspond to producers determining prices at each time point based on estimated future prices and operating oosts and present capital cost; intermediate and end-use consumers responding with a level of demand based on need, the price elasticity of enduse demand, and competition among producers; producers revising their prices, and so on. No explicit optimization is performed.

In operation, the computer program begins with initial estimates of values for the energy and dollar flows and iterates with the goal of eatisfying thc price/quaulily equations in every process subroutine. 


\section{Results of Interest to Users}

For LEAP Mode1 22C, there was no unique set of results defined by any particular narrow goal of the model sponsors or by the documented needs of a specific set of mode1 output users. Indeed, the audience for the Annual Report to Congress has quite diffuse interests. Analysis of (1) statutory requirements placed on the EIA, (2) the important conclusions stressed in the report to Congress containing the Mode1 22C, results, (3) the statements of key users of that report, and (4) modeler insight allowed seleotion of a set of important results that reflect some of the needs for public longterm energy projections, needs that may be addressed using a mode 1 1ike LEAP.

Those subjects considered to be the great energy issues of the day include the cost of energy, especially the portions that affect the international payments balance, and the interplay between national energy independence and how liquid fuel demand can be satisfied. Issues of slightly less importance include the extent to which coal resource use can be expected to dominate the energy market, the projected degree of electricity use, and identification of the most important future demand sectors. In general, the main interest is in trends rather than in particular commodity and dollar flows at specific future times.

To investigate these concerns within the LEAP framework, specific combinations of Mode1 22C results chosen for study in this report include:

- Total Energy Cost to A11 End Uses in 2020 as a fraction of the Gross National Product in 2020.

- Total Cost of Imported 0il, 0il Products, and Gas in 2020 as a fraction of the Gross National Product in 2020. 

of the Total Fuel Input to All Demand Sectors in 2020.

The authors estimated that these results needed to be known to within $\sim 10 \%, 100 \%$, 50\%, and $30 \%$ of the 1978 LEAP projections for year 2020 , in order that substantive conclusions based on these calculations could be reached with confidence. These values may be user-dependent even for a given issue or problem. However, it was found useful. in this evaluation to have estimated target accuracy requirements to which the results of the LEAP analysis could be compared.

\section{Findings and Conclusions}

\section{Usability}

Usability must be considered relative to the Congressional mandate on the DOE to provide projections of energy supply and use and to estimate the consequences of potential government actions. The LEAP system is very flexible as to what portions of the energy economy are represented in Aatail; theroforo, it can be a useful tnn! for studying the effects of various resource and energy conversion development assumptions. At least for LEAP-78, the final (energyrelated service) demand representation is essentially exogenous, and there is no real feedback between the energy. sectors and the remainder of the economy that determines energy demand and the relative costs of labor, capital, and materials. Thus, in its ARC-78 state, LEAP is most appropriate for addressing questions related to oncrgy supply allernatives, given an assumed level of demand for energy services. For example, impact of loan guarantees and tax incentives could readily be modeled.

Usability also depends on the capabilities available to a user to a1ter the mode1 and to obtain new results quickly. Although 
long-range models treat the time period of a professional career, results assuming modified policies or other data are often desired within a few hours of the time the idea is formulated. The overall turnaround time depends on the ease of preparing a revised mode1 and the computer system turnaround. LEAP has the major advantage that only one program is required rather than a chain of programs representing supply, demand, and integration. Some minor network revisions could be rapidly introduced using LEAP-78, but major network modification for the LEAP program will be an arduous process until additional software aids are constructed. However, to compensate for this difficulty, small models and partial models of any variety can be constructed from the available subroutine modules without any reprogramming. Data changes and process subroutine program modification (even for use in only a few activities) can be introduced very efficiently.

Computer system turnaround is inhibited because of the large storage required and the slow running times. Computing time for LEAP-78 depends on values assigned to input parameters, the quality of the starting guesses for price and quantities, and the convergence norm used. Typical rules-of-thumb for a model like $22 \mathrm{C}$ might be 25 seconds per iteration and up to 100 iterations to convergence ( $\leq 1 \%)$. LEAP-78 appears to require about twice the computer memory estimated by the present authors as being necessary, but programming changes required to improve space efficiency are considerable. LEAP-78 is not easily transportable. The proprietary nature of the LEAP-78 data base management system (System 2000) and the severe core memory requirements ( 2 megabytes for Model $22 \mathrm{C}$ ) are the two principle detrimental factors affecting transportability.

\section{Understandability}

A model is more understandable as it becomes simpler, as its results can readily be traced to their causes, and generally, as its documentation is enhanced. Simulation models like LEAP 
that represent identified industries and include their engineering parameters have a natural advantage in understandability. With the completion of the present evaluation project, the documentation of LEAP-78 is generally good and would likely be compliant with OAA except for the description of the data base. The data source information is, in the majority of cases, nonspecific, and it is not possible for the reader to determine exactly how a specific data value was chosen or how gocorate that value might be. Overall documentation for later versions could build on this existing 1iterature.

The recent publication of sensitivity coefficients for Model 22C permits the behavior of the model to be studied more readily. Studies performed on LEAP-78 revealed high sensitivities of energy cost, import costs, and fraction of liquid fuels to process parameters that should be measurable. There can be a reasonable basis from which to estimate process efficiencies (e.g.. electricity transport, oil refining, etc.), prices of materials and labor, resource cost curves (e.g., for Appalachian medium-high sulfur coal), plant load factors, and availabilities, even for the long term. other important quantities that may be more difficult to estimate include the price of imported oil and personal or cultural preference for energy fuel choice.

On balance, understandability is a potential plus for LEAP systems.

\section{Realise}

Because LEAP functions hy simulation of generio onginecring-ecouvinic activities, its limiting success must depend on whether the essential features of economic interactions have been included. Statistical estimation techniques have very limited application for this type of mode1, and as with all long-term models, global validation against empirical data is difficult. LEAP gains potential realism 
by permitting whatever subdivision of generic industries of interest is deemed necessary for the problem at hand, even though Model 22C suffered from very uneven treatment of its various sectors. The mode1 equations were obtained by modifying, on the basis of engineering judgment, a theoretical formulation of long-term economic equilibrium. The equations were not derived from any firm economic theory describing plant construction and operation decisions with competition among alternative suppliers in the complex energy network. For example, the form of the capacity factor function can lead to occasions where plants continue to operate for normul lifetimes while constantly sustaining cash losses. The expression for the oapacity factor could easily be changed to overcome this prob1em.

LEAP does not march stepwise through time looking only at the past; endogenous decision makers $100 k$ ahead at future prices. This feature adds realism if the forecasting formula resembles that used by the aggregate of real decision makers.

LEAP-78 realism suffered by failing to (1) allow input substitution-for example, of capital for other production factors through plant retrofit; (2) provide significant compling of demand to variables other than price; and (3) eliminate the plants with highest variable cost in periods when there is surplus plant capacity. The fixedcoefficient production function assumption (no within-process input substitution) is likely to introduce an upward bias in energy prices over time as relative input prices change. Substitution does exist, however, between competing types of processes. The supply of labor, capital, and materials is assumed to be infinite at a predetermined exogenous price. The effect of the rising cost of energy needed to produce these inputs is not included in the model. Consequently, a bias towards capital-intensive processes results. Although, sensitivities to the behavioral parameters seem modest, a rationale is required for choice of the various price sensitivities 
and behavioral lags to permit belief that they represent real economic factors, particularly in the market penetration algorithm.

Mode1 22C included an inadequate fuel import module, (unlimited oil imports available at predetermined prices), final demand that became elastic only for the next century, and electric utility pricing that was inconsistent with present pricing (but perhaps more representative of the future). The assumption of infinitely divisible plant sizes may be inappropriate for parts of the projected electric ntility and cynfuol industries; no provision was made for depletion of available sites as a finite resource, nor was any account taken of salvage values.

The numerical techniques in the LEAP system were adequate for obtaining convergence of Model 22C, but they do not have a firm mathematical basis. The convergence test used provides less convergence than would be assumed to be achieved for a chosen value of the convergence parameter. The original LEAP-78 relaxation algorithm had at least two theoretical problems. The first problem refers to the neglect of off-diagonal components inherentiy present; the second refers to the manner in which tho rolaxation cueffluturts were calculated (for which the evaluation group has not found a theoretical basis). A method for implementing a more rigorous relaxation scheme has been described, but must be coded and tested before assuming success.

Using the uncertainties for data estimated in this report, the propagated uncertainties in results of interest (as defined in Sect. C.3 of this snmmary) are liotod helow. Nute that the estiwales include neither the ancertainty in model specification, nor a complete set of uncertainties for all data elements, nor correlations among data elements, nor second- or higher-order effects. The full final uncertainty would likely be substantially larger than the numbers 1 isted below: 
1. Total Energy Cost to A11 End

Uses in 2020 as a fraction of the

2. Tota1 Cost of Imported 0il, 0il Products, and $G a s$ in 2020 as a fraction of the

3. Total Imports of 011 and 0 il Products in 2020

4. Liquids Fue1s Input to All Demand Sectors in 2020 as a fraction of the Tota1 Fue1 Input to A11 Demand Sectors in 2020

Because these ancertainties alone are comparable to the target accuracy requirements offered in Sect. C.3, the fu11 uncertainty in these parameters when all effects are included may be substantially larger than those suggested in this report as goals.

\section{Credibility}

Mode1 credibility depends not only on the level of documentation and a model's realism but also on the degree of familiarity with mode1 characteristics enjoyed by potential users and other interested professionals. LEAP credibility is enhanced by the broad use of generalized equilibrium models, the public nature of its origin, the broad publication and review of its results, and the relatively complete documentation of the 1978 Model 22C accomplished with the aid of the present project. Credibility is rednced by the lack of a we11-documented data base and by the fact that users ontside of DOE have little "hands-on" experience with the model. Public use would eventually lead to a variety of compatible subroutine packages with enriched intellectual content; this outcome requires that a future LEAP be readily transportable for use on smaller machines. 
For the overall evaluation of LEAP credibility as a public information model, its apparently unbiased origin and the archiving system now used for input and results are strongly favorable factors. The chief negative factor is the lack of full documentation of input quantities, including their original sources and explanations of any modifications made. The need for comprehensive input data documentation applies to other pub1ic information models.

\section{B. Recomendations}

\section{Sumary}

The economic representation of LEAP seems to reveal a sophisticated understanding of the interactions of various elements of the energy economy. The basic sectoral structure, the consideration of nonlinear interactions, and the modularity of the model are three of the elements that display this understanding. Many of the serious problems 1ie less with the LEAP framework than with the specific 1978 version employed. The effects of these problems (see previous section) restrict the applicability of Mode1 $22 \mathrm{C}$ for realistic longterm modeling, but do not restrict the potential of the LEAP system to provide the desired analytical capability.

At present, LEAP is generaliy weaker than other long-term mode1s with respect to energy-economy interactions and within-process substitution, but stronger than competitive models with respect to the dynamics of investment decisions and the ability to represent technological change. Rather than choosing another mode1, we believe it Lo bo $008 \mathrm{t}$ cffoctive to make the required improvements within the existing framework. Beyond the straightforward corrections, additional mode1ing effort should be directed toward better representation of demand, energy-economy interactions, capital-1abormaterial markets, the import sector, and within-process input substitution for selected activities. 


\section{Specific Issues}

The recommendations based on our study vary in scope from some that may apply to all EIA models to others that apply only to the 1978 LEAP Mode1 22C. The recommendations are presented generally in order of decreasing breadth, not importance.

a. Major conclusions from long-term analysis need not be developed annua11y. A 2- to 5-year cycle for generating markedy altered long-term projections would permit higher quality results, far better documentation of what was done, and more comprehensive evaluation.

b. Evaluated standardized energy- and economy-re1ated data should be developed along with associated software to process the given data to particalar forms used by alternative models. The generation and update of such data is costly; mechanisms for sharing such thoroughly reviewed information should be formally pat into place. In any case, input data for programs like LEAP should have complete documentation that allows the information to be traced to its exact source and provides an explanation of any modifications to the source information. Evaluated uncertainty estimates should be provided for data that have high sensitivity with respect to important results.

Standardized problems (benchmarks) similar to those considered by the Energy Modeling Forum should be developed as a means of comparing and evaluating results of alternative models.

c. Special efforts should be made to make energy-economy models, used by EIA in its projections, transportable and usable by interested parties in the general public. The concept of the "open" code is relevant here and provides a mechanism for external reyiew, feedback, and code maintenance that goes much 
further than the simple archiving of models used for annual projections. A nonproprietary data base management system and considerably reduced core requirements seem to be essential development areas if LEAP is to enjoy wider nse.

d. Models exist because problems need to be solved that, because of the number and nature of the complex interactions, cannot be addressed precisely using intuition and experience. However. analysis using these models is best focused by relating the issue of concern (e.g., cost of energy, satisfaction of liquid fuel demands) to an explicit combination of the model output values. Furthermore, target accuracies for desired results need to be developed to allow a determination of whether the model result with its associated uncertainty can meaningfully contribute to the resolution of the issue in question. Explicit ase of this concept in future Annual Reports to Congress would strengthen their impact.

e. The approach of calibrating the long-term output to match midterm model numerical outputs at year 1995, by adjusting various input parameters, is questionable. Rather than to adjust data, if mid- and long-term projections must agree, it would be more direct to start the long-term calculation at year 1995 using the midterm results as boundary conditions. (This approach would not be trivial to implement.) Generally, model input data should not be "tuned" to obtain desired projections. When this is done, it is difficult to nnderstand precisely what is uulput und what 18 1nput!

f. The fixed-coefficient production function in LEAP-78 energy conversion submodels (no factor substitution) appears to be a serious problem in model specification for a model designed to assess the long-term impacts of increasingly limited 
supplies of energy. Attempts to incorporate some measure of factor substitution within processes should be considered; otherwise, the number of activities modeled may need to grow unnecessarily. (A problem will be to increase flexibility while maintaining the clarity of a simulation model.)

g. The capacity factor specification of LEAP should be changed to correspond to a reasonable production function so as to avoid the situation of producers operating while sustaining cash losses. Making a change of this type appears to be a straightforward matter.

h. In LEAP Mode1 22C, the unlimited supply of capital, 1abor, materials, and oil imports at predetermined fixed prices are major assumptions that appear to be inconsistent with expectations of reality. Similarly, the essentially exogenous specification of demand limits the possible range of applications. Further model development in these areas seems justified. The relaxation algorithm currently used is not soundly based; the groundwork for using a more complete Newton scheme (still time-dependent, but including off-diagonal elements) should be tested.

i. The data specification errors discussed in the report for the ARC-78 version of the data base should not be retained in future LEAP versions. 


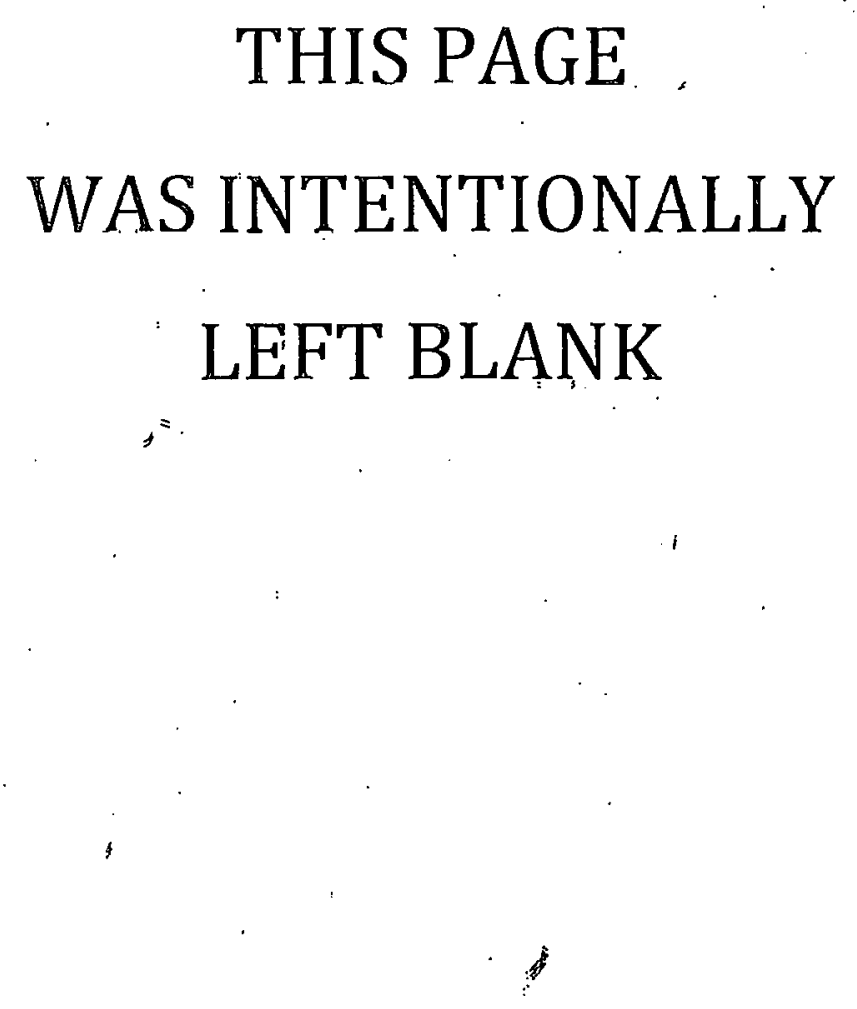




\section{ABSTIACT}

This report presents an evaluation of the Long-Term Energy Analysis Program (LEAP), a computer model of the energy portion of the U.S. economy that was used by the Energy Information Administration (EIA) of the U.S. Department of Energy for the 1995-2020 projections in its 1978 Annual Report to Congress. An overview of the 1978 version, LEAP Mode1 22C, is followed by an analysis of the important results needed by its users. The model is then evaluated on the basis of (1) the adequacy of its documentation; (2) the loc'al experienco in operating the mode1, (3) the adequacy of the numerical techniques used, (4) the soundness of the economic and technical foundations of the model equations, and (5) the degree to which the computer program has been verified. To show which parameters strongly influence the results and to approaoh the question of whether the model can project important results with sufficient accuracy to support qualitative conclusions, the numerical sensitivities of some important results to model input parameters are described. The input data are categorized and discussed, and uncertainties are given, for some parameters as examples. From this background and from the relation of LEAP to other available approaches for long-term energy modeling, an overall evaluation is given of the model's suitability for nse by the EIA.

Following poblication of reports from the present evaluation efforts, most aspects of the documentation of the LEAP Mode1 22C meet DOE standards; documentation of the model parameters does not. Members of the evaluation team were able to learn to operate and make minor modifications to the model resident on the EIA computer system, but the model was not readily transportable to other computer sites. Published LEAP results were replicated. The numerical techniques used in the LEAP system were adequate for obtaining convergence of Model 22C, but they do not have a firm mathematical basis. 
The LEAP modeling system is flexible and potentially useful for studying alternative energy supply patterns under (near1y) exogenously determined final demand. The usefulness of this system is conditional upon (1) the validity of future cost and economic behavior data estimated now; (2) the broad realism of the equations used to simulate market interaction and investment; and (3) the ability to represent in the model the alternative conditions and policies important to an energy agency. Even if questionable input parameters are accepted, the LEAP system for ARC-78 did not fully meet conditions (2) or (3); for example, it did not permit the study of retrofit of capital plant for the purpose of achieving improved efficiency, and not all regulatory policy options condd readily be handled in the system's framework. The model equations were obtained by modifying a partial equilibrium analysis on the basis of engineering judgment. They were not derived from any firm economic theory describing plant construction and operation decisions with competition among alternative suppliers in the complex energy network. In the specific LEAP model used for the 1978 Administrator's report, long-term regiona1 issues other than those related to coal development conld not have been addressed.

The summary of sensitivity studies, performed on the LEAP mode1 for ARC-78 through a novel application of adjoint sensitivity theory, shows relatively high sensitivities of total energy cost to parameters used in many activities and to others that affect demand and the economic efficiency of important activities. Observed nonlinear effects were sufficiently severe in model reruns with altered parameters that second-order sensitivity coeficients needed to be considered. The input data appear representative of data previously used in similar antecedent models, but they were not well enough documented to allow assessment of their appropriateness by. the public. Proper input to the model at EIA was apparently inhibited 
in a few cases by the imprecise data definitions available, to the agency.

Long-term energy analysis in some form is required by the statutes establishing the Department of Energy. The LEAP system should be appropriate to help meet a portion of these analysis needs, partioularly those involving alternative energy supply options for the early part of the next century. The LEAP modeling effort for the 1978 Administrator's report was a reasonable first attempt to obtain useful projections from the LRAP system. A number of recommendations are included for improvements in the LEAP system and the way it was used. 


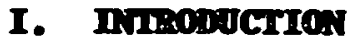

This report evaluates the Long-Term Energy Analysis Program (LEAP) compnter model used by the Energy Information Administration (EIA) of the U.S. Department of Energy (DOE) in preparing ARC-78, its 1978 Annual Report to Congress (EIA79a). Long-run, nationally aggregated projections of energy prices and flows from the model were published for the period 1995-2020 in Chapter 5 of that report (EIA79a). The computer model was developed for and enhanced by the Long Range Integrative Analysis branch of the Office of Applied Analysis, EIA, under the direction of John Pearson. EIA named the modeling system LEAP (Long-Term Energy Analysis Program), and the particular model network and data base used for the ARC-78 analysis was designated Model 22C. (In this report, the modeling system computer program used for Model 22C is called LEAP-78.) The results summarized in ARC-78 were the first published results from the LEAP system, although, as desoribed in Sect. II, there have been published results from earlier related models. The LEAP results are important in ARC-78 because they reflect EIA's in-house capability to explicitly analyze long-run issues affected by (1) depletion of resource bases and (2) tho complete turnover of the capital stock of energy conversion industries. These issues must be addressed by the EIA to fulfill the congressional mandate given that agency by the Energy Reorganization Act of 1977 (USC77).

This evaluation was performed by the multidisciplinary team shown on the title page, and was sponsored by the Office of Energy Information Validation (ORIV) of the EIA. OEIV was established as an indirect result of the Congressional mandate to assure, generally, that the public can be confident that information released by the EIA is continua11y being assessed (USC77, PAR79).

LEAP was the first model chosen for evaluation by the present team at the Oak Ridge National Laboratory (ORNL); therefore, the work on 
this model has acted as a focns for ORNL's evaluation methodology research. As part of the overall evaluation effort, an approach has been synthesized by Weisbin et a1. for evaluation of energy-economy models (Tei81). The present report follows this approach closely in coverage as well as in organization; the reader is encouraged to skip sections covering evaluation components of less-immediate interest. A principal ORNL contribution to evaluation methodology has been the use of global sensitivity studies and related input data analysis.

The questions" to be answered in a model evaluation (Ha179) can usefully be organized in a style different from that employed in the present report; therefore, this paragraph provides the transiation between the two forms. Readers not already familiar with generalized equilibrium modeling systems like LEAP may find the information in the overview of LEAP (Sect. II and Appendix A) to be a prerequisite to understanding the answers to the following questions.

1. Can the model, considered as a computer device, be understood by third parties?

See Sects. IV (Documentation), V.D and V.F (Operating Experience), VII.A (Economic Foundations-Assumptions), IX (Sensitivities), X.A and X.C (Data Classification and Precision of Definition), and the summary on this point in XI.B (Conci isions-Understandability).

2. What are the model's fundamental mathematical properties?

Sèe Sect. VI (Numerical Techniques).

3. What is the model's $10 \mathrm{gical}$ structure?

See Sect. II plus Appendix A (Overview) and Sect. VII.A (Economic Foundations-Assumptions) for answers from different viewpoints. 


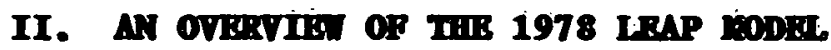

To facilitate understanding of the remainder of this report, the LEAP Mode1 22C of the U.S. energy economy is placed in context and described in this section and in Appendix A. Hansen et al. include an interesting overview that gives more emphasis to underlying assumptions (Han81, Sect. 2). Fairly complete reference is made in this section to the literature of similar models, but the references for LEAP itself are more thoroughly covered in Sect. IV.

\section{A. The Conceptuel Franeworl of Bu's Long-Texn Brexgy Annlysis Program (LRAP)}

Long-term energy models project scenarios for 20 or more years into the future. Long-term models differ from short- and mid-term models because in 20 to 50 years (1) much capital stock will be roplacod, (2) exhanstible resourccs aro expected to suffer major depletion, (3) significant popalation migration may occur following altered patterns of economic activity, and (4) aggregate demand patterns may be altered through caltaral shifts. Such cultaral shifts have generally not been included in energy models, but capital stock turnover and resource depletion must be considered in any longterm energy mode1. The model complexities that may be required to meet these needs are somewhat compensated by the typical user's willingness to ignore seasonal and annual weather vaxiulions and in some cases to suppress regionality. History has shown that government policies do not remain stable for extended periods of time; but, for present and contemplatcd policies, one must study the possible evolutionary patterns of the energy system that may occur in response to relative price changes induced by resource depletion and technology development.

Becanse government officials and the leaders of major industries must understand the future implications of current knowledge and policies, a uüuber of long-teim models have been developed. LEAP is a member 
of a particular family of long-term modeling systems, based on the motive of equilibrium in energy-related markets, called "generalized equilibrium" energy-economy modeling systems.

The LEAP modeling system allows an analyst to form and operate specific models to simulate interactions among generic activities within part or all of the energy-related portion of the economy. These selected generic activities (e.g., extraction of western 10 sulphur coal) are simulated with respect to investment in productive capacity, energy flows, and dollar flows. The generic aggregated activities (industries, often) that are modeled range from extraction of resources (e.g... oil) to conversions of energy form (e.g., synfuel or electricity production) and to representation of the time-dependent, end-use demand for energy services (e.g., space heat, industrial direct heat, and freight ton-miles). Import and export activities can represent energy transfers ontside the main geographic region of interest. Bach of the activities is modeled with a "process subroutine" that simulates with its formulae the intertemporal supply and demand functions for that activity. The major advantages of this type (LEAP) of modeling system are (1) that the modelex can ohoose a "network" (of generio activities and interconnecting links) appropriate to his problem and (2) that process subroutines from a relatively small computer library can be fed parameters to make them (arguably) represent the activities of interest." The biggest disadvantage so far has been that model networks that have been detailed enongh to seem realistic have often required large amounts of computer memory and considerable computer time.

In operation, a computer model in the LEAP system begins with initial estimates of values for the energy and dollar flows and iterates with the goal to satisfy the price/quantity equations contained in the process subroutine for each activity. These subroutines were developed with the ideas that (1) the market controls the long- 
4. What is the domain of model applications?

See Sects. II (Overview), VII.C. (Economic FoundationsApplicability), and the summary in XI.B. (Conclusions-Strengths and Weaknesses).

5. What is the nature of the data needed to implement, prepare forecasts, and test the model?

See Sect. X.A (Inpat Data-Classification) for answers to the first two; the third point is covered, to the extent possible, in Sect. VII.B (Economic Foundation-Comparison of Results).

6. Are the individual specifications and assumptions supported by data or theory?

Sections VII.A (Economic Foundations-Ássumptions) and XI.B (Conciusions-Realism) evaluate model specifications and assumptions relative to economic theory: Data from the economy have not, to our knowledge, been presented in direct support of any of the model specifications and assumptions.

7. What can be said about the reliability or uncertainty of the forecasts?

For different aspects of the enswer, see Sects. VI (Numerical Techniques), VII.B (Economic Foundations-Comparison), VIII (Program Verification), X.B through, X.E (Inpnt Data-Quality), XI.A (Conclusions-Uncertainty), and XI.B (Conclusions-Strengths and Weaknesses).

8. How is the model used? For what purposes is it suited?

The first question is answered in Sects. II (Overview), III (Kesults of Interest), and XI.B (Conclusions-Strengths and Weaknesses). The second question is answered in Sects. II (Overview), VII (Economic Fonndations-Domain of Applicability), and XI.B (Conclusions-Strengths and Weaknesses). 
Most of the central points can be found in the conclusions portion of each section.

Although no complete and unified evaluation of the 1978 LEAP model has been presented prior to this report, several relevant partial evaluations have appeared. One such evaluation, by Falk (Fa179), analyzes the methodology of the LEAP model. Another by OEIV (OEI80) mas based on early results from this project and on a qualitative analysis of mode1 inputs and the ARC-78 forecasts. An interim report (Als80) describes early phases of the present evaluation, and separate, detailed reports from this ORNL project are available and are referenced at appropriate points in the text.

The portion of the real economy addressed by LEAP models is complicated by a maze of uncertainty involving political, other social, and technical interactions; by contrast, a LEAP model generates its projections in a rote fashion in which uncertainty plays no real role. A modeler or model user must employ subtle skills to learn anything from such a model about the real future energy supply or the interactions that will govern it. The models themselves produce numerical results, and the user learns what he can from the behavior of these outputs. In this report, we evaluate LEAP-78 and Mode1 22C, not the subjective skills, imagination, and wisdom of mode1 users. The premise of this report is that models used to obtain published projections have identity apart from the modeler. 
term (40-year) behavior of investment and operating decisions in the energy sector, and (2) the agents in the market sense and respond to the discounted stream of future net-dollar flows to each of the activities in the network. These economic assumptions are more folly detailed below, as are the modifications to their strict application that are included in the process equations to capture the behavior in the real marketplace.

To recapitulate, a LEAP modeling system consists of a computer program capable of (1) recognizing the generic economic activities the analyst wishes to consider, (2) setting up the "network" of energy and dollar flows chosen by the analyst to interconnect these activities, (3) associating the selected "process submodel" or subrontine package with each activity to provide the desired simulation over time of the supply- and demand-curve. behavior of that activity in the network, (4) providing to the process submodel the values of parameters selected by the analyst to represent each activity, (5) "solving" the resulting model by successive triai such that the computed energy flows and energy prices are compatible with the supply/demand relations for each activity, and (6) displaying and tabulating the resulting prices and quantities (dependent endogenous variables) in whatever form is required by the analyst. The LEAP system also includes features for on-line editing of data and control of the set of prices, and quantities to be varied during various stages of the iterative sequence of trials leading to a solution. In summary, the analyst defines the network, decides which process subroutine to use for each activity, and provides parameters (discussed later) required by each process subrontine for each activity it represents. The analyst is provided the quantities of energy/year computed to flow between activities, the dollar flows that pay for that energy, and (if desired) the new capacity put on line for each period the model computes values. LEAP models solve for several time points at once-usually ten points spaced at 5-year intervais. 
LEAP was developed from a demonstration model delivered by Decision Focus, Inc. (DFI), to the Office of Applied Analysis (OAA) of the RIA, along with preliminary versions of the DFI documentation (Ad178 and Caz78). A group led by John Pearson (OAA) modified the program package including some of the process subroutines to form the "1978 LEAP Economic Modeling System"; Pearson et al. concurrent1y developed LEAP Mode1 22C using this LEAP-78 framework.

The reader who desires to obtain greater understanding of the generalized equilibrium class of models may study documents covering other modeling systems that share a common origin with LEAP. Brock and Nesbitt (Bro77) show, for a much-simplified case, how supply and demand curves can be considered to be propagated, aggregating demand, through a network of commodity flows that resembles those for LEAP; in this case; the elementary ideas of economic equilibrium are shown tó apply. The Stanford Research Institute (SRI) National Energy Model was described in Chapter 4 of Brock and Nesbitt (Bro77) and in more detail by Cazalet (Caz77). It is often called the Gulf-SRI Model becanse it was initiated within a study for Gulf Oil Corporation that analyzed opportunities for that corporation in synthetic gas production. The model was later used to aid an analysis of President Ford's proposed synthetic fuels program (Caz79a), for a Council on Environmental Quality study (Caz76), and to produce a documented set of fuel and energy price projections for the Rlectric Power Research Institute (EPRI) (SRI77). The 1ast two references include information on the data base, and two of these reports (Caz76; SRI77, Vol. 2) cover the mode1 specification in some detail. The Livermore Economic Modeling System is based on the same concepts as the Gulf-SRI system, but is programmed to be very flexible for the user at that laboratory (Rou78). The Gulf-SRI idea was al so reprogrammed and extended at DFI, using a more detailed model of a generic industry. This modeling system and the supporting software were documented by Adler (Ad179) and Cazalet (Caz79b). The Adler et a1. document (Ad179) includes plausibility arguments and 
related derivations for the equations used in the process subroutines that simulate the portions of the economy considered important.

In addition to the above general literature, two reports generated within the present project can aid the reader in understanding the general framework of the LEAP economic modeling system. The interim project report by Alsmiller et al. (Als80,. Sect. IV.A) describes in detail the functioning of the LEAP program with a very sma11 test network; and Hansen et al. (Han81, Sect. 2), in their overview description of LEAP Mode1 22C, give simplified netmork diagrams and supply/demand curve representations that illustrate the model operation.

The paragraphs above and the cited reports describe the class of mode1s to which LEAP belongs. Because any of the process subroutines can be modified and because the links between processes can represent flows other than energy and money (e.g., specific materials), the framework is so flexible that the rest of this report deals primarily with the LEAP model as it was used in generating the projections contained in ARC-78 (EIA79a).

\section{B. The 1978 ABC Vorsion of BIA's Long-Torn Rnorgy Analjsis Program}

Dofinition of Hodel 22C. Mode1 22C of LEAP was developed by EIA's Office of Applied Analysis to demonstrate the LEAP-78 stage of the evolving LEAP economic modeling system and to provide long-run projections of energy flows and prices suitable for inclusion in EIA's 1978 Annual Report to Congress. To meet this particular need. it was dectded that the input assumptions should be consistent $\$$ ith the mid-range (to 1995) base-case projections described in the same document (EIA79a). 
LEAP Mode1 22C is precisely defined by the model input tables (identified here as MIT 3 through 22), which are input to the LEAP-78 program by the modeler to (1) determine the model network of economic activities and energy flows, (2) identify the computer "proceṣs" subroutines chosen to represent the various energy-economy activities, and (3) give numerical values for all the input parameters. Ford et al. (For81) identify the data sets on the DOE computer systom that contain these input data and the FORTRAN programs, and they a1so provide lists of the model program and input tables. The equations contained in all the process subroutines have been listed by Goldstein et al. (Go181a). Although the input parameters can be found in the model input tables, their study is facilitated by their presentation in the report by Stewart and Goldstein (Ste81). The material in the above references is necessary for a detailed study of Model 22C, but the general description of the model (given here and in Appendix A) should be adequate for the reader of this evaluation report.

The notwork. Figure II-1, based on a figure supplied by the office of Applied Analysis (Die79), illustrates the sector-level network design of Model 22C. Each link (1ine in the figure joining two sectors) represents an annual energy or energy-related commodity flow and the corresponding dollar flow for each of the ten time points, 1975 through 2020 at 5-year intervals. The model is for the Onited Stetes, for which the demand for energy is represented by coal exports and the four sectors illustrated at the top of Fig. II-1.

*The model variables are actually prices per nnit energy, so that the dollar flow is this price multiplied by the related quantity variable. A shadow price for each link is carried by the mode1; it always corresponds to the free market clearing price for LEAP-78. For a controlled market, this price conld differ from the transaction price that corresponds to the real dollar flow. In Model 22C, these prices are always equal. All prices and costs are in units of dollars of "fixed (1975) value." 
LEAP MODEL 22 INTERSECTORAL LINKS

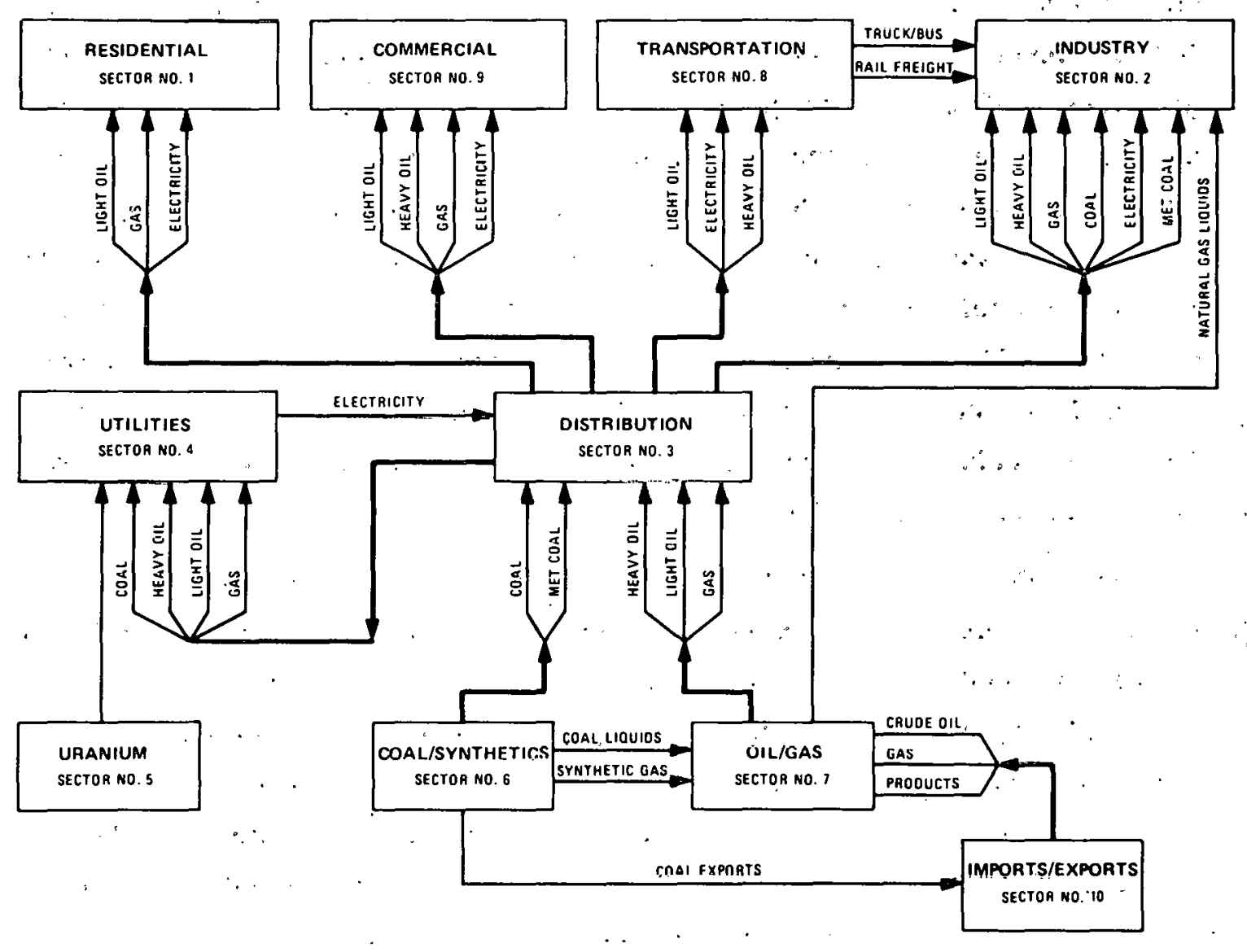

Figure II-1. Overa11 network diagram of LRAP Mode1 22 nsed for the 1978 LEAP analysis. The lines joining the boxes representing the several sectors represent intersectoral links along which the model estimates energy and payment flows for each of ten time points, $1975,1980, \ldots ., 2020$. The heavier lines represent bundles of links. See Figs. A-1 through A-9 for the detailed network of each sector. 
Energy supplies that deplete domestic fixed-resonxce bases are represented by the Coa1, 0il/Gas, and Uranium sectors at the bottom of the illustration. Additional energy is supplied by import and by using renewable resources represented within the individual sector networks diagrammed in Appendix A. The energy conversion facilities for central electricity production are included in the Electric Utility sector. The Distribution sector in this model disaggregates each class of energy supply to meet the requirements of the various demand sectors and corrects for the differences between the average prices paid by generic consumers in these sectors.

Figure II-1 illustrates the central properties of Mode1 22C that do not depend on how the details of the individual sectors are modeled. The model is national in the sense that it considers only the national totals for most variables (coal production is an exception). Thus, population shifts and other changes in the relative production and use of energy in different parts of the country are not accounted for. Materials, labor, and capital markets are not explicit and cannot therefore affect model output. Outside the United States, the model assumes that oil and gas will be available in unlimited quantities at exogenous prices and that coal will be exported in exogenous quantities at the asked prices. Therefore, the intertemporal supply curves for imported oil cannot reflect the diversity and volatility of oil-exporting contries. Appendix A contains the detailed network diagrams that show how individual aggregate activities are linked within each of the sectors i11ustrated as boxes in Fig. II-1.

The network diagrams of Model 22 in Appendix A indicate on the box for each activity, using numerical codes, the exact process subroutine and parameter set used to simulate that activity. Table A.1 in Appendix A tabulates the number of activities in each sector that use each process subroutine. This table and the network 


\section{II-9}

diagrams themselves illustrate the diversity of application of the most-used submodels.

For every inter-activity link shown on the network diagrams of Appendix A, the Mode1 22C solution yields quantity flows and prices for the ten time points $1975,1980, \ldots, 2020$. The model results tabulated in ARC-78 (EIA79a) are in most cases selected aggregates of these variables.

Note in the detailed network diagrams that all energy industries are not treated in equivalent detail. The oxiginal use of antecedent mode1s, as well as current interest, has led to a quite detailed treatment of synthetic fuels industries, for instance. By contrast, there is a relatively aggregated treatment of established industries like extraction of domestic oil and gas.

The process subsodels. The nature of the various process submodels used in Mode1 22C is indicated in the discussions of underlying assumptions in Sect. VII and in a report by Hansen et al. (Han81). Very brief descriptions of the ation of each process subroutine package are given below.

The allocation process is used (1) to allocate demand for energy or an energy-related service among competing generic classes of suppliers and (2) to set the average price of the combined energy flow. The output market shares depend on the relative prices, the market shares in the prior period, and the exogenous input parameters representing price sensitivity and behavioral lags. In the special case' in which only one ("common") supplier is linked to an allocation activity, the program simply combines demands for each model time point and links them to the common supplier. Footnotes $b$ and $c$ in Table A.1 (Appendix A) indicate how price increments can be included on the associated links. 
The electric power loading process is used in modeling the electric ntility industry to link an agregate central electricity demand to the combined supplies from electric utility energy conversion facilities separately optimized for base, intermediate, and peak-1oad service.

The energy conversion processes are used to model all manner of generic energy conversion facilities. The "basic conversion process" is used to model an enormons range of activities, from kitchen stoves to synfuel plants. The load-profile conversion mode handles the electric generating facilities designed for the varions load classifications. As used in Mode1 22C, each basic conversion process has one input and one output link, and the vintage profile of installed capacity may be recorded. Prices of the energy form supplied by the modeled activity for each model year are computed from (1) the input parameters and (2) the price vector (vs. time) for the inpat energy supply to the process. No explicit optimization (e.g., of profit) is performed within this subroutine package. The vector of input energy quantities over time depends primarily on the efficiency of the conversion process and on the quantities of energy demanded from the process. (If an energy-related commodity such as freight ton-miles is the output, the process efficiency parameter is not dimensionless.) In Mode1 22C, the basic conversion process (with no input 1ink) is used to represent use of renewable resources such as solar power.

The resouroe process for oil and gas is distinguished by the assumption that production from each year's aggregate of new wells declines exponentially in time. This submodel gives for its single link the vector of prices required to provide the demanded stream of quantities from the resonxce. The cost of the lease from the resource owner is included, and input parameters define an exponentially shaped resource curve for the cost of developing nndiscovered resources into reserves. 
The coal resource process is a similar resonrce submodel for coal or other resonrces for which production from a given mine can be taken as being constant over the mine 1 ife.

The transport process used in LEAP-78 is different from that described in the DFI documentation (Ad179). The capital costs of transport facilities are not explicitly included, but transportation price increments and energy losses are represented. (Note that the transport process is not used in tho LEAP-78 Transportation sector, but is nsed elsewhere as in the Coal sector.)

The import process models the importation of oil, gas, and oil products from ontside the United States and assumes the availability of any desired quantity at the prices (over time) specified as input parameters. Coal export is handled in an analogous fashion with preset quantities over time (see DUMWY).

The demand subroutine gives the stream of final end-use demands for energy-related quantities for the vector of offered prices. Each specific end-use demand is treated independently; Model 22C has 19 separate classes of demand divided among four sectors. Althorgh enduse demand is parameterized in terms of increases in the real GNP and exogenous demand sensitivity coefficients, the formulae reduce to specification at input time of streams of demand over time ("quantity path") that are modified during iteration by a lagged price elasticity for times after 1995.

The DUMY process, in this report, refers to the specification that no process subroutine be called for a particolar activity. This lack of action is specified for a fer activities (e.g., export). The precise effect depends on how an activity so represented fits into the network. Obviously, a process subroutine that does not exist cannot modify the initial estimates of prices or quantities on the associated links. Therefore, depending op pUMY usege, either prices or quantities for all model time points are maintained at the values 
estimated prior to the initiation of iteration toward a solution. They become exogenous variables.

Tho Paranoter Imput Date. For each resource extraction and energy conversion activity, LEAP-78 requires the values of the exogenous parameters that are needed to estimate, at each model time point, the present value of plant additions and of the stream of expected future net dollar flows. The resource processes also require the data that describe real cost increases as the resource bases are depleted. The allocation processes require the relative energy flows (market shares) of the various inputs for the initial model year (1975) and the parameters modeling market penetration. The demand activities require for each link the (1) indexes of activity (taken as projected GNP annual percent increments) and the sensitivities of each individual end-use demand to these activity indexes, (2) price elasticity and 1 ag parameters, and ( 3 ) the quantities for the initial year. Energy import prices, hydroelectric production, and metallurgical coal export quantities are required for each time point. Altogether, a few thousand parameters were input for Model 22C.

Historical economic data, previous energy models, process coṣt estimates, the opinions of experts, and the outputs of other models were used to determine values for all these parameters (EIA79a, Die79). The mode1s from which output was taken included macroeconomic projections through 1995, outputs from the EIA MidTerm Economic Forecasting System through the year 1995, extrapolation of these projections, and other more informal (simple, undocumented) models. Parameters were taken directly from the macroeconomic model output, but were determined indirectly from the mid-term models through a process of data adjustment that cansed Hodel $22 \mathrm{C}$ to give about the same results through 1995. In LEAP-78, output limits on industries could be represented only by such adjustment of costs or of demand allocation parameters. (This weakness was mitigated 


\section{II-13}

in later LEAP versions.) See Sect. $X$ of this report for more information about the Mode1 22C input parameters.

The network, process mode1, and input parameter choices were made to enable nominal long-range projection of the U.S. energy system. The comparisons exhibited in the 1978 Annual Report to Congress (EIA79a) indicated that the results were comparable to those obtained from other models using approximately the same input data assumptions. 
III-1

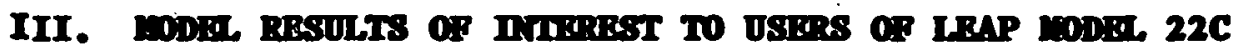

To proper1y focus the evaluation of a complex model, "responses" (i.e.. numerical results from the model) of primary interest to users must be explicitly defined (Wei81). A response is a specific mathematical combination of the model output values chosen because it expresses a nser interest in a precise manner. The responses chosen should be attributes of the projection(s) that are as close as possible to the central concerns. of usors (e.g., national cost of energy) so that the numerical values of the responses will be minimally influenced by parameter values or by parts of the model specification (formulation) that are not very relevant to these concerns. Careful choice of the response for study can minimize the chance that an analyst will be misled. For this reason, the responses selected for study will not always be simple sums or averages of the model outputs. (For LEAP-78, the model outputs at the solution point include capacity additions for the conversion and electric power activities, reserve additions for the resonrce activities, and all the prices and energy flows on all the links. Summary tables are also generated.) This section discusses the sources of information used by the authors in assessing user concerns and lists and explains the responses selected for the present evaluation. A nser interest may not resolve itself to any response based on a single projection, but for simplicity this report makes that assumption.

\section{A. Infomsion Sources Used in Response Dofinition}

There was no unique set of responses for LEAP Mode1 22C defined by any particular narrow goal of the model sponsors or by the documented needs of a specific set of model output users. However, (1) the statutory requirements placed on the Energy Information Administration (RIA), (2) the important conclusions stressed in the report to Congress containing the Model 22C results, (3) the 


\section{III-2}

statements of key DOE users of that report, and (4) expressions of modeler insight all establish criteria for selection of an important set of responses that reflects some of the needs for public information on long-term energy projections, needs that might be addressed using a model like LEAP.

Statenonts of Statutory Goals. The Department of Energy (DOE) Organization Act (PL 95-91) (USC77) designated the- EIA to carry out new functions as well as some functions of predecessor agencies. A carry-over requirement of the Federal Energy Administration (FEA) Act of 1974, as amended [PL 93-275, Sect. 57 (a)(2)], states that an annual report must be submitted to Congress that includes (at least) projections of

...short-, medium, and long-term energy consumption and
supply trends and forecasts ander various assumptions;
and to the maximum extent practicable, a summary or
schedule of the amonnts of the mineral fuel resources,
nonmineral energy resources and mineral fuels that can
be brought to market at varions prices and technologies
and their relationship to forecasted demands.

Section 657 of the DOE Organization Act requires the annual report that is described as follows in Sect. 15 of the FEA Act:

15(b) The Administrator sha11 prepare and submit directly to the Congress and the President every year after the date of enactment of this Act a report. which shall include -

...(3) a projection of the energy supply for the midterm and long term for each of the major types of fuel and the potential size and impact of any anticipated shortages, including recommendations for measures to-

(A) minimize deficiencies of energy supplies in relation to needs;

(B) maintain the health and safety of citizens;

(C) maintain production and employment at the highest. feasible leve1;

(D) equitably share the buxden of shortages among individuals and business firms; and 
(E) minimize any distortion of voluntary choices of individuals and firms;

...(6) an analysis of the energy needs of the United States and the methods by which such needs can be met, including both tax and nontax proposals and energy conservation strategies...

Section 657 also requires annal reporting from DOE that includes:

$\therefore 657(1)$ projected energy needs of the United States to meet the requirements of the general welfare of the people of the United States and the commercial and industrial life of the Nation, including a comprehensive summary of data pertaining to all fuel and energy needs of residents of the United States residing in-...

(2) an estimate of (A) the domestic and foreign energy supply on which the United States will be expected to rely to meet such needs in an economic manner with due regard for the protection of the environment, the conservation of natural resources, and the implementation of foreign policy objectives, and (B) the quantities of energy expected to be provided by different sonrces (including petrolen, natural and synthetic gases, coal, uranium, hydroelectric, solar, and other means) and the expected means of obtaining such quantities;

(3) current and foreseeable trends in the price, quality, management, and ittlization of energy resonrces and the effects of those trends on the social, environmental, economic, and other requirements of the Nation;...

Presumably, the reports required in the above portions of sect. 657 are part of EIA's responsibility. Although these statutory requirements are not cast in terms perfectly matched to the analysis of published LEAP results, they do define results that are of interest to the Congress. Note that the main interest is in trends rather than in projections of commodity and dollar flows at specific future times. Mode1 22C directly provides the latter.

Buplasis in the BIA Anmul Roport To Congress. Becanse the public has ready access to the LEAP Mode1 22C results only through Chapter 5 of EIA's Annual Report to Congress (EIA79a), the results of interest to users within the scope of this evaluation must be related to 
a subset of those results that are given some emphasis in ARC-78. Because the output of EIA's Midterm Economic Forecasting System through 1995 was used indirectly to "calibrate" some of the Model $22 \mathrm{C}$ input parameters (Ste81), the output values of major interest relate to the years 2000 through 2020. Table III.1 lists some of the major conclusions of the long-term analysis that are given emphasis in ARC-78, along with the supporting numerical values from the mode1. The qualitative findings are likely to be of greater interest to users of ARC-78, but the numerical values help one judge the quantitative variation that could occur in the ontput without substantial modification of the conclusions.' In choosing which conclusions to 1 ist in Table III.1, projections of total energy use were'avoided. Apparent1y, model responses focusing on conclusions such as those presented in Table III.1 can be defined and should be appropriate as a basis for evaluating LEAP Model 22C.

Interviews vith Specific Dsers Outside BIA. To assess the nature of interest in the LEAP program and in Model 22C results among DOE staff ontside of EIA, interviews were held with two groups. Each interview stressed identification of important. long-term responses and the respondent's interest in information about the uncertainties in model results. The first group (Pow79), whose members were involved in R D strategic planning, was concerned with issues involving interfuel competition and the allocation of national resources among competing technologies. Recommendations for such allocations were to be made on the basis of criteria such as potential market penetration by the end of the century, savings in future energy cost, and the quantity of imported oil. This group was considering use of a program 1ike LEAP to obtain projections of the major energy flows for various fuel types. Simpler, faster, and less expensive techniques (not specified) would in any case be used for the group's decision making. The second group interviewed (Nai79) was from the office of Analytical Services of DOE Policy and Evaluation. This group used the FOSSIL2 model (Nai77). However, they found LEAP Mode1 22C 
TABU III.1

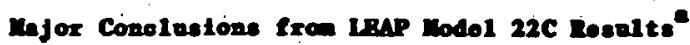

\begin{tabular}{|c|c|c|c|c|c|c|}
\hline & Quelitativo Conolusions & $\begin{array}{l}\text { Soinree Table in: } \\
\text { IAnC-78 (BIA79a }\end{array}$ & $\begin{array}{l}\text { bor } \\
\text { a) ] }\end{array}$ & 1977 & $\frac{1 \text { Pnlese bs }}{2000}$ & $\frac{T 09}{2020}$ \\
\hline 1. & Cos 1 becomes the dominant primary energy source. & $5 . \dot{2}$ & & $20 \mathrm{~s}^{\mathrm{b}}$ & 38. & $46 \%$ \\
\hline 2. & $\begin{array}{l}\text { Industrial sector will increasingly provide the } \\
\text { largest sectoral energy use. }\end{array}$ & 5.2 & . & $39 x^{c}$ & s1\% & $60 \%$ \\
\hline 3. & $\begin{array}{l}\text { Gas and liquid faels will deciline to one half the } \\
\text { total end-use consumption by year } 2020 \text {. }\end{array}$ & 5.6 & & $83 \%^{d}$ & 65\% & som \\
\hline 4. & $\begin{array}{l}\text { The relative electrification of our energy end-nses } \\
\text { will continue to increase through year } 2020 \text {. }\end{array}$ & 5.6 & & $118^{\circ}$ & 183 & 238 \\
\hline s. & $\begin{array}{l}\text { Totai domestic natural oil production will fall bolow } \\
\text { its present level before year } 2020 \text {. }\end{array}$ & 5.12 & & 20 quadf & 23 quad & 15 quad \\
\hline 6. & $\begin{array}{l}\text { Oil imports will steadily decline, reflecting a } \\
\text { definite trend toward energy independence. }\end{array}$ & 5.12 & & 18 quad & 11 quad & 7 qued \\
\hline 7. & $\begin{array}{l}\text { The } 1977 \text { total utilization of liquid fuols can be } \\
\text { maintained (despite items } 5 \text { and } 6 \text { above) becanse of } \\
\text { rapid production increases of shale oil and liquids } \\
\text { from cool. }\end{array}$ & 5.12 & $\cdot$ & 38 quad & 39 quad & 39 qued \\
\hline 8. & $\begin{array}{l}\text { Total direct and indirect end-use of renewable energy } \\
\text { sources (inciading hydroelectricity and geothermal) } \\
\text { is projected to grow slowly: officiencies were } \\
\text { approximated to obtain these. values from. data in } \\
\text { ARC-78 (EIA79a). }\end{array}$ & $5.8,5.9$ & . & 0.8 quad & 2 quad & 4 qued \\
\hline 9. & $\begin{array}{l}\text { By year 2020, most of the coal for electricity } \\
\text { goneration is expected to be used in the ner } \\
\text { technoiogies. }\end{array}$ & 5.8 & & $\mathbf{0}$ & $388^{8}$ & $59 \%$ \\
\hline 10. & $\begin{array}{l}\text { Primary energy prices will rise at } 28 \text { por year } \\
\text { from year } 2000 \text { to } 2020 \text {; (a) crude oil, (b) natural } \\
\text { gas, and (c) coel. (Prices aro in } 1978 \text { dollars por } \\
\text { million Bta.) }\end{array}$ & $\begin{array}{r}5.4(a) \\
(b) \\
(c)\end{array}$ & & $\begin{array}{l}1.6 \\
0.8 \\
1.0\end{array}$ & $\begin{array}{l}4.1 \\
3.4 \\
1.2\end{array}$ & $\begin{array}{l}6.0 \\
4.8 \\
1.6\end{array}$ \\
\hline
\end{tabular}

These conciusions were drawn from the anthors reading of ARC-78 (EIA79a) and are based largely on the emphasis that seemed to be given there. A more complote 1 ist is given by Alsmiller at al. (Alseo, Table III.2).

b The percentage of the tetal primary energy consumption that is provided by coal.

CThe percentage of total sectoral demand used by the industrial sector.

The percentage of all end-use consuption provided by gas and liquid fuels.

The percentage of all end-use consumption provided by electricity.

$f_{1}$ quad $=10^{13} \mathrm{Btu}=1.05 \times 10^{\mathrm{il}}=2.5 \times 10^{1 \mathrm{~T}} \mathrm{cal}=2.9 \times 10^{21} \mathrm{kTh}$.

${ }^{8}$ The percentage of all cosl consumed for electricity generation that is projected to be used in technologies not presently availablo. 


\section{III-6}

resplts very helpful: in providing base-case comparison points that supported the credibility of their own projections. Because LEAP can have greater sectoral detail, it is ultimately capable of being useful to this group. The respondents suggested that LEAP output on synthetic fuels and solar energy market penetration be considered key responses. Hore generally, the quantities of consumption and production by fuel type and economic impacts were considered to be the potentially important results of a long-run model such as LEAP.

Insignt of the bodolex. Modelers can be expected to have insight about the most important results from their models. In reviewing the selection of responses listed in a preliminary report of this work (A1 s80), M. Hutzler of EIA, who was the principal LEAP aser and modelex for the 1979 and 1980 Annual Reports to Congress, suggested five responses that may be considered the most important (Hut80); at least for sensitivity studies of the type described in sect. IX. These suggestions, quoted below, overiapped those 1 isted in Alsmiller's report (A1s80):

1. Total annual imports of crude oil and oil products.

2. Total annual cost of energy to end-users per dollar of GNP.

3. Oil and gas import cost per dollar of GNP.

4. Liquid fnel consumption as a fraction of total endnso.

5. Primary energy inputs to liquids as a fraction of total primary energy.

In addition, Hutzler indicated (Hut80) that the treatment of renerable energy resonrces in Model 22C did not parrant sensitivity studies. (Some later models based on the LRAP system have a more detailed treatment of "renewables.") 


\section{B. Solected Rosponses and Acouraey Targets}

Because LEAP Mode1 22C was a pub1ic information model designed to cover the entire energy system, a great many responses of interest to nsers conld be defined consistent with the criteria listed above. Table III.2 lists representative responses believed to be significant. Note that most of the responses are defined to be dimensionless. For illustrative purposes, they focus on varions parts of the Mode1 22C network; complete supporting information is given in Appendix B. The highest priority was given to projections relevant to those topics considered to be great energy issues of the day: (1) the cost of energy, especially the portion that affects the international payments balance, and (2) the interplay between national energy independence and how liquid fuel demand can be satisfied. Issues of silghtly less importance include: (1) the extent to which coal resource use can be expected to dominate the energy market, (2) the projected degree of electricity use, and (3) identification of the demand sector expected to be most important in the future. The last response in Table III.2 is a combination of derivatives of model variables with respect to a model parameter. Responses of this form should be useful in analyses of Red priorities. Some important long-term model responses (e.g., those involving explicit conservation efforts, solar energy, and other renewable energy resouroes) were omitted from Table III.2 because they cannot be supported in a Mode1 22C analysis (see Het80).

The 1ist in Table III.2 is too long to permit completion for each item listed of a comprehensive adjoint sensitivity analysis within the time frame of this study for inclusion in Sect. IX; however, some "direct" sensitivity results, based on Model 22 reruns using altered input parameters, are given in that section for all but the last response. Note that the time dependence of the responses often carries the most interest. For this roason, numerical values 
Trer III.2

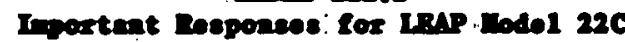

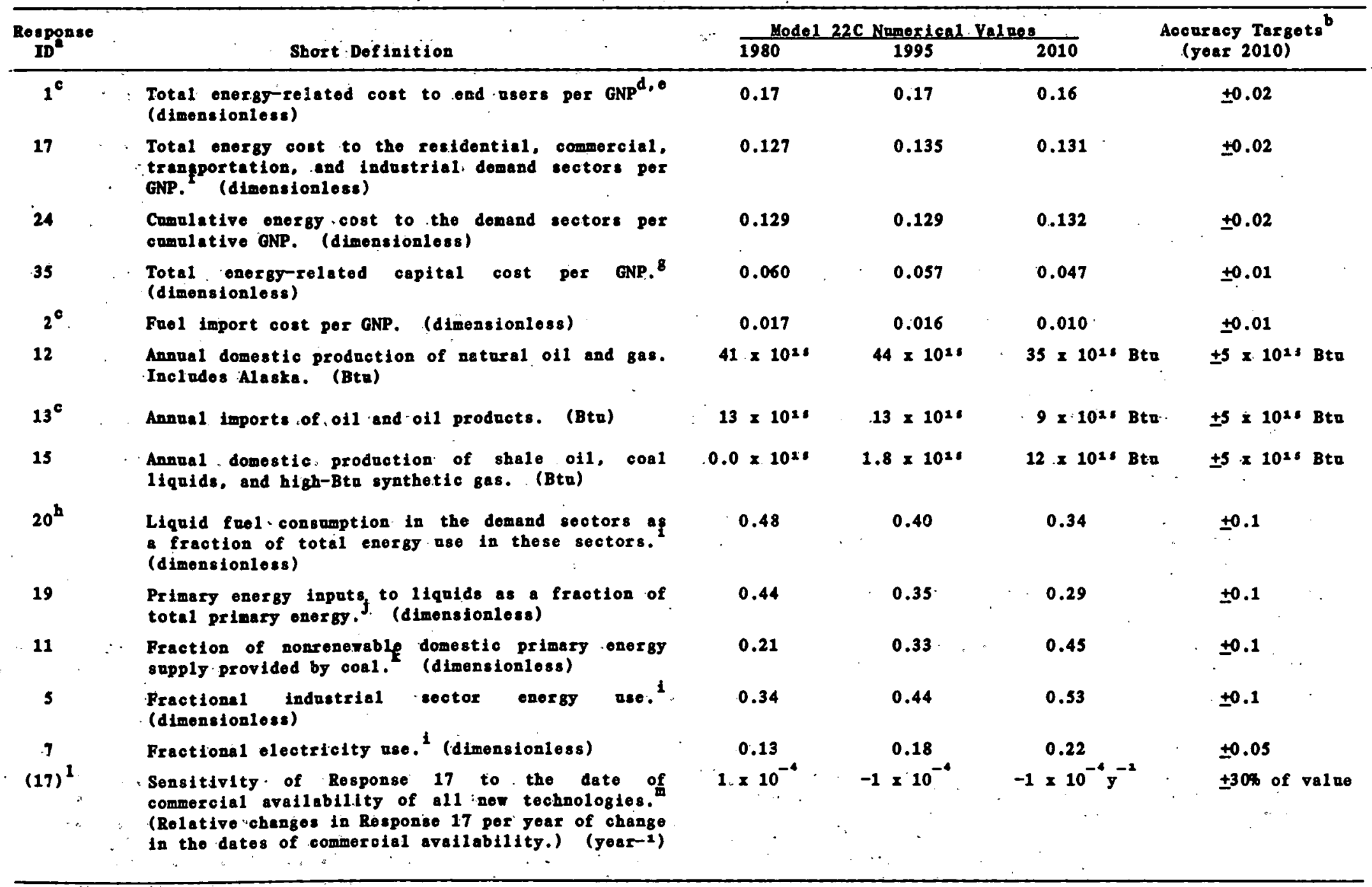


a These identification numbers are the key to the explicit response definitions of Appendix B.

bhese "accuracy targets" were estimated by the authors to orient the reader toward the general magnitude of projection accuracy necessary and are not firm data based on assertions by nsers. There is no Implication that Model $22 \mathrm{C}$ did or did not achieve these targets. A model vonld not necessarily have to achieve these target accuracies to be useful. particularly for scenario analyses contingent on major stated assumptions. The accuracy targets for each response are defined such that if the square root of the variances of the model projection. of that response is sualler than the estimated accuracy target, certain detailed conclisions from that response projection are expected to remain valid.

cThese responses for year 2020 mere used for the detailed adjoint sensitivity analyses given in Section IX.

Computed from link date to end-use demand activities.

Based on 1975 GNP of \$1.53 x 1022 (in 1975 \$). Report of the (J.S.) Conncil of Economic Advisors, D.S, Government Printing office, p. 183. (January 1979). The model input assumes that the 1980, 1995 , and 2010 GNPs will be \$1.9, $\$ 3.0$, and $\$ 4.3 \times 10^{22} .(1975$ \$), respectively. All model energy cost data are also in 1975 dollars.

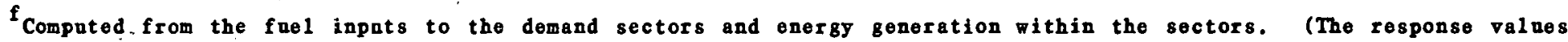
here and for Response 24 are printed to unwaranted precision to show how small the differences are among the computed values.)

${ }^{8}$ The transportation sector is not. included because of the parameter errors indicated in. Sect. $X$ and in the report by Stewart and Goldstein (Ste81). As calculated in Mode1 22C, transportation sector capital costs are negligible. The model's values of implied capital investment for the resource and electric utility sectors appear to be inconsistent with the 1975 valoes for eapital expenditures in Table 7.1 of ARC-78 (EIA79a) (see Table B.1, Appendix B of this roport, especially footnote a). As indicated in Sect. II.B, the transport process (gas pipelines, etc.) does not explicitly consider capital cost.

Adjoint sensitivity studies are reported in Section IX for the 2020 value of a closely related response in which total energy use does not include renowable energy generated within the sectors or the pipeline gas and electric line losses taken here to be transportation energy uses. Compared to a total projected energy use of $94 x 10 x$ Bta in 2010, these components are given by the model as $0.00,0.7$, and $2.3 \times 10^{2 s}$ Btu.

Isectoral electricity lnputs ere valued at their heat content. Total is based on residential. industrial, commercial, and transportation sectors measured at the sector input, plus generation within demand seotor. Bxported coal is not incladod. Pipelino gas and electric line 10888 are incladed (as part of the transportation component).

jotal primary enorgy inclades that obtained from. both renowable and nonrenewable resources.

Kefers to energy supplites esed donestically. Thas, exported coal is excluded, but imported fuels are incladed. Renerable resonrces aro excladod (geothermal is considered renewable here).

1 No sensitipity studies are presented in this report on responses of this typo that are themselves approximate dorivatives or consitivity coofficients. The valwo here was obtained from the change in Rosponso 17 from a negative s-yeax change. in the date of availabiltty rising Run 44 as dofinod in Appondix C.

"Includos "yoar of availability" ohanges for shalo" oli, all gynthotic fuel tochnologies, and the folloring nev olectric generation technologies: central renerables, low-Bto ges combined cyclo, fluidizod bod coal, biomss, coal-kibD, and advancod necloar. A sonsitivity of -3 y 10-4 was soon for goar 1990. Note that in Model 22C domestio oll prodnotion rises throngh yoer. 1995, and laported oll is rether inemenatvo. Soe Soot. IX.A, Caso 44 , for tho more dofinite offocts of this set of paranetor changes. 
are given for spaced time points through the year 2010.* Additional values are given in Table B.1 of Appendix B.

Some qualitative points should be noted. Most of the responses of Table III.2 are structured as ratios to isolate particular projected behaviors from the overall growth of the economy. Because the values of the deniominators axe known, the absolute quantities (numerators) can be recovered. The numerical values presented suggest, in some cases, a placid or even dull energy future (e.g.. the cost per GNP of energy to the demand sectors does not change): The near-constancy of the energy cost to the demand sectors (response 17) may obscure the future conservation efforts that were assumed by the modelers in formulating the input data (e.g., antomobiles with four times the present vehicle miles/gal). Other values, particularly for total energy-related capital costs, appear to bo inconsistent with present information (see footnote $g$ on Table III.2).

To indicate in an approximate way how accurate the projections of the priority responses must be to avoid leading the user toward an onsupported insight or conclusion, "accuracy targets" have been estimated by the authors and are listed in Table III.2. If model specification tand input data uncertainties imply a'projected response uncertainty, much larger than a target accuracy, tho'information formulated in LEAP Hode1 22C may not support the nser need on which the target value was based. Note, however, that the target accuracy values in Table III.2 are anthor estimätes rather than hard.data baṣed on nser'assertions.

-The year 2020 time point is not used in Table III.2 because, for. some conversion activities (anto-oil in the transportation sector in particular), the year 2020 prices and especially the capacity additions are inconsistent with extrapolated values based on the smoothly varying resilts for earlier timio points. : "Such inconsistencies may be expected from LEAP-78 because of the form of the resource and energy conversion submodels. 
The target values are important and valuable to establish the general magnitude of the uncertainty tolerable in the projected response values. These estimates of target accuracy were included in Table III.2 to permit the analysis in Sect. XI comparing these values to estimated data-related numerical uncertainties in key model results. The anthors' previous experience in engineering studies suggests the desirability of such comparisons even if the model is to be used primarily to gain "insight" through qualitative conclusions from mode 1 results.

Note that the accuracy targets, as well as the minimum projected uncertainties given in Sect. XI.A, are much broader than the accuracy implied by the number of digits usually printed from a model output. This outcome is fortunate because the underlying energy economy cannot be aggregated with a precision of 1\%. A recent "Topics" column on a New York Times editorial page (NYT80) makes this point nicely (emphasis added):

We mean this year also to carry the Enemy Words battle onto a second front: numbers. Even if literally correct, they can be used as mindlessiy and carelessly as words to undermine meaning and even truth. Consider this line from a current magazine: "According to the F.B.I.'s Uniform Crime Reports, violent crime rose 47.3 percent during the 1970's."

There's no doubting the literal accuracy or the source of the figure. But what docs that ".3" mean?

It implies that crime rates over a decade can be measured accurately down to a tenth of a percentage point. It implies that the writer has found data of surgical precision. And it implies that the surrounding words and thoughts are as impressive1y exact as the number. A11 such implications aro unjustified.

Crime cannot be measured so precisely, no matter how good a job the F.B.I. does gathering statistics, for there is wide variation in the quality of reporting.

And even if reporting were better, crime would still be understated.... Where does that leave the .3 in 47.3 ? If crime is truiy two times higher, would the "accurate" figure be 94.6 percent? 
No. The .3 is not a significant number; the 7 probably isn't either; and even the 4 may be off. It wonld be more accurately informative to say that "violent crime increased by about 50 percent in the 1970's." This is no isolated example; others arrive every day in, say, economic forecasts carried out to even more decimal places. They all look precise; in fact, they exaggerate truth. Banned.

Convenience often leads to printing of digits that an author would not defend. The following detailed points explain the choice of responses and the magnitude of the assigned tolerances:

- Total energy-related end-use cost per GNP (Response 1) is the simplest approach to a total energy-related cost per unit GNP. This response is computed using price and quantity values on the network links that feed the final demand activities at the top of each network diagram in Appendix A. However, the cost of the furnace that uses the energy is included here, although it is not included in the common understanding of energy cost. Also, the value is perturbed by the incorrect (too sma11) capital cost and nonfuel operating cost parameters in the transportation sector, as indicated in Sect. $X$ and in the report by Stewart and Goldstein (Ste81). The accuracy target was estimated from the great economic importance ascribed by national leaders to oil price deregulation, which added roughly $\$ 4.1010$ per year to the nation's energy costs compared to a 1979 GNP of abont $\$ 2.4 \times 10^{12}$ in current dollars.

- Annual and cumulative energy cost per GNP for the four demand sectors (Responses 17 and 24) handle energy costs per unit GNP based on model fuel costs at demand sectior inputs, in agreement with the concept of total energy cost rather than total energy-related cost. Response 24 deals with cumulative values for this ratio with no disconting. The values are printed in Table III.2 to unwarranted precision to show the urexpected constancy of the numerical values for the Model 22C 
analysis. Note that this constancy does not imply equality of the corresponding sensitivity coefficients. The accuracy target is estimated ụsing the same values used for Response 1 above.

- The total energy-related capital cost per GNP (Response 35) addresses the question of whether energy-related facilities will strain the capital markets. Scaling the values by use of the GNP is an approximation becanse the debt portion should be scaled against the expected totals in that market, and the equity portion should be scaled against the projected net profits in the industrios involved. The former scaling factor is not available in the model. The response values are actually obtained from the net present value of capital cost computed for each activity in the LeAP-78 program." Because there is inarked concern about differences in federal budget imbalance on the order of $\$ 20$ billion, partly because of feared impact on the debt market, an accuracy target of 0.01 GNP is assigned.

- The energy import cost per GNP (Response 2) addresses fuol import cost (not net of coal export). This quantity is considered more sensitive than total energy. cost becanse the international payments balance is involved, and changes as small as 0.01 of GNP are regrlarly considered quite significant (e.g.. at present, a change of 0.01 corresponds to a change of about \$15 per barrel of imported oil, assuming current import of about $2 \times 10^{\circ} \mathrm{bb} /$ /year of oil):

- Responses measuring domestic oil and gas production, oil and oil product import, and synfuel production including shale oil (Responses 12, 13, and 15), address the crucial question of how liquid fuel noeds will be met. They axe based on the assumption that imported gas will not become important and that domestic natural gas and syngas can replace liquid fuel. The 
accuracy targets of about 5 quadrillion Btu/year are based on widespread concern that world oil supply can be unbalanced by world consumption (or production) changes of about $2 \times 10^{6}$ bb1/day of crude oil. (This accuracy target value is most appropriate for oil and oil products imports.)

- Values of the total liquid fuel consumption in the four demand sectors (see top of Fig. II-1), relative to total energy use in these sectors (Response 20) provide potential users with an insight on the future relative dependence of the demand sectors on liquid fuels. The accuracy target was assigned so that a response uncertainty larger than the value given would imply that a user would probably be misled.

- Relative (1) primary energy to líquids, (2) energy supply from coal, (3) energy use by the industrial sector, and (4) electricity usé (Responses 19; 11, 5, and 7) were 1 so chosen to emphasize major relative energy flows, and, as is true for Response 20 above, the accuracy targets were assigned to assure that the numerical data for these responses can support qualitative user conclusions.

- The sensitivity of energy cost per GNP to the year of commercial availability of all new technologies, the last response in Table III.2, has a form that is important to R6D priority studies. It includes all the undeveloped technologies in Mode1 22C; therefore, this response addresses only the global question of whether successful efforts to speed the development of new technologies could produce national energy cost reductions. The accuracy target was assigned on the basis that, in such analyses, one must have great confidence that the sign of the difference (benefit minus cost) is supported by the projection. If the response is extremely sma11, as indicated by Mode1 22C, the relative accuracy target should be broadened. Responses of similar form (sensitivity coefficients) would 


\section{III-15}

likely be of greater interest if confined to particular classes of new technologies.

The responses 1 isted in Table III.2, together with their detailed definitions and components given in Appendix $B$, are representative of those that would be of interest in the outpnt of any long-term onergy model; but the list would be broader if Model 22C had wider applicability (see Sect. VII). More thorough analysis would likely lead to values of accuracy targets typically varying by $50 \%$ or more from those assigned, but such refinement is unwarranted until full model ontput uncertainty analyses become available.

Future evaluations would benefit from inclusion of response definitions designed to (1) focus directly on trends rather than on point values and (2) relate more directly to policy options. 


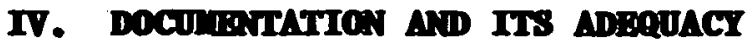

This section evaluates LEAP documentation from the perspective of (1) a reader of output information (e.8., ARC-78) who wants to understand the basis of that information and (2) a potential user of the LEAP modeling system. Documentation standards have been established for models used by the Office of Applied Analysis (OAA) of the Energy Information Administration (EIA) (Lad78). A comparable sot of documentation standards has been given by the O.S. General Accounting Office (USGAO) (GA079). These standards have been described by Weisbin et al. (Fei81), and a list of standards that includes the recommendations of both the OAA and the USGAO is given in Tables 4 and 7 of that report. To date, the documentation of few, if any, energy models conform in all particulars to these comprehensive standards.

LEAP is a general modeling system. LEAP-78 is the version of the system and Model 22C is the specific model that were used for the 1978 Annual Report to Congress (EIA79a). Documentation may refer to the LEAP system, to LEAP-78, or to Mode1 22C. However, the LEAP system is continually changing, and therefore documentation of the LEAP system may often be ont of date, at least in detail. LRAP-78 and Model 22C, on the other hand, are static in the sense that the FORTRAN oode for LRAP-78 and the model inpot tables for Mode1 22C that describe the network and all input data are fixod (For81). The evaluation here will be primarily concerned with the documentation available for LEAP-78 and Model 22C, but at the end of this section some comments on the documentation of the general LEAP system will be given.

\section{A. Docurontation by LMAP lodelers}

The Hodel 22C results and some discussion of the assumptions used in obtaining these results are given in the 1978 Annual Report 
to Congress (EIA79a). This discussion is very general, and while it provides considerable information on the results, it provides relatively little information on the details of obtaining the results. Some of the discussion in ARC-78 (EIA79a) has been documented in the report by Kydes and Pearson (Kyd79). Considerably more information on Model 22C is contained in the work of Diedrich et al. (Die79). This document provides substantial information on the Mode1 22C network and some information on the sources of the data used in Model 22C. Unfortunately, the data source information is, in the majority of cases, nonspecific, and it is not possible for the reader to determine exactly where a specific data value came from or how it was chosen (Ste81). The numerical values used are available from the model input tables (For81), but considerable information about the operation of the code is required before it is possible to understand how these values are actually used in the FORTRAN code, a listing of which is also available (For81). The FORTRAN 1isting contains a goodly number of comments, and this helps considerably in understanding the code.

A user's guide to the LEAP system used in LEAP-78 is available (Coh79). This user's guide gives specific information on the operation of LEAP-78 and describes how data may be modified in the Model 22C data base to carry out sensitivity studies. The user's guide does not address the questions of how a completely new set of model input tables may be constructed to form a new network and a new data base.

The mathematical methodology of LEAP-78 is considered in some detail by Falk et al. (Fa179). This report describes the LEAP-78 methodology and attempts to place it in the context of general economic theory. This is done rather generally, however, and the report does not include a description of all the equations ised in LEAP-78. This report also includes a rather extensive discussion 


\section{IV-3}

of the solution techniques that are used to solve the large set of nonlinear equations that constitutes LEAP-78.

The quite complex resource submodels in LEAP-78 are documented in the work of Cherniavsky and Juang (Che80). One of these resource submode1s (CESORC) is different from that used in any of the antecedents to LEAP-78, and thus docamentation of this submodel was much needed. In this reference, the equations used in these LEAP submodels (RESORC and CESORC) are presented, and some discussion of the rationale behind the equations is given.

The documentation described in the previous three paragraphs is essentially all of the documentation of LEAP-78 and Model 22C that is available from the OAA. It is not quite all in that there are several internal memoranda that are very helpful, but these are not considered here as documentation because they are not publicly catalogued. It should be noted that much of the documentation discussed above (Kyd79, Die79, Coh79, and Che80) is available only in draft form and thus may also not be readily available to everyone. The documentation from the $O A A$ is extensive, but does not, in our view, satisfy the standards set out by the OAA (Lad78) or by the USGAO (GA079). The documentation of LEAP-78 and Mode1 22C is deficient in that (1) the complete set of equations used in the model is nowhere available, other than in the FORTRAN listing, and (2) the information required to construct new model networks with new data bases is not available. The forms of the DEMAND and TRANSPORT equations were not given at a11 in the antecedent documentation most pertinent to LEAP (Ad179). Finally, the OAA documentation is deficient in that sources of the large number of parameters in Mode1 $22 \mathrm{C}$ are not available in enough detail to allow a reader to determine independently whether or not the data values used were reasonable.

Available OAA documentation does not include a sample problem for LEAP-78. A sample problem (small mode1) that requires only very 
modest amounts of computing time is a useful learning device and should be included as part of the documentation. [Such a sample problem was developed at the Oak Ridge National Laboratory (ORNL) from material supplied by the OAA and was partially documented by Ford et a1. (For81) and by A1smiller et a1. (A1s80, Sect. IV), but was not documented for external use.]

Some understanding of LEAP-78 and Mode1 22C can be obtained by studying the documentation of the other models of the same family as LEAP (Caz77, Caz79b, and Ad179), but because this documentation does not refer to LEAP-78, all material must be carefully checked for compatibility with the FORTRAN listing of LEAP-78. Therefore, the reports on related models do not, in our view, serve as adequate documentation of LEAP-78.

\section{B. Docwentation Aids from tho Bvaluation Bffort}

As part of the OEIV work related to the ORNL program on the evaluation of LEAP-78 and Mode1 22C, considerable information on LEAP-78 has been pub1ished. This information effectively supplements the documentation by the modelers. In particular, the Office of Energy Information Validation (OEIV) of the EIA has, by using some preliminary ORNL results and extensive independent effort, published an Analysis Quality Report of LEAP-78 (OEI80). This OEIV report attempts to assess the level of uncertainty of the Mode1 22C forecast and, in so doing, provides considerable information about many aspects of LEAP-78 and Mode1 22C. The documentation produced by ORNL is included in the numerous evaluation reports that form the basis of the present report. Much of the ORNL documentation is referred to throughout the present report, but for the sake of completeness, a very brief description of it follows. The complete equations of all the submodels used in Model 22C have been given by Goldstein et a1. (Go181a). Complete and, in some cases, corrected parameter definitions (relative to Ad179), together with cross references to 
the parameter names used in the equations of Goldstein et a1. (Go181a) and the FORTRAN code, have been given in the report by Stewart and Goldstein (Ste81). This report (Ste81) also describes in some detail the data used in Mode1 22C. The convergence algorithm used in LEAP-78 and the mathematical properties of the model are described by $0 \mathrm{blow}(\mathrm{Ob} 181)$, and the economic foundations of the submode1s used in LEAP-78 are discussed by Hansen et a1. (Han81). Experiences with replicating the results of Model 22C and with carrying out parameter variations have been described by Ford et al. (For81), and the analyses of the results obtained with these parameter variations have been given by Stewart and Goldstein (Ste81) and in Sect. IX.A of this report. The report by Ford et al: also describes in some detail the problems that new users of the LEAP system might encounter. Finally, for several results of interest, the most important data parameters determined by applying adjoint sensitivity theory have been given (A1s81) (see also Sect. IX.B of this report).

\section{Docwentation of the Brolving LRAP Systen}

Al1 of the documentation referred to above, with the possible exception of the LEAP nser's guide (Coh79), refers specifically to LEAP-78 and.Mode $122 \mathrm{C}$ and not necessarily to the current LEAP system. The evolving LEAP system has changed, at lèst in some respects, sinoo the 1978 Annual Report to Congress (EIA80). From the network diagrams provided in the 1979 Annual Report to Congress (EIA80), it is clear that the model used in 1979 is somewhat more complex than Mode1. 22C. From the discussion in the Appendix, it seoms clear that some of the equations of the process submodels have been changed, but the changes are not specified in detail. Because the information contained in the 1979 Annual Report to Congress is the only documentation that is available (other than a FORTRAN listing of the LEAP code nsed and the model input tables), this model is essentially undocumented. The documentation of LEAP-78 is still to 


\section{IV-6}

some extent applicable, but the degree of applicability will not be known until the changes between LEAP-78 and LEAP-79 are documented. 
TA:TS IV-1

Arailab10 Doownentation on LRAP-78 and Modol 22C

\begin{tabular}{|c|c|c|}
\hline Standard & Doowentation & Coments \\
\hline $\begin{array}{l}\text { Model purpose and } \\
\text { capabilities }\end{array}$ & $\begin{array}{l}\text { Ad179*, Als80, A1s81, EIA79a, } \\
\text { EIA80*, Caz77*, Caz79b*, } \\
\text { Die79, Han81, OEI80 }\end{array}$ & Adequate \\
\hline $\begin{array}{l}\text { Logical (physical, } \\
\text { statistical, eco- } \\
\text { nomic, engineer- } \\
\text { ing) structure, } \\
\text { rationale, and } \\
\text { assumptions }\end{array}$ & $\begin{array}{l}\text { Ad179*, EIA79a, EIA80*, Fa179, } \\
\text { Che80, Han81, OEI80 }\end{array}$ & $\begin{array}{l}\text { Substantial information, but not } \\
\text { completely adequate in all } \\
\text { details. }\end{array}$ \\
\hline $\begin{array}{l}\text { Mathematical des- } \\
\text { cription including } \\
\text { equations of model, } \\
\text { method of solntion, } \\
\text { and limitations im- } \\
\text { posed by mathemati- } \\
\text { cal model }\end{array}$ & $\begin{array}{l}\text { Ad179*, Als81, Che80, Fa179, } \\
\text { Go181a, Ob181, ORI80, Ha180 }\end{array}$ & $\begin{array}{l}\text { The description of Hodel } 22 \mathrm{C} \\
\text { is adequate, but some of the } \\
\text { generality allowed in LBAP-78 } \\
\text { and not used in Hodel } 22 \mathrm{C} \text { is not } \\
\text { covered. }\end{array}$ \\
\hline $\begin{array}{l}\text { Data analysis: qual- } \\
\text { ity and sonrces }\end{array}$ & Die79, Han81, OEI80, Ste81 & $\begin{array}{l}\text { Not adequate. Complete data } \\
\text { base and definitions have been } \\
\text { published, but most parameter } \\
\text { values have not been explained } \\
\text { in terms of published or other } \\
\text { specific sources. }\end{array}$ \\
\hline $\begin{array}{l}\text { Software/hardware } \\
\text { information }\end{array}$ & Caz79b*, Coh79, For81 & $\begin{array}{l}\text { Information about constracting new } \\
\text { networks and data bases for such } \\
\text { notworks is available ouly iu } \\
\text { Caz79b*, and this information is } \\
\text { not specifically for LEAP-78. }\end{array}$ \\
\hline $\begin{array}{l}\text { Transportability } \\
\text { and osage }\end{array}$ & Coh79, For 81 & $\begin{array}{l}\text { Adequate for operating the model } \\
\text { on the EIA computer, bnt } \\
\text { not adequate for implementing } \\
\text { LEAP-78 on some other computer. }\end{array}$ \\
\hline
\end{tabular}

-This documentation 18 very helpfal in anderstanding LEAP-78 and Mode1 $22 \mathrm{C}$, bat it does not apply specifically to LEAP-78 and Model 22C; therefore, specific informetion in these documents may not be appilcable. 
IV. 8

THIS PAGE

WAS INTENTIONALLY

LEFT BLANK 


\section{Conclusions and Recomendations on Docunentation}

When all of the documentation mentioned above is considered, it is our view that for LEAP-78 and Mode1 22C many, but not a11, of the documentation standards of the OAA and the USGAO are satisfied. This view is summarized in Table IV-1, where a list of documentation standards (Wei81, Table 7), together with the references that apply to each element in the list and comments on that available documentation, is given. As indicated in the table, the most serious deficiency is in the area of input data traceability, where the information available is not adequate for a concerned user of the model output to determine if appropriate values of input parameters have been chosen and not adequate for EIA to evaluate the worth of a proposed change. In several other areas, the available information is incomplete, but the inadequacies are, in genera1, not thought to be nearly as serious as those in the area of input data documentatiơn.

The full documentation of a model system as complex as LEAP-78 and of a mode1 as extensive as Mode $122 \mathrm{C}$ is an extreme1y time-consuming and expensive procedure. If the policy of improving the LEAP system and providing a new projection each year based on an extensively revised network and data base is to be continued, a very substantial effort will be required to keep the documentation carrent. If, on the other hand, the documentation is not kept current, the information required to assess the meaningfulness of the projections will not be available. To some extent, documentation of a new model would be easier if it could be referred to a well-documented previous mode1, but this is still a formidable task if the mode1s in question are as different as Mode1 $22 \mathrm{C}$ and the long-range model used in the 1979 Annual Report to Congress (EIA80). In our view, a long-range projection by a public information agency is useful only if it is accompanied by adequate documentation. Therefore, our recommendation would be that available resources be allocated between projections 
and documentation so that adequate documentation can be available with the projection, even if this means that projections are not possible on a yearly basis. 


$$
\mathrm{V}-1
$$

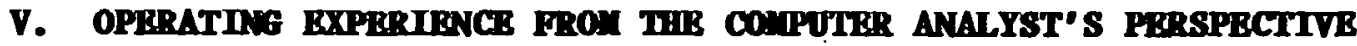

As defined in the Oak Ridge National Laboratory (ORNL) evaluation guidelines (Wei81), this evaluation component documents the experience obtained in actual operation of the LEAP-78 model from the point of view of a computer analyst--one who works directly with the mode1 program and its input/output. This evaluation component entails reporting "hands-on" experience, including:

- Precise model definition.

- Model access and assessment of mode1 transportability.

- Generation of sample problems.

- Report of cost, computer running time, and learning investment.

- Review of plans for continued model maintenance.

- Experience in obtaining solutions and rcplicating results.

The material in this section, which discusses each of these items, is drawn from the more detailed work of Ford et al. (For81).

\section{A. Precise Definition of the Model}

The LEAP system consists of the LEAP computer code, including its data editing and display system: a data transfer system; and a data base storage system. The entire system was the responsibility of the Long-Term Energy Analysis Division (LTEAD) of the Integrative Analysis Group in the Office of Applied Analysis (OAA) of the Energy Information Administration (EIA). A frozen version of the LEAP-78 program and the Model 22C data base were made available to ORNL in June 1979 .

Ford et a1. (For81) provide a microfiche listing of the LEAP-78 source program (211 subroutines) and input tables that characterize the Model 22 network and the Model 22C data. Also included in 
the Ford report are subroutine hierarchical flowcharts that indicate the calling relationship between routines. Finally, Ford provides the job control language needed to execute LEAP-78, and Mode1 22C in particular. Hence, complete information is presented which characterizes the ARC-78 (EIA79a) version of the LEAP mode1 being evaluated.

\section{B. Modol Access and Assessment of Model Transportability}

The LEAP-78 system is not easily transportable. The LEAP data base is accessed by the LEAP code via a commercial data base management system, System 2000 ( $S 2 K$ ). S2K is leased by EIA (MRI Systems Corporation) and is provided as a software package on the EIA computer facility. The proprietary nature of the LEAP data base management system and the severe core memory requirements (about 2 megabytes for Model 22C) are two principal detrimental factors affecting transportability.

Mode1 22C (and similar LEAP-78 mode1s) is executed remotely by ORNL on the DOE Forrestal Computing Facility (FCF) in Washington, D.C. Project personnel must adhere to the DOE-FCF computer system security and privacy policy. Putting an acceptable remote configuration into place took several months. Now that a remote system is in place, the communication link is proving to be an adequate system for executing LEAP and other EIA models in connection with model evaluation. The precise configuration of the ORNL segment of the ORNL-FCF 1ink (including terminals, printers, transmission rates, and maintenance of equipment) is described by Ford et a1. (For81).

\section{Generation of Sample Problens}

The modular structure of LEAP allows construction of very simple models that, al though much less complex than Model 22C, still contain major features of the LEAP system. Availability of such a model was deemed essential for the LEAP evaluation because research could then 
be performed on a model that runs in less than 1 min CPU rather than the half hour sometimes required by Model 22C. Existence of such a model would be important to any new user of LEAP.

"Mode1 88" was provided to ORNL by LTEAD as an illustrative example of a relatively simple network. LTEAD had used this model in early stages of gaining familiarity with LEAP. ORNL developed a simple two-sector model (denoted as Model 82) by combining the Mode1 88 network representation with relevant data drawn from the Mode1 22C input tables (Als80, Chapter IV). This sample problem has the same core requirements as Mode1 22, but exhibits adequately short running time.

It must be pointed out that, although many variations in data were conducted during the course of this study, there was no case in which the ORNL model evaluation team built an independent network. The team has significant experience with 1arge (Mode1 22C) and smal1 (Mode1 82) LEAP-78 networks, but the course and resources of the evaluation process did not afford the opportunity to explore firsthand the LEAP system with respect to mode1 building.

\section{Cost, Computer Tino, and Lesrning Investment to Operate LRAP-78}

Execution time for a LEAP-78 problem that is as complicated as Mode1 22C depends on values assigned to input parameters, the quality of the starting guesses for prices and quantities, and the convergence criteria used. A typical rule-of-thumb is that about 25 seconds per iteration on the IBM 3033 at the DOE-FCF and 10 to 100 iterations are required to obtain convergence ( $\leq 1 \%)$, using the modified (constant a) relaxation technique suggested at the end of Sect. VI.C.

Because of the compating region requirements (about 2 megabytes) and computing time required ( $>2$ min CPU) to execute a typical case, the DOE-FCF computing system places LEAP in a job class that usualy iesults in tho job boing execnted after normal working hours. This 
classification leads to a real turnaround of 1 or 2 days, depending on the FCF workload and the operational status of equipment.

Personnel with extensive experience in computing applications were selected to execute LEAP. We estimate that it now takes approximately 1 month for such an individual (at ORNL, for example) with no prior LEAP experience, to gain expertise in running LEAP problems independently using the ORNL-FCF computing link. This estimate assumes initial familiarity with IBM operating systems and time-sharing terminals, but no prior experience with the several software systems associated. with LEAP and the FCF (e.g... Executive, S2K, PERUSE, DFI Computer Modeling Software, SUPERWYLBUR).

Part of the significant ORNL startup time (several months) had to do with the time required to establish the computing link, the remote operation (1ack of easy proximity to the modeler), and problems with documentation.

Throughout the evaluation, the LTEAD personnel provided invaluable assistance to ORNL personne1. The LTEAD staff freely shared I.F.AP snnree decks, load modules, and dala bases and rèsponded to innumerable questions. LTEAD provided draft copies of evolving documentation and provided job control languge to facilitate execution: Without such cooperation, it is doubtful that this evaluation could have been completed in its present form.

\section{B. Revier of Plan for Continued Maintenance}

There is now a policy within EIA to archive versions of codes and data sets used in the generation of supporting material for the Annual Report to Congress. This policy was formally instituted after the ARC-78 effort. Although its effectiveness is not yet completely tested, archiving is undoubtedly an important step toward assuring that the entire calculational process could be reproduced. Archiving of LEAP models requires detailed information because it is evidently 
common practice to stop the calculation during execution, make a change (e.g., in a relaxation parameter), and restart.

In the future, it would be desirable to take steps to make LEAP generally available becanse critical review and use by the private sector (e.g., universities, laboratories, industry) might add considerably to the credibility and improvement of LEAP. The documentation developed in the course of this project should help in this regard. However, a nonproprietary data base management system and considerably. reduced core requirements seem to be essential development requirements. Through January 1981, the LEAP system has been maintained and used for projections in at least two more EIA Annual Reports to Congress (ARC-79 and ARC-80). Modifications have been made in the system, and a draft user's document for LEAP-80 is available (Coh81).

\section{F. Bxperionce in Obtaining Solutions and Roplicating Roselts}

Considerable effort was expended (For81) to verify whether ORNL could replicate the ARC-78 long-term results (EIA79a) by using the version of LEAP and data sets transmitted to ORNL by LTEAD. A constant relaxation parameter of 0.5 [see Sect. VI.A of this report, Eq. (VI-3)] was used to converge results of Mode1 22C to a relative change of 0.0005 (for quantities greater than 0.1 quad). Because the LEAP-78 system was never actually archived by LTEAD, it is virtualiy impossible (and probably unnecessary) to achieve the exact results of BIA for ARC-78 because the number of iterations, input, and sequence of calculation were not documented. Hence, for purposes of this study, we considered results from ORNL runs to be in agreement with ARC-78 values if they were consistent within $3 \%$ becanse a $3 \%$ convergence criterion in Eq. (VI-5) was used to obtain the Model 22C resu1ts at EIA. Because $3 \%$ differences between small energy flows were considered insignificant, a 0.1 -quad criterion was used for energy flows q such that $0.03 q<0.1$ quad. 
Most of the numbers reported in ARC-78 can be found directly in the Mode1 22C report summary produced by the LEAP-78 program. However, results for residential solar energy use were obtained "off-line" by using logic that is not documented and is not generally available (see next paragraph). Furthermore, assumptions must often be made as to where prices compiled in ARC-78 (EIA79a) were computed, how they were aggregated, and whether they included transportation costs (see Sect. VIII of this report). Tables 5.2, 5.3, and 5.6 through 5.12 of ARC-78 were compared in detail with results calculated at ORNL, and the results are given in the report by Ford et a1. (For81). With only a few exceptions indicated there, all the calculated prices and quantities in these tables from ARC-78 (EIA79a) were replicated within the criteria given above.

The principal exceptions were that values for solar energy enduse consumption in the residential sector are not found (1ess than $1 \times 10^{-3}$ quad/year) in the Mode1 22C output for the solar heat activity; likewise, values for electrical energy usage are less than the value given in the model output by a corresponding amount. Diedrich (Die79) indicates that the lack of adequate data on solax installations led the OAA to "drop" that activity from the model and correct the electric heater activity to cover the combined input. A subsequent communication of Pearson (Pea79) confirmed the modification of the solar and electric contributions based on an of line estimate.

One last comment related to operating experience is appropriate here. In the LEAP runs made (about 100) within the Mode1 22 framework, including those with significant differences in data, convergence was achieved in all cases. For most of this experience, the modified relaxation technique (with constant a) indicated near the end of Sect. VI was used. 


\section{G. Conc1usions}

1. With respect to computer operation, complete information is available which precisely characterizes LEAP-78.

2. LEAP-78 is not easily transportable. The proprietary nature of the LEAP data base management system (System 2000) and the severe core memory requirements (about 2 megabytes for Mode1 22C) are the two principal known detrimental factors affecting transportability. A remote communication 1 ink to the FCF computer complex has proven to be an adequate system for evaluating LEAP and other EIA mode1s.

3. Computing time for LEAP-78 depends on values assigned to input parameters, the quality of the starting guesses for price and quantities, and the convergence criteria used. A rule-of-thumb is that about 25 s/iteration on the DOE-FCF IBM 3033 and 10 to 100 iterations to convergence $(\leq 1 \%)$ using a modified relaxation algorithm are required.

4. We estimate that it now takes about. 1 month for personne 1 with extensive computing experience, but no prior LEAP experience, to gain expertise in running LEAP problems when independently using the ORNL-FCF computing 1 ink.

5. With only a few exceptions indicated here in the text and references, all the calculated prices and quantities in ARC-78 (EIA79a), Tables $5.2,5.3$, and 5.6 through 5.12 were replicated at ORNL within $3 \%$ (or 0.1 quad).

6. In the LEAP runs made within the Mode1 22 framework, including significant differences in data, convergence was achieved in all cases by using a constant relaxation parameter (see Sect. VI).

7. If LEAP continues to be nsed by EIA, steps would be desirable to make the program generally available. Use of LEAP in the 


$$
\text { V-8 }
$$

private sector might clarify the credibility of LEAP and lead to its improvement. For this, development of a nonproprietary data base management system and reduction of the computer memory requirement seem to be essential. 


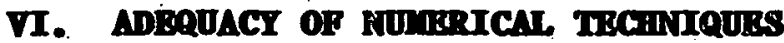

\section{A. Introduction}

This chapter evaluates the mathematical foundations of LEAP in general and LEAP-78 in particular. Following the Oak Ridge National Laboratory (ORNL) proposed evaluation guidelines (Fei81), components include a description of the numerical procedures, the criteria for convergence, the behavior of successive iterations and relaxation schemes, and research related to nniqueness of solution. The material contained herein is important to a user because it governs the meaning of "solutions" to the model equations; it is arawn from the topical report on the mathematical foundations of LEAP (Ob181).

This introdnction discusses the numerical algorithm and is followed by a description of convergence tests (Sect. B).. Relaration techniques used in LEAP-78 are discussed in Sect. C. Section D gives what information is available abont the potential for multiple LEAP solutions. Section $E$ presents conclusions in the area of numerical techniques.

The LEAP model constitutes a set of coupled, nonlinear algebraic equations in prices and quantities over time, represented symbo1ically as

$$
\overline{\mathbf{N}}(\overline{\mathrm{p}}, \overline{\mathrm{q}})=\mathbf{0},
$$

where $\bar{N}$ is a nonlinear algebraic function, and $\bar{p}$ and $\bar{q}$ are vectors representing prices and quantities at discrete time points for all links among activities in the model. The dimensionality of $\bar{p}$ and $\bar{q}$ (i.e., the total number of components) is of the order of several thousand for Model 22. The time structure of Eq. (VI-1) is such that there are time intervals before and after the time period defining the solution space. The needed prices and quantities. in these intervals are specified exogenously or are 
modeled as functions of model parameters and act as boundary values for the problem. Equation (VI-1) can therefore be characterized as a nonlinear boundary value problem. The numerical procedure for solving Eq. (VI-1) is described below in general terms and is then clarified relative to LEAP-78.

An iterative algorithm is used to solve the equations. The physical processes being simulated during iteration correspond to producers determining prices (based on estimated future prices and operating. costs and present capital cost) at assumed output levels; consumers responding with a level of demand for each year corresponding to the price (based on need and competition among producers): and producers revising their prices.

After a complete iteration in which prices and quantities are reestimated for each activity in the network, the quantity of some commodity (denoted as $q_{n}^{(0)}$ ) computed at the $n^{\text {th }}$ iteration is examined relative to the estimate $q_{n}^{(I)}$ of the quantity prior to the $n^{\text {th }}$ iteration. A decision rule is then used in an attempt to improve the estimate for the next iteration. This apdate procedure is of the form,

$$
\bar{q}_{n+1}^{(I)}=q_{n}^{(I)}+A^{-1}\left[\bar{q}_{n}^{(0)}-\bar{q}_{n}^{(I)}\right]
$$

where $A$ is a matrix of "relaxation parameters" (discussed below), and $\bar{q}_{n}^{(I)}$ and $\bar{q}_{n}^{(0)}$ are the vectors of quantities prior to, and at the output of, the $n^{\text {th }}$ iteration.

- Falk (Fa179) notes that LEAP is not formulated explicitly as an optimization problem; standard numerical mothods of optimization solution are therefore not nsed. 


\section{VI-3}

The two special forms of Eq. (VI-2) used in LEAP are the GaussSeidel and successive overxelaxation (SOR) cases. For the SOR case, the matrix $A$ is assumed to be diagonal so that the components of $\bar{q}_{n}$ (i.e., $q_{n, i}$ ) for all model links and time points are relaxed individually by a relaxation coefficient, $a_{i}$ :

$$
q_{n+1, i}^{(I)}=q_{n, i}^{(I)}+a_{i}\left(q_{n, i}^{(0)}-q_{n, i}^{(I)}\right)
$$

Gauss-Seidel is a specific case of Eq. (VI-3) modified further so that $a_{i}=1$ and $q_{n+1, i}^{(I)}=q_{n, i}^{(0)}$ (i.e.. no relaxation).

In general, for all prices and quantities in modules other than allocation, the Gauss-Seidel version of $\mathrm{Bq} .(\mathrm{VI}-3$ ) is used. In all allocation processes, the Gauss-Seidel equation is used for all prices, and a particular version of SOR, denoted Newton-Secant [see Eq. (VI-6) below], is used for input link quantities. The solution technique updates prices and quantities for all times for a given activity before proceeding to the next activity. In LEAP-78, market shares (fraction of total quantity demanded) rather than quantities [Eq. (VI-2)] are actually relazed. The reported capacity additions are also relaxed. Later versions of LEAP (as for ARC-80) were changed in order to relax quantities rather than shares.

When quantities into allocation processes have stabilized to within some user-specified tolerance, a "converged" solution is said to have been attained.

\section{B. Convorgenen Tosts}

As indicated above, the convergence test was applied only to allocation process input quantities; thus, the degree of convergence of all other prices and quantities in the code was assumed to be adequate or was checked manually. (These assumptions did not cause problems for the Model 22 versions studied.) The pointwise convergence test actualiy implemented in LEAP-78 for allocation 
process input quantities differed from that described in the original Decision Focns, Inc. (DFI), documentation (Ad179). The LEAP-78 test vas

mas

$\therefore \therefore$

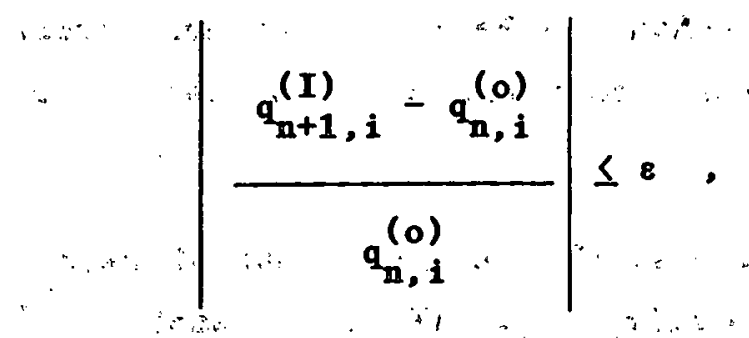

(VI-4)

where $\&$ is the exogenously supplied convergence criteria, and $q$ (I) is the input quantity to the $n+1$ st iteration. Use of Eq. (VI-5), which depends on the value of the relaxation parameter $a_{i}$, rather than the DFI suggested norm,

$$
\left|\frac{q_{n, i}^{(0)}-q_{n, i}^{(I)}}{q_{n, i}^{(0)}}\right| \leq \varepsilon, \cdots
$$

led to convergence of some quantities for ARC-78 to within $e /\left(1-a_{i}\right)$ rather than the desired convergence $(\varepsilon)$, where $a_{i}$ is the relaxation parameter [Eq. (VI-3)]. Becanse $a_{i}$ was about 0.5 for most of the quantities, the reported converged results actualiy satisfy a convergence criteria of abont 28 (i.e., about $6 \%$ in Mode1 $22 \mathrm{C}$ as converged by EIA):- During the analysis of Mode1 22C resuits Eq. (VI-4) was changed to Eq. (VI-5), and the resulting converged quantities were compared with the Model 22C results: No changes greater than $1 \%$ were observed in any major result. The change from Eq. (VI-4) to Eq. (VI-5) has been made in current versions of LEAP. 


\section{Rolaxation}

In an attempt to achieve convergence, relaxation techniques IE். (VI-2)] are applied within the LEAP' system.' However, at least two approximations made while implementing Eq. (VI-2) introduce significant limitations, leaving little theoretical basis for presuming the resulting numerical scheme to be generally convergent (i.e., the accuracy of the result improves as the number of iterations increases).

First, while the DFI documentation describes a Newton-Secant method [a particular scheme for implementing Eq. (VI-2)], each (I) component is actually assumed to act'independently on only $\left.q^{(n, j}\right)^{j}$ This approximation reduces $A$; of Eq. (VI-2), to a diagonal matrix, with the following specification for $a_{i}$ in $\mathrm{Eq}$. (VI-3) based on a secant approximation to the derivative $\left.\partial q_{i}^{(0)} / \partial q_{i}^{(I)}\right)$ :

$$
a_{i}^{-1}=\left[1-\left(\frac{q_{n, i}^{(0)}-q_{n-1, i}^{(0)}}{q_{n, i}^{(I)}-q_{n-1, i}^{(I)}}\right)\right]
$$

This diagonal approximation seems unwarranted because, "at an allocation process, changes in the quantities on one allocation link will surely affeot quantities on another.

Second, the picture is somewhat more complicated becanse Eq.. (VI-6) was not the actual equation implemented in LEAP-78. Rather, what was actoally done is: 


$$
a_{i}^{-1}=\left[1-\left(\frac{q_{n-1, i}^{(I)}-q_{n, i}^{(0)}}{(I)-q_{n-i}^{(I)}}\right)\right]
$$

ORNL was not able to find any theoretical justification or rationale for the use of Eq. (VI-7). Finally; in practice, the values for $a_{i}$ were constrained so that $0.1 \leq a_{i} \leq 0.9$. Thus $a_{i}$ was always positive and less than anity.

The conclusion drawn is that the original LEAP-78 relaxation algorithm [Eqs. (VI-3) and (VI-7)] is not theoretically a convergent scheme because it has not been shown able to reduce the left side of Eq. (VI-5) with increasing iterations when LEAP-78 is started with price and quantity vectors that are close to the solution point (i.e., within 5\% for any mode1). This conclusion is supported by experience on a small test model, which showed that tightiy converged, results are often not achieved. [Mode1 82 is described by Ford et al. (For81) and by Alsmiller et al. (Als80).] Numerical experience also seems to indicate that the most successful choice for $a$ is a constant $(0.2$ to 0.5$)$ rather than Eq. (VI-6) or Eq. (VI-7) when using the scheme described in Eq. (VI-3).

In his evaluation report, Oblow (Ob181) describes a technique for ostimating the A matrix [see Eq. (VI-2)] for a given time and activity using the given allocation process transformation functions. Although this technique appears potentially attractive, it must be tested in practice before drawing strong conclusions.

\section{Uniqueness}

For complex nonlinear problems, such as the solution of Model 22, it is well known that a general equation set can admit multiple solutions. Falk (Fa179) notes that even the mildest requirements to establish existence, uniqueness, and stability (assumptions that are 


\section{VI-7}

relatively standard in the economic literature) do not seem to be met by LEAP. Falk also discesses the possibility that LEAP can oscillate between distinct vectors, neither of which is an equilibrium solution of the system equations. During the course of this study, we were not -able to identify alternative solntions to.Mode1 22C. Pan1 Ferbos (Wer81) has indicated that, under certain assumptions, the existence. of solutions: for LEAP-78 models can be. proven.. 
THIS PAGE ,

WAS INTENTIONALLY
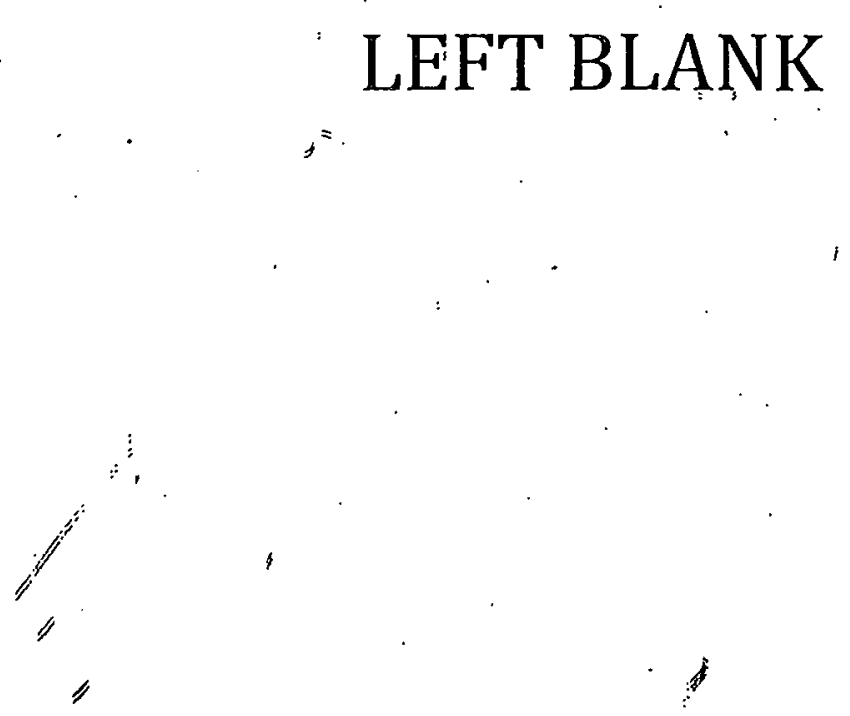


\section{B. Conclusions}

1. The convergence test in the LEAP-78 algorithm was found to be weak in two respects. First, the norm used generally permitted larger changes between successive iterations than would be expected for an assigned tolerance; and second, the convergence test is used only for allocation process inpat quantities, so that the degree of convergence of all prices and other quantities in the code is not automatically tested. The first. problem was the more serious one.

2. The original LEAP-78 relaxation algorithm had at least two theoretical problems. The first problem is the neglect of offdiagonal components (inherently present at allocation nodes); the second problem is the manner [Eq. (VI-7)] in which the diagonal elements were calculated (for which the present evaluation group has not found a theoretical basis).

3. The fact that in Mode1 22C the relaxation coefficient [Eq. (VI-7)] was nearly constant (about 0.5 ) may have helped to achieve convergence in Mode1 22C to the nomina1 $3 \%$ level. However, this success seems fortuitous in the light of experience with a small mode1 using LEAP-78. A method for implementing the Newton scheme, including off-diagonal 'elements, is described in Oblow's report (Ob181), but must be coded and tested before assuming suooess. 


\section{BCONOTIC RODAATIONS}

This section explains and evaluates the conceptual economic bases of LEAP in general and LEAP-78 in particular. The overview in Sect. II described briefly the structure of LEAP and the role of the conversion, resource extraction, allocation, and demand submodels. Each of these "process" submodels is investigated in greater detail in this chapter.

Following the evaluation guidelines of Weisbin et al. (Wei81), the tasks involved in analyzing the rationale and suitability of the model specification include:

- Assessment of major assumptions, structure, and theoretical basis of the model.

- Bvaluation of the statistical foundations for the model.

- Testing of the model, where appropriate, against historical observations.

- Assurance of correspondence between the conceptual and mathematioal model.

- Discussion of consequent domain of applicability and, if possible, comparison with alternative model formulations.

Much of the work discussed herein is drawn directly from the final topical report on the economic foundations of LEAP Mode1 22C (Han81). In particular, Hansen (Han81) details the major assumptions and structure of LEAP and evaluates its theoretical basis. This subject is" covered"in Sect. VII.A. Hansen indicates the very limited use of statistical information; the model is an engineering-economic simulation model rather than a statistically estimated model. Only limited testing of the model against empirical data has been performed; the material reported in Sect. VII.B on such testing is 
taken from the work of Goldstein (Go181b). No work to assure the correspondence between the conceptual and mathematical model has been performed at ORNL; indeed, documentation other than the mathematical model formulation is rarely available to describe the original conceptual approach of the model developer. Information about the domain of applicability of LEAP and comparison with alternative model formulations is presented in. Sect. VII.C. The description of these two areas is developed from the views of the ORNC Model Evaluation Team economists and of the anthors of this report. Finally, a summary with recommendations is offered in Sect. VII.D.

\section{A. Major Assumtions and Bașis of LRAP Lodol 22C}

In any economic mode1, assumptions must be made about the nature of the underlying economic processes and the behavior of the economic agents. Items 1 through 4 below describe these assumptions for the LEAP-78 processes (submodels) for energy conversion, resource extraction, allocation, and demand, respectively. General considerations (discussed in part in Sect. II) include the minimal regional representation and the unlimited supplies of foreign oil at exogenously specified prices (see Sect. VII.c).

\section{Conversion Process}

\section{a. Assuptions}

The conversion process is the mechanism used to model most production activity in Mode1 $22:$ Inputs to each conversion process consist of capital, energy. (feedstock), and labor-materials, A few conversion processes (e.g., solar heat, geothermal, central renewables) have no energy input because they are nondepletableresource-extraction processes that require no primary feedstock. The electric power conversion process is a special case of the generic conversion process, which deals with several load categories (base, intermediate, and peak). 
The economic assumptions that underlie the Model 22C conversion processes are:

- Long-run profit-maximizing producers.

- Fixed coefficient production; no within-process, capital labormaterial substitution.

- Constant returns-to-scale production and perfectly divisible capitai stock.

- Arailability of infinite quantities of capital and labormaterials input at exogenousiy fixed prices.

- Perfect foresight investment (see Sect. VII.A.1.b).

- No within-process technical change, except for exogenous time dependence of some thermal efficiencies.

- Perfectly competitive markets.

- Minimal governmental regulation of economic activity.

- An inflation rate that is commodity and time-independent and that, for Model 22c, is set equal to zero.

- No explicit recognition of net salvage values.

Although many of these assumptions are detailed in Hansen's report (Han81), some of the major ramifications of these assumptions are discussed below.

Becanse of the assumption of fixed-coefficient production, biased results can occur. This bias will appear in three forms. First, to the extent that technology permits firms to adapt their production processes to changes in relative input prices, production costs ill he overstated by the Mode1 22 fired-coefficients specification. In general, there seems to be 1ittle justification for assuming that the elasticity of substitution in LEAP processes should be zero; some aggregate representation of substitution elasticities for the energy 
sectors of the economy seems worth investigating. In particular, investment decisions currently associated with plant retrofitting (e.g., investments that make the existing plant more energyefficient, investments that extend the plant lifes, etc.) could be incorporated if the capability for treating input substitution were available. If an aggregate representation of substitution elasticities is not feasible, then it may be worthwhile to consider explicitly those processes where substitution possibilities are likely to be important and to add greater model detail in those areas. Although input substitution does not occur within conversion processes in Mode1 22, it does occur in substitution between conversion processes.

Second, because the cost of capital is exogenously fired and constant in Mode1 22C, the price of industrial goods used as input to energy production processes does not rise as the energy costs of producing those units of capital increase. Consequently, as the price of energy rises, units of capital will appear to be less expensive in the model than they real1y are.

Finally, the model uses only one energy input for each process (this has been changed for ARC-80). This specification ignores the large quantities of secondary energy inputs that are essential to some processes. Treating this secondary energy-related input as a part of the labor-materials input (which has an exogenously fixed price) will tend to bias the model's results in favor of those processes that require multiple energy sources because the secondary sources will be underpriced. The LEAP structure itself incorporates provisions for several energy inputs; the decision to use only one of these provisions was made by the designers of version $22 \mathrm{C}$. 


\section{VII-5}

\section{b. Imvestment}

- Production in a Nondeclining Indnstry

A nondeclining industry here is one for which product demand is large enough to require some capital addition at a given time. Total current period output is equal to the sum of output from existing plants and current period output from newly constructed plants. Output from an old plant is a function of its operating cost (which, in turn, depends on the plant's age). the output market price (based on new plants), and other mode1-related parameters (e.g., inputs that determine the shape of the capacity factor). Output from new plants is a function of the excess demand for energy (over available supply).

In accordance with the underlying assumptions in LEAP-78, tho following conditions are assumed:

- There is a range of vintages of plants.

- In any period, each old plant can produce at a constant input/ontput ratio np to its nameplate capacity and can produce nothing in excess of that capacity at any price.

- New plants can be constructed so as to produce any desired quantity at a constant input/output ratio.

Specifically, the quantity of energy produced by the conversion process at time $j$ is given by

$$
\operatorname{Prod}(j)=\sum_{k=1}^{j} C_{f}(k, j) \mathbb{N}_{w}(k)
$$


viI-6

where $C_{f}(k, j)$ represents the capacity factor (i.e.. the ratio between actual and maximum possible production) of a plant biilt at time $k$ and operating at time $j \cdot N_{w}(k)$ is the capacity adäitions at time $k$. (A unit of capacity will produce a unit of energy per year if the capacity factor is unity.) Hence, production is directiy related to the capacity factor.

One might imagine constraining production for a plant built at time $k$ and operating at time $j$ as follows:

$$
\begin{array}{ll}
c_{f}(k, j)=\beta & \text { if } P(j)>\phi(k, j), \\
C_{f}(k, j)=0 & \text { if } P(j) \leq \phi(k, j) .
\end{array}
$$

(VII-2)

where

$\phi(k, j)=$ variable operating cost of a plant built at time $k$ and operating at time $j$.

$P(j)=$ price per nnit of energy at time $j$.

$\beta=$ maximum value of the capacity factor.

The developers of LEAP believed that, although this specification was theoretically consistent, it produced abrupt changes that were not generally observed in the real world. As a result, they designed a smoothing mechanism, which enables the nser to specify the capacity factor of old plants as a function of price and operating cost. This mechanism is portrayed in Bq. (VII-3):

$$
C_{f}(k, j)=\frac{\beta}{1+\left[\frac{a \phi(k, j)}{P(j)}\right]^{\gamma}}
$$


VII-7

where $a$ is a capacity factor cost multiplier taken as unity for Mode1 $22 \mathrm{C}$.

In this expression, when $a \nmid(k, j)$ is equal to $P(j)$, tho output from the aging unit of capital is equal to $\beta / 2$. As price exceeds $a p(k, j)$, output increases, causing $C_{f}(k, j)$ to approach the value of $\beta$. As price falls below average variable cost, the denominator in Eq. (VII-3) becomes larger, causing $C_{f}(k, j)$ to approach zero. The rate of change of output with respect to the ratio of price and operating cost is governed by $\gamma$; as $\gamma$ approaches infinity, Eq. (VII-3) becomes a zero/full capacity switch; that is, it behaves as does Eq. (VII-2).

The relationship in $\mathrm{Eq}$. (VII-3) was presumabiy added to make the model more realistic. Unfortunately, Eq. (VII-3) also produces several contradictions with the apparent basic model assumptions. For example, Hansen (Han81) indicates that É. (VII-3) implies a marginal cost curve that is timedependent, rather than the fixed-coefficient, constant returnsto-scale function discussed previously. Thus, the only way in which LEAP-78 can be made internally consistent is if the user specifies a $\gamma$ that is sufficiently high to make Eq. (VII-3) act as a zero/full capacity switch. If $\gamma$ in $\mathrm{Eq}$. (VII-3) is relatively small, this outcome will not occur. In that case, the mechanism will reduce the output of all plants somewhat, rather than shutting down the more ineficient plants (i.e., those plants with highex variable operating costs). In Model 22C, the value actually used is approximately 15.

After determining the level of production from old plants, it is then only necessary to determine the level of output from plants instailed in the current period. This is accomplished by subtracting the output from old plants from the total demand. 
VII-8

The LEAP-78 model is based on the assumption that investment in one type of plant does not preclude other investments in either the current period or in future periods. Therefore, decisions that firms confront daily in the real world, such as choosing between capital projects or deciding whether to delay a project to increase its return, are not modeled in LEAP.

- Pricing in a Nondeclining Industry

Prices from the conversion process are computed from the set of Eqs. (VII-4). The present value of the capital cost for a unit of capacity is set equal to the sum of the discounted stream of net cash flow from that unit. (The capital cost term includes a return on each firm's equity.)

$$
\begin{aligned}
-N_{C o}(j) & +\sum_{k=j+1}^{2 N_{p}+N-1}[P(k)-P(j, k)] C_{f}(j, k) D(j, k) \\
& +\left[P^{\prime}(j)-b(j, j)\right] C_{f G}(j, j) D(j, j)=0, \\
& j=N_{p}+1 \text { to } N_{p}+N,
\end{aligned}
$$

where

$$
\begin{aligned}
N= & \text { number of global time points, points at which } \\
& \text { results of interest are obtained, } \\
N_{p}= & \text { number of local time points before the first } \\
& \text { global time (prehorizon points) and after the } \\
& \text { last global time (post-horizon), } \\
P^{\prime}(j)= & \text { price per unit of energy at time } j, \text { calculated } \\
& \text { from Eq. (VII-4), } \\
P(j)= & \text { price per unit of energy at time } j \text {, equal to } \\
& P^{\prime}(j) \text { except for the last global time point. }
\end{aligned}
$$


VII-9

$$
\begin{aligned}
N_{C o}(j)= & \text { present value of capital expenditure for a unit } \\
& \text { of capacity at time } j, \\
\phi(j, k)= & \text { variable operating cost of a plant built at } \\
& \text { time } j \text { and operating at time } k \text { (defined } \\
& \text { previously), } \\
C_{f}(j, k)= & \text { capacity factor of a plant built at time } j \text { and } \\
& \text { operating at time } k \text { [see Eq. (VII-3)], } \\
C_{f G}(j, j)= & \text { approximate capacity factor of a plant built } \\
& \text { and operating at time } j \text {, } \\
D(j, k)= & \text { discount factor to obtain present value at time } \\
& j \text { of net cash flow evaluated at time } k \text {. (This } \\
& \text { factor includes the spacing of the model's time } \\
& \text { points, usually } 5 \text { years.) }
\end{aligned}
$$

It is assumed that industries setting the price on production from new plants know the vector of all future prices of their product and variable costs for production of their productthat they have perfect foresight. It may be possible to more realistically model investor uncertainty in the future by either (1) exploiting the foresight option in LEAP (not used in Mode1 22C), which effectively takes weighted averages of perfect and 1 imited foresight in some user-defined combination, or (2) explicitly breaking the modeling period into two time frames-one before and one after a "shocking" event-by using different foresight rules or exogenous assumptions in different time periods.

Note that, although each year's production function exhibits constant returns to scale, marginal cost does not equal the average cost of production of plants from all existing vintages (embedded cost) in the model because the cost per unit of output w111 not be equal for plants constructed at different times. LEAP bases conversion process pricing on marginal, not embedded, costs; hence, only plants built in the current period 


\section{VII-10}

are considered when calculating current-year prices. Also, electricity is priced to consumers in a manner that differs somewhat from the pricing mechanisms of other conversion processes. The three types of electricity (base, intermediate, and peak load) are priced separately. Following an allocation process, electricity is priced to consumers as a fixed-weighted average of the prices associated with each load category.

In LEAP-78, the same price is computed for a declining industry as for a nondeclining one (Go181a, Sect. II.B), although a more realistic model would allow the price to drop toward the variable portion of the operating cost.

\section{c. Techrical Change}

Two types of technical change are available in LEAP-revolutionary and evolutionary change. Revolutionary technical change occurs as new processes become commercially available over time (e.g., electric cars, advanced nuclear energy, solar energy). Evolutionary change occurs as more knowledge is gained about specific processes and the costs of these processes change.

In Model 22C, revolutionery technical change parameters include the availability date of each new process, their initial costs and fuel efficiencies, and a "ponalty" for early implementation. Thus, new processes can be brought on 1 ine before their commercial availability dates if a specific penalty is added to the initial cost.

In LEAP, evolutionary technical change parameters are introduced as exogenous factors that affect the amounts of capita1, 1abormaterials, and energy required to produce a given amount of output over time. In the LEAP-78 conversion processes, the amount of labormaterials input per unit of capital input is assumed to increase over time. This device, called an "aging factor," is built into the model to account for the increased maintenance costs associated with older 
VII-11

plants: It provides a method of allowing capital to "die" withont explicitly modeling decisions about the levels of production from old plants. Similarly, by properly setting the parameters, a user can represent a wide variety of labor-augmenting, capital-augmenting, and thermal-efficiency-angmenting technical change scenarios. Although this flexible but exogenous structure of evolutionary technical change is available in the LEAP code, it was not, except for the allowed changes in thermal efficiency, much used in Model 22C. Revolutionary change is the main technical change element used in Mode1 $22 \mathrm{C}$.

There are many conceptual similarities between input substitution and technical change. Both concepts refer to an alteration in the combination of inputs required to produce a given output quantity. Input substitution refers to a change in production techniques selected endogenously at any given time. Technical change refers to a change in the set of possible production techniques over time.

\section{d. Illnstretivo Hodel 22C Comversion Process Huborieal Vilues}

The purpose of this section is to present some of the numerical values that are used in Eq. (VII-4), the net present value equation. Two nodes, antomobile oil (Sector 8, Activity 2 in Fig. A-8 in Appendix A, called "Activity 8.2 " here) and indirect heat from coal (Sector 2, Activity 16 in Fig. A-2), are considered. (In each case, the generic industry represented in the model is an intellectual construct; for anto oil, one can imagine that all auto transport is provided by leasing firms that charge only by the vehicle mile.) In the first case, the capacity factor is computed to be relatively 10\%, whereas in the second, the capacity factor is significantly higher. With respect to units of measurement, prices and fuel costs in Activity 8.2 are expressed as dollars per 1000 anto-vehicle miles; capacity factors are dimensionless; and nev capacity additions are expressed as units of 1000 anto-vehicle miles per year. In Activity 


\section{VII-12}

2.16, prices and variable operating costs are expressed as dollars per million Bta's, new capacity additions in miliion Bta's per year, and the capacity factor is dimensionless.

For purposes of illustration, consider first the case of the automobile that is produced in 1975 (denoted as year $j$ ). He defino k as the year of operation (1.e., 1975, 1980, 1985) for an automobile with an estimated life of 10 years.

Tabie VII.1 presents prices [P(k)]; variable operating costs $\left[(f(j, k)]\right.$; capacity factors $\left[C_{f}(j, k)\right]$; discount factors $[D(j, k)]$; differences between prices and operating cost times capacity factor and discount factor: and the net present valine of capital cost $\left[N_{\dot{C O}}(j)\right]$.

Table VII.1 shows that in the years 1980 and 1985 the capacity factor is still significanty positive ( 0.19 and 0.03 , respectively) despite the fact that the variable operating cost is greater than the price. Prices decrease at later times because new antos are assumed then to have lower operating cost. The form of the capacity factor function discussed above, even with value of $\gamma=15$ [see Eq. (VII-3)], is such that plants (autos) can continue to operate, even at a loss! [In this example, had capital costs been correctly entered (Ste81), prices would have been higher, and the anomaly would not have appeared as important.]

Consider Table VII.2, which presents the same information for Activity 2.16, indirect heat from coal. Here, the results indicate that, with prices significantly greater than operating costs and a value of $\gamma=15 \mathrm{in} \mathrm{Eq}$. (VII-3), the conversion process estimates a relatively high and constant capacity factor.

In conclusion, for "industries" such as indirect heat from coal, the LEAP simulation appears reasonable, with large capacity factors for industries that are profitable. However, the analysis for Activity 
TABIB FII.I

An Rramination of the Cocoponents of the Not Present Velwo Bquation for Aotivity 8.2 (Awto. O11) sthows that Plants oan Continuo to Oporato in LRAP Bven vhen Prices aro Bolor Variablo Operating Costs

\begin{tabular}{|c|c|c|c|}
\hline \multirow[b]{2}{*}{ Parameter } & \multicolumn{3}{|c|}{ Year of Operation $(k)^{a}$} \\
\hline & $\overline{1975}$ & 1980 & 1985 \\
\hline Price ${ }^{b}, P(k)$ & 44.2 & 40.4 & 37.0 \\
\hline Variable operating cost $t^{b}, \phi(1975, k)$ & 42.3 & 44.2 & 46.0 \\
\hline Capecity factor ${ }^{c}, C_{f}(1975, k)$ & 0.59 & 0.19 & 0.03 \\
\hline Discount factor ${ }^{d}, D(1975, k)$ & 4.2 & 3.4 & 2.8 \\
\hline$[P(k)-P(j, k)] C_{f}(j, k) D(j, k), j=1975$ & 4.6 & -2.5 & -0.8 \\
\hline $\begin{array}{l}\text { Net present value of capital cost, } \\
N_{\text {co }}(1975)\end{array}$ & 1.2 & 1.2 & 1.2 \\
\hline
\end{tabular}

${ }^{a}$ The years of operation specified in the table are defined by $C_{f}(j, k)>0$. For al1 years following $1985, C_{f}(j, k)=0$.

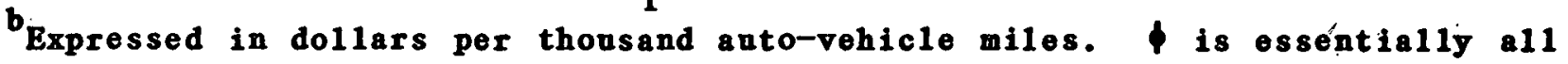
fuel cost for the parameters chosen for Model $22 \mathrm{C}$.

CDimensionless.

dimensions of years.

expressed in dollars per thousand vehicle miles per year. (Note that this value implies that for $\$ 12$ one could by a car with a "nameplate capacity". of $10^{4} \mathrm{miles} / \mathrm{year}$. See Sect. X.) 
TABIS VII.2

Compononts of the Not Present Value Bquetion

for Aotivity 2.16 Appeax P1susibie

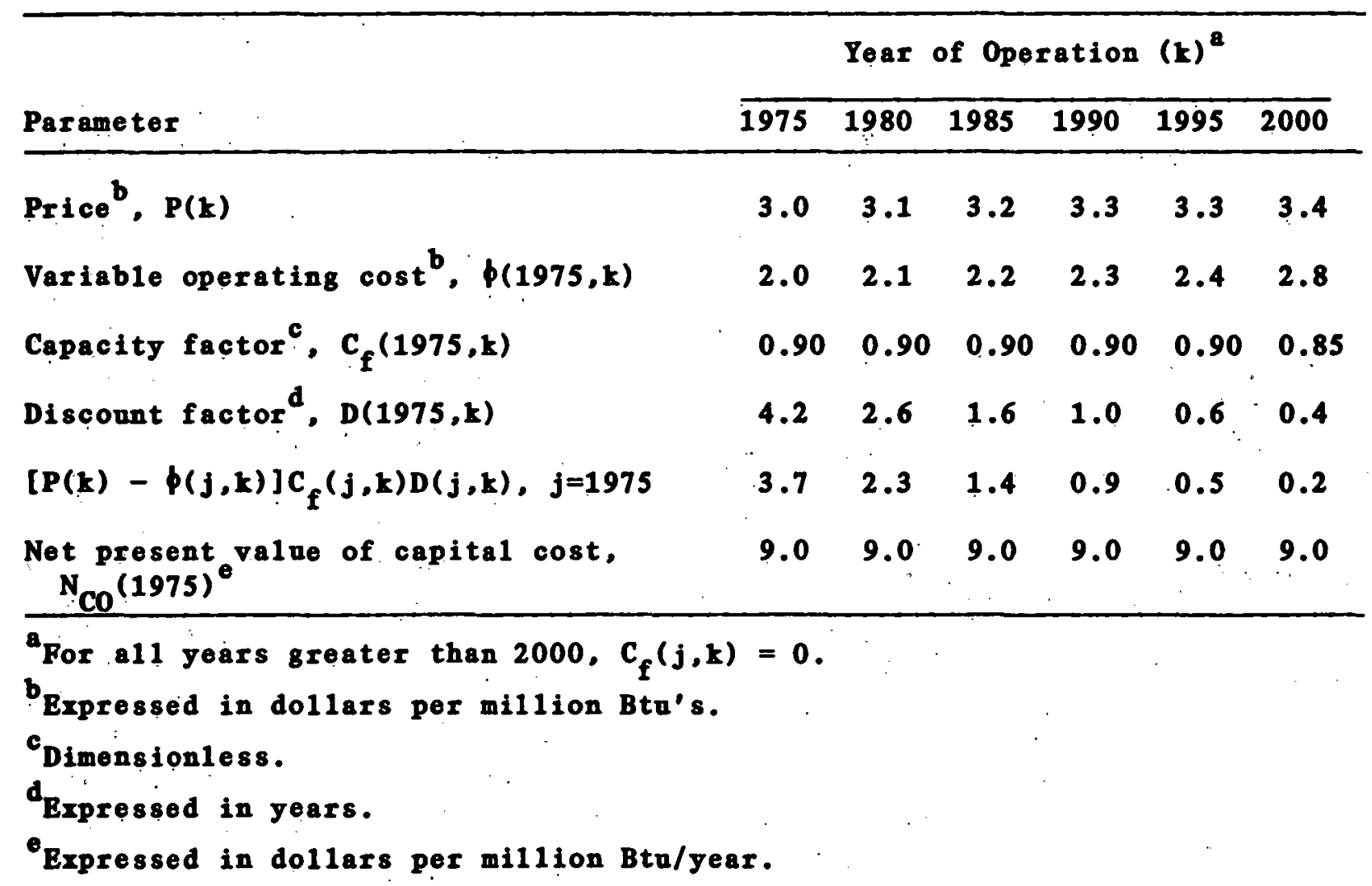


8.2 shows that the LEAP-78 mode1 can produce results that are not feasible; plants can continue to run for most of their lives even when they are sustaining losses. This behavior appears to be a direct result of the form of the capacity factor function and the particular Mode1 22C data. Oblow (Ob181) has recently shown that another form for the capacity factor function

$$
\begin{array}{rlrl}
C_{f} & \sim \beta\left(1-e^{-\gamma(p-\phi) / w}\right), & p & <\phi, \text { and } \\
& =0, & p<\phi,
\end{array}
$$

where $\gamma$ and $w$ are appropriately chosen new parameters, would likely eliminate such problems.

\section{Rosource Ixtraction Process.}

A resource process subroutine receives the amounts demanded over time and must calculate the prices necessary to bring forth those quantities. Consequentiy, there are two functions that a resource process must perform: (1) it must compute the schedule according to which new reserves mist be found and developed to supply. the quantities demanded over time, and (2) given this schedule of resonrce commitments to reserves, the resource process must calculate the price necessary to bring forth this schedule of commitments without delay.

The basic approach for simnlating an industry that onderlies the LEAP conversion process also serves as a basis for the resource extraction process. The fundamental difference between the two is that LEAP resonrce processes explicitiy model the depletion of (1) existing oil and gas wells and (2) each in-place resonrce base. 
There are four basic types of resources* represented in Model 22C: crude oil, natural gas, coal, and uranium. Domestic crude oil production is modeled by four resonrce activities: Alaskan oil, shale oil, enhanced crude recovery, and other domestic crude. Domestic gas production is modeled by three processes: Alaskan gas, enhanced recovery, and other domestic gas. There are six different types of coal in the mode1, with distinctions made on the basis of geographic location and sulfur content. The six coal processes are Western low sulfur, Western medium-high sulfur, mid-continent, Appalachian medium-high sulfur, Appalachian 10 sulfur, and Appalachian premium. The resource activities are the principal examples of regional distinctions in Mode1 22. A11 uranium mining and milling is handled in a single process.

0 il and gas production are modeled entirely in separate processes; there is no explicit treatment of associated and dissolved gas. This is a significant omission for two reasons: (1) it is difficult in reality to separate oil and gas exploration expenses as clearly as is indicated in Mode1 22C; and (2) when gas is associated with oil in a single reservoir, the production rates and costs of each are not entirely independent of one another.

A distinction is made between the production from oil and gas reserves and the production of coal, uranium, and oil from shale. In the case of oil (except shale oil) and gas, after a well is opened, it is assumed that maximum production declines over time as the quantity remaining in the reservoir falls. This depletion is completely separate from the aging factor discussed in the conversion process section; it acts directly on output. In adition, depletion of the resource base causes the costs of opening and operating new wells to rise over time. Once a well is in operation, Model 22C assumes no increase in costs due to depletion.

-See Appendix A: The LEAP-78 Network and Its Interpretation. 
In the coal, uranium, and shale oil extraction processes, the resource base also declines over time, causing an increase in costs associated with production from new mines. However, once open, the maximum amount produced in each time period does not dwindle over time, as it does with gas and oil. Instead, maximum production is constant in each year until the mine is depleted.

Producers* will view those resources that they choose to. leave in the ground as an investment; the higher prices they expect to receive in the future constitute the return on that investment. To induce producers to produce and sel1 a nit of resonce now instead of later, they must be paid not only the cost of production but also a premium equal to the profit they would receive if they sold in the future instead of selling now. This "user cost" is calculated in Mode1 22C on the assumption that producers have fall knowledge of all future resource prices.

The detailed equations for the resource process become quite complex when such factors as rents, depletion, and taxation are taken into account. In LEAP-78, the oil-gas resource market is not exp1icitly regulated. The interested reader is referred to the specific equations used in Model 22, documented and verified as part of the ORNL evaluation (Go181a).

\section{Allocation Process}

Allocation processes are used throughout the model to represent the process in which buyers and sellers conduct market transactions. The allocation process is used in conjunction with supply and demand estimates from the resource and conversion processes described in the provious sections.

*The owner and producer are assumed identical for purposes of this discussion. Note that when the government is tho reconrco owner, policy considerations may dictate that no lease payment optimizations occur. 


\section{VII-18}

This is done to extend the modeling capabilities from treatment of representative technologies (resource and conversion processes) to the analysis of individual sectors of the energy economy. Buyer preferences and policy are also incorporated in allocation through the introduction of various parameters. In the conversion process, a high degree of "clairvoyance" is assumed in the calculation of net present value (e.g., assumptions with respect to the exact level of prices at all future time periods). In the allocation process, the market share calculation is assumed to depend on current estimates and market shares in the immediately preceding period [see Eq. (VII-7)]-obvịously a more myopic view than that assumed in conversion processes.

In their simplest form, stripped of lags, markups, and priceresponsiveness parameters, allocation processes are devices that either (1) allocate a single demander's purchases preferentially but not exclusively toward the lowest-priced supplier or (2) allow each demander to obtain what he needs at the supplier's price. This simple picture is complicated by equal-price market-share parameters, price responsiveness parameters, markaps, and behavioral lags.

Algebraically, these concepts may be related in a fairly straightforward manner, Consider that demand for a commodity has to be allocated among $I$ competing suppliers. At some specific allocation node (the node index is suppressed below for convenience), if the demand were allocated instantly (static allocation), the share of supplier on link $i$ at time $j$ is modeled as follows:

$$
\widehat{s}_{i, j}=\frac{f_{i}\left(P_{i, j}\right)^{-\gamma}}{\sum_{i=1}^{I} f_{i}\left(P_{i, j}\right)^{-\gamma}}, j>1 \text {, }
$$


where

$$
\begin{aligned}
\hat{\mathbf{s}}_{\mathbf{i}, j} & =\text { static market share of each supplier } i \text { at time } j \text {, } \\
\mathbf{f}_{i} & =\text { equal price share parameter for supplier } i \\
p_{i, j} & =\text { price per unit energy for supplier } i \text { at time } j, \\
\gamma & =\text { sensitivity parameter of share to price. }
\end{aligned}
$$

The quantities $\widehat{S}_{i, 1}$ are computed from the initial-year quantities on the links. Market shares at equal prices, $f_{i}$, need to be specified; these are sometimes used to represent any bias the decision maker may have with respect to the varions suppliers. If no bias exists,

$$
f_{i}=\frac{1}{I} \quad i_{8}[1, I]
$$

The price responsiveness parameter, $\gamma$, mode1s the sensitivities (derivatives) of the market shares to prices. Specifically, larger values of $\gamma$ increase the sensitivity of the output market shares to price differentials. Very large $\gamma$ values correspond to the simulation of perfectly competitive markets (i.e., demander cost minimization).

Behavioral 198 parameters reflect the rate with which the economic agents represented by the allocation processes will be able to change the flow of commodities from one source to another in response to relative price changes. Sources of inertia may exist, such as investment in capital goods or supplier loyalties. The behavioral lag parameter accomplishes the transition from static allocation, illustrated by Eq. (VII-5), to dynamic allocation, wherein market shares serve as a vehicle for expressing the process dynamics.

In the spirit of simplification, excluding the relaxation procedure for the market shares mentioned in Sect. VI, the behavioral lag 
treatment is implemented as follows to compute the final time-1agged market shares $S_{i, j}$ :

$$
s_{i, j}= \begin{cases}F(\beta) \hat{S}_{i, j}+G(\beta) s_{i, j-1}, & i=1, \ldots I ; j \geq 2 \\ \hat{s}_{i, j}, & i=1, \ldots I ; j=1 \quad(V I I-7)\end{cases}
$$

where

$$
\begin{aligned}
\beta= & \text { behavioral lag coefficient }(0<\beta<1) \text { which } \\
& \text { is input in the code, } \\
F(\beta), G(\beta)= & \text { coefficients in Eq. (VII-7) that are complex } \\
& \text { functions of } \beta, \\
\hat{\mathbf{S}}_{\mathbf{i}, j}= & \text { share of energy as defined in Eq. (VII-5). }
\end{aligned}
$$

LEAP-78 has provisions for several types of allocation processes. See Table A.1 in Appendix A.

In Mode1 22C, the allocation process values of $\gamma$ range from 2.5 to 12.5, with 5 and 10 being common values. The $\beta$ specification is typically arranged to provide a $50 \%$ adjustment in periods ranging from 3 to 20 years, with a typical value of about 9 years.

Major changes have been introduced in the LEAP-80 allocation process. Although the detailed specifications for the new process equations are given elsewhere (Bar81), the most significant aspects include recognition of the different sensitivity to price differentials between existing demand and new (excess) demand and the use of constraints on market shares.

The market share formulation presented in Eq. (VII-5) is similar to the representation derived assuming that (1) producer prices are distributed in the form of a Weibull distribution (prices for the 
same commodity will vary depending on site, etc.), and (2) the market share captured by a particular technology is considered to be the estimated fraction of instances in which that technology offers the lowest price among competitors (EIA80a). Although such a justification was not offered for ARC-78 methodology, the same basic formula is obtained; therefore, the important possibility of a firm theoretical basis is present. The relation of the average producer price to an average transaction price would have to be worked ont to avoid inconsistencies in the dollar flows at allocation activities.

\section{Planl Denand Process}

The last type of activity considered in this section is the specification of energy demand. There are four of these final demand processes in Model 22C: residential, industrial, commercial, and personal transportation demand. These activities separately calculate the demands for 19 specific energy uses, such as residential space and water heating, industrial indirect heat; commercial lighting, and vehicle miles (see Appendix A).

The basic LEAP-78 demand equation states that the quantity demanded in any period is a function of the value of an exogenously specified quantity path for the period, the departure of the previous period's actual demand from the exogenously specified path, and the departure of the present period market price from a specified price path:

$$
Q(J)=Q_{p}(J)\left(\frac{Q(J-1)}{Q_{p}(J-1)}\right)^{S} \quad\left(\frac{P(J)}{P_{p}(J)}\right)^{E_{L}},
$$

where

$$
\begin{aligned}
Q(J)= & \text { quantity demanded in period } J \\
Q_{p}(J)= & \text { value of a specified demand quantity path } \\
& \text { in period } J .
\end{aligned}
$$




$$
\begin{aligned}
\mathbf{P}(J)= & \text { market price in period } J, \\
\mathbf{P}_{\mathbf{p}}(\mathrm{J})= & \text { value of a specified price path in period } \mathrm{J}, \\
\mathbf{S}= & \text { user-supplied "sensitivity" parameter, } \\
\mathbf{E}_{\mathbf{L}}= & \text { user-supplied sensitivity parameter related to price } \\
& \text { elasticity. }
\end{aligned}
$$

The price path $P_{\hat{p}}(J)$ is set equai to $P(J)$ for years $\leq 1995$ and is held constant at $\mathrm{P}(1995)$ for all subsequent years. The quantity path is constructed froin several exogenons components:

$$
\begin{aligned}
Q_{p}(J) & =Q_{p}(J-1)[r(J) \cdot \gamma(J)]^{\Delta} J>1,(V I I-9) \\
& =Q_{0}, \quad J=1, \text { for the initial model year. }
\end{aligned}
$$

In the above,

$$
\begin{aligned}
r(J)= & \text { parameter related to national income, } \\
\gamma(J)= & \text { sector-specific parameter (Go181a, pp. 64-65). } \\
\Delta= & 1 \text { ength of time between model years (5 years in Model } \\
& 22 \mathrm{C}) .
\end{aligned}
$$

The firal demand process contains some of the most serious weaknesses in Mode1 22C. The period 1 valio of the quantity path is set equai to the initial quantity demanded; thus, unless the price deviates from the price path, demand will be completely determined by the exogenous quantity path. Because during the first five periods $\left(25\right.$ years) $P_{p}(J)$ is defined as being equal to $P(J)$; there is no demand price elasticity within this time frame. During the last five periods of the modei horizon, $P_{p}(J)$ is set equal to the market price in period 5; consequently, quantity diverged from the exogenous path. Hence, in Model 22C, final end-use demands are nearly user-specified quantities. 
An inherent weakness in the form of the final demand specification is the lack of cross substitution effects. For instance, the specification of the transportation end-use demand is one of the weakest in the mode1. This weakness is cansed by both the neglected substitution possibilities among final demand categories (e.8.. shipping freight by rail is clearly a close substitute for trucking) and the exclusion of relevant determinants. These problems may be partioulariy serious becanse of the relatively large portion of energy consumed by this sector. In partioular, one half of the oil use in the United States is acconted for by transportation.

Much of the policy analysis now being undertaken in the transportation sector is related to conservation (i.e.. measures to reduce liquid fuel consumption associated with transportation). Such conservation might be achieved through a shift from automobiles to mass transit, an improvement of vehicle fuel efficiency, cost reduction of electric vehicles, or a shift from highway vehicles to rail for transport of freight. The effects of some of these shifts could be only partially captured by the Model 22 transportation sector.

To permit modeling substitution, the basic demand variable should be passenger-miles rather than vehicle-miles. An allocation process conld then be used to apportion passenger-miles among the varions options such as single-occupant antomobiles, car pools, buses, and trains.

B. Compertson of Solocted IRAP lodol 22C Rosults fith Indopondont Date

In a recent study by Goldstein (Go181b), a comparison is made of the LEAP्P Mode1 22C outpat for years 1975 and 1980 with compiled historical data drawn from Volume 2 of ARC-79 (BIA80) and Volume 2 of ARC-78 (EIA79b) for the years 1975 through 1979. A1 though this type of comparison against extrapolated historical data is not very secure, it is the only available historical check on Model 
22C. Because neither ARC-79 nor ARC-78 could include observed data for 1980, the analysis was performed by comparing LEAP Model 22C results with smoothly extrapolated values of ARC-79 for the years 1975 through 1979. The results may depend on the extrapolation law nsed. Care was taken to ensure that the EIA compilation in Volume 2 of ARC-78 and ARC-79 and the LEAP Mode1 22C output were compared on the same basis (i.e., minor variances in assumptions, such as imports of coal or exports of crude oil, were corrected so that the information could be compared). The conclusion is that most of the quantities output from LEAP Model 22C for 1975 and 1980 are in reasonable agreement (within about 2\%) relative to Volume 2 of ARC-79.

The energy flow results of LEAP Model 22C for 1975 are smaller, in general, than the 1975 data in the ARC-79 report. That is, the data for the Model 22C initial-year energy balance does not appear to be equivalent to the 1975 historical data in the same series of reports. (Recall that 1975 end-use demands and market shares for all multiplesupplier allocation activities are input quantities in LEAP-78.) The main differences are that

- Domestic gas production is lower in LEAP Model 22C by 1.6 quads (8\%) .

- Domestic coal production is lower by 1.0 quad (7\%).

- $0 i 1$ consumption is lower by 1.4 quads (4\%).

- Passenger car fuel rate is lower by $0.5 \mathrm{mile} / \mathrm{gal}$ (3\%).

- Total energy supply is lower by 2.4 quads (3\%), and the total energy consumption is lower by 1.9 quads (2\%).

The difference in miles per gallon is attributable. to the offhighway gasoline usage, which although taken into account by LEAP, is not included in the figures provided by the Federal Highway Administration. 
Assuming a smooth 10w-order extrapolation of 1975 through 1979 data from ARC-79, the following quantities predicted by LEAP Mode1 22C for 1980 appear to be in reasonable agreement with that compiled historica1 data:

- Total domestic oil production.

- Imported refined products.

- Coal supply (including exports).

- Imported gas.

- Nuclear supply and consumption.

- Hydropower supply and consumption.

- Domestic coal consumption.

- Passenger cars fuel rate (miles/gallon).

- A11 primary electrio input fuels.

- Consumption of energy by residential and commercial sectors.

- Consümption of energy by transportation sector.

- Total consumption of energy.

The following projected quantities appear to be higher than the data from Volume 2 of ARC-79:

- Domestic gas production (by about $4 \%$ ).

- Gas consumption (by about 10\%) (Fig. VII-1).

- Consumption of energy by the industrial sector (by about $2.5 \%$ ).

Finally, three projected quantities are lower in comparison with the ARC-79, Volume 2, compiled data:

- Imported oil (by about 30\%) (Fig. VII-2).

- Oil consumption (by abotit $10 \%$ for linear extrapoiation) (Fig. VII-1).

- Total energy supply (by $2.5 \%$ ).

Apparently from this work of Goldstein (Go181b), there is no straightforward connection between the predicted vs "real" data 
VII-26

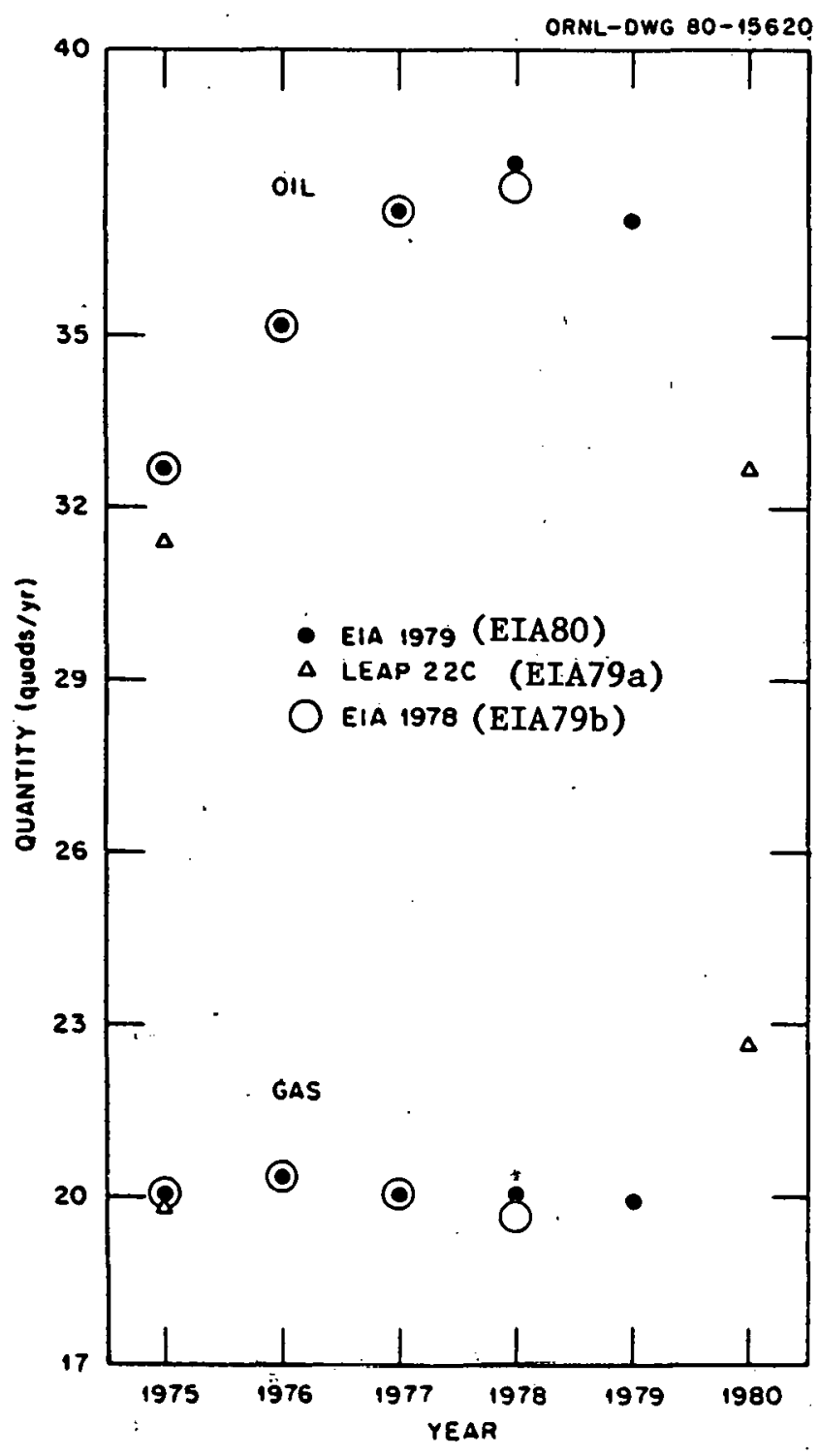

Fignre VII-1. 0 il and gas consumption estimates from LEAP Model 22C are not consistent with extrapolated values from ARC-79 (EIA80). The open and solid circles represent historical data compiled in ARC-78 (EIA79b) and ARC-79 (EIA80), while the triangles represent the Model 22C results from ARC-78 (EIA79a). 
VII-27

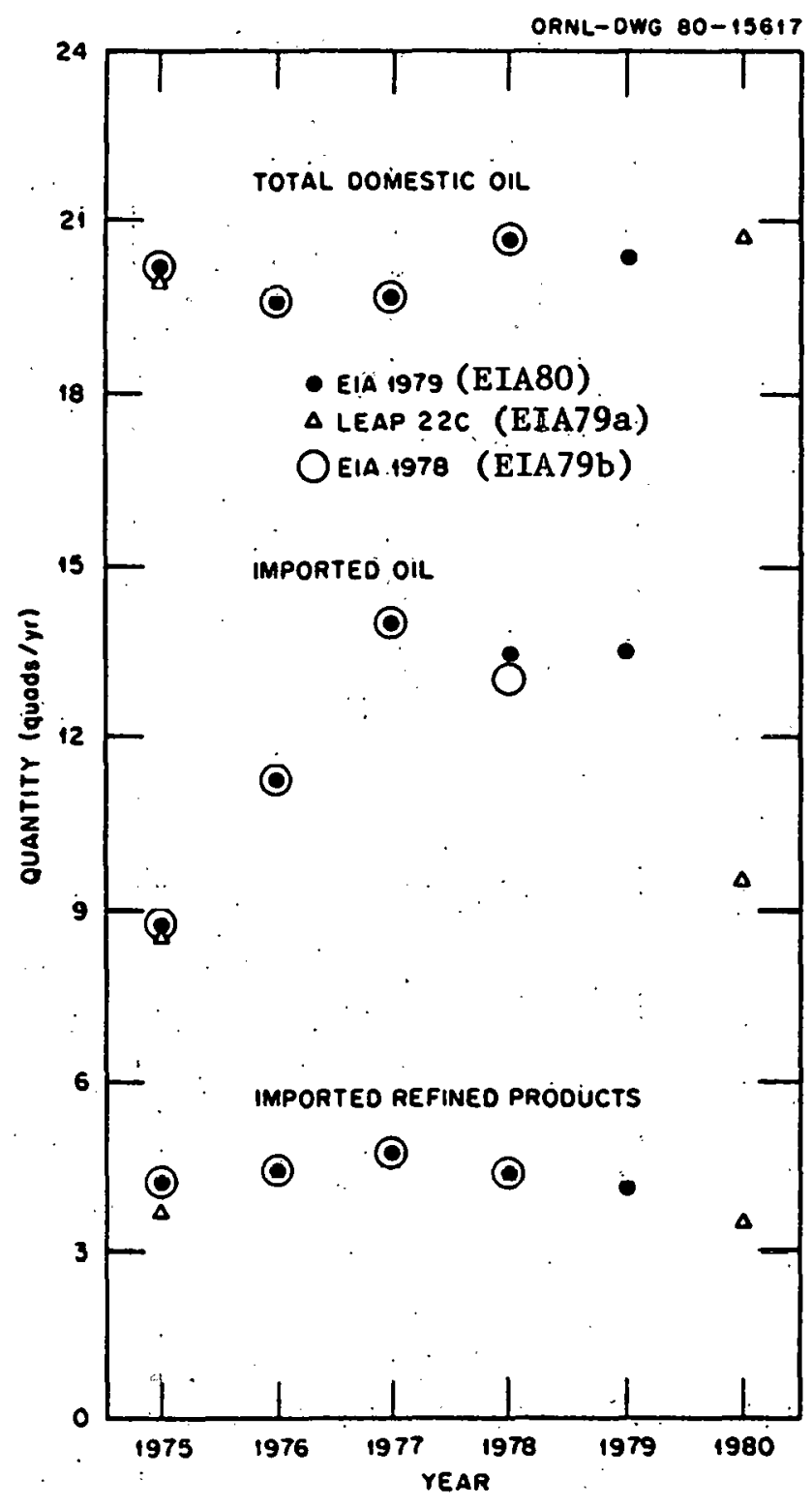

Figure VII-2. Imported oil estimates from LBAP Model 22C for 1980 are not consistent with extrapolated values from ARC-79 (BIA80). (See Fig. VII-1 for further explanation of symbols.) 
differences in 1975 and 1980 . In other words, the differences between the predicted and (extrapolated) real data encountered in 1980 are not always accompanied by similar differences in 1975. För example, the domestic gas production and the gas consumption are predicted to be higher than the real data for 1980 , whereas in 1975, the Mode1 22C results are lower and equal to the real data. On the other hand, the Model 22C quantity for imported oil in 1980 is lower, whereas in 1975 it is in good agreement with the real data. Therefore, the differences between the model projection and extrapolated real data encountered in 1980 cannot be explained on the basis of the 1975 differences. Further work is needed to fully understand the reason for these differences.

\section{Comparison vith Altornative bodels and Consequent Domin of Applicability}

The purpose of LEAP is to produce long-term energy forecasts for DOE/EIA. Among the models that address similar problems are the Decision Focus, Inc. (DFI) Generalized Equilibrium Modeling System (Ad179); the Stanford Research Institute-Gulf Oil Corporation Nationa1 Energy Model (Caz77); the DRI-Brookhaven, Hnyilicza, HudsonJorgenson, Kennedy-Niemeyer, PILOT, and Wharton Models (EMF77); the ETA and ETA-Macro Mode1s (Man77); and the Nordhaus Model (Nor79).

Comparisons of LEAP with the aforementioned models that would involve actual model runs based on standardized input scenarios were impractical for the purposes of this report. However, in terms of the broad comparison criteria used in the analysis of six models by the Bnergy Modeiing Forum (BMF77), some useful comparisons can be made: The results of that comparison are presented in Table VII.3, augmented by the authors of this report only with respect to the added LRAP-related information at the bottom of the tabie. For a detailed explanation of the table, the reader should consult its source (EMF77). In Table VII.3, LEAP and the six models considered by the Energy Modeling Forum are compared on the basis 
of aggregation, substitution, dynamics, and exogenous trends for producers and consumers. Furthermore, a comparative assessment in terms of the systems' objectives and dynamics of the model solution is presented. The table is drawn from the Energy Modeling Forum report (EMF77, pp. D-16 and D-17) with features of LEAP added for comparison. Comparison of models that have inherently different objectives, algorithms, and data is difficult. Nevertheless, Table VII.3 indicates that LEAP (Mode1 22) is generally weaker than other models with respect to energy-economy interactions and within-process substitution, but perhaps stronger than competitive models with respect to the dynamics of investment decisions and the ability to model technological change.

A detailed comparison of long-term energy models is beyond the scope of this report. For comparative assessments of long-term energy mode1s, however, the interested reader can consult (1) the aforementioned volume produced by the Energy Model Forum (EMP77); (2) a similar study conduoted by Charles River Associates, Inc., for the E1ectric Power Research Institute (EPR79); and (3) a report prepared by P1anco, Inc., for the Department of Energy (D0E79). Each study consists of a detailed assessment of approaches to energyeconomy modeling and analyzes the approach, strengths, and drawbacks of various we11-known energy-economy mode1s.

Consideration of the economic scope of these alternative energyeconomy mode1s may be informative. In genera1, such models can be categorized as macroeconomic growth models, interindustry models, energy sector models, market segment (i.e., individual industry) models, or a combination of the four. The Hudson-Jorgenson (B-J) Model is a neoclassical macroeconomic, variable-coefficient interindustry model embracing the first three model categories presented above. In the H-J specification, energy is analyzed in the context of the long-run equilibrium of supply and demand for goods in the entire economy. It was designed, in part; for the purpose 


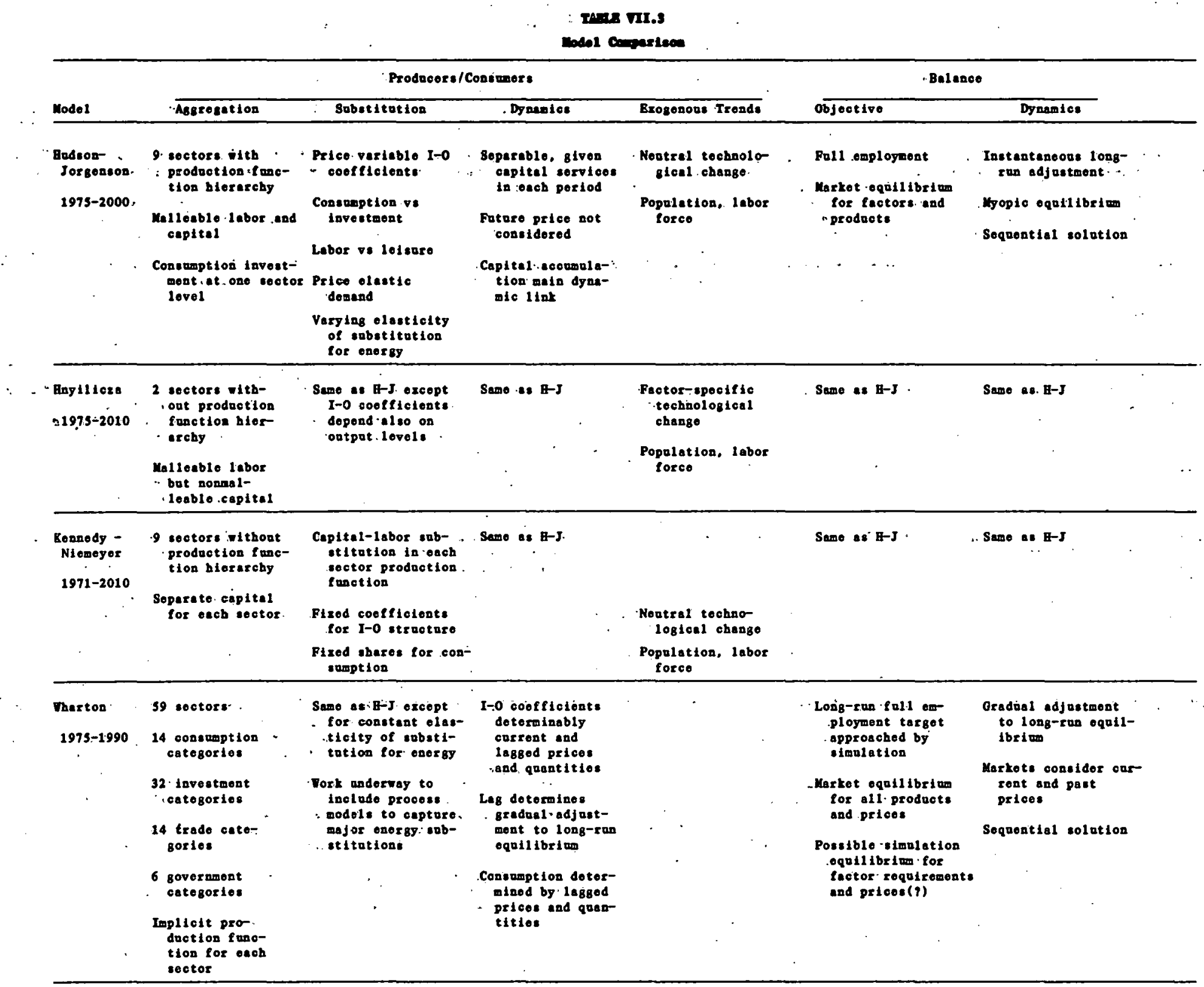


TABES VI.3 (continaed)

\begin{tabular}{|c|c|c|c|c|c|c|}
\hline \multirow[b]{2}{*}{ Mode1 } & \multicolumn{4}{|c|}{ Prodboersiconeduers } & \multicolumn{2}{|c|}{ Belence } \\
\hline & Aggrogation & Subetitation & Dynamices & Brogenous Tronds & objeotive & Dyandces \\
\hline $\begin{array}{l}\text { Pror } \\
1973-2012\end{array}$ & $\begin{array}{l}23 \text { interinduetry } \\
\text { sectors } \\
\text { Dieaggrogated } \\
\text { procoss wode1s } \\
\text { for onergy pro- } \\
\text { duction 10volv } \\
\text { ing } 18 \text { proossos }\end{array}$ & 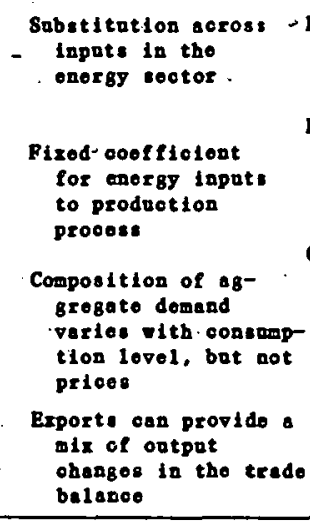 & 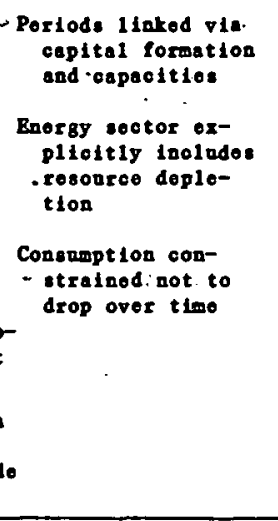 & $\begin{array}{l}\text { Neutral tochnological } \\
\text { change } \\
\text { Population, lobor } \\
\text { forco }\end{array}$ & $\begin{array}{l}\text { Maximization of ag- } \\
\text { grogate sonsump- } \\
\text { tlon subjoot to } \\
\text { physical con- } \\
\text { otraints } \\
\text { Excopt gor oxports, } \\
\text { go bobevtoral } \\
\text { liake of pricos } \\
\text { - and quastitios }\end{array}$ & 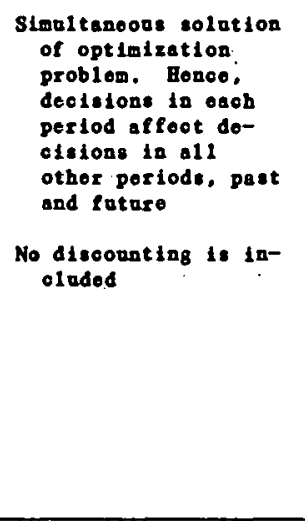 \\
\hline $\begin{array}{l}\text { DRI - } \\
\text { Brookhaven }\end{array}$ & Same as E-J & Same es E-J & Same Af B-J & $\begin{array}{l}\text { Noutre1-tocbnologlosi } \\
\text { ohango }\end{array}$ & Samo ac E-J & Samo As B-J \\
\hline $1975-2000$ & $\begin{array}{l}110 \text { interindus- } \\
\text { teg soctors } \\
\text { D1 sagszoseted } \\
\text { procoss models } \\
\text { for energy pro- } \\
\text { duction involv- } \\
\text { Ing } 30 \text { procossos }\end{array}$ & 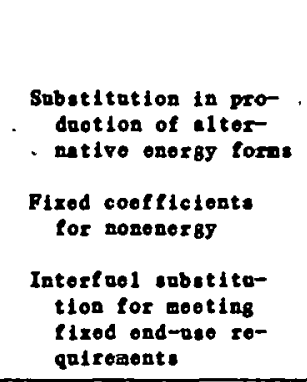 & 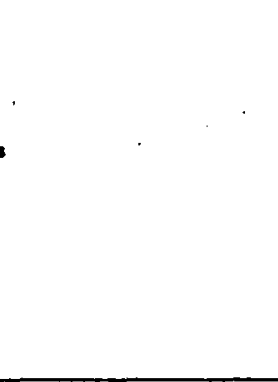 & $\begin{array}{l}\text { Population, labor } \\
\text { forco } \\
\text { Ilmo-trendod toohni- } \\
\text { cel cooffiolonts }\end{array}$ & $\begin{array}{l}\text { Minimization of cost } \\
\text { of moeting onorgy } \\
\text { demends oubjoot to } \\
\text { pollotant onlselon } \\
\text { constreint: }\end{array}$ & \\
\hline $\begin{array}{l}\text { LRAP (Modo1 } \\
22 C) \\
1975-2020\end{array}$ & 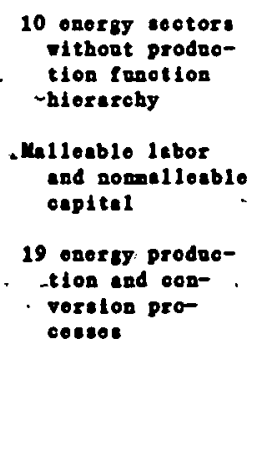 & 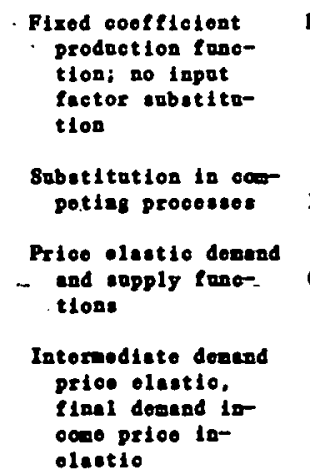 & 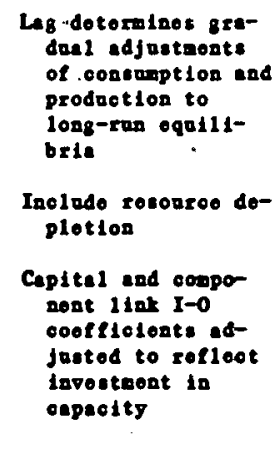 & 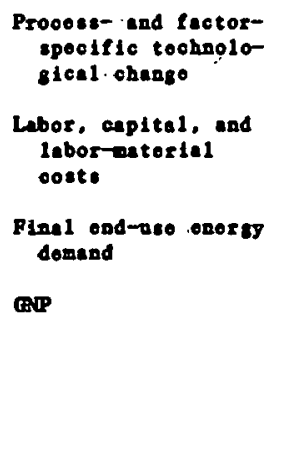 & $\begin{array}{l}\text { Markot oquilibrium } \\
\text { - for factors and } \\
\text { products, given } \\
\text { ond-ose domand }\end{array}$ & $\begin{array}{l}\text { Simaltenoous solotion } \\
\text { Long-ran oquilibrium } \\
\text { Markots consider cor } \\
\text { rent end futase } \\
\text { pricos } \\
\text { Discount rate taoluded }\end{array}$ \\
\hline
\end{tabular}


of integrating the energy sectors with the macroeconomy over a long time frame with emphasis on equilibrium in the entire economy. The Hnyilicza, Wharton, Kennedy-Niemeyer, and PILOT models are similar in scope and content to the H-J framework, except that the KennedyNiemeyer and PILOT models incorporate fixed coefficients in the production process. The DRI-Brookhaven and LEAP mode1s, on the other hand, are much more limited in scope with respect to the linkage between the energy sector and the economy. The DRI-Brookhaven model is essentially a static 110-sector, fixed-coefficient, input-output mode1. It has been used primarily for 1 inking the $H-J$ and Brookhaven energy sector models.

LEAP is a detailed, dynamic formulation of energy supply and demand in the United States. It is a model of the energy sector only and, as such, does not represent the economy in a general equilibrium framework. Although the possibility oxists that it could be linked with other macroeconomic and interindustry models, it has been used as a se1f-contained nnit. Consequently, LEAP and other models of the energy sector must use information from other sources for its exogenous parameters becanse the model does not reflect the myriad interactions of a complex economy.

All these models share several common deficiencies, including treatment of government regulation, modeling the end uses (e.g., home heating rather than aggregate quantities of energy), recognition of the availability of capital for financing, and representation of regional dependence.

LEAP's reliance on exogenous inputs notwithstanding., the model is used to address issues of national significance (see Table III.1) in the U.S. energy picture. Important results available from the mode1, which include those listed in Table III.2, deal with energyrelated costs (fuel and capital), alternative sources of domestic energy supply, and energy fuel inputs. With the major exception 
of the resource extraction sectors, the domain of LEAP is such that energy costs and supply are apportioned on a national basis for a given model of demand. 


$$
\text { VII - } 34
$$

\section{THIS PAGE}

\section{WAS INTENTIONALLY LEFT BLANK}




\section{Sumary and Recomendations}

The economic representation in LEAP seems to reveal a sophisticated understanding of the interactions of various elements of the energy economy. The basic sectoral structure and the modularity of the model are two of the elements that display this understanding. Most of the serious problems in the representation of the energy economy 1ie less with the LEAP modeling system than with the specific 22C version. Several specific deficiencies may be sumarized:

- The final demand representation is essentially exogenous in Mode1 22C. Price elasticities are in effect too close to zero.

- The prices of all commodities are assumed to increase at the same rate. The inflation rate in LEAP-78 does not depend on either the type of commodity or the time frame of the mode1; and for Model 22C, the inflation rate was set equal to zero.

- Investments in Mode1 22C are made with perfect foresight with regard to prices. No attempt is made in LEAP-78 to model unexpected events or investment decisions under uncertainty.

- Unlimited oil imports are available in Mode1 22C at predetermined prices. Without modeling oil imports explicitly, one could input a quantity-dependent price.

- The fixed-coefficient production function assumption in LEAP-78 (no within-process input substitution) is likely to introduce an upward bias in energy prices over time as relative input prices change. This assumption also inhibits modeling of conservation and retrofitting. Substitution does exist, however, between different types of processes.

- In LEAP-78, the supplies of 1abor, capital, and materials are assumed to be infinite at predetermined exogenous prices. The effect of the rising cost of energy needed to produce these inputs is not included in the model. Consequent1y, a bias 
towards capita1-intensive processes results. Little use is made in Mode1 22C of the available capital and labor "learning" representation.

- Net salvage values are not explicitly represented in LEAP-78.

- A1though the resource process in LEAP-78 does contain a complex treatment of economic rent, there are specification errors in the oil and gas sector. No provision ts made for modeling the costs of associated or dissolved gas. Also, the tradeof $f$ between production rate and total recoverable reserves is not modeled.

- Because perfect competition and unlimited availability of capital at a fixed price are assumed in LEAP-78, real-world investment choices are not modeled. It is unnecessary in the mode1 to order potential projects by profitability or to assess the optimal timing of investment expenditures.

- Because only one energy input is used for each production process in Mode1 22C, the price escalation of secondary energy inputs is not modeled. The result is a bias in favor of those processes that actually do have significant secondary energy sources.

o The output price from a declining industry in LEAP-78 is computed just as if new capacity were being added; the price from a real industry might be expected to drop.

The effects of the above assumptions and limitations inherently restrict the applicability of Model 22c limitations could be overcome within the existing LEAP framework. Significant additional modeling would be required to well represent energy demand, capital and labor-materials markets, the import sector, and within-process input substitution. 
VIII-1

\section{LAAP-78 COMPJTRR PROGRAM VERIRICATION}

This section summarizes our knowledge about the extent to which the numerical values from the LEAP-78 computer program in ARC-78 (EIA79a) correspond to the documentation of the LEAP-78 mode1. The LEAP-78 mathematical model was precisely defined by its computer listing and documentation based on that listing (Go181 and Ste81) rather than through definitive documentation by the modelers. For this reason, the discussion below follows a pattern that differs somewhat from that recommended in the Weisbin et a1. report (Wei81). For examp1e, here it would not make sense to seek an "...explicit listing of all departures from model specifications," as recommended in that report.

\section{A. Consistency of the LRAP-78 Computer Progran with the Rxisting Docunentation}

For those cases in which the busic equations are given, the discussions in Sect. VII and in the report by Hansen et al. (Han81) define the form of the mathematical process models of LEAP-78. Except for the coal resource, IMPORT, TRANSPORT, and DEMAND submodels, the forms of these models are fairly consistent at the solution point with the documentation of earlier models referenoed in Sect. II (e.g., Ad179). Note, however, in Sect. VI and in Oblow's report (0b181) that the solution algorithm used by the Energy Information Administration (EIA) in LEAP-78 was not consistent with the documentation of earlier models of the same family.

Except for the resource models documented by Cherniavsky and Juang (Che80), the detailed model equations and input parameter translation equations for LEAP-78 are documented and publicly available only in the reports by Goldstein et al. (Go181a) and Stewart and Goldstein (Ste81), prepared as part of the present. project. The anthors of these reports used the LEAP-78 computer program reproduced in Ford et al. (For81) as their basis, relying on documentation of earlier models as a guide for what might be found. In the study 
leading to this report, no conflicts were noted between the LEAP-78 subprograms and the detailed mathematical resource models description by Cherniavsky and Juang (Che80). The de facto detailed mathematical models for basic and electric power conversion must be taken as those reproduced in the equations of Goldstein et a1. * These detailed equations have the form of the equations of Sect. VII. The IMPORT program was very simple, corresponding to the word description given in ARC-78 (EIA79a). The DEMAND routine is consistent with statenents in that reference, but it and the simple TRANSPORT subprogram were not documented before preparation of the Goldstein et a1. report (Go181a).

Numerical output values of the quantities and prices from the DEMAND, TRANSPORT, and ALCHNO (a11ocation) submode1s were checked against hand calculations. Hand calculations were not performed within the present evaluation effort to check the more complex basic and electric power conversion submode1s or either of the two resource extraction submodels.

Also, no hand calculations were performed to demonstrate, on the basis of the DATA REPORT edit from the LEAP-78 program. (see below), that an equilibrium solution was in fact obtained for any major portion of the Mode1 22C network. To the extent that direct and adjoint-method derivatives of model outputs with respect to the parameters are shown to agree in Sect. IX.B below, there is independent verification of a definite, but difficult to define, portion of the LEAP-78 computer program.

* Note that Goldstein et a1. (Go181a) give the equations for the energy conversion processes for the case of one "short period" per 5-year model "long period." This is the value used for Model 22C. The LEAP-78 program can be used with larger integers NSHORT, but such cases were not studied. 
In summary, the LEAP-78 computer program is consistent with the nowdocumented set of detailed model equations and is consistent in form with the short form of the LEAP-78 model equations discussed in Sect. VII. Numerical results from the energy conversion and resource extraction submodels have not been checked against hand calculations.

\section{B. Commuication of Input Parameter Values to the Process Subnode1s}

Because the portions of the LEAP-78 computer program that communicate parameter values from the input tables (glven in For81) to the main submodels discussed in Sect. VII are complex and were not studied in the present effort, it was necessary to demonstrate that the input data reach the appropriate submodels. If they are properly communicated, the translation equations included in Stewart and Goldstein's report (Ste81) show how the actual LEAP-78 program converts input data to the form corresponding to the model equations listed by Goldstein et al. (Go181a). Stewart and Goldstein do show that one of these translation equations was programmed in error relative to documentation of earlier models (e.g., that for CFSENS, the capacity factor price sensitivity parameter). However, this difference may have been compensated by the Model 22C parameter choice.

A check on data communication has nocurred during the course of our work because the PERUSE subprogram (Coh79) that is used to modify parameters for sensitivity tests accesses the computer data storage arrays by using the same utility routines nsed by the process submode1s. Thousands of parameter accesses and changes have been performed during this study, inciuding alteration of every model parameter in the adjoint sensitivity work of Sect. IX.B., without any evidence of utility subroutine malfunction.

A second check was made possible by the DATA REPORT feature of the LEAP-78 program (Coh79). On request, this surveillance edit prints the values of the input parameters and the model variables from most 
VIII-4

activities as the model migrates, activity by activity, up and down the network on a selected complete iteration. If input parameters are correct as printed in the DATA REPORT, then correct transmission of data is assured. Such a check was performed and did demonstrate that the parameter values communicated to the submodel were the same as those in the model input tables and in the report by Stewart and Goldstein (Ste81).

\section{Were Mode1 22C Output Data Compiled for Publication as Intended?}

As suggested above, the prices, quantities, and capacity additions for each model year may be found in the DATA REPORT edit, which can be printed for most activities during the final iteration. No values of the aggregate capital cost of capacity additions from Model 22C have been published except those in Tables III.2 and B.1 of Appendix B.

Prices from Mode1 22C are given in two tables of the ARC-78 report (EIA79a, Tables 5.4 and 5.7). In an early study, K. Tech (Tec79) determined that most of these prices could be obtained from the DATA REPORT outputs from appropriate activities after compensating with a factor of 1.19 for the ratio between 1975 and 1978 dollar values. The oil prices in Table 5.4 were difficult to reproduce because a note on the table was ambiguous as to, the points in the network at which the prices were measured. The average prices for "raw materials" in Table 5.7 were reproduced in spite of the table caption's failure to define the types of average taken.

The energy flow quantities given in ARC-78 can be obtained from the RPORT (Coh79) edit of aggregated quantities discussed by Ford et a 1 . (For81) and in Sect. V. of this report. By reading the portions of those references dealing with replication of published results, one can appreciate the difficulty of determining whether the intended and labeled quantities were properly compiled. Three criteria are 
VIII-5

available for verifying the energy flow aggregates used in the RPORT program.

a. Is the aggregation reasonable for the labels on the quantities in ARC-78 (EIA79a)? A11 the aggregations of the RPORT program seem plausible, except for the inclusion as an industrial use in Table 5.9 of some electric utility combined-cycle gas production.

b. Is the aggregation consistent with the input data documentation? Based on the Appendix to ARC-78 (EIA79a) and the draft report of Diedrich et al. (Die79), many consistencies and few inconsistencies were found. For example, the RPORT aggregations are generally consistent with the fractions of natural gas loss attributed to various causes (Die79).

c. Were the text and table captions of ARC-78 (EIA79a) sufficiently clear to define uniquely the meaning of the tabulated values in terms of Model 22C energy flows? Not always.

The difficulty noted in item c above, which plagued the present authors in defining the responses of Sect. III and Appendix $B$ of this report, is inherent in the energy problem. The language does not provide a sufficiently precise meaning for the various energy sectors to allow a determination, for instance, of whether refinery losses are in the oil/gas or industrial sector, or of where energy transportation costs belong. Thus, while the text and table captions of ARC-78 (EIA79a) contain considerable definition of the tabulated items, the evaluation team found great difficulty in reproducing the pablished tables from model flows before the detailed operation of the obscure and incompletely documented RPORT program was understood. This important finding indicates the need for even more careful labeling of material tabulated in EIA reports. To provide explicit definition of tabulated quantities, tables 


\section{VIII-6}

equivalent to (but possibly simpler than) Table B.2 of Appendix B are required. Table captions and footnotes should at least clarify major points, such as whether oil production includes synthetic liquids from coal as well as shale oil. By extending the program RPORT or its equivalent, such tables could be produced on request and could have certain consistency with the RPORT tabulations themselves. As indicated in the New York Times quotation in Sect. III.B, tabulated quantities are not more precise than their definitions. 


\section{VIII-7}

\section{Conc1usions on LRAP-78 Verification}

The LEAP-78 mathematical model was defined only by the computer subprograms themselves rather than by documentation by the modelers, although the principal submodels representing generic energy-economy activities do have the general form specified in the documentation of earlier models of the same family. (The equations have now been documented as part of the present project.)

The model parameters entered into its input tables were properly communicated by the program to the model subroutines.

The evaluation group experienced difficulty in reprodncing the tables of aggregated model results in ARC-78 (EIA79a) because the table captions and table footnotes there did not uniquely define what the tabulated values represented. It is recommended that future published tabulations of LEAP results be more carefully defined and that the subprogram (RPORT in LEAP-78) that provides the aggregated results for the published summary tables be programmed to provide. a readable 1ist that explicitly identifies the components of each tabulated quantity. 


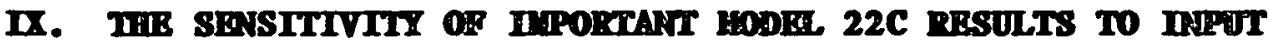

\section{PARAMGTrR cianges}

To gain understanding of a mode1's behavior as inputs are altered, to project the uncertainty in model results induced by input data uncertainty, or to focus input data analysis efforts toward those parameters for which greatest accuracy is needed, it is useful to know at least the first derivatives of important model results with respect to model input parameters. The first two of these purposes are essential goals of a model evaluation (Wei80). (Some important model results, or "responses," for Mode1 22C are defined in Table III. 2 and Appendix B.)

Even for the complex and rather slow-running Model 22C, one may "measure" by program rerun the derivatives ("sensitivity coefficients") of desired responses with respect to input parameters believed to be important. This "direct (recalculation) sensitivity study" technique has the advantage that, following a rerun, one has the information needed to approximate derivatives of all responses to the changed parameter, provided that the observed response differences are large enough to be significant with respect to the model convergence tolerances. With more reruns, some higherorder derivatives can also be obtained. However, use of the direct sensitivity mothod to obtain all the first derivatives is not practical, for long-running programs with thousands of parameters, to obtain values of large sensitivities to parameters that were not previously recognized to be important. The alternative "adjoint sensitivity technique" can, in principle, give the derivatives with respect to each of thousands of input parameters, especially if sensitivitios are needed for only a few critical responses (0b180).

For the present evaluation, both types of studies have been performed. Subsection A below describes sensitivity studies for 
responses from Table III.2 for a number of important parameter or parameter-group changes. The idea was to obtain indications of the model response to a few parameter changes comparable in magnitude to the uncertainty in those parameters. Subsection $B$ gives the main results of a novel and comprehensive first-order adjoint sensitivity study for four responses.

\section{A. Sensitivities of Hodel $22 \mathrm{C}$ Responses to Sano Couplod Paraneter Changes}

In the direct rerun studies, the approach was to test sensitivities to parameters used in groups of similar activities. In the case of "global" parameters that automatically apply to many activities, this was easily done. In other cases, simultaneous changes were made in the same parameter for a number of related model activities. This strategy tended to assure that some of the observed response changes would be large relative to the model convergence uncertainty. but it left open the question of the relative contribution of any specific activity to the measured derivatives. Some other parameter changes were made to test the consequences of apparent input errors and questionable parameter values.

...

In this subsection, tables of response changes or sensitivities are given for three model years for responses from Table III.2. These responses are precisely defined in Appendix $B$. .

Hothod. To perform the studies summarized in this subsection, the "base" case Mode1 22C (i.e.. original parameter set) was first converged to a (relative) tolerance of $5 \times 10^{-4}$ using Eq. (VI-5) (see sect. V.F). The parameter changes for a particular rerun, specified in detail and identified by "case number" in Appendix C, were then entered, and the revised model was run to convergence with a tolerance of 10-3. The "response" values were computed for 
normal and perturbed cases, and the response change $\Delta R$ was obtained by subtracting the normal from the perturbed.*

Bffects of some paranetex alterations. Table IX.1 gives response changes for some marked alterations in parameters. The results of Table IX.1 are not useful for estimation of derivatives (sensitivity coefficients) because the parameter changes (for this tab1e only) show the impact of what we interpret as input errors or other rather major input alterations that are inconsistent with the definition of a derivative. Values of change that approach the magnitude of the accuracy targets of Table III.2 are underlined. For orientation, the value of the response itself from Model 22C is listed at the right side of each sheet for year 2010. Note that the response changes listed in this table are in the same units as the response itself; for example, Case 1 indicates that setting the operating cost aging rate to 0.03 results in a decrease in year 2010 total energy-related capital cost per GNP (Response 35) of 0.011 , over $1 / 5$ of the value itself. Unless labeled, the values in the table are dimensionless. The cases are discussed in turn below.

\footnotetext{
-The parameter modifications given in Appendix C for each case were entered using the PERUSE option of LEAP-78 (Coh79). The prices, quantities, and capacity aditions for all activities (after the perturbed model run) were rolled onto disk files using a minor modification of the subprogram called by the DISPLA command of PERUSE. The prosont values of capital cost per unit of capacity (NPCC) for all conversions activities and the resource lease values were obtained ising one of the debug edits of LEAP-78. The needed portion of the output information was edited using the SUPERWYLUUR utility. This extra effort was required only for the base (Model 22C) case and those other cases that altered the capital cost and owner's profit calculations. Becanse the se unit cost factors are computed directly from inpat parameters, model iteration was not required to obtain numerical values. All calculations were performed on Department of Energy (DOE) Forrestal Computing Facility (FCF) computer systems.
} 
TABLB ㅍ.1

Chenges in sero important responses for soloctod eajor parenoter altorations"

\begin{tabular}{|c|c|c|c|c|c|c|c|c|c|c|c|c|}
\hline \multirow{3}{*}{$\begin{array}{l}\text { Rosponse } \\
\text { Nuibor }\end{array}$} & \multirow[b]{3}{*}{ Short Rosponse Derinition } & \multicolumn{3}{|c|}{ Case 1} & \multicolumn{2}{|l|}{ Cave 2} & \multicolumn{2}{|c|}{ Case 28} & \multicolumn{3}{|c|}{ Case 31} & \multirow{3}{*}{$\begin{array}{l}\begin{array}{c}\text { Rosponse } \\
\text { Valles }\end{array} \\
2010\end{array}$} \\
\hline & & \multicolumn{3}{|c|}{$\begin{array}{l}\text { Opozatiag Cost Agfins } \\
\text { Rate Corroction" }\end{array}$} & \multicolumn{2}{|c|}{$\begin{array}{l}\text { Price Blostlofity } \\
\text { Correction }\end{array}$} & \multicolumn{2}{|c|}{$\begin{array}{l}\text { Incase Glastiolts } \\
\text { Rrtrapolgtion } \\
\text { Canase }\end{array}$} & \multicolumn{3}{|c|}{$\begin{array}{l}\text { Bqual Markot Bhozos at } \\
\text { Bqual Prioes }\end{array}$} & \\
\hline & & $\overline{1980}$ & 1995 & 2010 & 1995 & 2010 & 1999 & 2010 & $\overline{1980}$ & 1995 & 2010 & \\
\hline 1 & $\begin{array}{l}\text { Total energy-related cost } \\
\text { to end nsers per GNP }\end{array}$ & $-3 \times 10^{-4}$ & $-3 \times 10^{-4}$ & $+4 \times 10^{-4}$ & -0.0001 & -0.0014 & 0.001 & $\underline{0.015}$ & -0.0050 & -0.0093 & -0.0098 & 0.16 \\
\hline 17 & $\begin{array}{l}\text { Total ener.gy cost to the } \\
\text { four demand sectors per } \\
\text { GNP }\end{array}$ & 0.0024 & 0.0057 & 0.0068 & -0.0001 & -0.0013 & 0.001 & $\underline{0.013}$ & -0.0056 & $-0,013$ & -0.014 & 0.13 \\
\hline 24 & $\begin{array}{l}\text { Cumulative energy cost to } \\
\text { the demand sectors per } \\
\text { cumulative GNP' }\end{array}$ & 0.0021 & 0.0036 & 0.0053 & $-1 \times 10^{-4}$ & $\therefore-6 \times 10^{-4}$ & 0.0006 & 0.0037 & -0.0041 & -0.0090 & -0.0113 & 0.13 \\
\hline 35 & $\begin{array}{l}\text { Total energy-related capi- } \\
\text { tal cost per GNP }\end{array}$ & $-0,013$ & -0.010 & -0.011 & $0.0 \times 10^{-4}$ & $-2.6 \times 10^{-4}$ & $4-0.0$ & $\underline{0.0075}$ & -0.0041 & -0.0055 & -0.0044 & 0.047 \\
\hline 2 & Fuel import cost per GNP & $3.9 \times 10^{-4}$ & $411.7 \times 10^{-}$ & $-411.5 \times 10^{-4}$ & $-4-0.2 \times 10^{-4}$ & $-1.1 \times 10^{-4}$ & 0.0002 & 0.0012 & 0.0021 & $\underline{0.0073}$ & $\underline{0.0084}$ & 0.010 \\
\hline 12 & $\begin{array}{l}\text { Annual domestio production } \\
\text { of natural oil and gas; } \\
\text { incladiag alaska (quad) }\end{array}$ & 0.28 & 1.49 & 1.41 & 0.05 & -0.23 & -0.30 & 1.71 & -1.41 & -2.21 & -0.49 & 35 quad \\
\hline 13 & $\begin{array}{l}\text { Annual imports of oil and } \\
\text { oil products (quad) }\end{array}$ & 0.29 & 0.74 & 0.83 & -0.01 & -0.09 & 0.16 & 1.00 & 0.42 & 2.87 & 5.17 & 9 qued \\
\hline 15 & $\begin{array}{l}\text { Annual domestic production } \\
\text { of shale.oil, coal liquids, } \\
\text { and high-Bta synthetic gas } \\
\text { (quad) }\end{array}$ & 0.00 & -0.10 & -0.12 & -0.012 & -0.22 & 0.046 & 1.59 & $-1 \times 10$ & -0.75 & -2.68 & 12 qued \\
\hline 7. & Fractional electrictty ase & -0.0014 & -0.0026 & -0.0008 & -0.0000 & 0.0015 & 0.0001 & -0.0017 & -0.010 & -0.035 & $=0.044$ & 0.22 \\
\hline
\end{tabular}




\begin{tabular}{|c|c|c|c|c|c|c|c|c|c|c|c|}
\hline \multirow{2}{*}{$\begin{array}{l}\text { Rosponse } \\
\text { Tuaber }\end{array}$} & \multirow[b]{2}{*}{ Bhort Rosponse Dofinition" } & \multicolumn{3}{|c|}{$\frac{\text { Case } 32}{\text { Seal1 alloontion prico }}$} & \multicolumn{3}{|c|}{$\begin{array}{c}\text { Case } 33 \\
\text { Lerge ellocation price } \\
\text { aensitivitices }\end{array}$} & $\begin{array}{l}\text { Largo al } \\
\text { tiviti }\end{array}$ & $\frac{\text { Caep } 11}{\text { cation pr }}$ & $\operatorname{sen}^{\operatorname{sen} 1-}$ & \multirow{2}{*}{$\begin{array}{l}\text { Dosponse } \\
\text { Valne }\end{array}$} \\
\hline & & 1980 & 1995 & 2010 & 1980 & 1995 & 2010 & 1980 & 1995 & 2010 & \\
\hline 1 & $\begin{array}{l}\text { Total energy-related cost } \\
\text { to end users per GNP }\end{array}$ & 0.0022 & 0.0044 & 0.0049 & -0.0042 & -0.0098 & -0.0119 & -0.0059 & -0.0103 & -0.0104 & 0.16 \\
\hline 17 & $\begin{array}{l}\text { Total energy cost to the } \\
\text { forr demand sectors per } \\
\text { GNP }\end{array}$ & 0.0023 & 0.0045 & 0.0050 & -0.004 & -0.012 & -0.014 & -0.006 & -0.014 & -0.015 & 0.13 \\
\hline 24 & $\begin{array}{l}\text { Cumulative onergy cost to } \\
\text { the demand sectors per } \\
\text { comulative GNP }\end{array}$ & $0.001 ?$ & 0.0032 & 0.0041 & -0.0026 & -0.0073 & -0.0104 & -0.0050 & -0.0100 & -0.0123 & 0.13 \\
\hline 35 & $\begin{array}{l}\text { Total energy-related capi- } \\
\text { tal cost per GNP }\end{array}$ & -0.0004 & 0.0014 & 0.0005 & -0.0019 & -0.0046 & -0.0028 & -0.0042 & -0.0052 & -0.0043 & 0.047 \\
\hline 2 & Fue1 import cost per GNP & $4.4 \times 10^{-4}$ & $12 \times 10^{-4}$ & $7.3 \times 10^{-4}$ & $-5.9 \times 10^{-4}$ & $4.0 \times 10^{-4}$ & $-4.0 \times 10^{-4}$ & 0.0025 & 0.0073 & 0.0075 & 0.010 \\
\hline 12 & $\begin{array}{l}\text { Angual doemstic production } \\
\text { of natura: oil and gas, } \\
\text { including Alaska (quad) }\end{array}$ & 1.03 & 1.50 & -0.07 & -0.43 & 1.71 & 0.28 & -1.61 & -2.15 & -0.76 & 35 quad \\
\hline 13 & $\begin{array}{l}\text { Annual impozts of oil and } \\
\text { oil products (quad) }\end{array}$ & 0.26 & 0.68 & 0.59 & -0.37 & -0.52 & -0.64 & 0.48 & 2.60 & $\underline{4.42}$ & 9 quad \\
\hline 15 & $\begin{array}{l}\text { Annual domestic prodaction } \\
\text { of shale ofl, coal liquids, } \\
\text { and high-Btu synthetic gas } \\
\text { (quad) }\end{array}$ & $2 \times 10^{-5}$ & 0.42 & 1.61 & -0.00 & -1.34 & 0.29 & $-1 \times 10$ & -0.52 & -1.34 & 12 quad \\
\hline 7 & Fractional olectricity ase & -0.0007 & -0.0034 & -0.0045 & -0.011 & -0.033 & -0.026 & -0.010 & -0.035 & -0.044 & 0.22 \\
\hline
\end{tabular}

${ }^{a}$ For complete response definitions, see Appendix B. The complete definitions of the parametor changes are given in Appendix C. All values are dimensionless unless units are assigned. 1 quad $=10$ s Btu.

${ }^{b}$ Case 1 -operating cost aging rate $=0.03$.

${ }^{c}$ Case 2--Price elastizity of demand $=-0.34$. Haintained long-term price elssticity at -0.5 by a corresponding change in SENS.

${ }^{d}$ Case 28-income elasticities at 1995 values for later gears.

${ }^{e}$ Case 31-market sharos at equal prices are all equal.

fase 32-no allocation prico sensitivities abore 5.0.

${ }^{8}$ Case 33-No allooation price senstivities less than 12.5.

h Case 41--same as case 33, but also decrease supply-side allocation behaptoral lags $30 \%$. 
Case 1 reduces the variable-operating cost aging rate (VOAGRT) to the intended value of 0.03 ; it was entered incorrectly by EIA as a 3. in Mode1 22C (Ste81). The effect of the error was that increased costs ascribed to aging occured precipitously in Model 22C when plants reached their nominal lifetimes. Except for those changes for energy-related capital costs, the response changes resulting from setting VOAGRT $=0.03$ were all less than one-third of the accuracy targets given in Table III.2. Therefore, for the selected responses, the VOAGRT input error had significant, but not dominant; consequences. Recall that Responses 1 and 17 represent two ways of measuring total energy cost per GNP in the model. (Response 1 includes the capital and operating costs to consumers of end-use equipment such as furiaces, boilers, etc.) It is interesting that these responses react so differently to this particular parameter change and, therefore, cannot be considered equivalent.

Case 2 indicates the changes in the values of selected responses on correction of the iikely error made at EIA by inputing the 1year short-term price elasticity of demand instead of a value for one (5-year) model period as was indicated. The table shows that the correction made no significant change in the selected responses for year 2010. Recali that the price elasticity in the end-use demand model takes effect only after year 1995; therefore, changes np through that time should be very small. As expected, the general effect of the correction is to reduce demand.

Case 28 investigates an alteration of the income elasticities of demand tabulated in ARC-78 (EIA79a). to hold them at their 1995 values for years beyond that time. Some of the elasticities used.to estimate the demand quantity paths were scaled down markedly toward year 2020 in Mode1 22C to reflect the low population growth rate and the saturation of per capita demand that were assumed (Ste81, graphs in Appendix C). The underlined changes for relative total and capital cost approach the accuracy targets of Table III.2. As 
expected, this change increased energy demand in the late model years.

Case 31 tests the effect of setting the market shares at equal prices (FREQPR) to be the same for each link at each multiple-supplier allocation activity. Although the use of very different equal-price shares is questioned in Sect. $X$, the axbitrary use of equal values in Model 22C would also have been inappropriate. The idea here is to test what the maximum effect would be of changes toward equality. Relative to the accuracy targets previously established, the primary impacts were to (1) greatly increase energy import quantity and cost. (2) decrease electricity production, and (3) reduce the projeoted overall energy cost. Although the tested case was an extreme. one, it illustrates that the Mode1 22C unequal FREQPR values did significantly impact important responses.

Cases 32 and 33 test the importance of the variety of values for the allocation price sensitivity parameter that is used throughout the model. Case 32 sets the parameter for all allocation activities to 5.0, the lowest value used in Model 22C; whereas in Case 33 , all lower values were changed to the highest common value of 12.5 . Reducing the high serisitivities in Case 32 increased projected energy costs, but had no impacts larger than about one-third the accuracy targots of Table III.2. Increasing sencitivity values in Cace 33 toward the ideal of more perfect competition reduced projected costs by an amount significant for changes in a single class of parameters. Case 41, in which shortened supply-side allocation behavioral lags were combined with the higher price sensitivities of Case 33 , shows the general energy cost reductions of Case 33 plus greatly increased fuel import projections and yet-smaller eloctricity nse. These cases illustrate that the hard-to-estimate allocation behavioral parameters can have significant impact on model results. In partioular, the 15to 20-year behavioral lags in the oil resource area apparently acted to reduce significantly the projected importance of oil imports. 
IX-8

Sonsitivity coefficients for coupled parameter changes. Results are given below for sensitivity coefficients estimated in two different ways from model reruns detailed in Appendix $C$.

For some of the examples of coupled parameter changes below, only one perturbed case was run and the first-order sensitivity coefficient $S 1=d R / d x$ was approximated by the ratio $\Delta R / \Delta x$, where the numerator is the change in the response that was "measured" when stated Model 22C parameters were a1tered by an amount $\Delta x$. (Becanse some responses may not be linear functions of the parameter $x$, the size of the perturbation $\Delta x$ used is significant.) For othex examples, two or more magnitudes of perturbation $\Delta x$ were studied so that both first- and second-order sensitivity coefficients could be obtained by fitting a parabola to the observed response changes according to the expression

$$
\Delta R=S 1 \cdot \Delta x+(S 2 / 2)(\Delta x)^{2}+(\text { higher-order terms }) \quad(I X-1)
$$

Here, $S 1$ is the first-order sensitivity coefficient previously defined, and $S 2\left(\tilde{=}^{2} R / d^{2}\right)$ is an approximate value of the secondorder coefficient. The $\Delta x$ in $\mathrm{Eq}$. (IX-1) can correspond to an absolute change $\Delta P$ in one or more parameters (e.g., dollars per unit of capacity or years) or to a relative change $\Delta P / P$, depending on the example. Note that $S 1$ and $S 2$ are absolute sensitivity coefficients rather than the relative ones that are often defined as in Sect. IX.B. below.

Table IX.2 gives twelve sets of absolute sensitivity coefficients of important model responses with respect to changes in selected parameters. For the first five and for the 12 th examples, values of both S1 and S2 were obtained; for the others, only S1 was determined. In either case, the number of figures given assures that the 1ast figure has some numerical significance if the relative uncertainty in the converged responses is $\leq 1 \pm 10^{-4}$. (Experience shows that 
TANB $\mathbf{X x . 2}$

Absolute consitivitios of sen inportant responsos to parameter ohenges"

\begin{tabular}{|c|c|c|c|c|c|c|c|c|}
\hline & \multirow{3}{*}{ Rosponse } & \multicolumn{6}{|c|}{ 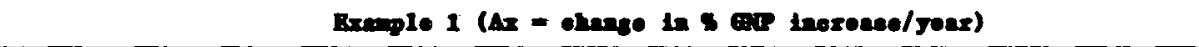 } & \multirow{3}{*}{$\begin{array}{l}\text { Iosponse } \\
\text { Valwo }\end{array}$} \\
\hline & & \multicolumn{3}{|c|}{$\mathbf{s 1}$} & \multicolumn{3}{|c|}{80} & \\
\hline & & 1980 & 1995 & 2010 & 1980 & 1995 & 2010 & \\
\hline 1 & E-re1atod cost to DEMAND per GNP. & 0.0024 & 0.0048 & 0.0045 & 0.0002 & 0.0015 & 0.0040 & 0.16 \\
\hline 17 & E cost to domand sectors per-GNP & 0.0024 & 0.0058 & 0.0068 & 0.0002 & 0.0012 & 0.0033 & 0.13 \\
\hline 24 & Cum E cost per cun. GNP & 0.0022 & 0.0035 & 0.0057 & 0.0002 & 0.0006 & 0.0019 & 0.13 \\
\hline 35 & E-re1eted capital cost per GNP & $-0.34 \times 10^{-3}$ & $3.29 \times 10^{-3}$ & $0.43 \times 10^{-3}$ & $-0.02(1) \times 10^{-3}$ & $0.49 \times 10^{-3}$ & $1.35 \times 10^{-3}$ & 0.047 \\
\hline 2 & Fuel import cost per GNP & $0.35 \times 10^{-3}$ & $1.04 \times 10^{-3}$ & $0.73 \times 10^{-3}$ & $0.04 \times 10^{-3}$ & $0.30 \times 10^{-3}$ & $0.7 \times 10^{-3}$ & 0.010 \\
\hline 12 & $\begin{array}{l}\text { Domestic oll/gas production, } \\
10^{2} \text { Btu }\end{array}$ & -0.53 & $\underline{3,98}$ & 4.7 & $-0.008(5)^{b}$ & 0.22 & 1.1 & 35 quad \\
\hline 13 & $\begin{array}{l}\text { Oil/oil product loports, } \\
\text { 1026 Btu }\end{array}$ & 0.244 & 2.45 & $\underline{3.2}$ & 0.012 & 0.54 & 1.5 & 9 grad \\
\hline 15 & $\begin{array}{l}\text { Synthotic oll and gus prod.. } \\
\text { 102: Btid }\end{array}$ & $s(2) \times 10^{-5}$ & 0.74 & $\underline{5.6}$ & $0 \times 10^{-5}$ & 0.19 & 1.1 & 12 quad \\
\hline 20 & Fractionsl liquid E to demand & $0.19 \times 10^{-3}$ & -0.0060 & -0.0162 & $0.09 \times 10^{-3}$ & -0.0003 & $-0.0005(2)$ & 0.34 \\
\hline 19 & Fractions 1 primary E to liquids & $0.14 \times 10^{-3}$ & -0.0039 & -0.0090 & $0.10 \times 10^{-3}$ & 0.0000 & -0.0014 & 0.29 \\
\hline 11 & Coal fraction of dos. priascy $E$ & $1.37 \times 10^{-3}$ & 0.0087 & 0.0144 & $-0.15 \times 10^{-3}$ & 0.0006 & -0.0037 & 0.45 \\
\hline 7 & Fractional electricity uso & $0.36 \times 10^{-3}$ & $4.7 \times 10^{-3}$ & $5.3 \times 10^{-3}$ & $-0.01(1) \times 10^{-3}$ & $-0.5 \times 10^{-3}$ & $-2.0 \times 10^{-3}$ & 0.22 \\
\hline
\end{tabular}

Tho responses are dofined procisely by number la Appendix B, and the paramoters are precisely defined by case number in Appendix C. Numerical rosponse values are in Table III.2 and Table B.1 ln Appondix B.

byares in parenthesos are the uncortainty in the last fignre, given if faliure to fit an intermediate deta point is taken as equitalent to a convergenco tolerence (only given when lerge). 


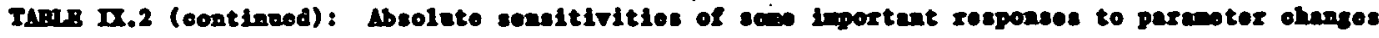

\begin{tabular}{|c|c|c|c|c|c|c|c|c|}
\hline & \multirow[b]{3}{*}{ Rosposse } & \multicolumn{3}{|c|}{ Bxamplo 2 (Ax = relative } & \multicolumn{4}{|c|}{ sonsitivities) } \\
\hline & & \multicolumn{3}{|c|}{$\mathbf{s i}$} & \multicolumn{3}{|c|}{$\mathbf{s}$} & \multirow{2}{*}{$\begin{array}{l}\text { Posponse } \\
\text { Valwe } \\
2010\end{array}$} \\
\hline & & 1980 & 1995 & 2010 & 1980 & 1995 & 2010 & \\
\hline 1 & E-related cost to DEMAND per GNP & -0.0074 & -0.0112 & -0.0114 & 0.008 & 0.009 & 0.005 & 0.16 \\
\hline 17 & E cost to demand sectors por GNP & -0.0075 & -0.0111 & -0.0100 & 0.009 & 0.009 & $0.002(2)^{b}$ & 0.13 \\
\hline 24 & Cum E cost por cum. GNP & -0.0016 & -0.0089 & -0.0097 & 0.006 & 0.008 & 0.007 & 0.13 \\
\hline 35 & E-related capital cost por GNP & -0.0026 & -0.0035 & -0.0014 & 0.0007 & 0.0012 & $0.001(2)^{b}$ & 0.047 \\
\hline 2 & Fuel import cost per GNP & -0.0007 & -0.0006 & -0.0015 & 0.000 & 0.002 & 0.003 & 0.010 \\
\hline 12 & $\begin{array}{l}\text { Dowestic oil/gas production, } \\
\text { 1013 Bta }\end{array}$ & -0.91 & 1.2 & $-0.9(3)$ & 2.0 & 1 & $s(2)$ & 35 quad \\
\hline 13. & $\begin{array}{l}\text { 011/oil product imports. } \\
\text { 10" Bta }\end{array}$ & -0.39 & -0.70 & -1.35 & 0.0 & 0.3 & 1.6 & 9 quad. \\
\hline 15: & $\begin{array}{l}\text { Synthetic oll and gas prod.. } \\
\text { 1013 Bta }\end{array}$ & -0.004 & -1.8 & $-0.5(3)$ & 0.02 & $0.6(8)$ & $-1(3)$ & 12 quad \\
\hline 20 & Fractional liquid B to domand. & -0.014 & -0.028 & -0.026 & $0.002(2)$ & 0.012 & $0: 02$ & $0: 34$ \\
\hline 19 . & Fractionel primary E to liguids & -0.007 & -0.018 & -0.023 & $0.004(2)$ & 0.032 & 0.060 & 0.29 \\
\hline 11 & Cosl fraction of dow. primary $E$ & 0.017 & -0.006 & -0.048 & -0.01 & $-0.02(1)$ & $0.02(2)$ & 0.45 . \\
\hline 7 & Fractional electricity use & -0.017 & -0.028 & -0.008 & 0.011 & $0.001(1)$ & -0.013 & 0.22 \\
\hline
\end{tabular}




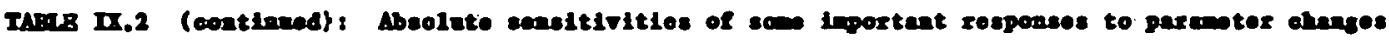

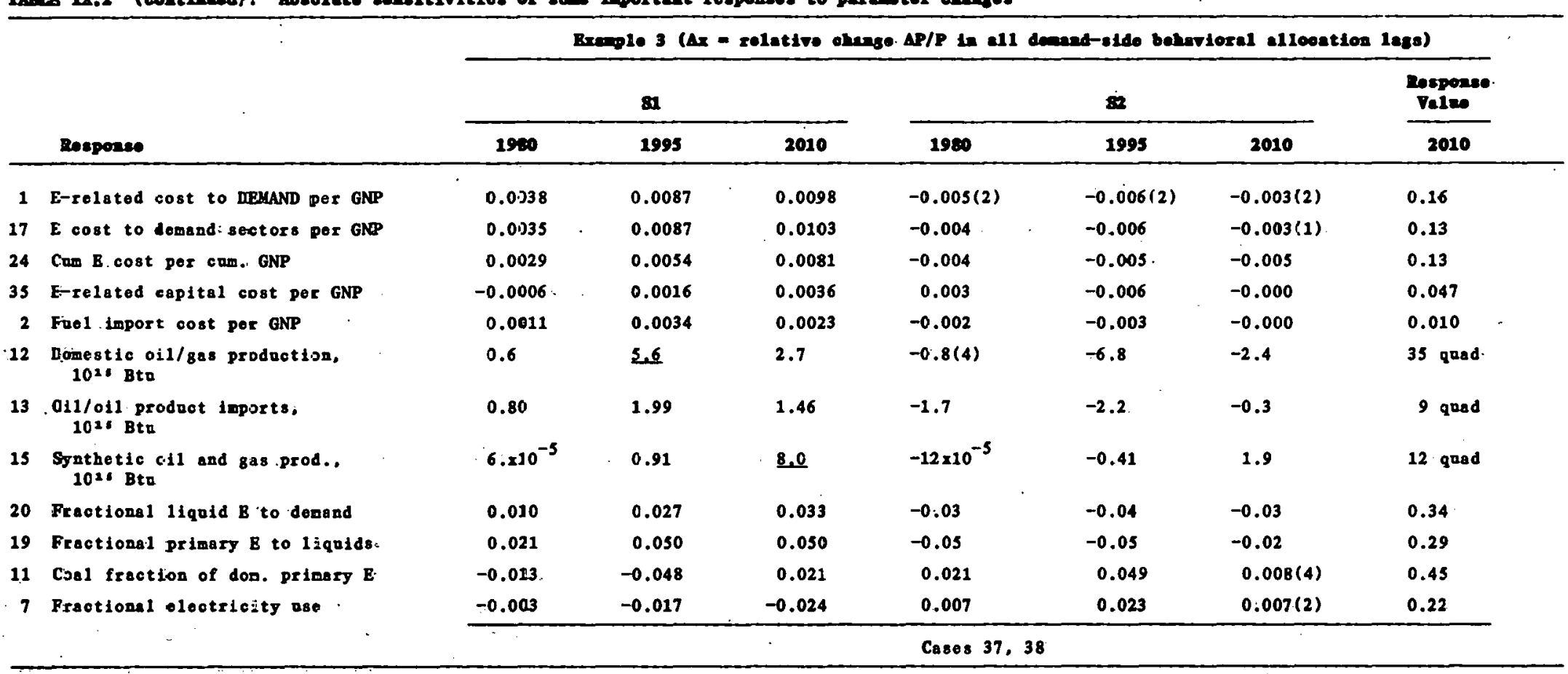




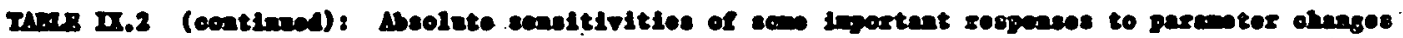

\begin{tabular}{|c|c|c|c|c|c|c|c|c|c|c|}
\hline & \multirow[b]{3}{*}{ Despones } & & \multicolumn{8}{|c|}{ 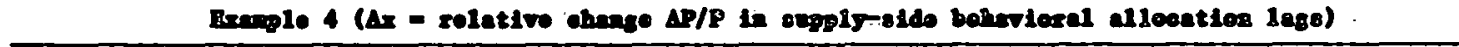 } \\
\hline & & & \multirow{2}{*}{ 1980 } & \multicolumn{2}{|l|}{$\mathbf{x}$} & \multicolumn{3}{|c|}{80} & \multirow{2}{*}{\multicolumn{2}{|c|}{$\frac{\begin{array}{c}\text { Rosposes } \\
\text { Valuos }\end{array}}{2010}$}} \\
\hline & & & & 1995 & 2010 & 1920 & 1993 & 2010 & & \\
\hline 1 & E-related cost to DEMAND per GNP & & 0.0037 & 0.0054 & 0.0032 & $0.001(2)^{b}$ & $0.005, .$. & 0.007 & 0.16 & \\
\hline 17 & B. cost to demend sectiors por GNP & & $0.0036^{\prime}$ & 0.0056 & 0.0032 & $0.001(1)$ & 0.005 & 0.007 & 0.13 & \\
\hline 24 & Com B cost per cow. GNP & & $0.0035^{\circ}$ & 0.0046 & 0.0045 & $0.001(1)$ & 0.003 & 0.005 & 0.13 & \\
\hline 35 & E-related capital cost per GNP & & -0.0011 & $-0.0002(1)$ & $0.0001(1)$ & $0.002(1)$ & 0.005 & 0.002 & 0.047 & \\
\hline 2 & Fuel import cost per GNP. & . & 0.0002 & 0.0012 & 0.0023 & -0.0012 & -0.0069 & -0.0081 & $0.010^{\prime}$ & \\
\hline 12 & $\begin{array}{l}\text { Domestic oll/gas production, } \\
\text { 1028 Bta }\end{array}$ & & -0.4 & -0.9 & 2.4 & 1 & 3 & -2 & 35 quad & \\
\hline 13. & $\begin{array}{l}\text { 011/o11 product imports, } \\
\text { 1021 Btu }\end{array}$ & & 0.10 & 0.91 & 1.99 & -0.8 & -5.4 & -7.7 & 9 quad & \\
\hline 15 & $\begin{array}{l}\text { Synthetio oll and gas prod.. } \\
\text { 10x' Btu }\end{array}$ & & $-2.6 \times 10^{-4}$ & -0.95 & -5.39 & $7.2 \times 10^{-4}$ & 2.77 & 9.7 & 12 quad & ". \\
\hline 20 & Fractional liquid E to demand & & $-0.001(1)$ & -0.004 & -0.005 & -0.00 & -0.00 & $-0.006(4)$ & 0.34 & \\
\hline 19 & Fractional primary B to liquids & & $-0.002(1)$ & -0.006 & -0.010 & 0.00 & 0.00 & 0.014 & 0.29 & \\
\hline 11 & Coal fraotion of dom. primary $E$ & & 0.003 & 0.006 & -0.013 & $-0.002(2)$ & 0.014 & 0.08 & 0.45 & : \\
\hline \multirow[t]{2}{*}{7} & Fractional electricity ase & & $0.0004(2)$ & 0.0020 & 0.0015 & 0.00 & 0.00 & $0.002(2)$ & 0.22 & $\therefore$ \\
\hline & - & & $\cdot$ & & & Cases 39, & & & & \\
\hline
\end{tabular}




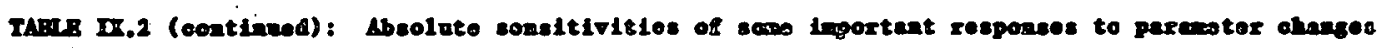

\begin{tabular}{|c|c|c|c|c|c|c|c|c|}
\hline & \multirow[b]{3}{*}{ Rosponse } & \multicolumn{7}{|c|}{ 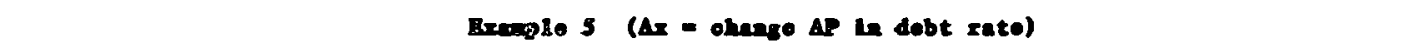 } \\
\hline & & \multicolumn{3}{|c|}{$\mathbf{8 1}$} & \multicolumn{3}{|c|}{82} & \multirow{2}{*}{$\begin{array}{l}\text { Response } \\
\text { Valvo }\end{array}$} \\
\hline & & 1980 & 1995 & 2000 & 1980 & 1995 & 2010 & \\
\hline 1 & E-related cost to DEMAND per GNP & 0.117 & 0.105 & 0.099 & 0.00 & $-0.06(3)$ & -0.13 & 0.16 \\
\hline 17 & E cost to desand sectors per GNP & 0.015 & 0.022 & 0.027 & $-0.03(2)$ & -0.08 & -0.12 & 0.13 \\
\hline 24 & Cum E cost per cum. ONP & 0.014 & 0.018 & 0.022 & $-0.03(2)$ & -0.05 & -0.08 & 0.13 \\
\hline 2 & Fuel import cont per GNP & 0.0006 & 0.0038 & 0.0085 & $-0.005(3)$ & -0.024 & -0.011 & 0.010 \\
\hline 12 & $\begin{array}{l}\text { Domestic oil/ges production, } \\
\text { 10:" Btu }\end{array}$ & -1.1 & $-0.4(1)$ & 22.2 & $6(6)$ & $-26(7)$ & -66 & 35 quad \\
\hline 13 & $\begin{array}{l}\text { oil/oll product lmports, } \\
\text { 10Ni Bto }\end{array}$ & 0.44 & 2.84 & 6.5 & $-3(2)$ & -14 & $-2(1)$ & 9 quad \\
\hline 15 & $\begin{array}{l}\text { Synthetic oil and gas prod., } \\
\text { 102" Bti }\end{array}$ & $9 \times 10^{-5}$ & -6.41 & -34.4 & -0.0007 & 53 & 98 & 12 quad \\
\hline 20 & Fractional liqudd E to domand & $-0.002(1)$ & 0.004 & $0.001(1)$ & 0.0 & 0.0 & 0.0 & 0.34 \\
\hline 11 . & Conl fraction of dom. primary $E$ & 0.016 & -0.038 & -0.243 & 0.0 & 0.4 & $0.3(1)$ & 0.45 \\
\hline \multirow[t]{2}{*}{7} & Fractional olectricity use & 0.019 & 0.060 & 0.061 & 0.0 & $-0.05(3)$ & -0.13 & 0.22 \\
\hline & & \multicolumn{7}{|c|}{$\begin{array}{l}P \text { in base case }=0.04 \\
\text { Cases } 46,47,49\end{array}$} \\
\hline
\end{tabular}




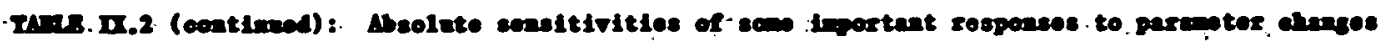

\begin{tabular}{|c|c|c|c|c|c|c|c|c|c|c|c|}
\hline & \multirow[b]{3}{*}{ Dospones } & \multicolumn{3}{|c|}{ 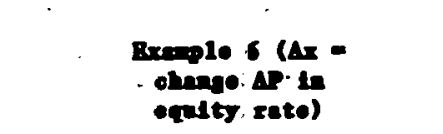 } & \multicolumn{3}{|c|}{ 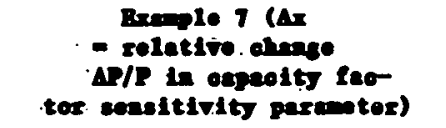 } & \multicolumn{3}{|c|}{ 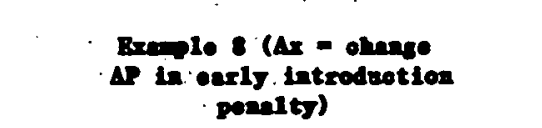 } & \multirow{3}{*}{$\begin{array}{l}\text { Desponse } \\
\text { Daleo } \\
2010 \\
\end{array}$} \\
\hline & & \multicolumn{3}{|c|}{8} & \multicolumn{3}{|c|}{$\mathbf{x}$} & \multicolumn{3}{|c|}{$\mathbf{8 1}$} & \\
\hline & & $=1900$ & 1995 & .2010 & 1980 & 1995 & 2010 & 1980 & 1995 & 2010 & \\
\hline 1 & $\begin{array}{l}\text { E-relat od cost to } \\
\text { DEMAND per GNP }\end{array}$ & $=0.246$ & 0.236 & 0.237 & 0.0131 & 0.0112 & 0.0069 & -0.0014 & $0.0007(3)$ & 0.000 & 0.16 \\
\hline 17 & $\begin{array}{l}\text { E cost to demend } \\
\text { sectors per GNP }\end{array}$ & 0.068 & 0.082 & 0.088 & 0.0117 & 0.0117 & 0.0075 & $-0.0005(3)$ & 0.0010 & 0.000 & 0.13 \\
\hline 24 & Cun. E cost per cun. GNP & 0.062 & 0.075 & 0.082 & 0.0088 & .0 .0111 & 0.0104 & 0.0000 & $0.0007(3)$ & $0.0005(3)$ & 0.13 \\
\hline 33 & $\begin{array}{l}\text { E-roleted capital } \\
\text { cost per GNP }\end{array}$ & -0.149 & -0.169 & -0.122 & $0: 0050$ & 0.0030 & 0.0020 & -0.0011 & .0 .0000 & 0.0000 & 0.047 \\
\hline 2. & $\begin{array}{l}\text { Fuel import cost } \\
\text { per GNP }\end{array}$ & 0.0045 . & 0.0172 & 0.0252 & 0.0015 & 0.0016 & 0.0008 & 0.0018 & 0.0010 & $.0: 0002$ & 0.010 \\
\hline 12 & $\begin{array}{l}\text { Domestic 011/ges } \\
\text { production, 102s Btu }\end{array}$ & -8.2 & -12.6 . & 45.5 & 1.83 & 1.53 & -0.14 & -0.9 & -0.3 & 0.4 & 35 quad \\
\hline 13 & $\begin{array}{l}\text { 011/oil product } \\
\text { imports, 102s Bta }\end{array}$ & 3.0 & 12.3 & 21.3 & 1.21 & 1.25 & 0.65 & 1.47 & 0.72 & 0.17 & 9 quad \\
\hline 15 & $\begin{array}{l}\text { Synthotic oil and } \\
\text { gas prod.. 102: Btz }\end{array}$ & 0.0049 & -14.7 & -78 & $6.7 \times 10^{-5}$ & 0.43 & 1.78 & -0.099 & -0.176 & -0.14 & 12 quad \\
\hline 20 & $\begin{array}{l}\text { Fractional liquid } E \\
\text { to demand }\end{array}$ & $-0.006(5)$ & 0.007 & -0.017 & 0.0197 & 0.0161 & 0.0112 & 0.007 & 0.003 & $0.002(1)$ & 0.34 \\
\hline 19 & $\begin{array}{l}\text { Fractiona } 1 \text { primary } \\
\text { B to liquids }\end{array}$ & -0.03 & -0.11 & -0.20 & 0.0171 & 0.0140 & 0.0102 & $0.005(1)$ & 0.002 & 0.001 & 0.29 \\
\hline 11 & $\begin{array}{l}\text { Coal fraction of dom. } \\
\text { primary } E\end{array}$ & 0.04 . & -0.14 & -0.71 & -0.0075 & -0.0043 & 0.0047 & -0.014 & -0.004 & 0.000 & 0.45 \\
\hline \multirow[t]{2}{*}{7} & $\begin{array}{l}\text { Fractional olectricity } \\
\text { ase }\end{array}$ & 0.070 & 0.196 & 0.170 & $-0: 0076$ & -0.0115 & -0.0100 & 0.0019 & 0.0019 & $0.0007(4)$ & 0.22 \\
\hline & & \multicolumn{3}{|c|}{$P=0.10: \Delta P=-0.01$} & & $\begin{array}{l}/ P=-0 . \\
\text { Case } 4\end{array}$ & & \multicolumn{3}{|c|}{$P=0.10 ; \quad P=-0.05$} & \\
\hline
\end{tabular}

This 18 the largest change peraitted in the model of the basic conversion snd eloctric power conversion processes. The change laitiated at the input was ectually $\triangle P / P=-0.20$. and this chango vas pormitted by the resonrce extraction submodels. The indicated valuo of -0.104 vas used to ostimate sonsitiplty ooefficlents becase in Mode1 $22 \mathrm{C}$ the resource processes oporate near unity capacity factor. 


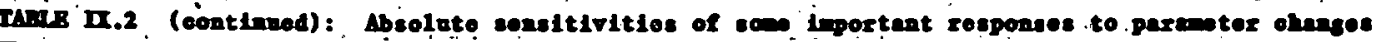

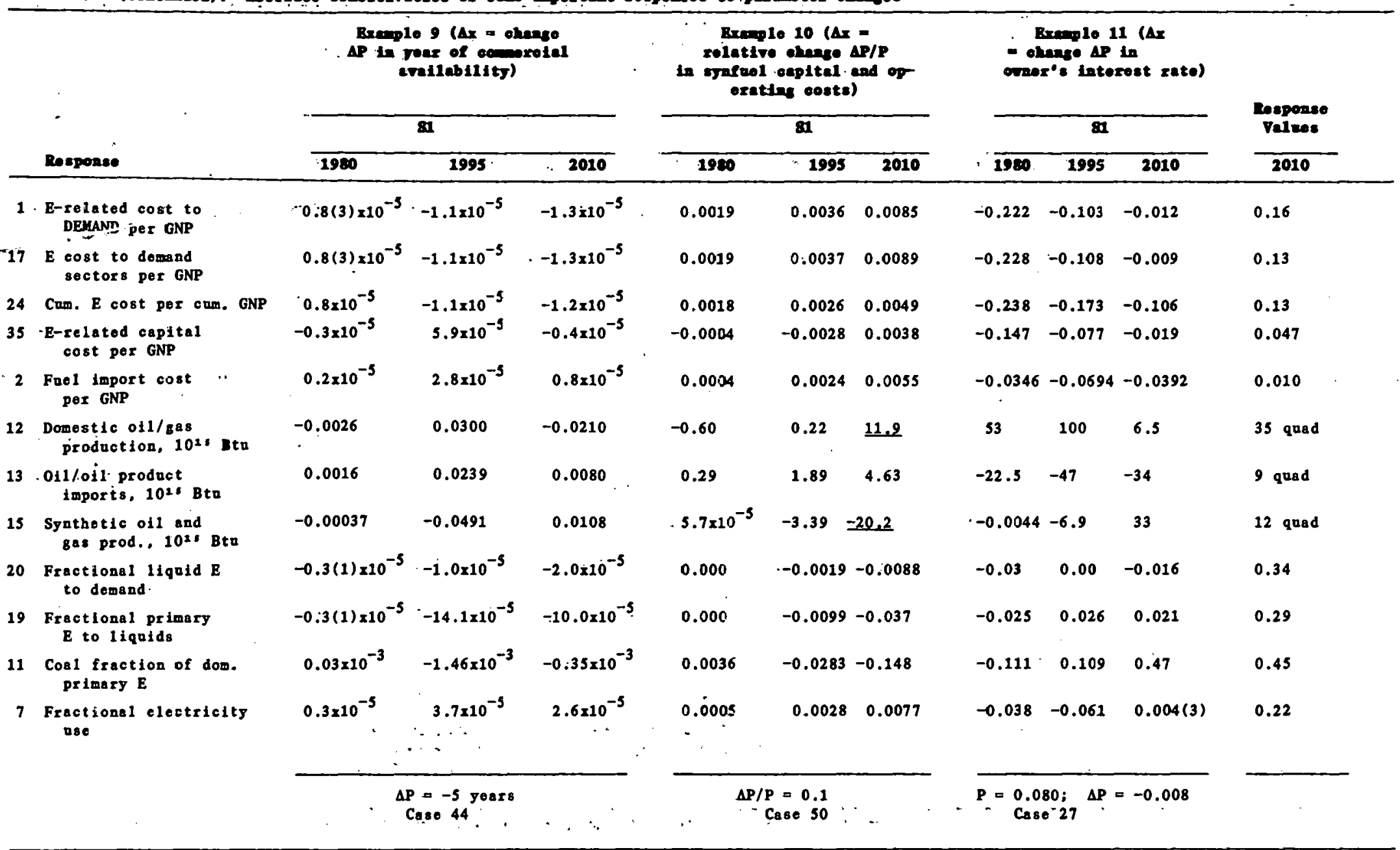




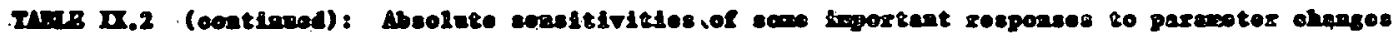

\begin{tabular}{|c|c|c|c|c|c|c|c|c|}
\hline & \multirow[b]{3}{*}{ Poopenese } & \multicolumn{7}{|c|}{ 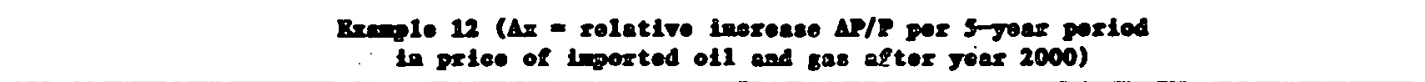 } \\
\hline & & \multicolumn{3}{|c|}{$\mathbf{8 1}$} & \multicolumn{3}{|c|}{8} & \multirow{2}{*}{$\begin{array}{c}\text { Bespense } \\
\text { Velive } \\
2010\end{array}$} \\
\hline & & 1980 & 1993 & 2010 & 1980 & 1995 & 2010 & \\
\hline 1 & E-related cost to DEMAND per GNP & $0: 0003$ & 0.0014 & 0.0203 & -0.006 & -0.019 & -0.076 & 0.16 \\
\hline 17 & E cost to demand sectors per GNP & 0.0002 & $0.001 \dot{4}$ & 0.0213 & -0.006 & -0.019 & -0.082 & 0.13 \\
\hline 35 . & E-related capital cost per.GNP & 0.0000 & 0.0000 & 0.0096 & 0.001 & 0.000 & -0.082 & 0.047 \\
\hline 2 & Enorgy 1mport cost per.GNP & $0.05 \times 10^{-3}$ & $0.50 \times 10^{-3}$ & $6.03 \times 10^{-3}$ & $-1.1 \times 10^{-3}$ & $-6.1 \times 10^{-3}$ & $57.6 \times 10^{-3}$ & 0.010 \\
\hline 12 & $\begin{array}{l}\text { Domestic oll/.gas production, } \\
\text { 10201Btu }\end{array}$ & -0.09 & -0.40 & 1.40 & 1.7 & 8.1 & -30.5 & 35 qued \\
\hline 13 & $\begin{array}{l}\text { 0i1\%il product Imports, } \\
\text { 10\%. Btu }\end{array}$ & $0.02(1)$ & .0 .032 & -9.56 & -0.8 & -4.1 & 60.8 & 9 quad \\
\hline 15 & $\begin{array}{l}\text { Syathetic oll and gas prod.. } \\
\text { 1023.Bta }\end{array}$ & $-1.5 \times 10^{-5}$ & $-0: 200$ & 10.2 & $0.0 \times 10^{-5}$ & $-0.05(1)$ & -62.0 & .12 quad \\
\hline 19 & Fractional prinary E to -1lquids & $0.0005(2)$ & 0.0007 & $-0: 0023$ & $-0.002(2)$ & $-0.001(2)$ & $-0.008=$ & 0.29 \\
\hline 11 & Coñ_fefaction of dom...primary $E$ & $0.0001(1)$ & -0.0053 & 0.070 & $-0.004(1)$ & $0.006(2)$ & -0.35 & 0.45 \\
\hline 7 & Fractional olectricity nse & $0.0001(1)$ & 0.0005 & 0.0089 & $-0.002(1)$ & -0.007 & -0.047 & 0.22 \\
\hline
\end{tabular}


the major flows in the model are much more tightly converged than the value of the convergence tolerance.) Where more than two parameter changes of the same type were made, results were checked to assure that they were consistent with the indicated significance. In reading Table IX.2, one must note whether the parameter variations were absolute $(\Delta x=\Delta P)$ or relative $(\Delta x=\Delta P / P)$; the $\Delta R$ of $E q$. (IX-1) is always absolute in the sense that it has the same units as the responses defined in Table III.2 and listed for year 2010 at the right side of each sheet. Column headings and footnotes differentiate between these possible interpretations and give the Case numbers from Appendix $C$ that led to the tabulated ralues.

Example 1 in Table IX.2 states, for instance, that if the post-1980 real GNP increase per year assumed in Mode1 22C (2.4 to 3.5\%/year) is increased by $1 \% /$ year for all years 1981 to 2020 (to 3.4 to 4.5\%/year), domestic oil/gas production (Response 12) in year 2010 is projected to increase by $\Delta R=S 1 \cdot 1+1 / 2 \cdot S 2 \cdot 1^{2}=4.7+1 / 2(1.1)$ $=5.2 \times 10^{13} \mathrm{Btu} /$ year. For the same case, the 52 term is relatively much more important for Response 1; for the same $\Delta x=1 \% /$ year, the 2010 response change would be 0.0045 if only $S 1$ is considered and 0.0065 if both terms are included. By contrast,. in Example 2 of Table IX.2 on market share price sensitivity relative change, $\Delta x=0.5$ corresponds to a $50 \%$ increase in all allocation price sensitivities. This change would increase the year 2010 domestic oil/gas production by $\Delta R=(-0.9)(0.5)+0.5(5)(0.5)^{2} \cong+0.2 \times 10^{25}$ Btu/year (if third-order coefficients are not important), even though the value of $\mathrm{S} 1$ for Response 12 is negative.

It is evident that Table IX.2 contains a great deal of information both about the sensitivity of Model 22C responses to synchronized parameter changes and about the degree to which first-order sensitivity coefficients can be applied for relatively large parameter changes for Mode1 22C. Based on the form of Eq. (IX-1), one can estimate the relative importance of the 52 coefficient at, 
say. $\Delta x=0.5$ by noting the relative magnitude of $S 1$ and $s 2 / 4$. To study the tables, it is necessary to have in mind the magnitude of interesting parameter changes for the case of interest becanse these values range in magnitude from 10 years for a date of commercial availability to 0.02 for one of the discount rates. It is also necessary to have in mind the magnitude of interesting changes in each response. If the target accuracies of Table III.2 are taken as a guide, magnitudes of interest vary from 0.01 for oil import cost/GNP to 5 quads for the oil production and import responses.

Table IX.3 tabulates sensitivity coefficients for six combinations of parameter changes in the oil/gas resonce extraction activities. These are particularly interesting because the ability to handle resonrce depletion is quite important for a long-range model. For changes in the parameter values comparable to expected uncertainties (see Sect. X.E), it appears that significant changes would occur in projections of natural oil and synfuel production and sometimes in capital cost/GNP.

Estimation and use of sensitivity coefficients is easier in cases where only the first-order coefficients $S 1$ are required. The secondorder derivatives for some of the cases in Tables IX.2 and IX.3 permit a judgment of their degree of importance.: Behavior with GNP increase was relatively linear except that the second-order term is important for the energy-related capital cost. Dependence on debt rate appears adequately 1inear. Dependence on market share price sensitivities is roughly linear, except for domestic oil production, if parameter changes of about $50 \%$ are considered. For other. cases tested; the second-order derivatives appear to be important for some parameter changes that are consonant with the approximate parameter uncertainties shown in Sect. $X$. If similarly. large values apply for those examples where only a single rerun was made, the interpretation of $\Delta R / \Delta P$ as an approximate derivative is in jeopardy. 
TANB $\mathbf{n . 3}$

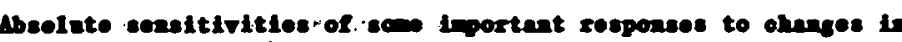

ollices resonsen olute parentere

\begin{tabular}{|c|c|c|c|c|c|c|c|c|c|c|c|}
\hline \multirow[b]{3}{*}{$\therefore$} & \multirow[b]{3}{*}{ Desponsen } & \multicolumn{6}{|c|}{ 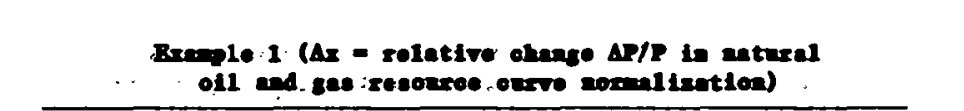 } & \multicolumn{3}{|c|}{ 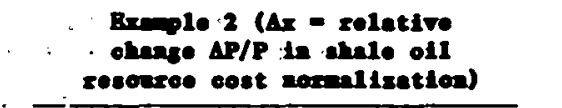 } & \multirow{3}{*}{$\begin{array}{l}\text { Rosponse } \\
\text { Palno } \\
2010\end{array}$} \\
\hline & & $\therefore$ & $\therefore$ & & \multicolumn{3}{|c|}{$g$} & \multicolumn{3}{|c|}{82} & \\
\hline & & 1980 & $r 1985$ & 2010 & 1980 & 1985 & 2010 & 1980 & 1995 & 2010 & \\
\hline 1 & $\begin{array}{l}\text { E-roleted cost - to } \\
\text { DEMAND per GNP }\end{array}$ & 0.027 & 0.019 & 0.009 & -0.016 & -0.024 & -0.022 & $0.19 \times 10^{-3}$ & $0.93 \times 10^{-3}$ & $2.25 \times 10^{-3}$ & 0.16 \\
\hline 17 & $\begin{array}{l}\text { B cost to dowand } \\
\text { sector: per GNP }\end{array}$ & 0.028 & 0.020 & 0.009 & -0.016 & -0.024 & -0.022 & $0.19 \times 10^{-3}$ & $0.94 \times 10^{-3}$ & $2.32 \times 10^{-3}$ & 0.13 \\
\hline 24 & Cun $E$ cost por oum. GNP & 0.031 & 0.024 & 0.019 & -0.013 & -0.021 & -0.022 & $0.17 \times 10^{-3}$ & $0.42 \times 10^{-3}$ & $1.17 \times 10^{-3}$ & 0.13 \\
\hline 35 & $\begin{array}{l}\text { E-related capital } \\
\text { cost por GNP }\end{array}$ & 0.0192 & 0.0164 & .0 .0062 & -0.012 & -0.012 & -0.003 & $-0.06 \times 10^{-3}$ & $-0.25 \times 10^{-3}$ & $0.65 \times 10^{-3}$ & 0.047 \\
\hline 2 & Fuel leport cost per GNP & 0.0048 & 0.0104 & 0.0046 & 0.0000 & 0.000 & -0.0005 & $0.08 \times 10^{-3}$ & $0.72 \times 10^{-3}$ & $1.00 \times 10^{-3}$ & 0.010 \\
\hline 12 & $\begin{array}{l}\text { Domostic o11/gas } \\
\text { production, : 1021 Btz }\end{array}$ & -7.8 & -20.3 & -19.0 & 7.2 & 12 & 25 & -0.07 & 0.66 & 1.42 & 35 quad \\
\hline 13 & $\begin{array}{l}\text { 011/o11 product } \\
\text { imports, 1026 Btn }\end{array}$ & $3: 44$ & 7.0 & 3.8 & -2.3 & -2.8 & -0.8 & 0.07 & 0.63 & 0.98 & 9 quad \\
\hline 15 & $\begin{array}{l}\text { Synthetic oil and } \\
\text { gas prod., 1016 Bta }\end{array}$ & 0.00086 & 3.53 & 8.8 & -0.00064 & 0.23 & -14 & $-0.7 \times 10^{-3}$ & -1.34 & -2.71 & $12 \cdot$ quad \\
\hline 20 & $\begin{array}{l}\text { Fractional liquid E } \\
\text { to deand }\end{array}$ & 0.0011 & -0.003 & -0.0020 & $-0.002(3)$ & 0.009 & 0.017 & $-0.0 \times 10^{-3}$ & $-0.5 \times 10^{-3}$ & $-2.2 \times 10^{-3}$ & 0.34 \\
\hline 19 & $\begin{array}{l}\text { Fractional primary } \\
\text { B to liquids }\end{array}$ & $.0 .0008(3)$ & -0.004 & 0.0052 & $-0.003(2)$ & 0.016 & $-0.004(2)$ & $-0.1(1) \times 10^{-3}$ & $-0.7 \times 10^{3} \quad-0.3$ & $3 \times 10^{-3}$ & 0.29 \\
\hline 11 & $\begin{array}{l}\text { Coal fraction of dom. } \\
\text { priary } E\end{array}$ & 0.033 & 0.072 & 0.078 & $-0.06(1)$ & -0.06 & -0.13 & $0.0 \times 10^{-3}$ & $1.3 \times 10^{-3}$ & $.12 .4 \times 10^{-3}$ & 0.45 \\
\hline 7 & $\begin{array}{l}\text { Fractlongl electrleity } \\
\text { age }\end{array}$ & 0.0058 & 0.0167 & $\because 0.0107$ & 0.003 & -0.018 & -0.016 & $0.00 \times 10^{-3}$ & $0.07(4) \times 10^{-3}$ & $0.66 \times 10^{-3}$ & 0.22 \\
\hline & 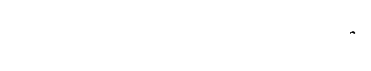 & & & cases & 14,13 & & 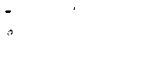 & & $\begin{aligned} & P / P=0.5 \\
& \text { Case } 16\end{aligned}$ & & \\
\hline
\end{tabular}




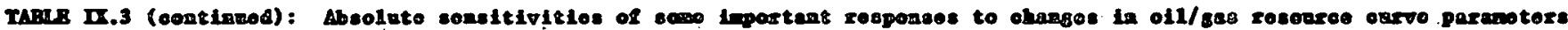

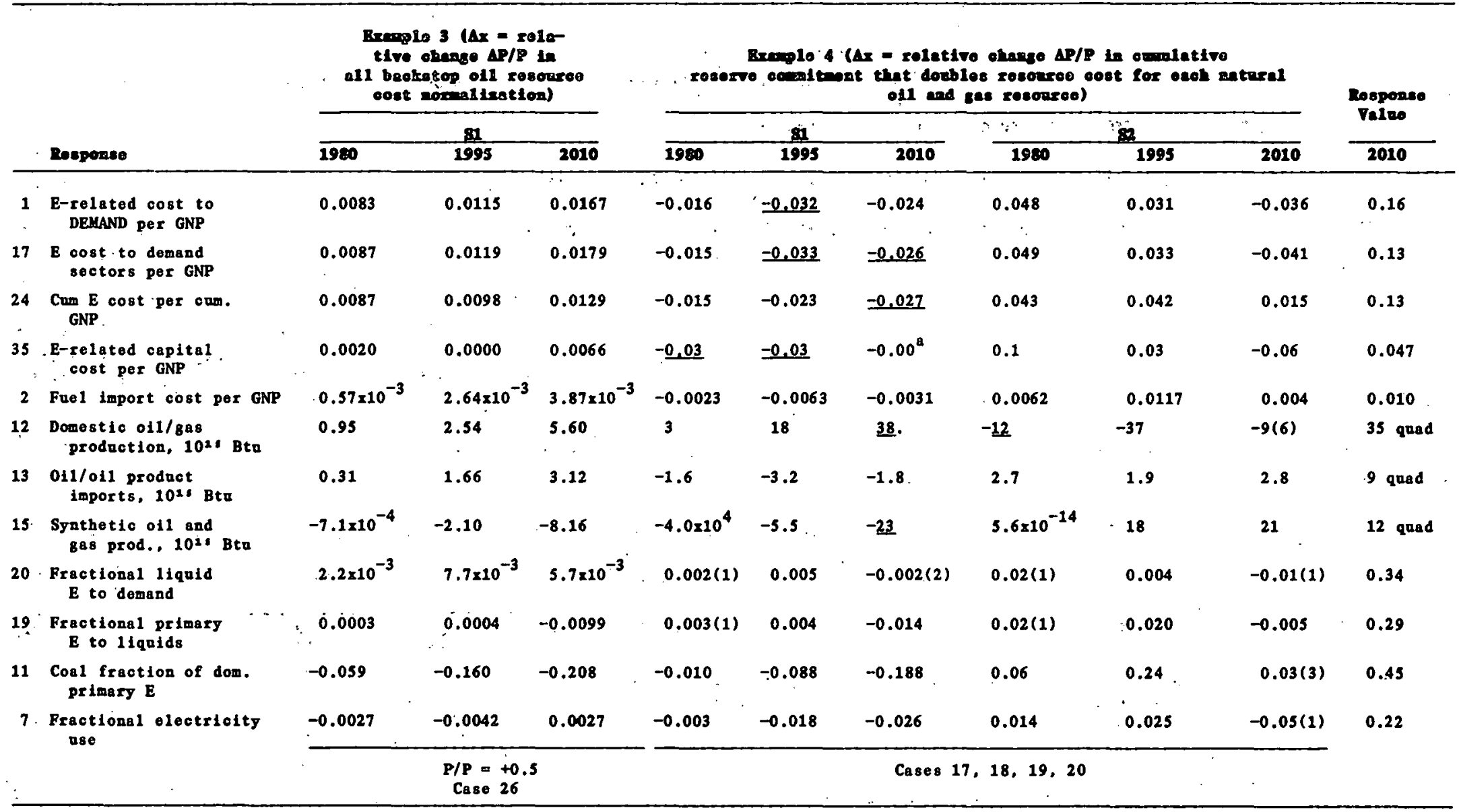




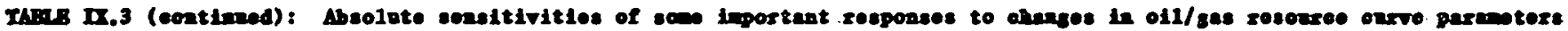

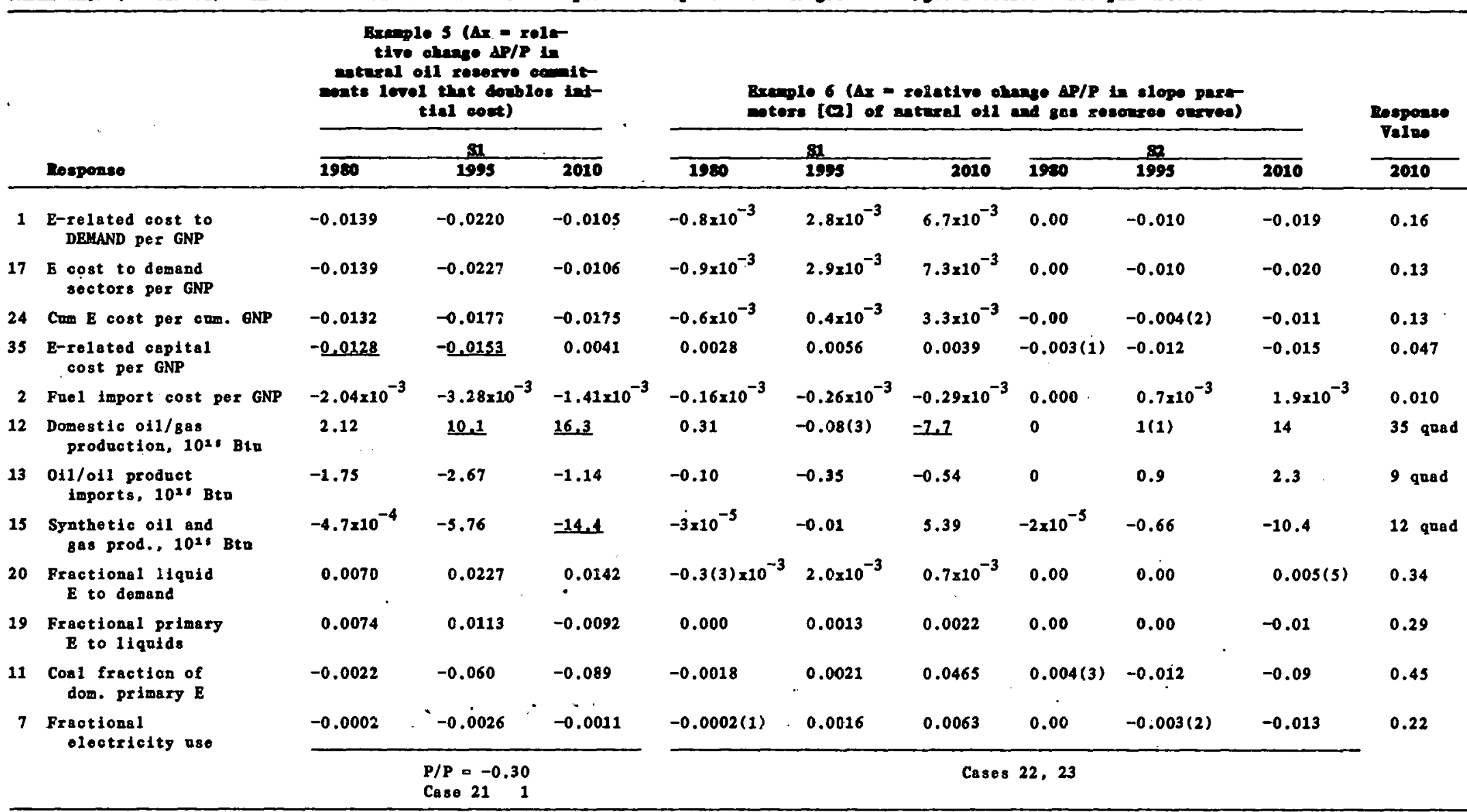


In these tables, the values are underlined for which parameter changes comparable to the uncertainties of Table X.1 would lead to response changes comparable to the accuracy targets of Table III.2. At this level of change, several of the parameters strong1y influenced the liquid fuel responses, whereas only the resource base'. parameters and equity rate had a strong influence on the global energy cost responses. Note in Example 1 of Table IX.1 how different the results would have been if these costs had not been measured relative to the GNP; a 1\%/year change for 40 years induced large changes in the costs themselves. (In defining the responses, it was assumed that the costs were important largely in relation to the current GNP.)

Throughout Tables IX.2 and IX.3, the sensitivities are almost equal for the total energy-related costs per GNP (Response 1) and the total cost of energy to the demand sectors per GNP (Response 17), except that they differed greatly for the sensitivities to debt and equity rates. This difference must arise from the cost of investments (e.8., boilers, refrigerators) in the residential, commercial, and industrial sectors that by definition are not included in Response 17.

User interests in these sensitivities vary. For some applications (e.g., uncertainty estimation), a number of parameters may be varied, sometimes in a correlated way. Therefore, many of the coefficients not underlined may be large enough to be important.

- Transportation sector investments were not involved becanse of the input data problems described in Sect. $X$. Investments in activities modeled with the transport process (e.g., gas pipelines, the Alaska oil pipeline, electric line loss) were not modeled as part of the transportation sector. 


\section{IX-23}

of the sensitivities shown, those for change in the date of commercial availability seemed surprisingly. small to the anthors. The 5-year date change did produce a large relative change in the values of response 15 (shale oil, coal synfuels production) for years 1985 and 1990 , but in these years the projected production levels were less than $1 \times 1015$ Bta. 


$$
\text { IX. } 24
$$

\section{THIS PAGE}

\section{WAS INTENTIONALLY LEFT BLANK}


Conclusions from rexun sensitivity studies. The tests that led to Tables IX.1 through IX.3 demonstrated that direct sensitivity studies can be useful if important or interesting parameters or parameter combinations have been identified. Such studies may offer a method for developing and presenting information on model behavior. However, the data handing to obtain the tabulated values was cumbersome.

The direct sensitivity studies of this subsection indicated that

1. The Model 22C input error on the variable operating cost aging rate affected the ARC-78 published results significantly relative to some accuracy targets.

2. The input error on the demand price elasticity lag parameter had no important impaot on the particular responses studied in 2010 .

3. Setting post-1995 income elasticities at their year 1995 values rather thán at Mode1 $22 \mathrm{C}$ values led to sufficiently larger year 2010 demands that the projected total cost of energy per GNP in that year was increased by the greater portion of the accuracy target 1 isted in Tab1e III.2.

4. Concerted modifications to the allocation behavioral parameters can produce important changes in some cost and liquid fuel production responses.

5. Second- or higher-order, as we1l as first-order, sensitivity coefficients are required to express the dependence of some selected responses on long-term GNP annual increases, global market share price sensitivity and behavioral lag changes, undiscovered resources of oil and gas that can be committed at up to twice the 1975 cost, and the oil and gas resource curve shape parameters. 


\section{IX-26}

6. Of the limited set of coupled parameter sensitivity coefficients measured, those most important for propagation of uncertainties to the selected responses were the (synchronized) GNP annual increases, demand-side behavioral lags, synfue1 capital and operating costs, and the natural oil and gas resource curve parameters. 


\section{B. First-Order Sensitivitios Obtained Jging Adjoint Sensitivity Thoory}

Mode1 22C relies on a data field that contains thousands of elements (i.e.. for Mode1 22C, a few thousand numbers must be specified before a result of interest can be calculated). In genera1, not all of these data elements are of equal importance in producing a given result, but in the past, it has been very difficult to systematically determine which data elements have the most influence on producing a given result. This can be done by systematically varying the data elements one at a time and completely redoing the calculations each time, but this method is prohibitive unless the computing time for each variation is very short.

A mathematical methodology called adjoint sensitivity theory has been available for some time that determines, in principle, the sensitivity of reșults obtained by solving large sets of nonlinear equations to each element in the data field that enters into the calculations. More precisely, if $R$ is a result of interest, the methodology provides an economical means, in principle, of calculating $d R / d x$, hereinafter call the sensitivity of $R$ to $x$, for every element $x$ in the data field. After $d R / d x$ is known for all $x^{\prime} s$, it is a small matter to determine those $x^{\prime} s$ for which $d R / d x$ is 1arge. It should be emphasized that the methodology used provides only the first derivatives (i.e., the first-order sensitivities) and gives no information about the higher derivatives. The qualifier, "in principle," ased in the above sentences is introduced because, in an application such as that considered here, the very small sensitivities are difficult to calculate accurately. Because the small sensitivities are of little interest, no attempt has been made to improve their accuracy. The methodology has been applied in a variety of physical cases (see Cac80 for references to a largo number of these cases) and has been applied to Hodel 22C by Alsmiller et a1. (A1981). 
Mothodology. The theory as it applies to energy-economic models is discussed in detail in the report by Alsmiller et al. (Als81) and will not be described here. In general, the application of the methodology requires a very detailed knowledge of the equations of the model and considerable development time. In the conrse of applying the methodology to Model 22C, it was found, however, that for models of the special structure of LEAP, much of the work of applying the methodology could be avoided by using numerical techniques. This alternative numerical approach is discussed in some detail in the report by Alsmiller et al. (Als81), but was not used.

To carry out a sensitivity analysis, it is necessary to define the responses of interest. The responses considered here are a subset. of those listed in Table III.2 and defined precisely in Appendix B. The sensitivity coefficients could be computed for other results (responses) if needed. In particular, calculated results will be presented for responses $1,2,13$, and 20 (with qualifications--see Table III.2, footnote h).

The calculations required to determine $\mathrm{dR} / \mathrm{dx}$ for all $\mathrm{x}^{\prime} \mathrm{s}$ in Model 22C are substantial. In particular, in Model 22C there are 4359 system variables (prices and quantities), and the determination of $\mathrm{dR} / \mathrm{dx}$ requires that 4359 simultaneous linear equations be solved. In solving the equations, one is, however, helped substantially by the fact that the matrix defining the set of linear equations is very

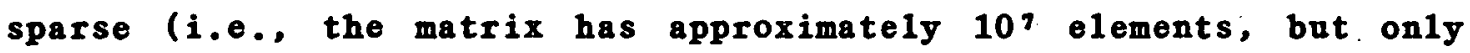
of the order $10^{4}$ are nonzero). The solution of the set of linear equations was obtained using the work by Duff (Duf77).

In principle, an estimate of $\mathrm{dR} / \mathrm{dx}$ can always be obtained by changing a parameter $x$ by an amonnt $\Delta x$ and calculating $\Delta R / \Delta x$ by completely repeating the LEAP calculations. To test the accuracy of the sensitivities calculated by adjoint methods, several sensitivities were obtained by direct calculations, and these will also be 
presented and discussed. For these direct calculations, if the response is not sufficiently linear in $x$, the value of $\Delta R / \Delta x$ will be a fuction of the size of the data perturbation employed.

Results and discussion. Results for the four responses considered here are given starting in Table IX.4. In the tables, the first column gives the sector number and activity number in this sector that identify the node or activity in which the data element, $x$, occurs. The sector number in column one is the same as the figure number in Appendix A that shows the activities in a sector. The term "many" in the first column is used to indicate that the data element occurs at more than one node and that the sensitivity expresses the rate of change of the response with respect to an increase in the data element everywhere that it occurs. The second column gives the descriptive name of the activity that is used in Figs. A-1 through A-9 (see Appendix A) if only one node is involved and the process submodel that is used at this node. When more than one node is involved, the comment in the second column gives an indication of the activities that are included.

The third column gives the name of the data element, $x$, being considered and the time or other index that is needed. to completely specify the data element. When 1 ink $i$ is specified, the $i$ refers to the numbers on the links in Figs. A-1 through A-9. The dula eleirent name given in the tables is the FORTRAN name used in the LEAP-78 computer code.. Information on the meaning of these data elements is given in the footnotes to the tables and in the discussion below. The fourth column in each table gives the value of the data element, $x$, in the Mode1 $22 \mathrm{C}$ base case. The fifth column in each table gives the relative sensitivity obtalned by adjuint methods, and the sixth column gives the relative sensitivities obtained by direct calculations using LEAP-78. In comparing sensitivities of different data elements, it is usualy preferable to consider the relative seusilivity defined by $(x / R)(d R / d x)$, where $x$ and $R$ are 


\section{IABR IX:4}

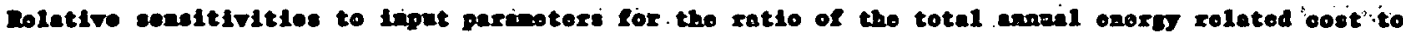

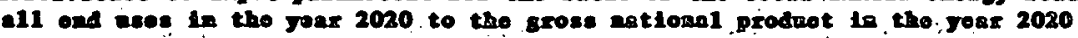

The response, called $\mathrm{R}_{1}(10)$, has the value 0.15 in the base case.

The relative sensitivities are listed in the order of decreasing absolute value.

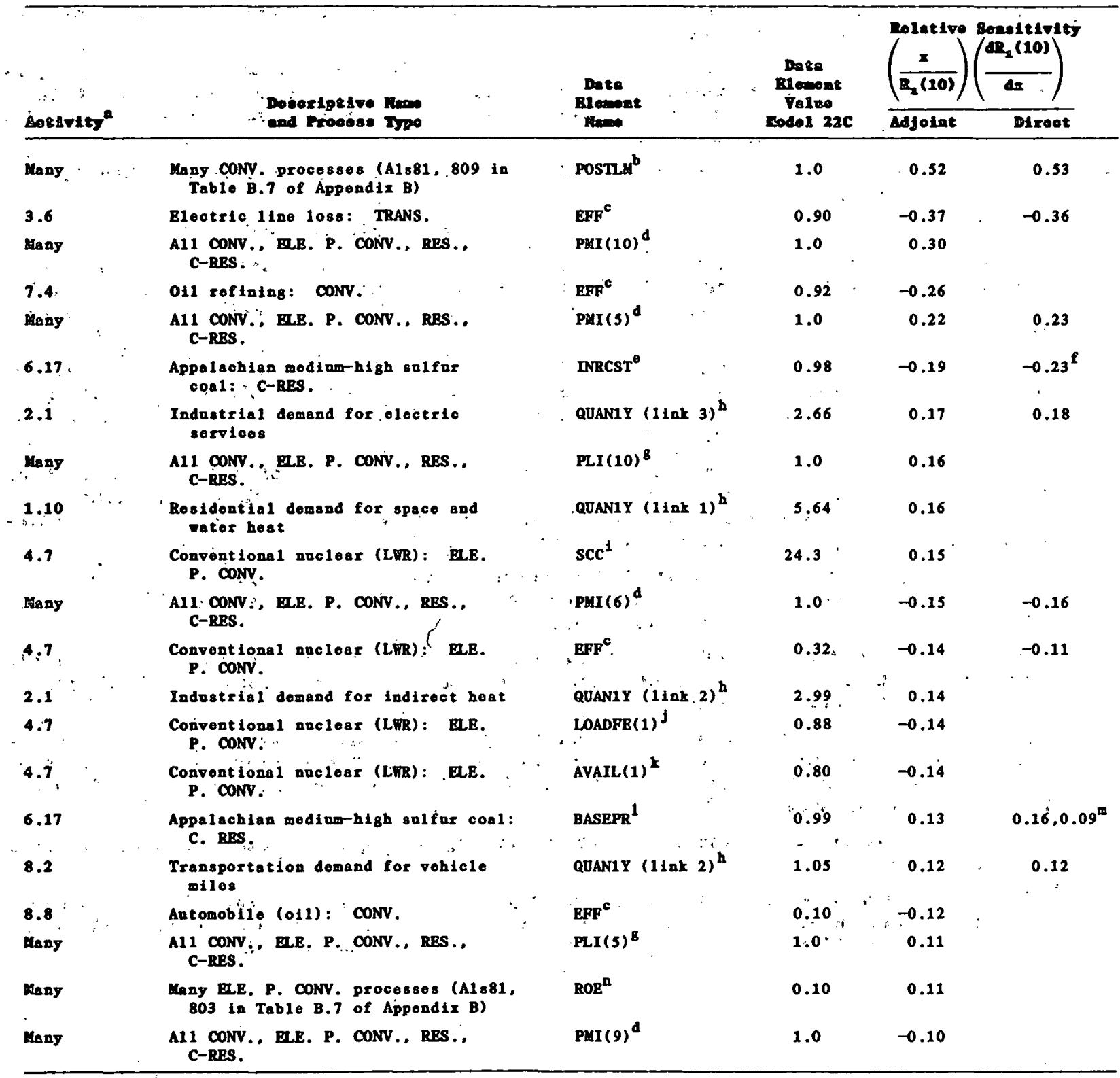


Pootnotes to Table $\mathbf{X . 4}$

${ }^{a}$ The first number denotes sector, and the second number denotes activity.

${ }^{b}$ POSTLM is the production time-based operating technological change limit. It is the ratio of the operating input-ontput coefficient, after taking into account industry operating experience in terms of time since commercial availability of the technology, to the base operating input-output coefficient (Ste81, def. 17 in Appendix A).

${ }^{C}$ EFF is the thermal efficiency of the process in 1975 or in the year the process becomes commercially available, whichever is later (Ste81, def. 9 in Appendix A).

${ }^{d}$ PMI $(J)$ is the price of materials in time $J$ (before these prices are modified by aging and technological time-dependent factors) relative to the price at $J=1$, where $J$ takes values 1 to 10 corresponding to the years 1975 to 2020 in five-year intervals. (Ste81. definition A-10 in Appendix A).

INRCST is the initial resonrce cost in 1975 billion dollars per quadrilion Bto (Ste81. def. 40 in Appendix A).

f INRCST was increased by $1 \%$ to obtain this sensitivity by direct recalcultion.

${ }^{B}$ PLI(J) is the price of labor at time $J$ (before these prices are modified by aging and technological time-dependent factors) relative to the price at $J=1$, where $J$ takes values 1 to 10 corresponding to the years of 1975 to 2020 in five-year intervals (Ste81, definition A-9 in Appendix $A$ ).

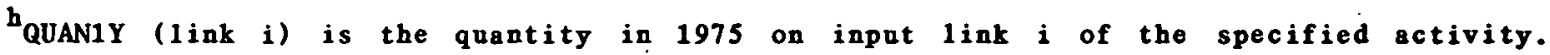
For industrial, residential, and commercial demands, this data element has anits of quadrilion Btu per year. For transportation demand, the units vary with input link (Ste81, def. 30 in Appendix A).

${ }^{i}$ SCC is the capital cost of a representative facility per unit of capacity in 1975 or the year the technology becomes available, whichever is later. This data element has units of 1975 billion dollars per unit of capacity, where a nit of capacity can produce a quadrillion Btu per year (Ste81, def. 5 in Appondir A).

$j_{\text {LOADFE }}(i)$ is the fraction of time that a demand in category $i$ is placed on an electric power conversion facility. In conversion processes, LOADFE is called LOADFC and has no argument (Ste81, def. 21 in Appendix A).

${ }_{\text {AVAIL }}(i)$ is the fraction of demand in load category $i$ that a plant can satisfy considering scheduled and unscheduled down time. In conversion processes, AVAIL has no argument (Ste81, def. 30 in Appendix A).

${ }^{1}$ BASEPR is the base resource price. Specifying the resources available at this price and at twice this price determines the resource curve for a given initial resource oost (INRCST). This data element has nnits of 1975 billion dollars per quadrillion Btu (Ste81, def. 41 in Appendix A).

me two sensitivity values correspond to increasing BASEPR by $1 \%$ and $10 \%$, respectively. in mode 1 reruns.

${ }^{n}{ }_{R O E}$ is the return on equity and can be time-dependent. In the case shown, ROE is assuned constant at all model time points, and thus, the relative sensitivity here is for a change in ROE at all model time points (Ste81, def. A-7 in Appendix A). 
the base case values; this is the manner in which the results are presented in Tables IX.4 through IX.7. The relative sensitivity may be interpreted as the percent increase in the response due to a 1\% increase in the data element (i.e., if the data element is multiplied by 1.01). As indicated in Alsmiller et a1. (Als81), 1\% increments in the noninteger parameters were used to estimate. some of the derivatives required in the adjoint sensitivity analysis.

For each response, the relative sensitivity has been calculated for each data element in Model 22C. For each response, there are 1614 nonzero sensitivities. The large majority of the sensitivities are. very small and, therefore, of little interest. Here, only the 20 largest sensitivities for each response will be given and discussed. It should be eimphasized, however, that for each response considered, the relative sensitivity has been calculated for each data element, and thns, those data elements that are considered in this section are, to within the accuracy of the calculations, known to be the data elements with the largest relative sensitivity. In Alsmiller's report (Als81), the relative sensitivities are given to many more data elements than are considered here. Relative sensitivities have boen obtained by direct calculations for only a few of the parameters considered in Tables IX.4 through IX.7, and thus, values are not given in column 6 for all parameters. Where there is no footnote on a direct sensitivity, the value was obtained for a relative parameter change of $10 \%$.

Explicit definitions of these data elements may be found in the report by Stewart and Goldstein (Ste81). The manner in which the data elements enter into the equations of the process submodels is shown in the report by Goldstein et al. (Go181a). "The symbols in Goldstein's report (Go181a) are not the FORTRAN names, but a complete cross reference between the symbols and the FORTRAN names is given by Stewart and Goldstein (Ste81). 
Response 1. The response considered in Table IX.4 is the ratio of the total annual energy-related cost to end uses in 2020 to the "GNP in 2020. The largest sensitivity in Table IX.4 is to the data element POSTLM. In LEAP-78, the change of operating cost resulting from technological changes is represented, and POSTL is a data element in this modeling. Basically, POSTLM is a data element that determines an ultimate relative change that can be obtained in production cost (see footnote b, Table. IX.4). This data element occurs in many conversion processes, and it is the option of the modeler to determine whether the value should be the same or different for many different conversion processes. If the modeler. determines that it should be the same in many places, he may specify this to be the case in the input data tables, thereby simplifying the input tables. In Mode1 22C, this was done.with the data element POSTLM, and that is what is indicated by "many". in. the first column of Table IX.4. In the sensitivity analysis, the convention established by the modeler has been followed, and the relative sensitivity given in Tab1e IX.4 is for a change in PoSTLM for all the activities for which the modeler specified that the same value should be used. To some extent, it should be. expected that a data element that is used very often in the model will tend to have a larger relative sensitivity than a data element that is nsed on1y. once.

In the case of POSTLM, the base case value of 1.0 (meaning that no technological change of this type is assumed) greatly: simplifies the equations and may have been used by the modeler for this purpose. If this is the case then, at least for the modeler, the sensitivity to POSTLM may have little significance. On the other hand, if the value is changed, the model does show the indicated sensitivity to the ultimate value of real operating cost increases:

* See Table B.7 in Appendix B in Ref. (A1s81). 
It should be clear that all of the sensitivities in the tables are independent; if the reader feels that POSTLM or any other data element should not be varied, he may ignore the corresponding sensitivity. The equations that contain POSTLM are such that, if POSTLM is increased above 1.0 , operating costs are increased, thereby increasing the cost of energy to end uses in 2020 as indicated by the positive relative sensitivity to POSTLM. In the case of POSTLM, calculations have been carried out by direct and adjoint methods, and the two results are in good agreement.

The second largest (absolute value) sensitivity in Table IX.4 is cansed by the efficiency (EFF) of the transport process that is used to model the electric line loss in transporting electricity. The equations of the transport process are quite simple, and an increase in efficiency has the effect of increasing the quantity ont of the process for a given quantity of input and thereby of decreasing the price per unit of energy of the output for a given input price (Go181a). A substantial fraction of the energy supplied to the demand sectors is in the form of electricity, and this form of energy has a somewhat higher price than some other energy supplied to the demand sectors. Therefore, this efficiency increase has a substantial effect on decreasing the total cost of energy to end users. That the effect of increasing the efficiency decreases the response is indicated by the negative sign of the relative sensitivity. For this, data element, the relative sensitivity has also been calculated by both adjoint and direct means, and the two results are in good agreement. In various places throughont Tables IX.4 through IX.7, direct and adjoint sensitivities are given. Hereinafter, the comparisons will be mentioned only if they are thought to be of particular interest.

The efficiency of the conversion process that is used to model oil refining also has a significant negative relative sensitivity. Efficiency here is defined in the standard manner (e.g., the ratio 
of the units of energy out per unit of energy into the process). Because oil accounts for a substantial fraction of the cost of energy to end uses, it is to be expected that an improvement in the efficiency of oil refining would significantly decrease the total cost of energy to end uses.

The data element, $P M I(J)$, represents the price of materials, other than fuel, at time index $J$ relative to the price of materials in 1975 ( $J$ takes values of 1 to 10 corresponding to years 1975 to 2020 in 5-year intervals). Likewise, PLI(J) represents the price of labor at time $J$ relative to the price of labor in 1975. The data elements $P M I(J)$ for each $J$ and $P L I(J)$ for each $J$ have the same value in all conversion, electric power conversion, resource, and coal resource processes. That is, it is assumed, for example, that in a given year, the price of materials is the same for every activity that uses one of these processes. Thus, an increase in either PMI(J) or PII(J) at a particular $J$ induces changes at many nodes simultaneously and can affect the model results in a variety of complex ways. The fact that PMI(10) and PLI(10) have appreciable positive relative sensitivities is reasonable because increases in these quantities in the year 2020 have a direct effect on increasing the cost of energy to end users in 2020. The fact that PMI(5) has appreciable positive relative sensitivity in Tuble IX.4 is not so obvious. An increase in PMI(5) can increase the annual cost of energy to end uses in 2020 because the LEAP equations are coupled in time, but one might at first expect that an increase in PMI(9) would have a more appreciable effect in 2020 than an increase in PMI(5). The explanation for thc importance of PMI(5) lies in the demand equations. These equations are such that each demand is independent of the price of energy through year 1995, but is dependent on the ratio of the price of energy in later years to the price of energy in 1995 with a negative elasticity (Go181a). Thus, each price of energy 
in 1995 has direct influence on demand for energy in 2020, and prices of energy in 1995 are directly affected by the data element PMI(5).

The relative sensitivity of the data elements PMI(5) and PMI(10) are positive, whereas the relative sensitivity of $\mathrm{PMI}(6)$ is negative. The fact that an increase in PMI(6) decreases the cost of energy to end users in 2020 is probab1y again due to the form of the demand equations. For the years after 1995, the demand equations contain a lagged price elasticity that decreases demand in the following years as prices increase. The response being considered depends both on the quantities and the prices, and the fact that an increase in the price of material decreases the annal cost of energy to end uses indicates that the decrease in demand is more important than an increase in prices for an earlier year.

The sixth largest (absolute value) relative sensitivity in Table IX.4 is for the parameter INRCST (initial resource cost) that appears in the coal-resource process that is used to model the mining of Appalachian medium-high sulphur coal. It is convenient to consider this parameter in conjunction with the parameter BASEPR (base resource price) because if one of these parameters has a high absolute relative sensitivity, the other often does also, and the two parameters are related. In the resource and coal resource processes, the increase in both capital and operating cost as a resource is depleted is modeled (Ad178, Che80, Go181a). The data elements INRCST and BASEPR enter into the determination of this change in cost. These data elements enter in a rather complex manner that is discussed in detail in the reports by Adler and Cherniavsky (Ad178 and Che80). It is not in general possible to determine how changes in these parameters will affect the resource curves without considering the base case value of these parameters as well as several others that enter into the determination of the resource curve. (However, if these two parameters are changed proportionaly.for a particular activity, the effect is just to vary 
by the same ratio the normalization of the curve relating resource cost to the cumulative commitments to reserves.) In Table IX.4, INRCST at activity (6.17) (Appalachian medium-high sulphur coal) has a negative relative sensitivity, and BASEPR has a positive relative sensitivity. The high relative sensitivity of Appalachian mediumhigh sulphur coal to INRCST and BASEPR appears to arise because changes in these parameters have a significant effect on the price and quantity of energy from the coal allocation activity (6.1) in Fig. A-6. These parameters also have some effect on the price of energy from the synfuel allocation activities (6.2) and (6.3) in Fig. A-6, but this does not appear to be a major cause of the observed sensitivities. In the case of INRCST and BASEPR, sensitivities have also been obtained by direct calculations. In the case of INRCST, a $1 \%$ increase was considered; and in the case of BASEPR, increases of $1 \%$ and $10 \%$ were considered. A $10 \%$ INRCST could not be used becanse BASEPR must be greater than INRCST, and this is not the case at node (6.17) if INRCST is increased by $10 \%$. The agreement between the adjoint and direct sensitivities are satisfactory. In the case of BASEPR, the difference between the two direct relative sensitivities may be indicative of a nonlinear effect (i.e., may indicate that $\Delta R / \Delta x$ is not an accurate value for $d R / d x)$. Also, $R$ may not be a continuous function of $x$. In the calculations of resource rents (Go181), a maximization procedure is used; and because the function being maximized is calculated only at discrete points, a parameter change might induce a discontinuous change in the maximum value obtained. Investigation indicates this effect is very minor.

The relative sensitivities to the data elements QUAN1Y appear in Table IX.4 for specific input links into various demand activities. The quantity of energy per year in 1975 on each input 11nk, $i$, of a demand node is culled QUAN1Y ( 1 ink $i)$ and is specified in LEAP-78 as an initial value (i.e., is not changed daring the calculations). The demand for energy (or for an energy-related quantity in the case 
of transportation demand) on a given input link at a11 later years is directly affected by an increase in QUNN1Y. [This is seen from the form of the recurrence relation Eq. (VII-8) in Sect. VII.A.4.] Thus one would expect, as shown in Table IX.4, that the relative sensitivity to QUAN1Y would be positive. The data elements QUAN1Y (1ink 3) for activity (2.1) and QUAN1Y (1ink 1) for activity (1.10) have an appreciable affect on the annual cost to all end uses in 2020 because the industrial demand for electric services and the residential demand for space and water heat constitute an appreciable fraction of the total demand for energy in 2020 .

The specific capital cost (SCC) of the electric power conversion process that models the production of electricity by conventional nuclear facilities has a significant positive sensitivity. The capital cost of a production facility is directly influenced by this data element, and thus, the price of electricity generation by a conventional nuclear facility will be increased when this data element is increased. In the year 2020, conventional nuclear facilities are projected by Mode1 22C to produce a sizeable fraction of the total electricity demand at a cost that is somewhat below that of other types of production facilities. Therefore, an increase in the capital cost of the conventional nuclear facilities would be expected to have a significant increase on the annual cost of energy to end users in 2020. Several other data elements from this electric power conversion process appcar in the table, and the reason for these sensitivities is similar to that given for scC. In particular, the base load factor and base-load plant availability data elements LOADFE(1) and AVAIL(1) enter into the determination of the capacity factor at which a plant operates at a given time. Increases in either of these data elements increase the capacity factor, thereby decreasing cost to end users as indicated by the negative sensitivities in Table IX.4. 
The cost of vehicle travel is a substantial fraction of the annual cost of energy end uses in 2020; it is to be expected that parameters in transportation demand and the conversion process that represents automobile (oil) should have appreciable relative sensitivities. An increase in QUAN1Y for auto vehicle miles [1ink 2 into activity (8.5) in Fig. A-81 increases the demand in 2020 and gives a positive sensitivity. However, an increase in efficiency for oil-powered autos [activity (8.2) in Fig. A-8] decreases cost and gives a negative sensitivity.

Response 2. In Table IX.5, the relative sensitivities of the ratio of the annal cost of imported oil, oil products, and gas in the year 2020 to the gross national product in 2020 are given.

The data element POSTLM has the largest relative sensitivity for essentially the same reasons as those discussed in conjunction with lable IX.4. The disagreement between the direct and adjoint sensitivity for POSTLM in Table IX.5 is larger ( 20\%) than in Table IX.4, but considering the rather elaborate calculations that are involved, the agreement is considered satisfactory.

The data elements INRCST and BASEPR fór Appalachian mediumhigh sulphur coal, activity (6.17) (Fig. A-6), have quite large sensitivities. These data elements were discussed in conjunction with Table IX.4, and much of that discussion is applicable here (e.g., INRCST has a negative sensitivity, and BASEPR has a positive sensitivity). The reason for the high sensitivity of the response $R_{2}(10)$ to INRCST and BASEPR for this activity appears to be, as in the case of the response $R_{1}(10)$, that these parameters have a significant effect on the price of coal from the coal allocation activity (6.1); and, through interfuel competition, this price change has the effect of changing. the projected quantities of impurtcd oil, oil producte, and gas needed to satisfy demand. The prices of these imported products are fixed exogenously, so any change ili 


\section{IX-40}

TABXB TA.5

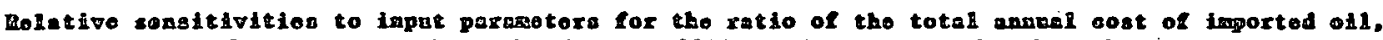
oll product8, and gas in tho goar 2020 to tho gross antionel prodnet is

che yoar 2020

The response, called $\mathrm{R}_{3}(10)$, has the value $6.8 \times 10^{-3}$ in the base

case. The sensitivities arc listed in the order of decreasing absolute magnitude.

\begin{tabular}{|c|c|c|c|c|c|}
\hline Aotivity & $\begin{array}{l}\text { Doucriptive Nareo } \\
\text { ad Procoss Thpe }\end{array}$ & $\begin{array}{l}\text { Deta } \\
\text { BHomiont } \\
\text { Newo }\end{array}$ & $\begin{array}{c}\text { Data } \\
\text { Elesont } \\
\text { Elodol 22C } \\
\text { Value }\end{array}$ & $\frac{\left(\begin{array}{c}x \\
\mathbb{R}_{3}(10)\end{array}\right)^{\text {Dolativo }}}{\text { Adjoint }}$ & $\frac{\left(\frac{\mathrm{dR}_{\mathrm{B}}(10)}{d x}\right)}{\text { DIsoot }}$ \\
\hline Many & $\begin{array}{l}\text { Many CONV. processes (see } 809 \text { in } \\
\text { Table B.7 of Appendiz B of A1s80) }\end{array}$ & POSTL $\mu^{b}$ & 1.0 & 0.79 & 0.96 \\
\hline 6.17 & $\begin{array}{l}\text { Appalachian medium-high sulfur coal: } \\
\text { C-RES. }\end{array}$ & INRCST $^{c}$ & 0.98 & -0.67 & $-0.84^{d}$ \\
\hline 10.1 & Price of imported oil in 2020: IMPORT & $\operatorname{PRICIT}(10)(1 \text { ink } 1)^{e}$ & 4.35 & 0.59 & \\
\hline 7.4 & oil refining: coNv. & $\mathrm{EFF}^{\mathrm{f}}$ & 0.92 & -0.59 & -0.65 \\
\hline 6.17 . & $\begin{array}{l}\text { Appalachian medium-high sulfur coal: } \\
\text { C-RES. }\end{array}$ & BASEPR $^{8}$ & 0.99 & 0.48 & $0.59,0.31^{h}$ \\
\hline 7.20 & Transport of imported gas: TRANS. & $\mathrm{EFF}^{\mathrm{f}}$ & 0.98 & 0.47 & \\
\hline 3.6 & Electric line loss: TRANS. & $\mathrm{EFF}^{\mathbf{f}}$ & 0.90 & -0.43 & -0.35 \\
\hline 6.25 & $\begin{array}{l}\text { Westorn liquids, medium-high sulfur } \\
\text { cos1: CONV. }\end{array}$ & IYRAVL $^{i}$ & $1995-1975$ & 0.41 & $0.38,0.20,0.11^{\mathrm{J}}$ \\
\hline 7.10 & Shale oil-mining and retort: C-RES. & BASEPR $^{B}$ & 2.57 & 0.40 & \\
\hline Many & A11 CONV., ELE. P. CONV., RES., C-RES. & $\operatorname{PMI}(1)^{\mathrm{k}}$ & 1.0 & -0.37 & -0.29 \\
\hline 8.5 & $\begin{array}{l}\text { Trunsportation demand for auto vehicle } \\
\text { miles }\end{array}$ & QUAN1Y $(1 \text { ink } 2)^{1}$ & 1.05 & 0.35 & 0.44 \\
\hline 8.2 & Autonobile (oil): CONV. & EFF & 0.10 & -0.35 & \\
\hline 7.16 & Transport upgrade (shale oil): TRANS. & EFF $\mathbf{f}$ & 0.95 & -0.35 & \\
\hline Mány & A1. CONV. . ELE. P. CONV., RES., C-RES. & $\operatorname{PMI}(9)^{2}$ & 1.0 & 0.32 & \\
\hline 4.7 & $\begin{array}{l}\text { Conventional nuclear (LWR): ELE. P. } \\
\text { CONV. }\end{array}$ & $\operatorname{scc}^{12}$ & 24.3 & 0.31 & \\
\hline Many & A11 CONV., ELE, $P$. CONV., RES., C-RFS. & $\operatorname{PMI}(s)^{k}$ & 1.0 & 0.30 & 0.37 \\
\hline 6.25 & $\begin{array}{l}\text { Wostorn liquids, medium-bigh culfur } \\
\text { coal: CONV. }\end{array}$ & $\operatorname{scc}^{m}$ & 10.8 & 0.27 & \\
\hline 6.25 & $\begin{array}{l}\text { Western liquids, medium-high sulfur } \\
\text { coal: coNV. }\end{array}$ & AVAIL $^{n}$ & 0.90 & -0.27 & \\
\hline 7.3 & Crude oil: Alloc. & FREQPR $(1 \text { ink } 4)^{\circ}$ & 0.20 & 0.26 & $\therefore$ \\
\hline 1.7 & $\begin{array}{l}\text { Conventional nuclear (LHR): ELE. } \\
\text { P. CONV. }\end{array}$ & LOADFE(1) ${ }^{\mathrm{r}}$ & 0.88 & -0.26 & \\
\hline 4.7 & $\begin{array}{l}\text { Conventional nuclear (LWR): ELE. } \\
\text { P. CONV. }\end{array}$ & $\operatorname{AVAIL}(1)^{\mathrm{D}}$ & 0.80 & -0.26 & \\
\hline
\end{tabular}




\section{Rootnotes to Tab10 $\mathrm{IX}_{0} 5$}

${ }^{a}$ The first number denotes sector, and the second number denotes activity.

bostla is the production time-based operating technological change limit. It is the ratio of the operating input-output coefficient, after taking into account industry operating experience in terms of time since commercial availability of the technology, to the base operating input-output coefficient (Ste81, def. $17^{-}$in Appendix A).

cINRCST is the initial resource cost in 1975 billion dollars per quadrillion Btu (Ste81, def. 40 in Appendis A).

dINRCST was increased by $1 \%$ to obtain this sensitivity by direct recalculation.

${ }^{e}$ PRICIT(J) (link 1$)$ is the exogenously spocified price of imported oil at time index J. This data element has units of 1975 billion dollars per quadrillion Btu (Ste81, definition A-14 in Appendix A).

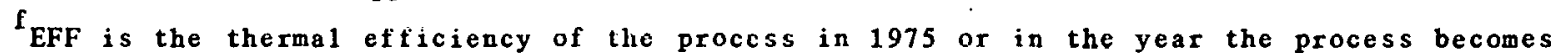
commercially available, whichever is later (Ste81, def. 9 in Appendix A).

${ }^{8}$ BASEPR is the base resource price. Specifying the resources available at this price and at twice the price determines the resource curve for a given initial resource cost (INRCST). This data element has units of 1975 bilition dollars per quadrillion Bta (Ste81, def, 41 in Appendix A).

The two sensitivity values correspond to increasing BASEPR by $1 \%$ and $10 \%$, respectively, in mode 1 reruns.

iYRAVL is the ycar when the technology first became available. The code uses the actual year availuble (e.g., 1995). To define relative sensitivity here, the data element year IYRAVL has been defined by subtracting 1975 (Ste81, def. 12 in Appendix A).

j IYRAVL was increascd by $0.25,1$, and 2 years to obtain these sensitivities by direct recalculation. Because LEAp-78 expects IYRAVL to be an integer, the code was changed internally to make the 0.25 -year change.

${ }^{k} P M I(J)$ is the price of materials in time $J$ (before these prices are modified by aging and technological time-dependent factors) relative to the price at J=1, where J takes values 1 to 10 corresponding to the years 1975 to 2020 in 5 -ytar intervals (Ste81, definition A-10 in Appendix A).

${ }^{3}$ QUAN1Y (1ink i) is the quantity in 1975 on input link i of the specified activity. For industrial, residential, and commercial demands, this data element has units of quadrillion btu per year. For transportation demand. the units vary with input link (Ste81, def. 30 in Appendix A).

${ }^{m}$ SCC is the capital cost of a representative technology per unit of capacity in ig7s nr the year the technology becomes available, whichever is 1ater. This data element has units of 1975 bilion dollars per unte of capucity, whore a nit nf capacity can produce a quadrilition Btu per year (Ste81, def. 5 in Appendix A).

${ }^{n}$ AVAIL(i) is the fraction of demand in load category i. that a plant can satisfy considering scheduled and unscheduled down time. In conversion processes, AVAIL has no argument (Ste81, def. 30 in Appendix A).

OFREQPR (1ink i) is the equal-price share on link $i$. It is the fraction of the demand that would be allocated to link i if all input links to the allocation process had equal prices and no behavioral 1 ag applied (Ste81, def. 3 in Appendix A).

PloAdFE(i) is the. fraction of time that a demand in category is is placed on an electric power cuuversion faoility. In conversion processes, LOADFE is called LOADFC and has no argument (Ste81, def. 21 in Appendix A). 
the imported quantities has a direct influence on the import-cost response. Changes in these INRCST and BASEPR values also have an influence on the production of coal liquids (activity 6.2) and highBtu synthetic gas (activity 6.3), but this does not appear to be a major effect. Direct sensitivities have again been obtained for a $1 \%$ increase in INRCST and for a $1 \%$ and $10 \%$ change in BASEPR. The diferences between the adjoint and forward results are again of the order of $20 \%$. The large difference between the $1 \%$ and $10 \%$ BASEPR direct calculations appears to be due to nonlinear effects. As stated previously, it could, in principle, be due to a discontinuity; but in this instance, this is not thought to be the case. That is, the difference is not due to a change in the time index at which the maximum in the resource rent calculation occured (see previous discussion) in the medium-high sulphur Appalachian coal resource equations (activity 6.17), but there are many resource and coal resource processes and, in principle, a discontinuity in the response can be caused by a change in the time index of the maximum in any of these processes.

The third largest sensitivity in Table IX.5 is for the data element PRICIT(10) that represents the exogenously specified price of imported oil in 2020. Because the response being considered is the cost of imported oil, oil products, and gas in 2020, it is not surprising the the price of imported oil in 2020 should have a large positive sensitivity.

The fourth largest (absolute value) sensitivity in Table IX.5 is for the efficiency of the conversion process that is used to model oil refining. Because the cost of imported crude oil accounts for a part of the cost of imported oil, oil products, and gas and because imported crude oil goes through the oil refining process (see Fig. A-7), it is expected that an increase in the efficiency of oil refining would significantly reduce the import-cost response. 
The efficiency of the transport process that is used to mode1 the cost of transporting imported gas has a rather large positive sensitivity. The sign of the sensitivity in this case is interesting because an increase in the transportation efficiency caused an increase in import cost. The positive sign arises because the increase in pipeline efficiency reduced the price of gas out of the transport process, and because of this reduced price, imported gas became competitive with the other sources of gas and more gas was imported.

The efficiency of the transport process that is used to model electric line loss has negative sensitivity because an improvement in the competitive position of electricity is projected to decrease the quantity and the total cost of imported fuel needed to satisfy overall demand.

The year of commercial availability (IYRAVL) of the conversion process (activity 6.25 ) that is used to model the production of liquids from medium-high sulphur western coal is computed to have an appreciable positive relative sensitivity. In the mode1, the year of availability is input as an absolute integer time (e.g., 1995). To define a relative sensitivity, this data element was defined by subtracting 1975. This definition is somewhat arbitrary and does affect the magnitude of the relative sensitivity (i.e.. if some year other than 1975 had been used in the definition, a different relative sensitivity would have been obtained). In the curversion process, the year of availability is not used as the time before which production is not possible, but as the time before which a price premium is required, and becanse of this premium, very little is produced. The fact lhat a delay in the year of availability, which is 1995 in the base case, has a significant affect on the cost of imports in 2020 appears to be due to the behavioral 1ug built into the allocation process. If liquid production from medium-high sulphur western coal (activity 6.25) is delayed beyond 1995, only a 
small share of the market is allocated to this source in 19.95 by the coal liquids allocation process (activity 6.2, see Fig. A-6 in Appendix A). Then, because of the lag, this small share influences the share allocated to activity (6.25) in subsequent years. The behavioral lag for the coal liquids allocation activity is only 3 years; it is interesting that the effect persists into years as late as 2020. The direct relative sensitivities in this case are rather interesting becanse they show an appreciable nonlinearity. [It is to be noted that, in general, those quantities that are specified to be integers in the input to LEAP-78 can be changed by nothing smaller than 1 year. In the present case; a change of 0.25 years was nsed (by changing the code internal1y) because the 1-year change was too large to obtain agreement between the forward (recalculated) and the adjoint results.]

The data element BASEPR for the coal-resource process that is used to model shale oil-mining has an appreciable positive relative sensitivity in Table IX.5. When this base price is increased, the price of oil from shale oil is increased, and oil is imported to replace the more expensive oil from shale.

The data elements PMI(J) occur in a variety of places in Table IX.5. These data elements have been discussed in conjunction with Table IX.4, and much of the discussion there is equaly applicable here.

The data element QUAN1Y for auto vehicle miles that appears on 1 ink 2 into the transportation demand (activity 8.5) has a reasonably large positive sensitivity. An increase in this data element increases the demand for oil in 2020, thereby increasing oil imports and the cost of oil imported in 2020. Conversely, an increase in the efficiency of the oil-powered antomobile conversion process (activity 8.2) decreases the cost of oil imports. 
An increase in the specific capital cost of a conventional nuclear facility raises the cost of electricity from such facilities and thus through interfuel competition increases the amount and cost of imported oil. Similarly, an increase in the specific capital cost of western liquids from medinm-high sulphux coal increases the cost of imported oil.

The data element AVAHL(I) and LOADFE(I) were disoussed in conjunction with Table IX.4. In conversion processes such as that for liquids from western coal, these quantities have the same meaning as in electric power conversion prooesses, but have no arguments, and LOADFE is called LOADFC. In Table IX.5 the data elements of AVAIL for western liquids from medium-high sulphur coal and AVAIL(I) and LOADFE(I) from conventional nuclear generation of electricity all have negative relative sensitivities, as wonld be expected from the previous aiscussion.

The data element FREQRR ( 1 ink 4) for the crude oil allocation process occurs near the end of Table IX.5. The data element FREQPR (1ink i) desigmates the fraction of the demand that would be allocated to a given suppliex (after behavioral lags have rum their course) if all suppiiers offered the same price. Input limk 4 to activity (7.3) (see Fig. A-7 in Appendix A) represents the allocation of crude oil demand to imported crude oil. In the base case, FREQPR (1ink 4) has the value 0.20 , and thus, if there were no price differential between the suppliexs to this crude oil allocation activity, only 0.20 of the demand rould be allocated to imported crude oil. Even when there is a price differential, this data element still enters the determination of the fraction of the demand that is allocated to a given supplier, and un iuciease in this data elpment on liuk $i$ increases the fraction of the demand that is allocated to the supplier on 1 ink $i$. In Table IX.5 an increase in FREQPR ( 1 ink 4) inoreases the fraction of the demand that is supplied by imported crude oil and thus increases the cost of imported fuel. 
Response 3. In Table IX.6, the relative sensitivities of the total annual imports of oil and oil products in year 2020 are presented. This response is in some ways similar to that considered in Table IX.5, but because quantities rather than costs are considered and becanse imported gas is omitted, the sensitivities differ. Since many of the data elements in Table IX.6 are similar to those 1 isted in Tables IX.4 and IX.5, they will not be discussed again. Also, in Table IX.6 as in Tables IX.4 and IX.5, a variety of comparisons between adjoint and direct sensitivities are given. For the most part, these comparisons are similar to those given previously, and they will be discussed only if they are thought to be of particalar interest.

Near the end of Table IX.6, the data element NEWRS2, for the resource process that is used to model Domestic 0il and Natural Gas Liquids, appears (activity 7.12 ). This data element, which represents new resources at twice the "base price," is related to the data elements INRCST and BASEPR because it is used to determine the changes in capital and operating, cost as the resource is depleted (Ad178), (Che80), (Go181). The actual manner in which this data element enters in the determination of the resource curve is complicated and is explained in detail in Refs. (Ad178) and (Che80). An increase in NEWRS2 for domestic oil and natural gas liquids in this case increases the cost as the reserves are depleted; because this increase makes domestic oil less competitive, more oil (and oil products) is imported.

Near the bottom of Table IX.6, the data elements QUAN1Y occur on links 4 and 5 into the activity (7.3) that allocates crude oil (see Fig. A-7 in Appendix A). Although the data elements QUAN1Y on input links to allocation processes serve as initial conditions in somewhat the same way as the data elements QUAN1Y on input links to demand processes, there are significant differences. For allocation processes QDAN1Y (1ink i) is not itse1f the initial value that is 
used, but the quantity $\operatorname{QUAN} 1 Y(j) / \sum_{i} \operatorname{QUAN} 1 Y(i)$ (where the sum over $i$ is over all input links to a given allocation node) is used as the initial value. That is, the quantity on 1 ink $i$ in the final solution is not in general the QUAN1Y (1ink $i$ ) that was specified initially. An increase in QUAN1Y (link 4) increases the share of the demand in 1975 that is allocated to imported crude oil. Because of the behavioral lag, which is 15 years in this case, an increase in QUAN1Y increases the share of the demand in 2020 that is allocated to imported crude oil. Thus, an increase in this data element increases the quantity of crude oil imported and has a positive sensitivity. On the other hand, an increase in QUAN1Y (1ink 5) increases the share of the demand in 2020 that is allocated to domestic oil and natural gas liquids, thus decreasing the amount of imported oil and producing a negative sensitivity.

Near the bottom of Table IX.6, the data element VOC (variable operating cost) appears for the production of liquids from western medium-high sulphur coal. An increase in this data element increases the cost of production in all years after the technology becomes commercially available. Thus, an increase in this data element increases the cost of coal liquids and makes them less competitive with imported oil, resulting in more oil imports.

Fina11y, at the end of Table IX.6, the data element $Y(2)$ * appears. Th1s data element represents percent annual increase in the gross national product in the period 1976 to 1980 . It enters into the demand equations (Go181a) in such a manner that it tends to increase demand in al1 subsequent years. Because an increase in $Y(2)$ increases demand in 2020 , it has a positive sensitivity because more oil and oil products are imported to satisfy this demand.

*Here, $Y(J)$ is noted to be defined somewhat differently than the corresponding quantity in Eq. (VII-9). 
Tanus D.6

Rolstsvo soasitifitios to iapet paraseters for tho total arnual lagorts of oll and oll prodeats in tho joar 2020.

The response, called $R_{,}(10)$, has the value 7.4 quadrillion Btu per year in the base case. The relative sensitivities are 1 isted in the order of decreasing absolnte value.

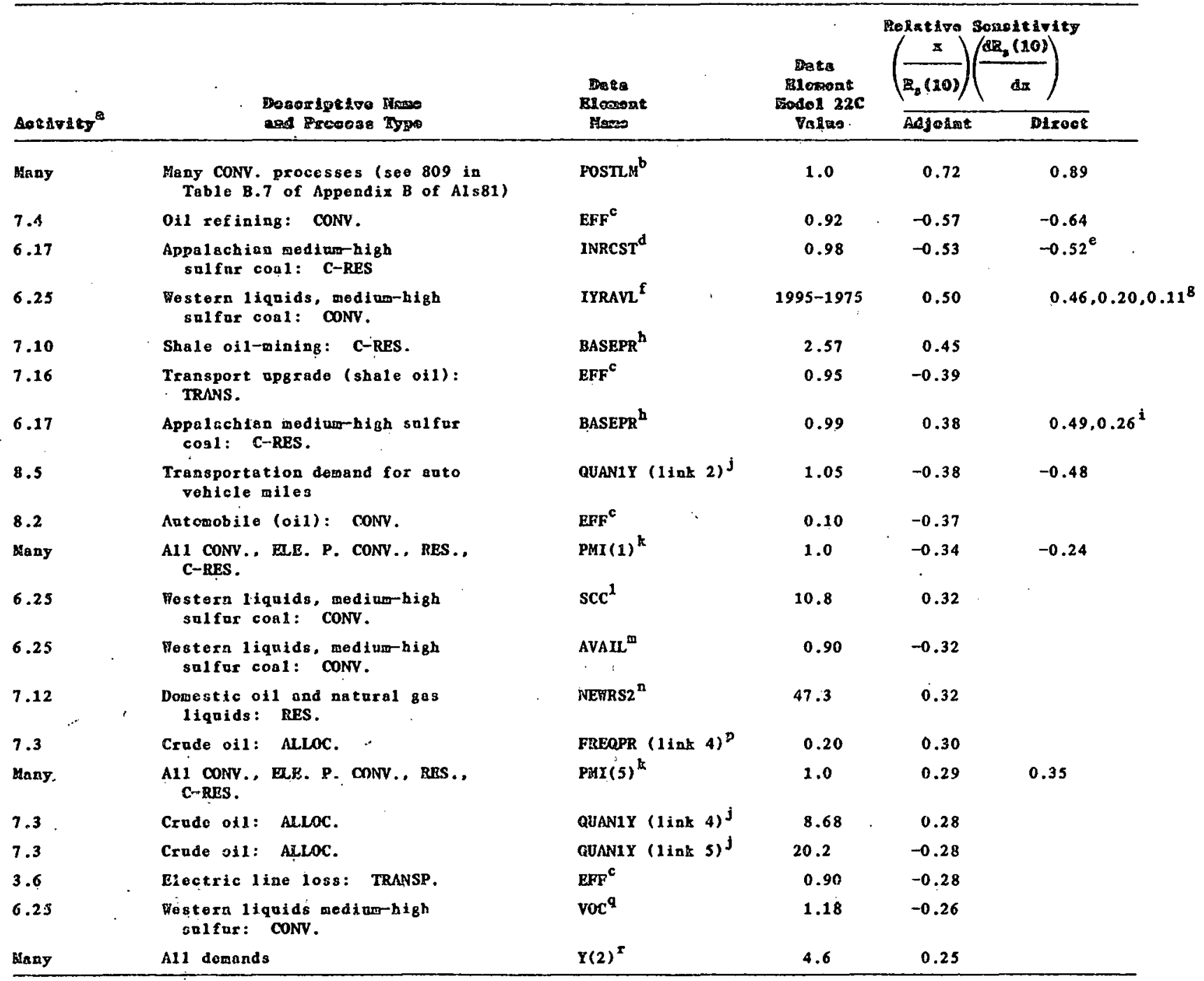


Rootnotes to Table IX.6

${ }^{a}$ The first number denotes sector, and the second number denotes activity.

${ }^{b}$ POSTM is the production time-based operating technological change limit. It is the ratio of the operating inpat-output coefficient, after taking into account industry operating experience in terms of time since commercial availability of the technology, to the base operating input-output coefficient (Ste81, def. 17 in Appendiz A).

cEFF is the thermal efficiency of the process in 1975 or in the year the process becomes commercially available, whichever is later (Ste81, def. 9 in Appendix A).

dINRCST is the initial resource cost in 1975 billion dollars per quadrillion Btu (Ste81, def. 40 in Appendix A).

'INRCST was increased by $1 \%$ to obtain this sensitivity by direct recalculation.

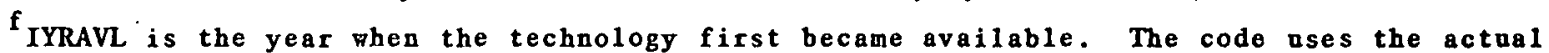
year available (e.8., 1995). To define relative sensitivity here, the data element year IYRAVL has been defined by subtracting 1975 (Ste81, def. 12 in Appendix A).

EIYRAVL was increased by $0.25,1$, and 2 years to obtain these sensitivities by direct recalculalion. Decause LENP-78 expects IYRAV., to be an integer, the code ras changed internally to make the 0.25 -year change.

${ }^{b}$ BASEPR is the base resouxce price. Spcoifying the resources available at this price and at twice this price determines the resonrce curve for a given initial resource cost (INRCST). This data element has anits of 1975 billion dollars per quadrillion Btu (Ste81, def. 41 in Appendix A).

${ }^{i}$ The two sensitivity values correspond to increasing BASEPR by $1 \%$ and $10 \%$, respectively. in direct model rerans.

joUAN1Y (1ink i) is the quantity in 1975 on input link $i$ of the specified node. For industrial, residential, and commercial demands, this data element has units of quadilion Btu per year. For transportation demand the units vary with input link (Ste81, def. 30 in Appendix A).

${ }^{k}$ PMI $(J)$ is the price of materials in time $J$ (before these prices are modified by aging and technological time-dependent factors) relative to the price at $J=1$, where $J$ takes values 1 to 10 corresponding to the years 1975 to 2020 in 5 -year intervals (Ste81, definition A-10 in Appendix A).

${ }^{1}$ SCC is the capital cost of a representative facility per unit of capacity in 1975 or the year the technology becnmes available, whichever is later. This data element has units of 1975 billion dollars per unit of capacity, where a nit of capacity can produco a quadrillion Bta per year (Ste81, def. 5 in Appendix A).

maVAIL (i) is the fraction of demand in load category i that a plant can satisfy considering scheduled and unscleeduled down timo. In conversinn processes. AVAIL has no argument (Ste81, def. 20 in Appendiz A).

${ }^{n}$ NEWRS2 is the new resource at double base price. It is the amount of resources in addition to resources at the beginning of the model horizon, including expected new discoveries, that could be produced withont a loss. It has units of quadrillion Bta (Ste81, def. 42 in Appendix A).

PFREQPR ( 1 ink $i$ ) is the equal price share on 1 ink $i$. It is the fraction of the demand that would be allocated to 1 ink $i$ if all input links to the allocation process had equal prices and if no behavioral lag applied (Ste81, def. 3 in Appendix A).

anc is the variable operating cost in 1975 or the year of commercial availability, whichever is later. It has units of 1975 billion dollars per quadrillon Blu ( $3 t e B 1$, def. 7 in Appendix A).

${ }^{r} \mathrm{Y}(J)$ here is the rate of change (\% per year) in gross national products at time index $J$, where $J$ takes values 1 to 10 corresponding to the years 1975 to 2020 in 5 -year intervals (Ste81, def. A.3 in Appendix A). 
Response 4. In Table IX.7, the most important relative sensitivities of the ratio of the liquid fuels (annual) input to all demand sectors to the total fuel input to all demand sectors are given. This response differs somewhat from those considered previously because it involves many more links and is therefore more complex. Again, many of the data elements that appear in Table IX.7 are similar to those that appear in Tables IX.4, IX.5, and. IX.6; thus, on1y those that are thought to be of particular interest will be discussed. Also, the comparisons between the adjoint and direct sensitivities are very similar to those given previously and will, therefore, not be discussed.

In the early part of Table IX.7, the data element VOCRAT occurs for the conversion process that is used to model the oil-powered antomobile (activity 8.2). This data element is used in Mode1 22C to represent the rate of change of efficiency with time due to technological improvements. Its value determines how long it will take for the altimate improvement allowed due to technological change to be reached. Because the value assigned this parameter implies that the improvement will not have "saturated" by year 2020, an increase in this data element has the effect of increasing efficiency and decreasing cost. In the case of the oil-powered automobile, an increase in VOCRAT decreases the quantity of liquid fuel needed to satisfy a major transportation demand, thus causing a decrease in the response considered in Table IX.7. The magnitude EFLIM of the eventual improvement in efficiency of the oil-powered auto also appears in Table IX.7; the reason is essentially the same as for the value of VOCRAT.

Near the end of Tab1e IX.7, the data elements G2(6) for demarid for industrial indirect heat (activity 2.1) and $G 2(6)$ for auto vehiclemile demand (activity 8.5) occur. The 2 in these data element names specifies link 2 , and the argument value 6 is the usual time index representing year 2000. An increase in these data elements has 
the effect of increasing demand on link 2 into activities (2.1) and (8.5) in all subsequent years. The time index 6 has a special significance because $G 2(J)$ values for $J=7,8,9$ axe obtained by linear interpolation between $G 2(6)$ and G2(10) (G0181). The two data elements are interesting because the relative sensitivities have opposite signs. In the case of ato vehicle-mile demand, an increase in 62 (6) increases the demand for 1iquid fue1; thus, for the response being considered, the sensitivity is positive. In the case of demand for industrial indirect heat, an increase in G2(6) increases the demand for energy, but not necessarily in the form of liquid fuel; thus, for the response considered, the relative change in the response denominator is larger than the change in the numerator. This results in a negative sensitivity. 


\section{IX -52}

TABRB $\mathbf{n . 7}$

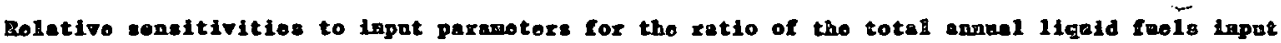
to 11 demand soctors is tho yoer' 2020 to tho total annesl fuel input to 11 denend soctors in the yosr 2020

The response, called $R_{a}(10)$, has a value of 0.32 in the base case. The sensitivities are listed in the order of decreasing absolute value.

\begin{tabular}{|c|c|c|c|c|c|}
\hline Aotivits" & $\begin{array}{l}\text { Dosoriptivo Namo } \\
\text { and Prosess Typo }\end{array}$ & $\begin{array}{c}\text { Data } \\
\text { Blowent } \\
\text { Mane }\end{array}$ & $\begin{array}{c}\text { Date } \\
\text { R1ement } \\
\text { Hode1 22C } \\
\text { Valvo }\end{array}$ & $\frac{\left(\frac{x}{E_{4}(10)}\right)}{\text { Roljoint }}$ & $\frac{\left(\frac{d x_{4}(10)}{d x}\right)}{\text { Diroot }}$ \\
\hline 8.5 & $\begin{array}{l}\text { Transportation demand for } \\
\text { vebicle miles. }\end{array}$ & QUAN1Y $(1 \text { int } 2)^{b}$ & 1.05 & 0.25 & 0.25 \\
\hline 8.2 & Automobile (oil): conv. & EFF $^{c}$ & 0.10 & -0.25 & \\
\hline 7.4 & Oil refining: conv. & $\mathrm{EFF}^{\mathrm{c}}$ & 0.92 & 0.22 & 0.22 \\
\hline 2.1 & $\begin{array}{l}\text { Industrial demand for } \\
\text { electric services }\end{array}$ & QUAN1Y $(1 \text { ink } 2)^{b}$ & 2.99 & -0.16 & \\
\hline 8.2 & Automobile (oil): coNv. & VOCRAT ${ }^{d}$ & 0.035 & -0.16 & \\
\hline 6.17 & $\begin{array}{l}\text { Appalachian mediuorhigh } \\
\text { coa1: C-RES. }\end{array}$ & INRCST $^{e}$ & 0.98 & -0.15 & $-0.13^{f}$ \\
\hline 2.1 & Industrial denand for electric services & QUANYY $(1 \text { ink } 3)^{b}$ & 2.66 & -0.11 & -0.11 \\
\hline 8.2 & Automobile (oil); CONy. & EFLIM $\mathrm{g}$ & 4.5 & -0.10 & · \\
\hline 2.1 & $\begin{array}{l}\text { Industrial demand for truck/bus } \\
\text { vehicle mile }\end{array}$ & QUAN1Y $(1 \mathrm{inK} 7)^{\mathrm{b}}$ & 0.28 & 0.099 & 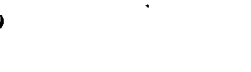 \\
\hline 8.3 & Truck, bus, diese1/gas: conv. & $\mathrm{EFF}^{\mathrm{c}}$ & 0.067 & -0.097 & \\
\hline 6.17 & $\begin{array}{l}\text { Appalachinn mediurr-high sulphur conl: } \\
\text { C-RES. }\end{array}$ & BASEPR ${ }^{h}$ & 0.99 & 0.093 & $0.090,0.49^{i}$ \\
\hline Many & $\begin{array}{l}\text { Many CONV. processes (see } 809 \\
\text { in Table B.7 of App. B of A1 s81) }\end{array}$ & $\operatorname{PosTL} M^{j}$ & 1.0 & 0.088 & 0.12 \\
\hline 8.3 & Truck, bus, diese1/gas: CONV. & EFLIMB & 1.5 & $\because \quad-0.086$ & \\
\hline 1.3 & 0il (+LPG) geater: CONV. & IDLIFE ${ }^{k}$ & 5 & -0.084 & 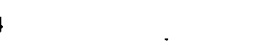 \\
\hline 2.1 & $\begin{array}{l}\text { Industrial demand for electrical } \\
\text { services. }\end{array}$ & G2 $(6)^{1}$ & 1.70 & -0.083 & \\
\hline 2.21 & Geotherma 1: CONV, & $800^{\mathrm{m}}$ & 2.84 & -0.082 & -0.60 \\
\hline 8.5 & $\begin{array}{l}\text { Transport demand for auto } \\
\text { vehicle alles }\end{array}$ & $62(6)^{1}$ & 1.1 & 0.082 & 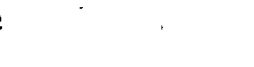 \\
\hline 2.21 & Geotherma 1: CONV. & AVAIL $^{n}$ & 0.90 & $\because 0.082$ & 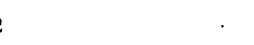 \\
\hline 2.1 & Industrial demand for direct heat & QUAN1Y $(1 \text { ink } 1)^{b}$ & 0.96 & -0.072 & \\
\hline 7.3 & oil (+LPG) heater: CONV. & $\operatorname{scc}^{m}$ & 51.0 & -0.072 & \\
\hline
\end{tabular}


Footnotes to Table DX.7

${ }^{8}$ The first number denotes sector, and the second number denotes activity.

${ }^{b}$ QUAN1Y (1ink $i$ ) is the quantity in 1975 on input link $i$ of the specified node. For indastrial, residential, and commercial demands this data element has units of quadrilion Btu per year. For transportation demand the units vary witb input link (Ste81, def, 30 in Appendix A).

EFF is the thermal efficiency of the process in 1975 or in the year the process becomes commercially available, whichever is later (Ste81, def. 9 in Appendix A).

dyocrat is the operating clange rate ( $\%$ per year) and is used to model change ia cost and thermal officiency due to expertence (SLe81, def. 18 in Appendix A).

enRCST is the initial resonrce cost in 1975 billion dollars per quadrillion Btu (Ste81, def. 40 in Appendis A).

InRCST was increased by $1 \%$ to obtain this sensitivity by direct recalculation.

${ }^{2}$ EFLIM is the thermal efficiency limit and is the ratio of the thermal efficieucy (for fuel) to the initial efficiency at the year of commercial availability or in 1975 , whichever comes later (Ste81, def. 19 in Appendix A):

${ }^{b}$ BASEPR is the base resource price. Specifying the resources available at this price and at $t$ ice this price determines the resource curve for a given initial resource cost (INRCST). This data element has units of 1975 billion dollars per quadrillion Bta (Ste81, def. 41 in Appendix A).

${ }^{i}$ The two sensitivity values correspond to increasing BASEPR by $1 \%$ and $10 \%$, respectively. in direct model reruns

${ }^{j}$ POSTLM is the production time-based operating technological change limit. It is the ratio of the operating input-output coefficient, efter taking into accont industry operating experience in terms of time since commercial availability of the technology, to the base-operating input-ontput coefficient (Ste81, def. 17 in Appendix A).

${ }^{k}$ IDLIFE is the term on long-term corporate debt. It is an integer and is expressed in years (Ste81, def. 25 of Appendiz A).

$1_{G I(J)}$ is the demand sensitivity on input 1 ink $I$ at time $J$ to a demand node. The demand sensitivity is the rate of change in the demand with respect to the rate of change in GNP (Ste81, def, A-4 in Appendiz A).

${ }^{m}$ ScC is the capital cost of a representutive facility per unit of capacity in 1975 or the year the technology becomes available, whichever is later. This data element has anits of 1975 billion dollars per unit of capacity, where a unt of capacity can produce a quadrillion Btu per year (Ste81, def. 5 in Appendir A). 


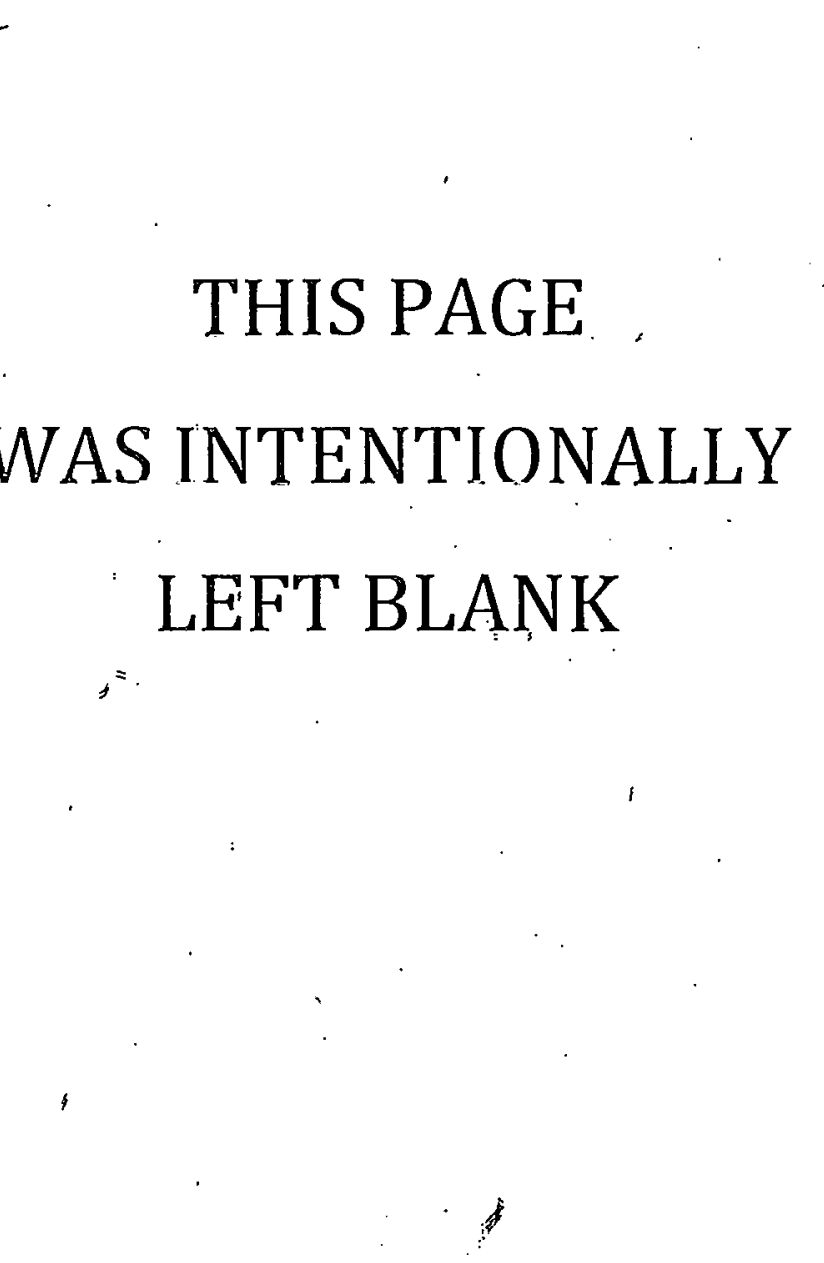


Conclusions from adjoint sensitivity studies. Relative to the innovative techniques used here, the applicability of adjoint sensitivity methodology to a large energy-economy model was demonstrated by applying the methodology to LEAP Mode1 22C. The agreement between the adjoint and direct sensitivities in Tables IX.4 through IX.7 indicates that the methodology can be applied successfully to give reasonably reliable results at least for sensitivities that are relatively 1arge. The method provides only first derivatives, but it is very powerful because it treats all data elements and determines, for a given response, which data elements have appreciable sensitivities. The methodology, as used here, required considerable development time because considerable analytical differentiation was required, and a substantial effort was needed to evaluate these derivatives. However, in the course of the work, an alternative method was developed that would allow all these derivatives to be obtained numerically by using the LEAP computer code.

Relative to the results of the sensitivity studies on LEAP Mode1 22C for the four responses covered above, one may conclude:

1. For the broad responses studied, no relative sensitivity coefficients were greater than unity in absolute value. Ten

- to twenty or more parameters for each response had relative sensitivities with absolnte values larger than 0.1 .

2. Data elements used in Model 22C to scale costs simultaneousiy in many modeled industries tended to have sensitivities of large magnitude. Two examples were the real cost escalation factors for materials and the global technological change parameters; in both examples the parameters themselves were set to unity in Model 22C. The high sensitivities to the technological change parameter POSTLM imply that major results like the projected total cost of energy were sensitive to the 
Mode1 22C assumption that there will be little future cost reduction through evolutionary technological change in generic industries already commercially available.

3. Important relative sensitivities were found for some parameters that affect the energy price mark-up in generic industrial activities like oil refining that process the major Model 22C energy flows. (This finding may not be very important for policy analysis because processes like nil refining and electric power transmission already enjoy relatively high thermal efficiency, and significant national effort would be required to change these average efficiencies by a few percent.)

4. Some of the parameters that had important relative sensitivity are known to be strongly correlated. For the example of the "base price" and "initial cost" resource cost curve parameters of Mode1 22C, the signs of the computed sensitivity coefficients indicate that an alternative parameterization of the resource curve would permit more effective sensitivity studies. (For more recent models than 22C, EIA has upgraded the parameterization of resource ourvos.) In othet casec, expected data correlations would effectively sum several minor sensitivities to produce an enhanced effect.

5. Many of the parameters found to have important sensitivities are amenable to measurement or firm estimation; this fact suggests that increased effort on input data can improve the reliability of LEAP output performance. Examples are initialyear energy balance, industrial process efficiencieg, plant overall availabilities, capital and operating costs of plant types already commercially proven, and even the resource curve cost parameters. There can also be a reasonable basis on which to estimate values for the important parameters reflecting expected technological change and the ratio of the future cost 
of labor and materials, compared to present experience; here the possibilities of countervailing future environmental or other regulations introduce uncertainty.

6. Some of the parameters having sensitivity coefficients of important magnitude depend more strongly on cultural preferences. These are amenable to estimation for the future only to the extent current trends continue. These parameters include automobile efficiency (miles per energy unit) within the bounds of technical feasibility, the discount rate for energy facilities, the times at which now technologies will be commercially proven, and most of all the parameters that determine future energy demand.

7. The 1ist of large sensitivity coefficients for the studied responses did not highlight any behavioral parameters like time lags and price sensitivity coefficients--parameters that represent imprecise concepts and therefore may be difficalt to estimate. One reason for this finding is that many of these parameters are individua11y assigned to each generic activity in the mode1. While each such parameter may have sma11 sensitivity, the values may be correlated to the extent that a common difficulty in their estimation leads to a significant collective effect. (See Tables IX.1 and IX.2, especially Examples 2-4.) This area deserves more study.

These conclasions are based on sensitivities computed from Mode1 $22 \mathrm{C}$ and are, therefore, the sensitivities of model responses and not necessarily those of the future energy market. To the extent that the model correctly represents foture trends, the listed sensitivities and those that conld be computed for alternative responses should be an aid to the student of energy affairs. 


\section{THE MODKL PARAIETERS FOR LRAP MODEL 22C}

The input to the LEAP-78 computer program included data that (1) caused the system program to organize computer storage for the needed model variables and input parameters, (2) defined for the program the energy flow network and the subroutine block to be associated with each modeled generic activity, * (3) gave values of the parameters required by the process model subroutines for each of these activities, and (4) gave the initial estimates for the model variables required to start the iterative solution process. This section addresses only the model parameter data; here, as in most of this report, the terms "data" and "parameters" are used interchangeably to refer to those input values of energy-economy parameters required to operate Mode1 22C of LEAP. A discussion and thorough display of these parameters may be fonnd in stewart and Go1dstein's report (Ste81).

\section{A. Classification of the Hodel 22C Input Paraneters}

Section II.B of this report contained a brief description of each of the process submodels used to represent the various energyrelated economic activities. For each energy conversion activity, Model 22C requires the technical, historical, financial, and nonfuel cost data needed to obtain, at each model time point, the present value of the capital cost and the stream of net (price minus cost) dollar flows associated with the model energy flows. The electric utility conversion activities require these data and the portions of electricity generation devoted to base, intermediate, and peak load service. In addition to the parameters required for basic conversion activities, the resource extraction activities require the resource curves that reflect the increasing effort required to recover entigy commodities from depleting resource bases.

"Model 22" was defined by its energy flow network and organization of parameter storage. With the assignment of a submodel for each activity and a particular set of model input parameters, Mode1 22C was defined. 
Each real allocation activity requires (1) the relative energy flows (market shares) of the various inputs from competing suppliers for the initial model year (1975), (2) the market shares that would eventually apply if the prices from all suppliers were equal, and (3) the parameters used in modeling the price- and time-dependent market penetration dynamic. Some allocation activities require price increments on input or output links to reflect differentials in quality, average transportation cost, etc. The "transport" activities require price increments and transport efficiency factors. The final demand activities require, for each c1ass of demand, the parameters to determine a demand path (nominal demand for each model year) and the short-term price elasticity and lag parameters used to modify the demand-path quantities in the later model years. The oil and gas import prices, hydroelectric production quantity, and metallurgical coal export quantity are required for each model time point. Most parameters, including prices for labor, materials, and capital, are assumed to be independent of time in Mode1 22C. The selection of values for these parameters depends on the submodels of the LEAP-78 program and the aggregation of the real economy chosen in the network definition for Mode1 22.

The data can also be characterized according to whether their values werc determined from (1) major assumptions of the scenario detailed along with the results in ARC-78 (EIA79a); (2) historical data on the national energy balance, facility costs, and trends in financing and tax accounting; ( 3 ) engineering estimates of values of cost, efficiency, and availability parameters for generic industrial technologies that are not yet "commercial"; or (4) parameterization of the departure of economic behavior from that expected under perfect competition within a compact geographic region. 


\section{B. Modelex's Method for Moeting Model 22C Imput Data Roquirononts}

The material in the 1978 Energy Information Administration (EIA) Annua1 Report to Congress and in the draft data report (Die79) indicates the main features of the EIA plan for obtaining the needed parameter values. Behavioral parameters (e.g., behavioral lags, price sensitivities) were chosen by the modelers at EIA or were taken from the authors of previous work using generalized equilibrium modeling (SRI77, DFI demonstration mode1). Data for advanced technologies were provided by the corresponding divisions of the EIA and sometimes other DOE offices. Data on existing and new technologies were obtained from the work of Bhagat et a1. (Bha79). Resource curves were obtained by reinterpretation and modernization of values given (using different definitions) by the U.S. Geological Survey (USGS) (Mi178) and the output of other models, and the 1975 energy balance was adapted from EIA data. More importantiy, becanse results from this model were needed primarily for the time period after 1995, output for times through 1995 was "calibrated" to assure a general tracking with output from the Midterm Economic Forecasting System of EIA, described in ARC-78 (EIA79a, Chapter 4 and elsewhere in that report). (See the following paragraph.) Parameters for certain activities were adjusted (away from the values initially chosen) to take into account information not directly parameterized in LEAP-78. For example, the use of biomass and renewables was "constrained" (EIA79a, p. 410); a price increment was included in the uranium fuel upgrade activity to equalize coal and nuclear costs (EIA79a, p. 410, Die79, item 5.2); future cost of electricity generation by oil and gas boilers was increased to incorporate expected government restrictions (Die79, items 4.9, 4.11); the penetration of oil product imports was constrained in the refined oil allocation activity (Die79); and "...Estimates of new technology penetration are obtained from preliminary targets developed for NEP-II analysis..." (EIA79a, p. 409). Finally, at 
least one tabulated result (residential solar use) was determined after the model runs because reasonable model parameters had not given a result satisfactory in the light of the modeler's knowledge (Pea79). Note that, overa11, the impact on the model projections of these assumption-driven parameter adjustments was quite significant.

Considering the number of parameters required and the modeling goals, the overall method for obtaining parameter values does not appear unreasonable for Mode1 22C considering manpower and schedule constraints. As an approach for future work, it would be unsatisfactory because data inconsistencies are likely when information is compiled from diverse sources. Advanced technology information must be obtained from experts, but evaluation is required to avoid nnrealistic estimates therefrom. The required data analysis effort is very large, and techniques for this analysis may not yet be developed. Most questionable was the method of adjusting the market share at equal prices and (sometimes) the allocation behavioral lag parameters of allocation activities to achieve results corresponding to the mid-range model output in 1995 (Die79, items $1.1,2.4,2.5,2.8,2.28$, and 9.1). The LEAP modeling efforts in 1979 and 1980 avoided use of the market shares at equal prices for mode1 "calibration" (Hut80b).

The method for acquiring Model 22C data involved use of a questionably large amount of information comparable to the output of Mode1 22C; inpat parameters were used to give the desired output values at least through the 1990 time period. Such calibration of model output against the results from another model of the same part of the economy is questionable becanse there seems little assurance that projections will extrapolate appropriately; however, use of other models may sometimes be valid if the other models contain information not available to the model being calibrated and if calibration will not waxp the analysis of those variables the receiving model can deal with. 


\section{Precision of Paraneter Definition}

At least two types of parameter definitions have proven very important in the evaluation of LEAP Mode1 22C. One is the definition of the parameters of the LEAP-78 program so that the model user can know fust what information is required. The other is the definition of the exact mode of aggregation used in the representation of the economy; this information is used by the modeler to prepare the inputs and is used by the modeler and implicitly by the ARC-78 reader to interpret the outputs. The paragraphs below detail problems in Mode1 22C with each of these classes of definitions.

Stewart and Goldstein (Ste81) report some instances where existing parameter definitions were sufficiently ambiguous that the LEAP modelers at EIA erred in preparing Mode1 22C 1nput data. Examples follow. Imprecision in the definition of the variable operating cost aging rate in Adler et al. (Ad179) (percent per year vs relative change per year) led to an input parameter in error by a factor of 100. Based on comments and format statements in the DEMAND subprogram, ambiguous definition led the price sensitivity and 1 ag parameters to be entered on a per year rather than per period ( 5 $y \in a r)$ basis. Confusion as to whether final auto demand was measured in units of $10^{9}$ or $10^{12}$ vehicle miles per year led to inconsistencies among the parameters for the oil/gas-powered automoblle. Analogous problems occurred for the other transportation demands. To forestall such mistakes in the future, Stewart and Goldstein (Ste81) furnish a complete set of corrected defintions of LEAP-78 input parameters, including many not used in Mode1 22C. Cherniavsky and Juang (Che80) have also provided some updated definitions for resource submodels, many of which apply to LEAP-78. The effects on some mode1 results of correcting two input mistakes were shown in Table IX.1, cases 1 and 2, of this report. Examples are also given in Stewart and Goldstein (Ste81). 
Options inevitably occur in aggregating the energy economy for a finite model. How does one treat natural gas liquids, the use of natural gas for power in the fie1d, and the separation of the coa1 resource by region and quality? The reader of the tables in ARC-78 (EIA79a) needs to be ab1e to learn exact1y how this aggregation was accomplished. The sophisticated user may obtain this information from the listing of the RPORT subroutine that produces the summary printout from which most of the tables in ARC-78 (EIA79a) were drawn and from the ENBAL/DATA data set used in that subroutine and discussed by Cohen (Coh79, Sect. 3) and Ford (For81). (Unfortunate1y for the student of ARC-78, no readable edit of this data set was programmed by the LEAP modelers at EIA.) One can alternative1y infer many of the aggregation decisions from the text of the draft document by Diedrich et a1. (Die79). Diedrich et a1. also clarify that many of the labels on the model input and output tables printed by LEAP from the Mode1 22C data base are misleading; however, this misdirection is no problem to the reader who depends entirely on the tables in ARC-78 (EIA79a).

Failure to document. exactly tho definition of model parameters injured the Mode1 $22 \mathrm{C}$ effort to an extent because, as a result, some parameter values were entered in error. In addition, imprecise definition of the exact market aggregation in the model network and the published output tables diminished the clarity of the results. Because not a11 of these definitions change from one model version to the next, the authors of the present report recommend that extra care be exercised to establish and publish precise definitions for each major set of projections.

\section{Traceability of Input Data to Its Original Source}

Some information on the sources of data used in Mode1 22C may be found in the published ARC-78 report (EIA79a) and in the text and computer listings of the draft report on data by Diedrich 
et a1. (Die79) of the Office of Applied Analysis (OAA) in DOE. The information from these reports is summarized in Stewart and Goldstein (Ste81). Generally, the available information steers the reader toward an information source, but does so with too little specificity to permit a review of the logic behind the chosen value. In somc cases, the referenced report used a different aggregation of energy supply or use from what was needed for Model 22C; in other cases, (1) the original data (e.g.., resource curves) were updated and reinterpreted to permit derivation of the required input parameters, (2) the parameter values were adjusted to obtain projections satisfactory to the modeler (see Sect. X.B above), or (3) the reference was just to an organizational unit within DOE that specialized in the required area. By contrast, the serious user requires a worksheet for each data element that shows how it was obtained from intermediate values, given precise sources. If the source is published, table and line number or equivalent are needed; if a private communication is the source, the name and organization are required, as well as the type of analysis that led to the value. Because this specificity is lacking, with few exceptions, for the Mode1 22C data base, the present authors concluded that a usefully complete input data andit trail would not generally be possible.

More recently, the analysts in the Long-Term Energy Analysis Division of OAA have maintained chronological log books that serve as permanent in-house documentation of the derivation of input parameter values. Perhaps this approach could be extended via computerization and careful formating to provide a data audit trail that is both complete and reasonably economical. The lack of such documentation restricts the ability of a user to upgrade the data in selected areas and 1 imits the credibility of the whole modeling effort. 


\section{B. Mode1 22C Data Quality and Uncertainty}

Data quality. As indicated above, the general failure for Model 22C to provide fully traceable data prevents assessment of data quality in terms of the validity of its sources and the care with which the primary data were processed to the form required. Quality could also be assessed by performing an independent parameter evaluation and then comparing the results of this evaluation against the Mode1 22C input; this process was found too expensive for the present study. At a less comprehensive leve1, the evaluator may compare input values against those values used by others in similar mode1s. In most cases, the Mode1 22C data base does contain roughy similar values, but the meaning of this qualitative assessment is constrained by the extent to which the alternative data base itself is documented. Finally, the evaluator may scan the data set for unreasonable values. Stewart and Goldstein (Ste81) indicate cases where such a scan of the Mode1 22C data base turned up flaws (e.g.. the high efficiency of future solar-assisted residential heat pumps without a corresponding capital cost). A limited review of much of the Mode1 22C data base is reported by Hansen et a1. (Han81). The assessors concluded that of the about 340 parameters examined, about "...35 percent were found to be within reasonable bounds, 8 percent appeared to be in conflict with information from known sources, and 21 percent appeared on intuitive grounds to warrant further examination. The group found the remaining 36 percent difficult to assess either because the parameter definition was incomplete or because it was insufficiently linked to known data or familiar concepts." Questionable values included the residential and commercial income elasticities of demand and some of the allocation market shares at equal prices. The Analysis Quality Report of the Office of Energy Information Validation (OEI80, Appendix B) also contains a discussion of the quality of the input information to Mode 1 22C. 
In summary, the present evaluation effort concludes that the Model 22C data base appears to contain some input errors, some anreasonable estimates, and some unrepresentative values chosen to force outputs toward assumptions. Many of the data, however, are plausible and similar to values used in comparable models. This is a much less favorable conclusion than a user might wish a model evaluation to reach! Note that, for a model the size of 22C, the input data preparation task is very large and the traditional practices of modelers and the support levels available have made it difficalt to produce the detailed documentation necessary for a high data quality rating.

Data uncertainty. In the authors' view, an adequate mode1 input data base would contain information on the uncertainties of the input data and any correlations among them. Only in this way (1) can the data analyst record his assessment of how well a value is known; (2) can a user or another modeler quickly determine which data require improvement; and (3) can one obtain, with the aid of sensitivity studies, the minimum ("perfect model specification") uncertainties in model outputs. Such uncertainties can be compared against accuracy targets for important responses (see Sect. III.B and Pee80).

$\Lambda$ properiy developed set of parameter uncertainties and correlations for Mode1 22C would be costly because in only a few cases do data sources [e.g., the USGS report on oil and gas resources (Mi178)] include any uncertainty data. Such a data base of uncertainty, information can reasonably be developed only as part of the effort to compile the paraweters themselves. Significantly increased effort would be required, so it would be important to concentrate this effort on the parameters most likely to be important. To evaluate uncertainties in a separate effort would also entail a reevaluation of the input data. However, it is possible without a detailed analysis to approximate the magnitudes of the uncertainties for the various types of parameters. To perform such an approximate 


$$
\frac{1}{\mathrm{X}}-\mathbf{1 0}
$$

analysis, one must take advantage of general knowledge about the types of data likely to be available to those who estimated the model input parameters and about the plausible range of variation of each type of parameter. Therefore, the uncertainty estimates are not strongly linked to the particular values chosen for Mode1 22C. Table X.1 gives a set of uncertainty estimates of this type that was developed by the present authors. Where mistakes of large magnitude affected Mode1 22C, as described in Stewart and Goldstein (Ste81), the uncertainties refer to the corrected values.

Correlations among the parameters are not explicitly treated in Table X.1, although in some cases they are likely to be large (e.g., cost parameters for types of facilities not yet commercially available and for the same parameter in different time periods). Where the uncertainty is given for a "global" parameter, the uncertainty is for the national average. Because relative costs presumably govern to a great extent the relative market penetration of new technologies, some known fully-correlated uncertainty components were intentionally omitted in this approximate analysis. For example, the uncertainty in the differential inflation rate for the cost of pipefitters would affect all complex onergy facilities in a similar way, though to different degrees.

In Table X.1, uncertainties are placed in broad categories for convenience and to emphasize the approximate nature of the values; that is, an entry of "20\%" corresponds to estimates from about 15 to $30 \%$, and uncertainties that may be at least as large as a factor of two are classified as 50\%. In this table, the same parameters for all similar activities are approximated to have equal uncertainties. Many parameters have been omitted from the table in the expectation that they are less important (see sect. IX.B). Generally, the values in such a table must be used with discretion because numerous footnotes would be required to detail al1 the qualifications. Moreover, in any use of these uncertainty 
TABIPB X.1

Approxinate uncertainty estinates for lodel 22C input paraneters

\begin{tabular}{|c|c|c|c|}
\hline $\begin{array}{l}\text { Idontification } \\
\text { Nuber }\end{array}$ & $\begin{array}{l}\text { FORTRAY } \\
\text { Nane }\end{array}$ & Short Definition & $\begin{array}{l}\text { Approrinate } \\
\pm \text { Uncertainty }\end{array}$ \\
\hline$A-1$ & SENS & Demand behavioral lag & $50 \%^{c}$ in $(-\ln$ SENS $)-1$ \\
\hline$A-2$ & ELAS & Price elasticity of demand & $50 \%^{d}$ in ELAS/ (1-SENS) \\
\hline$A-3$ & $\mathrm{Y}(\mathrm{JT})$ & GNP growth rates (average) & $2 \%$ per year \\
\hline$A-4$ & GAMMA & Income sensitivities of demand & $50 \%$ \\
\hline$A-5$ & TRANSI & Link differentials & $\$ 0.20 /$ MMB tu $(1975 \$)$ \\
\hline$A-7$ & ROE & Return on equity & $0.02^{f} y^{-1}$ \\
\hline$A-8$ & RDEBT & Return on debt & $0.01^{f} \mathrm{yr}^{-1}$ \\
\hline 1 & SHSENS & Allocation price sensitivities & $50 \%$ \\
\hline 2 & BELAG & Allocation behavioral lags & $50 \%$ \\
\hline 3 & FREQPR & $\begin{array}{l}\text { Allocation shares at equal } \\
\text { prices }\end{array}$ & $20 \%_{0}^{8}$ \\
\hline \multirow[t]{2}{*}{5} & $\operatorname{scc}$ & $\begin{array}{l}\text { Specific capital costs for } \\
\text { basic and electric power } \\
\text { conversion: }\end{array}$ & \\
\hline & & $\begin{array}{l}\text { Other than final conversions } \\
\text { Final conversions }\end{array}$ & $\begin{array}{l}10-20 \%^{h} \\
50 \%^{i}\end{array}$ \\
\hline 7 & VOC & $\begin{array}{l}\text { Variable nonfuel operating } \\
\text { costs }\end{array}$ & $20-50 \%^{h}$ \\
\hline \multirow[t]{2}{*}{9} & EFF & $\begin{array}{l}\text { Efficiencies for other than } \\
\text { final conversions }\end{array}$ & $2-5 x^{h}$ \\
\hline & & Some final conversions & $10 \%^{j}$ \\
\hline 10 & IPLTIM & Planning lead times & $50 \%$ \\
\hline 12 & IYRAVL & Year commercially available & $10 \mathrm{yr}$ \\
\hline 13 & EARLY & Precommercial premium per year & $50 \%$ \\
\hline 18 & VOCRAT & Operating cost change rates & $20 \%$ \\
\hline
\end{tabular}


Tab1e X.1 (continued)

\begin{tabular}{|c|c|c|c|}
\hline $\begin{array}{l}\text { Idontifiontion } \\
\text { Number }\end{array}$ & $\begin{array}{l}\text { Forimin } \\
\text { Nane }\end{array}$ & Short Dofinition & $\begin{array}{l}\text { Approximate } \\
\pm \text { Uncortainty }\end{array}$ \\
\hline 19 & EFLIM & $\begin{array}{l}\text { Limiting efficiency maltipliers: } \\
\text { Other than final conversions } \\
\text { Some final conversions }\end{array}$ & $\begin{array}{l}2-5 \%^{h} \\
50 \%^{j}\end{array}$ \\
\hline 20 & AVAIL & Plant availabilities & $10-20 \%^{h}$ of (1-AVAIL) \\
\hline 22 & ICLIFE & Facility lifetimes & $20 \%$ \\
\hline 23 & VOAGRT & Operating cost aging rates & $20-50 \%^{h}$ \\
\hline 25 & IDLIFE & Debt 1 ife & $20 \%$ \\
\hline 29 & EQFR & $\begin{array}{l}\text { Equity fractions of capital } \\
\text { cost }\end{array}$ & 0.2 \\
\hline 30 & QUAN1Y & Initial quantities & $5 \%^{k}$ \\
\hline 31 & RATIN & $\begin{array}{l}\text { Resource historical capacity } \\
\text { additions change rates }\end{array}$ & $0.02^{1} \mathrm{yr}^{-1}$ \\
\hline 37 & CFSENS & $\begin{array}{l}\text { Capacity factor price sensiti- } \\
\text { vities }\end{array}$ & $50 \%$ \\
\hline \multirow[t]{3}{*}{40} & $\begin{array}{l}\text { INRCST } \\
\text { BASEPR }\end{array}$ & \multicolumn{2}{|l|}{ Resource cost curve normalization } \\
\hline & & Established resource types & $10 \%$ \\
\hline & & $\begin{array}{l}\text { Oil shale, enhanced oil and } \\
\text { gas }\end{array}$ & $50 \%$ \\
\hline $41-43$ & (N) & $\begin{array}{l}\text { Cumulative resource cominitments } \\
\text { for which price is twice the } \\
\text { initial resource cost }\end{array}$ & $50 \%$ \\
\hline $41-43$ & C2 & $\begin{array}{l}\text { Slope parameters for resource } \\
\text { curves }\end{array}$ & $50 \%$ \\
\hline 44 & CCCF & $\begin{array}{l}\text { Current capital cost fractions } \\
\text { for resources }\end{array}$ & 0.2 \\
\hline 48 & ROWN & Resource owner's interest rate & $0.02^{f}$ \\
\hline-- & \multicolumn{2}{|c|}{$\begin{array}{l}\text { Oil/oil products/gas import price escala- } \\
\text { tion rate }\end{array}$} & $50 \%$ \\
\hline
\end{tabular}

(footnotes on next page) 


\section{FOOTNOTES TO TABLB X.1}

${ }^{a}$ Parameter number as in Appendix $A$ of Stewart and Goldstein (Ste81).

b Defined so that the probability is about $2 / 3$ that the true value of the parameter 1 ies within this range on either side of the assigned value. Therever this range extends beyond the region over which the input parameter is defined, a suitable correction is to be understood. (Behavioral parameters may not have true values because they may not correspond to valid concepts!) When given as a percentage, the uncertainty is that percent of the parameter value in the model or the indicated parameter combination, unless otherwise noted. These approximate uncertainties were assigned by the authors.

cThe relative uncertainty is given in the number of model time periods required for the demand to reach $\sim 60 \%$ of its eventual change following a step change in prico.

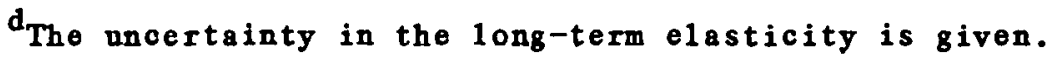

eGiven as a percentage of the prior year GNP, just as is the growth rate itself. This estimate is for the long-term average, not the 5-year averages entered in the data base. Because Mode1 22C assumes zero inflation, this is the uncertainty in the average real GNP growth rate.

fowner's interest rate and the returns on debt and equity are strongly correlated through the market. The uncertainties here are supposed to include the general long-term behavior that affects all of these, but not the variations that arise from perceptions of risk.

${ }^{B}$ Because this parameter was selected for several activities to make Model $22 \mathrm{C}$ outpat track the midterm model results, uncertainties here could be assessed on that basis, if midterm model output uncertainties were known. Otherwise, the FRBQPR uncertainty given is too sma11 when the various 1 inks have been assigned greatly different FREQPR values. FREQPR uncertainties are constrained by the unit sum over al1 1 inks.

h The smaller uncertainty applies to processes now commercially available, the larger to those not yet available.

${ }^{i}$ This applies to the conversion processes just "below" final demand where there is often a question just how much equipment is included. For example, does a heat pump include ductwork?

${ }^{j}$ This applies to the conversion processes just "below" final demand in the cases where final demand does not carry energy units. For example, the term "vehicle miles per gallon" requires a yet-undefined standard fleet-averaged vehicle. Whoro a true thermal efficiency is implied, this is the uncertainty for (1-ERF) or (EFLIM-1).

This value applies to disaggregated quantities; smaller relative uncertaintios generally apply to more highly aggregated quantities.

${ }^{1}$ This value does not apply to the artificial RATIN values used in Model 22C for the 0il-Gas sector and western coal resouroe activities.

${ }^{m}$ These parameters are combinations of input parameters for undiscovered resourcos and prices. Equation (1) in Stewart and Goldstein's report (Ste81, p. A-65) gives the equation for C2; the equation simplifies greatly for Model 22C. Adler (Ad179. p. 7-55) gives the equation from which one may derive the first parameter. Those two parameters are strongly correlated for a given resource.

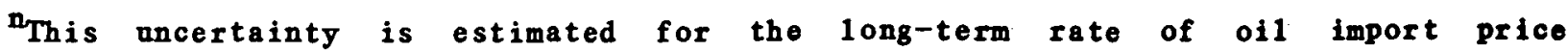
escalation. Model $22 \mathrm{C}$ has exogenous input prices by year as its parameters, but one can represent this inpat as au avorage $2 \%$ real rate of increase per year. So far, prices have risen much more rapidly than estimated. 
estimates, it should be remembered that they were obtained from general background knowledge rather than from an evaluation of the data base that conld be validated. For particular parameters in some of these categories, detailed uncertainty estimates might vary from those in Tab1e X.1 by a factor of 2 or more.

The reader can observe in Table $X .1$ that large uncertainties are estimated for many parameters. Perhaps more advanced techniques exist to obtain the parameter values than were assumed by the authors, or perhaps better techniques can be developed. Certainly, data correlations would not be treated as lightly in a thorough analysis as they are in this table. If the sensitivities for the grossiy uncertain parameters are sufficiently small for some important responses, then the data base can support projections for these responses (see Sect. $X I$ ). Note that energy analysts are accustomed to contingent studies. in which major assumptions such as final demand growth are taken as given (i.e., as having no ancertainty). 


\section{F. Conclusions and Recomendation on Hodel 22C Paraneters}

- The Mode1 22C data base included some errors, some unreasonab1e estimates, and some unrepresentative values chosen to force outputs toward assumed "futures." Many of the data, however, are plausible and similar to values used in comparable models.

o The modelers at EIA used methods for selecting parameter values that were generally adequate for the first LEAP modeling effort (22C). These methods would be inadequate for future LEAP models because (1) cost and performance data on the various technologies were obtained from a variety of possibly inconsistent sources and (2) in too many instances, information comparable to the output of Mode1 22C was used to adjust input data.

- The parameter values employed for Model 22C could not in general be traced to their precise origins. This lack of traceability limited model output credibility and the potential for EIA or others to build on the data analysis already performed. It is recommended that for comparable future models the EIA develop a computerized $\log$ of the sources and analysis steps that lead to each parameter value.

- Some of the LEAP-78 parameter definitions assembled by and for EIA were misleüling. This difficulty led to at least three significant parameter input errors. Also, imprecise definitions of the aggregation of the economy employed in Model 22C prevented the reader of ARC-78 from knowing the exact meaning of the tables published there. In both cases, it is recommended that EIA publish precise definitions to support any future use of a complex model like LEAP.

- Although approximate uncertainties can be obtained ex post facto for the various classes of parameters to permit a paradigm of uncertainty propagation, a thorough analysis of 
the uncertainties of input parameters must be performed in the same process as the evaluation of the nominal parameter values. Future EIA model input data analysis should work toward inclusion of ancertainties and correlations for the most important data elements, even though such an effort will be costly. The existence of such uncertainty information is vital to support rational decision analyses. 


\section{CONCLUSIONS AND RBCOMLTEDATIONS}

Some conclusions reached in this study apply only to Model 22C, whereas others apply. as well to the generic LEAP and to similar generalized equilibrium models. Because LEAP Model 22C and its data base are now obsolete, the recommendations apply to future models in the LEAP system.

\section{A. The Bffect of Input Data Dncertainty on Lapap Model 22C Results}

Using the relative sensitivities given in Tables IX.4 through IX.7 and the estimated data element uncertainties given in Table $X .1$, it is possible to obtain a preliminary estimate of the uncertainty (square root of the variance) for a given response. These uncertainty estimates can then be compared to the response accuracy targets specified in Table III.2 to see if there is reasonable probability of reaching these targets considering data element uncertainties alone. Estimates obtained here are very approximate because the data uncertainty estimates in Table $\mathrm{X} .1$ are preliminary and because only first-order sensitivities are considered. Also, propagated data uncertainties are only part of the total uncertainty. which also includes the effect of model specification difficulties (see Sect. VII).

To illustrate the procedure for propagating input data uncertainties, the uncertainty in each of the four responses considered in sect. IX.B (see Tables IX.4 through IX.7) due to estimated data element uncertainties will be given. Some of the data elements [e.g., PostLM, PMI (J), PLI(J), and load factors] that have appreciable sensitivities in Tables IX.4 through IX.7 do not occur in Table X.1. (A11 of these exceptions but the load factors have unit value in Mode1 22C.) For the purposes of the illustration here, if a data element uncertainty estimate is not given in Table X.1, that data element is not considered in the uncertainty analysis. 
The relative uncertainty in response $I$ in year $2020\left(\Delta R_{I}(10) / R_{I}(10)\right.$ is calculated as

$$
\begin{aligned}
& \frac{\Delta R_{I}{ }^{(10)}}{R_{I}(10)}=\left\{\sum_{i}\left[\left(\frac{x_{i}}{R_{I}(10)} \frac{d R_{I}(10)}{d x_{i}}\right)\left(\frac{\Delta x_{i}}{x_{i}}\right)\right]^{2}\right.
\end{aligned}
$$

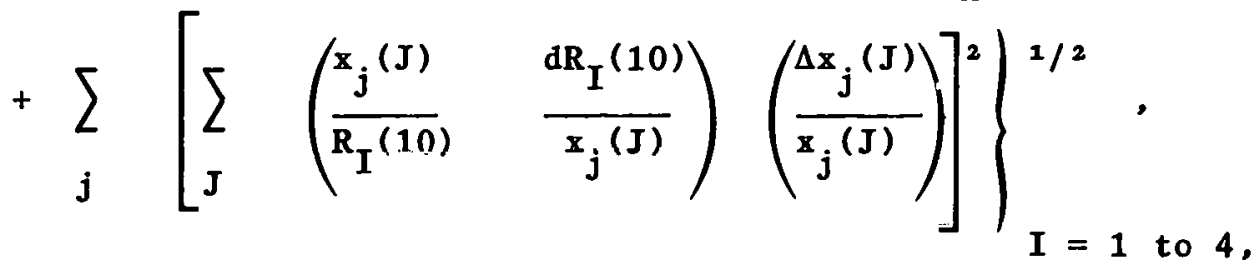

where the sum over $i$ is over all data elements that are assumed to be nncorrelated and the sum over $j$ is over time-dependent data elements that are assumed to be fully correlated. Those data elements that are assumed to be fully correlated over time are also assumed to be uncorrelated with the other data elements. Only a few time-dependent data elements (e.g., the price of imported oil, oil products, and gas) were assumed to be fully correlated in time. For the most part, correlations were neglected, and for this reason, the results presented here must be considered illustrative rather than definitive. Also, it is being assumed that first-order (i.e., linear) sensitivity coefficients are applicable independent of the magnitude of the uncertainty in the data element.

The results are given in Table IX.1. On the left in the table, the calculated uncertainties are given, and on the right in the table, the assumed accuracy targets from Table. III.2 are given. The calculated uncertainties in Table XI.1 contain contributions from a large number of the smaller sencitivity enefficients that worc not shown in Tables IX.4 through IX.7.

The estimated uncertainties for these particular responses are comparable to the assumed accuracy targets even though (1) the underlying parameter uncertainties did not include values for parameters like the relative price of materials and the technological 
Tab10 XI.1

Bstinated uncertainty in selocted joer 2020 rosponses duo to inpet data uncertainties. (Tho four responsos considored hore aro those considored in Tables $\mathrm{X.4}$ to IX.7, respectively.)

\begin{tabular}{|c|c|c|c|c|}
\hline $\begin{array}{l}\text { Rosponse } \\
\text { (Short Name) }\end{array}$ & Betiente & Unoortainty & $\begin{array}{l}\text { Assuned } \\
\text { Target }\end{array}$ & $\begin{array}{l}\text { Rolitive Acenracj } \\
\text { (Soe Tab10 III.2) }\end{array}$ \\
\hline \multirow{2}{*}{$\begin{array}{l}\text { Total energy- } \\
\text { related cost per } \\
\text { GNP }\end{array}$} & $\Delta R_{1}(10)$ & \multirow{2}{*}{$x 100 \%=15 \%$} & $\Delta R_{1}^{T}(10)$ & \multirow{2}{*}{$x 100 \%=12 \%$} \\
\hline & $\overline{R_{1}(10)}$ & & $R_{1}(10)$ & \\
\hline \multirow{2}{*}{$\begin{array}{l}\text { Cost of imported } \\
\text { fuel per GNP }\end{array}$} & $\Delta R_{2}(10)$ & \multirow{2}{*}{$x 100 \%=45 \%$} & $\Delta R_{2}^{T}(10)$ & \multirow{2}{*}{$x 100 \%=100 \%$} \\
\hline & $R_{2}(10)$ & & $R_{2}(10)$ & \\
\hline \multirow{2}{*}{$\begin{array}{l}\text { Imports of oil and } \\
\text { o.il products }\end{array}$} & $\Delta R_{3}(10)$ & \multirow{2}{*}{$x 100 \%=50 \%$} & $\Delta R_{3}^{T}(10)$ & \multirow{2}{*}{$x 100 \%=55 \%$} \\
\hline & $R_{3}(10)$ & & $R_{3}(10)$ & \\
\hline \multirow{2}{*}{$\begin{array}{l}\text { Fractional liquid } \\
\text { fuel use by the } \\
\text { demand sectors }\end{array}$} & $\Delta R_{4}(10)$ & \multirow{2}{*}{$x 100 \%=20 \%$} & $\Delta R_{4}^{T}(10)$ & \multirow{2}{*}{$x 100 \%=29 \%$} \\
\hline & $R_{4}(10)$ & & $\mathbf{R}_{4}(10)$ & \\
\hline
\end{tabular}


change 1imits, (2) most data correlations were not considered, and (3) the effects of higher-order sensitivities were neglected. As shown by some of the direct sensitivity rans of Sect. IX.A and the OEIV Analysis Quality Report (OEI80), the neglected effects are sometimes important. Also, these responses were designed to reduce the effect of some irrelevant data uncertainties. Therefore, if the data uncertainties of Table X.1 do represent current knowledge of the uncertainties in the parameters listed, one concindes that data uncertainties do not support these year 2020 response values, within the estimated accuracy targets, even if model specification unoortainties axe neglected. In turn, certain qualitative conclusions that could be drawn from these Mode1 22C response projections are indicated not to be supportable by the input data base. (Projection of oil/gas import cost per GNP is the possible exception. based on the present analysis.)

\section{B. Prinoipal Strongthe and Vouknosses of LRAP-78 and lodel 22C}

This subsection includes the authors' conclusions on the mode1's usability for meeting relevant DOE needs, its understandability to the model users and their clients, its realism in projecting the future impacts of what is now known about energy-related aspects nf our economy, and its credibility with potential users in the agency and particularly with interested members of the public. (Note the additional and more detailed conclusions at the ends of Sects. IV through VIII, IX.A, IX.B, and X.)

Jasility. Usability must be considored relative to the Congressional mandates on the DOE to provide projections of energy supply and use, under alternative assumptions and uncertainty, and to estimate the consequences of potential government actions.

LRAP is very flexible as to what portions of the energy economy are represented in detail; therefore, it can be a useful tool for studying the effects, of various resource and energy conversion 
development assumptions. Some model assumptions, noted under Realien below, affect the usefulness of the LEAP-78 modeling system for some applications. Also, not all policy options were readily modeled. The impact of loan guarantees and tax incentives should be readily modeled in LEAP-78, but limitations on industry output could not be modeled without use of a "shadow price" option not known to work: Regulation of supplier prices at values below those given by the model price forecasting system could not have been handled in LEAP-78, but such a feature could be compatible with the LEAP system. Price guarantees conld have been handled with difficulty and minor model revisions. If LEAP correctly represents a condition of economic efficiency from which the economy cannot deviate too far in the long run, the difficulties in handing regulation may not be significant for LEAP's modeling role. However, these deviations are crucial ones in policy analysis.

Usability also depends on a user's power to alter the model and to quickly obtain new results. Although long-range models treat the time period of a professional career, results assuming modified policies or other data are often desired within a few hours of the time the idea is formulated. The overall turnaround time depends on the ease of preparing a revised model as well as the computer system turnaround. LEAP has the major advantage that only one program is required rather than a chain of programs representing supply, demand, and integration. Some minor model network revisions conld be rapidiy introduced using LEAP-78, but major network modification for LEAP models will be an arduous process until additional software aids are developed. However, to compensate for this difficulty, small models and partial models of any variety can be constructed from the available subjiogram modules withont any reprogramming. Data changes and process subroutine program modifications (even for use in only a few activities) can be introduced very efficiently in LEAP-78.

Compater system turnaround is inhibited because of the large storage required and the slow running times. LEAP-78 appears to require 
about twice the computer memory estimated as being necessary; it uses a relaxation system of questioned efficiency that has caused excessive running time in some cases, and many intermediate quantities dependent only on the input parameters are repetitively recalculated twice per model iteration. All of these problems could be mitigated, but until such improvements are made, only very. sma11 LEAP models will enjoy short computer turnaround time.

Considering the problems described in Sect. V, usability of LEAP-78 by persons outside of EIA would have been even more restricted.

Dnderstandability. A mode1 is more understandable as it becomes simpler, as its results can readily be traced to their causes, and generally as its documentation is enhanced. Simulation models 1ike LEAP have a natural advantage in understandability because many of the data for LEAP are cast in engineering and financial terms for ready intercommunication with typical DOE users. The mode1 networks are easy to comprehend, but some of the process submodels are difficult to understand in any detail. With the completion of the present evaluation project, the documentation of LEAP-78 generally meets established standaris, except for the data base, and documentation on later versions could build on this base. (However, none of the documentation makes it easy for either an engineer or an economist to understand the detailed equations of the resource extraction or electric utility submodelo of LEAP-78.) With the publication and analysis of sensitivity coefficiente for Mode1 22C, the behavior of the model can be maxe readily studied. Some of the complexity of the LEAP program comes from the lengthy discounting formulae required to support the particnlar form of the parameterization of time-dependent discount rates used in LEAP-78; the complexity is not needed because a simpler form (e.g., rate constant within 5-year intervals) would suffice for the needed model capabilities. 
On balance, understandability is a potential plus for LEAP systems, but was a neutral factor for use of LEAP-78 at EIA. For users outside the agency, it would have been a negative factor.

Realisa. Because LEAP functions by simulation of generic energy activities, its limiting success must depend on whether the essential features of economic interactions have been included. LEAP gains the potential for realism by permitting whatever subdivision of generic industries of interest is deemed necessary for the problem at hand, even though Mode1 22C suffered from. very uneven treatment of its various sectors. LEAP does not march stepwise through time looking only at the past; current prices are based on estimates of future prices. This feature adds realism if the "perfect foresight" forecasting formula resembles the performance of the aggregate of real decision makers. For example, in LEAP it is possible to price resources at their scarcity value. LEAP-78 suffered by failing to (1) allow substitution of capital for other production factors through plant retrofit; (2) provide significant coupling of demand to variables other than price; and (3) eliminate the plants with highest variable cost in periods when there is surplus plant capacity. Although sensitivities to the behavioral parameters seom modest, a rationale is required for choice of the various price sensitivities and behavioral lags to permit belief that they represent real economic. factors, particularly in the market penetration submodel. Within the basic conversion modeling, the capacity factor has had inappropriate dependence on price vs operating cost, but improvement is readily possible. LEAP-78 suffered from a fully inadequate fuel import module, supplies of labor, capital, and materials that were available without limit at exogenous prices; final demand that became elastic only for the next century; and electric utility pricing that was inconsistent with present pricing (but perhaps more representative of the future). The assumption of infinitely divisible plant sizes may be inappropriate for parts of the projected 
electric ntility and synfuel industries, and no provision was made for depletion of available sites as a finite resource.

Credibility. Model credibility depends not only on the level of documentation and a model's realism but also on the degree of familiarity with model characteristics enjoyed by potential users and other interested professionals. LEAP credibility is enhanced by the broad use of generalized equilibrium models (see Sect. II), the public nature of its origin, the broad publication and review of its results. and the relativoly complete documentation of the 1978 Mode1 22C accomplished with the aid of the present projoot. Credibility is reduced by the lack of a well-documented data base and by the fact that users outside of DOE have 1ittlo "hands on" experience with the particular model. Public use would eventually lead to a variety of compatible subroutine packages with enriched intellectaal content; this outcome requires that a future LEAP be readily transportable for use at lower cost and/or on smaller machines. To obtain maximum possible credibility, LEAP would have to become an "open" code, one that is well documented, widely used, closely studied by members of the interested communities, and frequently modified by persons other than the originator.

For the overall ovaluation of LEAP credibility as a public information mode1, its public origin and the archiving system now used for input and results are strongly favorable factors. The ohief legative factor is the laok of full documentation of input quantities, including their original sources and explanations of any modifications thade. The need for comprehensive input data documentation may also apply to other public information models.

\section{Consolidated swonary of Reconondations}

The recommendations based on our study vary in scope from some that may apply to all EIA models to others that apply only to the 1978 LRAP Mode1 22C. The recommendations are presented generally in 
order of decreasing breadth, not importance. (Equivalent specific recommendations were included in the Execntive Summary.)

- Major conclusions from long-term analysis need not vary markedly in successive years. Thus, rather than developing and evaluating projections on an annual basis, a 2- to 5-year cycle for generating markedy altered long-term projections rould permit higher quality results, far better documentation of what was done, and more comprehensive evaluation.

- An evaluated and standardized energy- and economy-related data base should be developed along with the associated software needed to process the given data to particular forms used by alternative models. The data base should contain data uncertainties and correlations as well as the nominal values. The generation and update of such data would be quite costly; mechanisms for sharing such thoroughly reviewed information should be formally put into place. In any case, input data for programs like LEAP should have complete documentation that allows information to be traced to its precise source and provides an explanation of any modifications to the source information. Standardized problems (benchmarks) similar to those considered by the Energy Modeling Forum should be developed as a means of comparing and evaluating results of alternative models.

- Special efforts should be made to make energy-economy models, used by EIA in its projections, transportable and usable by interested parties in the general public. The concept of the "open" code is relevant here and provides a mechanism for external reviow, feedhack, and code maintenance that goes much further than the simple archiving of models used for annal projections.

- Models exist because problems need to be solved that, becanse of the number and nature of the complex interactions, cannot be 
addressed precisely using intuition and experience. However, analysis using these models is best focused by relating the issue of concern (e.g., cost of energy, satisfaction of liquid fuel demands) to an explicit combination of the model output values. Furthermore, target accuracies for desired results need to be developed to allow a determination of whether the model result with its associated uncertainty can meaningfully contribute to the resolution of the issue in question. Explicit use of this concept in future Annual Reports to Congress would strengthen their impact. However, development work is required to permit valid assignment and propagation of parameter uncertainties, particularly where higher-order sensitivities will be required.

The approach of calibrating the long-term output to match midterm model numerical outputs at year 1995, by adjusting various input parameters, unnecessarily complicates the evaluation of long-term mode1s. Rather than to adjust data, if long-term and midterm projections must agree, it would be more straightforward to start if possible the long-term calculation at year 1995 using the midterm results as boundary conditions. (Otherwise, it must be demonstrated that midterm models are adequate for determining the parameters for the long rnn.) Genorally, model input data should not be "tuned" to obtain desired projections. When this is done, it is difficult to understand precisely what is output and what is input !

The fixed-cuefficient production function in LEAP-78 energy conversion submodels (no factor substitution) appears to be a serious problem in model spooificatiun for a model designed to assess the long-term impats of increasingly limited supplies of energy. Endogenous consideration of conservation and other retrofit issues, for example, seems difficult (a1though not impossible) with the present approach. Attempts to incorporate some measure of substitution within processes should be 


\section{XI-11}

considered (see Sect. VII); otherwise, the number of activities modeled may need to grow. unnecessarily. (A problem will be to increase flexibility while maintaining the clarity of a simu1ation mode1.)

- The capacity factor specification of LEAP should be changed to correspond to a reasonable production function so as to avoid the situation of producers operating while sustaining losses (see sect. VII). Making a change of this type appears to be a straightforward matter.

- In LEAP Model 22C, the unlimited supply of capital, labor, materials, and oil imports at predetermined fixed prices are major assumptions that appear to be inconsistent with expectations of reality. Similarly, the essentially exogenous specification of demand limits the possible range of applications. Further model development in these areas seems justified. The relaxation algorithm currently used is not soundly based; the groundwork for using a more complete Newton scheme (still time-independent, but including off-diagonal elements) should be tested (see Sect. VI).

- The data specification errors discussed in Sect. $X$ for the ARC-78 version of the data base should not be retained in future LEAP versions.

The ARC-78 long-term modeling results represented a good first effort at using the LEAP economic modeling system. That system has good potential for helping the EIA meet statutory mandates for longterm energy-related projections. However, numerous developments are required to achieve the capability to obtain projections to the future of our present understanding of factual energy data and the political and economic interactions that modulate the texture of energy demand and the realities of its supply. We could not determine that generalized equilibrinm modeling systems 1ike LEAP are the most appropriate modeling tools for these èfforts, but LEAP was 
XI-12

a reasonable choice if one includes the inherent flexibility toward improvement. 


\section{PAGES $\mathrm{i}$ to $\mathrm{ii}$ WERE INTENTIONALLY LEFT BLANK}




\section{ACAVALDOGDIRTS}

We thank A. Loeb1, R. She1ton, and T. Wilbanks of the ORNL Energy Division and F. C. Maienschien of the Engineering Physics Division for their encouragement and successful efforts to make available personnel and other resonrces necessary to complete this project. We acknowledge the contributors shown on the title page for their many ideas, not all of which may be published elsewhere, and for their painstaking reviews of earlier drafts. The underlying study would have been very difficult without the many hours of careful explanations of difficult points by Mary Hutzler and Sam Cohen and other members of the staff of EIA's Long Term Energy Analysis Division. We are indebted to Science Applications, Inc., Oak Ridge, for editing and typescript production, and to many supporting staff members at ORNL and SAI for their aid in the research and the report production. Reviewers of the initial draft had a strong influence on portions of the present report: G. Widhelm, $R$. $J$. Opsut, D. Y. Choi, P. Werbos, and particularly D. R. Hale of the Bnergy Information Administration, DOE; C. J. Anderson and R. B. Be11 of Lawerence Livermore National Laboratory; and F. C. Maienschein, A. Loeb1, and T. J. Wilbanks of Oak Ridge National Laboratory. Each review led to modifications of the draft, even though some reviewers indicated positions on model evaluation and its reporting that are significantly different from those of the authors. The authors accept responsibility for inadequacies that remain after so many have given assistance. 


\section{PAGES iv to $\mathrm{V}$ WERE INTENTIONALLY LEFT BLANK}


The Following Pages are the

Reproduced Comments of

Jimmie L. Peterson, EIA 
001301

(7.)

oate 82P 8 in
U.S. DEPARTMENT OF ENERGY memorandum

Mepry io EI-422 (Data Analysis and Forecasting Branch)

warci Reviev of ORuL Draft Final Report on the LEAP Model

To Yvonne M. Bishop

Actina Director

stat listeal standards

This report presents a well balanced summary of the nearly threc Years worl: that Oak Ridoge National Laboratory (ORNi) did for the office of Eneray Information Validation (OEIV). to validate the LEAP model Ing system.

In summary, there is very little wrong whth the report. On the whole. the authorg arc to be commended: My comments on the recommendations at the end suggege several changes to the execueive cummary, but the principle comments in this review address the scope and emphasis in the study and the reports" reconmondations.

Commente on the scope

The scope of the report is not what would be expected alnce it doas not cover the essential components of the LEAP model uniformly. The ARC-78 version of LEAP contains $a i x$ major clements as tollows:

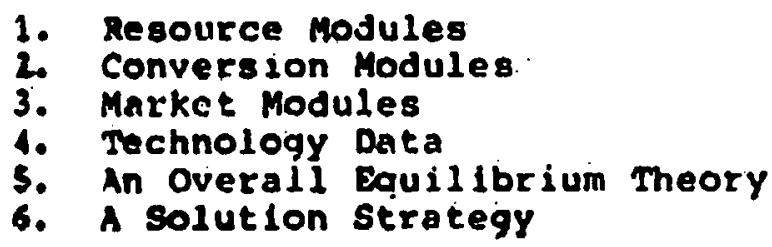

The original requese to OEIV was to validate lten 4. the technology data in the form of a Brookhaven. Natlonal Laboratory (BNi) stucy referenced in the report. Tha emphasis of the study was in fact on:

$\therefore$ Conversion Modules

b. S Solution Strategy 
In addition the study introduced neil subjects:

7. An adjolnt sensitivity analysis

8. The "usablility" of the modsi

9. The "environmene" of the model.

The ncw subjects unfortunately do not compensate for the lack of tetall on ltems $1,3,4$, and 5 . LEAP in many respeces. ropresents very different approacn to energy modeling and iraditionalistg raised many queselons both general and specific.

the stuity does not answer the following questlons directly re levant to the ARC-78 results.

1. Is the economic and enginccring basis for the pacroleur 3esource Modules theoretically sound?

2. Is the Marliet Modulc a correct chnracterization of market smpor fections and uncertainty?

3. Did the Technology Data represent any cnaracterization of realitey In T978t

4. Is there an overall market equil lbrium problem that ARC-78 solved by its strategy of decomposition. 1.e: . what docs an ARC-78 solution redresent?

These arc non-triviel problems. whose answers would be extremcly useful to future ennrgy modeling efforts and which were the focus of many unresolvad discussions within the office of Applied Anolysis.

The Emphrsis and Direction of the Actual study

mis section commonts on the study results in each of 1 ts areas.

The Conversion. Modules. The theoretical analysis of the conversion moriule stands out as being the most useful plece of analysis. In the study.

The analysiä indlcated important of the conseant returns to scale model, and its components such as the copacity. tactor equation and the lach of capitel-labor energy-material (RLEM) subatitution.

Howsver, the analysis liads to an execueive reconmendintion (that KLEM substitution be added), that is not only cursous but also indicates tre lack of understanding by the anilysts of how the conversion module is uscd in the ARC-7a moris. 
The recommendation is curious because:

- There is vary little data evcn at the national level to support KLEY analyses even for hiahly aggregacc models sucn as Jorgensons 9DGEH. Whereas ths ARC-78 would need at least technology specific national level data that does not exist. .

- Capital energy sudstitution is modelled in ARC-78 by letting many capital intensive technologies compete to satisfy an eneray demand.

In tocusing on the micro-level detalls, the analysts over looked the macro-ievel and for example did not anslyse whether the market allocation formula was appropriace to permit the capitalenergy substitution in those accrors for which data does exist.

The recommendation to include. RLEM in all conversion modules is certainly innovarive. No othor energy model in the U.S. does so at this level of detail and those that include it utilize the theory oxclusively in modeling aggregare energy demends in a sector.

The Solution strateqy. Here the analysts miene many useful coneribuelons, noe all of which were reporied in the summary volume.

The Adfoint Sensitivity analvsis. As the major consunct of scucy resources. che var zous sens 2 tivity analyses were the siggest disappointment of the study.

- The results that standout are unfortunately obvious. a. . rexinery gain and elcctrical loss factor are key ingle numbers to which the model is sensitive. Sowever. It is difficult to see how these data change :clative results.

- ' 'The results' that did not staodout. were prodably more imporiant. The market share analyses introduced koy uncertain paramerers ro which thc resuits are nor sensitivel This is a major resuit.

- The study team. in recommenoing further study. cloarly couid not make anything significant of the resuits and inis is the disappointment.

Prom discussions with the study tears 12 can be deducsd that a tremendous effort was put into the adjoint method: It woulo be useful to know at some stacie:

) How it was implenrnted?

3 Can the adjoint cquations of related to tha regular cquarzons oi the model?

- Is the method usable on other eneray moxicls? 
The final repore 28 silent on these issucs that probably caused the loss of other pieces of analysis.

The "Usab1l1ty" of the Mode1. This saction 1s conmentary in vacuum and displays the lack of experdenco of the revicwers of eneray modeling practice. Large energy models are large and difficuit to use, perioci. LEAP and ARC-78 were no exception. It would be nice if this were not true.

In the $1980^{\prime} \mathrm{s}$ all useful computer software is proprietary. The LEAP data base uses sỵstem 2000, a standard uata base packaje comnonly used for payroll systems. The only alternarives actively analyzed were aiso proprietary.

A core storage requirement of 2 meqabytes 13 not excessive. A version using less than 1 megabyte was snelved for lack of resources to complete it.

The "Environment" of the Mode1. Here the analysts completery talled to appreciate that the ARC-78 work was anc is done in - coniributory environment, to a puolication schedule.

Many comments and recommenciations polnt to this lack. of understanding:

- The scope or the ARC-78 mociel was defined in 2-4 months not 3 years.

- "Calibration to mid-term" results are a consequence of the organization.

- Oll import assumpeions are pursucd in a separace International Analysis.

o Demand assumptions are gpscified by separace sonsumpeion analysis.

ote.

Connentary in this area needs to address thess organizarional guestions to be usetul.

Corments on the Recommendations

The rccommendations in the oxscurlye suminary are ronatsably wali balencet, and with few exceptions difficult to tiro issue with.

1 soncur with the reconimendation for:

a. Less irequent long̣-torm analysirs.

j. Etandardized energy technology data.

i. improved error ansiysis.

3. Improved srpaciey vintaging. 
1 do not understand recommendations (1) on data specification errors. It needs to be specific or deleted.

Jnder recommendation $(C)$ most if not all of EIA's models. including LEAP, have an open code. However, the concept of individuals in the general public scurrying away whth a copy 18. and will always remain absurd. Only large organizations have the resources to undertake this work. Access is adequately maintalned for an organization. but resources will never or avaliable to provide individual access. Thus. I recommend deletion.

I do not understand $(e)$ and I recominend deletlon: ARC-78 never confused mid-term forecasts and $1 t$ is a fact of life that $E I A$ will not willingly put out two torecases ot the same 1 tem soneurrently. Thus mid-term and lonq-term have to be consistent. Starting from 1995 is hot a solution either. There is no 1995 forecast until ARC-78 forecasts are scheduled to be complete.

Pinally recoimmendation (f) suggese ing replacing sone sectors by natzonal aggregnce production tunctions taken for example from SDCEM work. This appears to be a sensible ldea. clearly it wuld not work at a fincr level of detall. It is this latter suggestion that is being made by the body of the repore. inis needs to be made clear.

In conclusion the report 18 good and over the yeats 1 t has been evident that much of the qoodrinss has been derived from the careful redirection of thin wort. by Doug Hale and his staff.

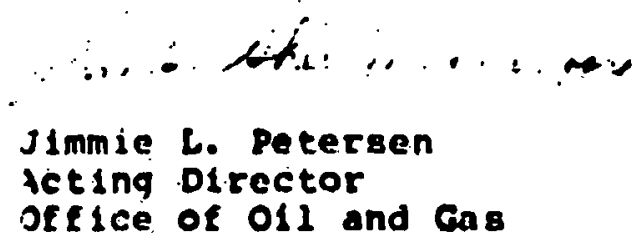




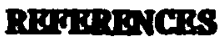

Ad178 R. Adler et a1, The DFI Energy-Economy Modeling System, Decision Focns, Inc., Palo Alto, California (1978). (Ear1y version of Ad179.)

Ad179 R. Adlex, E. Cazalet, S. Haas, R. Marshal1a, D. Nesbitt, and R. Phillips, The DFI Generalized Equilibrinm Modeling System, Decision Focus Inc., Palo Alto, California (1979).

Als80 R. Alsmiller, Jr., J. Barish, D. Bjornstad, D. Downing, W. Ford, J. Horwede1, C. Lee, J. McAdoo, E. Oblow; R. Peelle, F. Perey, L. Stewart, and C. Weisbin, Interim Report on Mode1 Evaluation Methodology and the Evaluation of LEAP, Oak Ridge National Laboratory Report ORNL/TM-7245 (1980).

Als81 R. Al smiller, Jr., J. Barish, J. D. Drischler, J. E. Horwode 1, J. L. Lucius, and J. W. McAdoo, Adjoint Sensitivity Theory and Its Application to LEAP Mode1 22C, ORNL/TM-7789 (1981).

Bar81 J. Barhen, J. Lucris, R. Alsmiller, C. Woisbin, Oak Ridge Energy Modeling System: 1. The Allocation Process, ORNL/TM-7707 (1981).

Bha79 N. Bhagat et a1., Evaluation of Technical Data in the DFI and PIES Mode1s, Brookhaven National Laboratory Report, BNL 50949 and DOE/EIA/00162 (1979).

Bro77 H. Brock and D. Nesbitt, Large Scale Energy Planning Mode1s: A Methodological Analysis, Stanford Research.Institute, Men1o Park, California (1977).

Cac80 D. Cacuci ot a1.. "Generalized Sensitivity Theory for Systems of Coupled Nonlinear Equations," Nuc1. Sci. Eng, 75:88 (1980).

Caz76 E. Cazalet et a1. A Western Regiona1 Energy Development Study, Vo1, 1: Economics; and Vo1, 2: SRI Modol Data Base. prepared by Stanford Research Institute for the Conncil on Environmental Quality (1976).

Caz77 B. Cazalet, Generalized Equilibrium Modeling: The Methodology of the SRI-GULF Mode1, Decision Focus, Inc., Palo Alto, California, and Stanford Research Institute; Menlo Park, California (1977).

Caz78 E. Cazalet et al., The DFI Computer Modeling Software (CMS), 
Decision Focus, Inc., Palo Alto, California (1978). See $\mathrm{Caz} 79 \mathrm{~b}$ for a later version.

Caz79a E. Cazalet, "The 1975 Synthetic Fuels Program Analysis: Interfaces Between Analysts and the Decision Process," in Proceedings of Energy Hode1ing II: The Interface Betreen Model Builder and Decision Maker, Angust 13-17, 1979, Colorado Springs, Colorado. Institute of Gas Technology, Chicago, Illinois.

Caz79b E. Caza1et, L. Deziel, Jr., S. Haas, T. Martin, D. Nesbitt, and R. Philitips, The DFI Computer Modeling Software (CMS), Decision Focus, Inc.. Palo Alto, California (1979).

Che80 E. A. Cherniavsky and L. L. Juang; Resource Submodels of the Long-Term Energy Analysis Package: Documentation, Energy Information Administration, draft (1980).

Coh79 S. Cohen and J. Pearson, The LEAP-EMS Users Manna1, Department of Energy (draft, release V2-10/22/79, to be pub1ished).

Coh81 S. Cohen and J. Pearson, The LEAP-BMS Users Mannal, Department of Energy (draft) (1981).

Cor79 Colleen Cornett, Energy Information Administration, private communication (1979).

Die79 R. Diedrich, C. Cornett, and J. Pearson, LEAP Network and Data Documentation-ARC78, Energy Information Administration, draft report (1979).

DOE79 R. Coates, D. Hanson, S. Juenger, and J. Kennington, Surver of the Research into Energy-Economy Interactions, Vol, I, P1anco, Inc.., HCP/I6346-01/1 (1979).

Duf77 J. Duff, MA-28, A set of Fortran Subrontines for Sparse Unsymmetrica1 Linear Equations, A.R.R.R. Report R.8730, HMSO, London (1977)

EIA79a Energy Information Administration, Annual Report to Congress, 1978, Vol. 3, Eorecasts, particulariy Chapter 5 and Appendix, DOE/EIA-0173/3 (1979).

EIA79b Energy Information Administration, Annual Roport to Congress, 1978, Vo1. 2, DOE/EIA-0173/2 (1979).

EIA80 Energy Information Administration, Annagl Report to Congress, 1979, Vo1. 2, DOE/EIA-0173(79)/2 (1980). 
ERF77 Energy Modeling Forum, Energy and the Economy, Vols. I and II, Stanford, California: Institute for Energy Studies, Stanford University (1977).

EPR79 E1ectric Power Research Institute, Review of Large-Scale Enexgy Mode1s, EPRI, EA-968, RP 333-1 (1979).

Fa179 J. Fa1k, G. McCormick, and R. So1and, Research into the Methodology of the LEAP Mode1, 'Prepared by George Washington University, Institute for Management Science and Engineering, Washington, D.C., for the Department of Energy, DOE/EIA-451887 (1979).

For81 W. E. Ford, III, J. Horwede1, J. HcAdoo, and R. G. Alsmiller, Jr., Operating Experience with LEAP from the Perspective of the Computing Applications Specialist, Oak Ridge National Laboratory Report, ORNL/CSD/TM-141 (1981).

GA079 U.S. General Accounting office, Guidelines for Mode1 Eva1uation, PAD-79-71, Washington; D.C. (1979).

Go181a M. Goldstein, R. G. Alsmiller, Jr., and J. Barish, Specification of the Equations for LEAP Mode1 22C, Oak Ridge. Nationa-1 Laboratory Report ORNL-5707 (1981).

Go181b M. Goldstein, LEAP Mode1 22C Resu1ts Versus EIA 1979 Report. Oak Ridge National Laboratory Report, ORNL/TM-7739 (1981).

Ha179. D. Hale, private communication to C. R. Weisbin on model evaluation needs, DOE Energy Information Administration (1979):

Ha180 D. Ha1e, The Long Term Energy Ana1ysis Package (LEAP): A Case Study in Model Evaluation. Prepared for the American Statistical Association Ad Hoc Committee on Energy Statistics (1980)."

Han81 J. Ḣansen, M. Becker, and J. Trimble, The Economic Fonndations of LEAP Mode1 22C, Oak Ridge Nationa1 Laboratory Report ORNL-5748 (1981).

Hut80 M. Hutzier, private communication to J. Finucane (EIA), Energy Information Administration, Department of Energy (1980).

Byd79 A. S. Kydes and J. D. Pearson, A Comparative Assessment of Five Long-Run Energy Projections, U. S. Department of Energy Report DOE/EIA/CR-0016-02 (1979). 
Lad78 G. Lady, Interim Mode1 Documentation Standards, Office of Analysis Oversight and Access, U.S. Department of Energy (1978).

Man77 A. Manne, Eta-Macro: A Mode1 of Energy Economy Interaction, EPRI-EA-592 (1977).

Mi178 B. Miller et al., Geological Estimates of Undiscovered Recoverable Oil and Gas Resources in the United States, U.S. Geological Survey Circular 725, fourth printing (1978).

Nai77 R. Nai11, Managing the Energy Transition, Cambridge, Massachusetts, Ballinger (1977). See also A. Kydes et al.. A Comparative Assessment of Five Long-Rnn Energy Projections. DOE/EIA/CR 0016-02, Section 2 (1979).

Nai79 R. Nai11, W. Veno, P. Budzik, and C. Brooks, private communication, Office of Analytical Services, Policy and Evaluation, Department of Energy (1979).

Nor79: $\dot{ }$. Nordhaus, The Efficient Use of Energy Resources, Cowles Foundation Monograph 26, New Haven, Connecticut: Yale University Press (1979).

NYT80 Topics, "No Parole," New York Times, December 3, 1980 (1980).

Ob180 E. Oblow, C. Heisbin, and R. Alsmiller, Jr., "Sensitivity Analysis for Energy-Economy Modelling," p. 425 in Energy Modeling II: The Interface Between Model Builder and Decision Maker, Institute of Gas Technology, Chicago, Illinois (1980).

Ob181 E. Ob1ow, Mathematical Foundations of LEAP, Oak Ridge Nationa 1 Laboratory Report ORNL/TM-5754 (1981).

OEI80 Office of Energy Information Validation. Analysis Quality Report: LEAP Mothodo1ogy. draft report (1980). To be pub1ished as DOE report number EIA/DOE-OA/WP/81-01.

PAR79 Professiona1 Andit Review Team, Activities of the Energy Information Administration, U.S. Government Accounting Office, Washingt on, D.C. (1979).

Pea79 J. Pearsun, RIA Office of Applied Analysis, private communication, EI-642 (L-TEAD) (1979). See also EIA79a, footrule 4 on $p .102$ and p. 411 . 
R. Pee1le, "The Quantification of Uncertainties in the Parameters of a Long Term Energy Mode 1," p. .437 in Energy Modeling II: The Interface Between Builder and Decision Maker, Institute of Gas Technology, Chicago, I11inois (1980).

Pow79 J. Powers, R. Gilbert, and C. Mande1baum, private communication, Energy Technology, Department of Energy (1979).

Ram78 J. Rambo and B. Coles, User's Manual for the Livermore Economic Modeling System, Lawrence Livermore Laboratory, UCRL-52526 (1978).

Rou78 W. Roussseau et al., Computer Code Documentation for the Livermore Economic Modeling System, Lawrence Livermore Laboratory, UCRL-52519 (1978).

T. Rousseau et al, Economic Models and Algorithms Used in the Livermore Economic Mode1ing System, Lawrence Livermore Laboratory, UCRL-52527 (1978).

S. Sussman and W. Rousseau, A New Language for Economic Genera1 Equilibrium Mode1s, Lawrence Livermore Laboratory, UCRL-52507 (1978).

S. Sussman and T. Rousseau, A Demonstration of the Capabilities of the Livermore Energy Policy Mode1, Lawrence Livermore Laboratory, UCRL-52508 (1978).

SRI77 SRI International, Fue1 and Energy Price Forecasts. Yol. 1. Quantities and Long Term Marginal Prices, prepared by Electric Power Research Institute for the Conncil on Environmental Quality (1977).

Ste81 L. Stewart and M. Goldstein, Input Parameters for LEAP and Analysis of the Mode1 22C Data Base, Oak Ridge National Laboratory Report; ORNL-5746 (1981).

Tec79 K. Tech, Output and Specific Input of Data Contained in the Long-Range Energy Analysis Package, unpublished Oak Ridge Nationa1 Laboratory GLCA/ACM Science Semester memorandum (1979).

USC77 United States Congress, Department of Energy Organization Act, PL 95-91, as amended from Fodera1 Energy Administration Act of 1974, PL 93-275 (1977).

Wei80 C. Weisbin and R. Alsmiller, Jr., "Highlights of the ORNL Model Evaluation Methodology and the Evaluation of LEAP," in Energy Modeling III: Dealing With Energy Uncertainty, Chicago, Illinois (1980). 
Wei81 C. Weisbin, R. Pee11e, and A. Loeb1, An Approach to Evaluating Energy-Economic Mode1s, Oak Ridge National Laboratory Report ORNL/TM-5742 (1981).

Wer81 P. Werbos, Energy Information Administration, private communication via D. R. Hale (1981). 


\section{APFUDIX A}

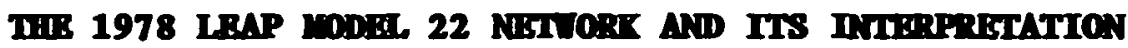

Section II of this report gave an overview of the 1978 LEAP model and included Fig. II-1, a diagram showing the interconnections among the sectors of the energy economy that are recognized in this model. The purpose of this appendix is to give additional details that may be required about the model for study of this final ovaluation report.

Figures A-1 through A-9 are the detailed Mode1 22 network diagrams, edited from those supplied to us by Colleen Cornett of the Office of Applied Analysis (Cor79) and subsequently cheoked against the input linkage tables of the "frozen" model version supplied to our group at ORNL (For81). (The figure number is in each case the same as the sector number, except that Sector 10 is shown on the same figure with Sector 5.) Each major circle, box, or other geometric figure on these diagrams represents a particular generic economic activity modeled using one of the process model subroutine packages listed in Table A.1. Each activity has an Activity Number in italics at the bottom of its box. Sector and Activity numbers together provide a unique identification for each activity in Model 22. Some (text) activity labels in the figures have been modified, on the basis of the draft network documentation. (Die79), to better correspond to the portion of the economy included; these labels are marked with an asterisk, and the figure caption cites the activily title that is given in the Model Input Tables (MITs). The numbered "tabs" at the periphery of the detailed figures indicate the links to other sectors; the numerical values are helpful only when studying the MITs.

Some of the allocation activity symbols (circles) in the figures include small triangles adjaoent to the links. These represent price increments that operate on the system variables before or after the operation of the usual allocation equations. The allocation variant for the electric utility sector includes treatment of the threo 
TABU A.1

Use of IRAP Subrontines in Model 22C

\begin{tabular}{|c|c|c|c|c|c|c|c|c|c|c|c|c|c|}
\hline $\begin{array}{l}\text { Subrou } \\
\text { Peckege }\end{array}$ & Nemo & UN & Tit1e & 1 & 2 & 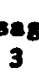 & 4 & 58 & 6. & $\frac{0 x}{7}$ & 8 & 9 & 10 \\
\hline \multirow[t]{6}{*}{ ALCNHO } & & 1 & Allocation of demand & 3 & 5 & $\mathbf{0}$ & $\mathbf{0}$ & $\mathbf{0}$ & 1 & 1 & 2 & 3 & $\mathbf{0}$ \\
\hline & & 4 & $\begin{array}{l}\text { Allocation of demand } \\
\text { for electricity }\end{array}$ & $\mathbf{0}$ & $\mathbf{0}$ & $\mathbf{0}$ & 1 & $\mathbf{0}$ & 0 & $\mathbf{0}$ & $\mathbf{0}$ & $\mathbf{0}$ & $\mathbf{0}$ \\
\hline & & 7 & $\begin{array}{l}\text { Allocation of demand } \\
\text { with price ipcre- } \\
\text { ments before }\end{array}$ & $\mathbf{0}$ & 1 & 0 & $\mathbf{0}$ & $\mathbf{0}$ & 3 & 3 & $\mathbf{0}$ & $\mathbf{0}$ & $\mathbf{0}$ \\
\hline & & 8 & $\begin{array}{l}\text { Allocation of demand } \\
\text { with price incre- } \\
\text { ments after }\end{array}$ & $\mathbf{0}$ & 0 & $\mathbf{0}$ & $\mathbf{0}$ & $\mathbf{0}$ & $\mathbf{0}$ & 1 & $\mathbf{0}$ & $\mathbf{0}$ & $\mathbf{0}$ \\
\hline & & $\begin{array}{c}1,7 \\
8\end{array}$ & $\begin{array}{l}\text { Common supplyd } \\
\text { Common supply with }\end{array}$ & $\begin{array}{l}2 \\
0\end{array}$ & $\begin{array}{l}5 \\
0\end{array}$ & $\begin{array}{l}0 \\
5\end{array}$ & $\begin{array}{l}4 \\
0\end{array}$ & $\begin{array}{l}\mathbf{0} \\
\mathbf{0}\end{array}$ & $\begin{array}{l}5 \\
0\end{array}$ & $\begin{array}{l}0 \\
0\end{array}$ & $\begin{array}{l}1 \\
0\end{array}$ & $\begin{array}{l}2 \\
0\end{array}$ & $\begin{array}{l}\mathbf{0} \\
\mathbf{0}\end{array}$ \\
\hline & & & $\begin{array}{l}\text { price increment } \\
\text { after }\end{array}$ & & & & & & & & & & \\
\hline ALDUPR & & 5 & Load duration process & $\mathbf{0}$ & $\mathbf{0}$ & $\mathbf{0}$ & 1 & $\mathbf{0}$ & $\mathbf{0}$ & 0 & $\mathbf{0}$ & $\mathbf{0}$ & $\mathbf{0}$ \\
\hline \multirow{2}{*}{\multicolumn{2}{|c|}{ CNHOLP }} & 9 & $\begin{array}{l}\text { Homogeneous flat-load } \\
\text { conversion (basic } \\
\text { conversion) }\end{array}$ & 9 & 13 & $\mathbf{0}$ & $\mathbf{0}$ & $\mathbf{0}$ & 8 & 1 & $\mathbf{5}$ & 11 & $\mathbf{0}$ \\
\hline & & 11 & conversion & 0 & $\mathbf{0}$ & 0 & 14 & $\mathbf{0}$ & 0 & $\mathbf{0}$ & $\mathbf{0}$ & 0 & $\mathbf{0}$ \\
\hline DUMMY & - & 17 & (No computation ${ }^{f}$ ) & 0 & 0 & $\mathbf{0}$ & 1 & 0 & $\mathbf{0}$ & 0 & $\mathbf{0}$ & $\mathbf{0}$ & 1 \\
\hline \multicolumn{2}{|l|}{ RESORC } & 20 & Resource process & 0 & $\mathbf{0}$ & 0 & $\mathbf{0}$ & $\mathbf{0}$ & $\mathbf{0}$ & 6 & $\mathbf{0}$ & $\mathbf{0}$ & $\mathbf{0}$ \\
\hline \multicolumn{2}{|l|}{$\mathrm{CESORC}^{\mathrm{B}}$} & 22 & Coal resource process & 0 & $\mathbf{0}$ & $\mathbf{0}$ & 1 & 1 & 6 & 1 & 0 & $\mathbf{0}$ & $\mathbf{0}$ \\
\hline \multicolumn{2}{|l|}{ TRNSPT } & 38,39 & Transportation & 0 & $\mathbf{0}$ & 2 & $\mathbf{0}$ & 1 & 4 & 6 & $\mathbf{0}$ & $\mathbf{0}$ & $\mathbf{0}$ \\
\hline \multicolumn{2}{|l|}{ IMPORT } & 40 & $0 i 1 / g a s$ import & 0 & $\mathbf{0}$ & $\mathbf{0}$ & $\mathbf{0}$ & $\mathbf{0}$ & $\mathbf{0}$ & 0 & 0 & $\mathbf{0}$ & 1 \\
\hline \multicolumn{2}{|l|}{ DEMAND } & 42 & End-use demand ${ }^{h}$ & 1 & 1 & 0 & $\mathbf{0}$ & $\mathbf{0}$ & 0 & 0 & 1 & 1 & $\mathbf{0}$ \\
\hline
\end{tabular}

${ }^{a}$ Numerical values Indicate the number of activities, by sector, that are modeled with the indicated subroutine and logical kind number. Sector numbers correspond to numbers in Fig. II- 1 .

${ }^{\text {For } L K N=7,}$ price increments are added to link prices from the alternative. sources of energy flow before the demand is allocated among these sonrces as for $L K N=1$ and before the weighted average price is calculated.

CFor LKN=8, price increments axe added to 1 ink prices for the various energy flow destinations without affecting the allocation of demand or the prior calculation of a weighted average price.

d

Allocation with only one source of energy flow. Rnergy demands are added to form an aggregate demand; all prices are the same.

ésyngas penetration actually has zero transportation increments.

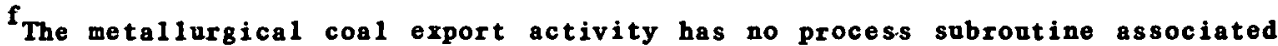
with it: therefore, initial estimates of quantity cannot be altered by the model during iteration toward a solution. Hydroelectricity production is also handled with a "dumb" process; the allocation of electricity demand treats this input as a special case.

$\varepsilon_{\text {Modified version of RESORC. }}$

hhe end-use demand process includes a separate demand function for each 1ink; thus, there are actually 19 such independent demand functions. 
sublinks for the load categories and a special treatment of the 1 ink having the highest index. This treatment forces the quantities on that link to retain their original values for all time points as iteration proceeds.

As indicated in Sect. II, each 1ine ("1ink") interconnecting two activity "nodes" represents an energy flow "up" the network diagram toward final energy demand activities and the associated credit flow "down" the network toward resource activities. The link identification numbers shown are important in locating model output values in the computer listings. The annual energy-related quantity flow and the associated price per unit of that commodity are stored by the model for each time point as endogenous variables that are refined as the model seeks to obtain a solution for the variables that are consistent with the equations contained in the process models for each economic activity. As the iteration process proceeds, the computer program progresses from one activity node to the next, first "up" the overall network of Fig. II-1 toward end-use demand to compute prices and then "down" toward resource and import activities to compute energy quantities. At each node, the solution is updated for all time points starting at the more distant times (year 2020) for prices and ith the initial year for quantities. See Sect. VI for a description of the relaxation tochniques psed daring the iteration process.

The network diagrams, Figs. A-1 through A-9; contain the information codes (from MIT 7) that precisely define the mode1 "equations (subroutines) and the data elements from the MITs that are to be used in these equations in Model 22C. (Network 22, parameter set C.) Each activity label in the figures shows in parentheses (LKN, GP, SP) the logical kind number (LKN), generic process (GP) type, and specific process (SP) type, as defined in the data input Activity 
Pointer Table (MIT 7). Functions of these keys are indicated in the next paragraphs.

The MITs associate an LKN with each activity in the model, and a master subroutine (SOLVE) associates each of these LKNs with a subroutine package. Sometimes several different LKNs lead to the same subroutine package, but define different flows of computer control through that package. Table A.1 tabulates the number of activities in the various sectors that use the different subroutine packages in Mode1 22C. As indicated above, the subrontines 1 isted in Table A.1 are in most cases subroutine packages; the calling hierarchy in each case is detailed by Ford et al. (For81). Table A.1, in its footnotes, also attempts to clarify the various types of "allocation" processes that are used in Mode1 22C.

Generic and specific process indexes given on the flowcharts precisely identify many of the input parameters required by the process subroutines for particular generic activities. For example, time-independent-parameter sets that are held fixed for whole classes of activities are given different $G P$ indexes and are tabulated in MIT 11, whereas the parameter sets that are rather unique to one or a few activities are identified by (GP, SP) pairs and are tabulated in the more extensive MIT 12 .

The form of the detailed network, as well as the submodels and data sets, strongly affects the realism and usability of any LEAP mode1: 
ORNL - DWG 80.7671

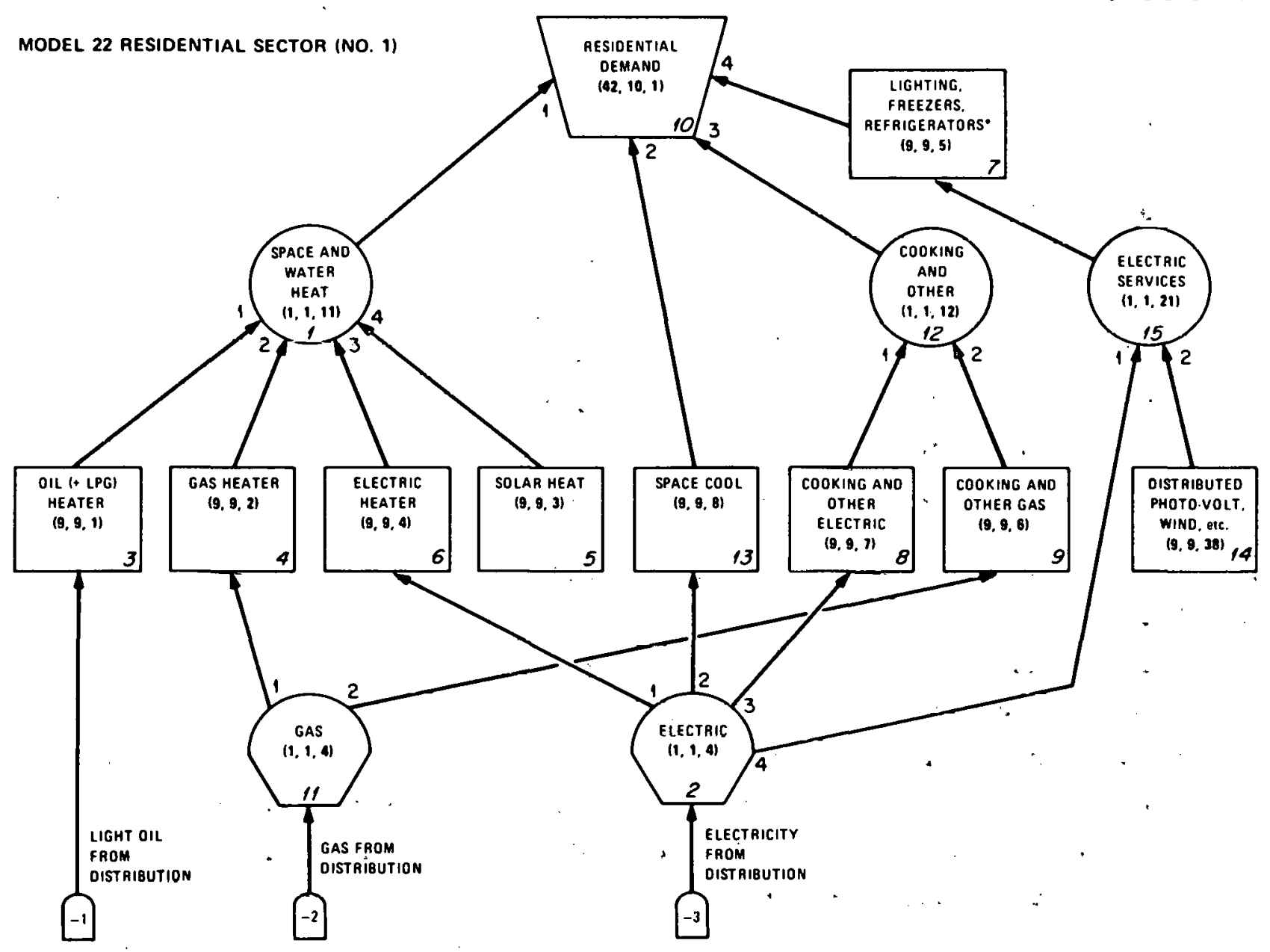

Figure A-1. Network diagram for the residential sector of the 1978 LEAP Model 22. "The numbered boxes represent aggregate national energy-related economic activities, and the lines represent the links between them along which the model estimates energy commodity and payment flows for the time points 1975 through 2020. The 1 inks are numbered in accordance with model input and output tables. The circles represont the process of allocation of demand among two or more competing suppliers. The intersectoral links can be traced in Figure II-1.

*Activity 7 is labeled "Lighting and E1ectrical Appliances" in the model input tables. 
MODEL 22 INDUSTAIAL SECTOR (NO. 2)

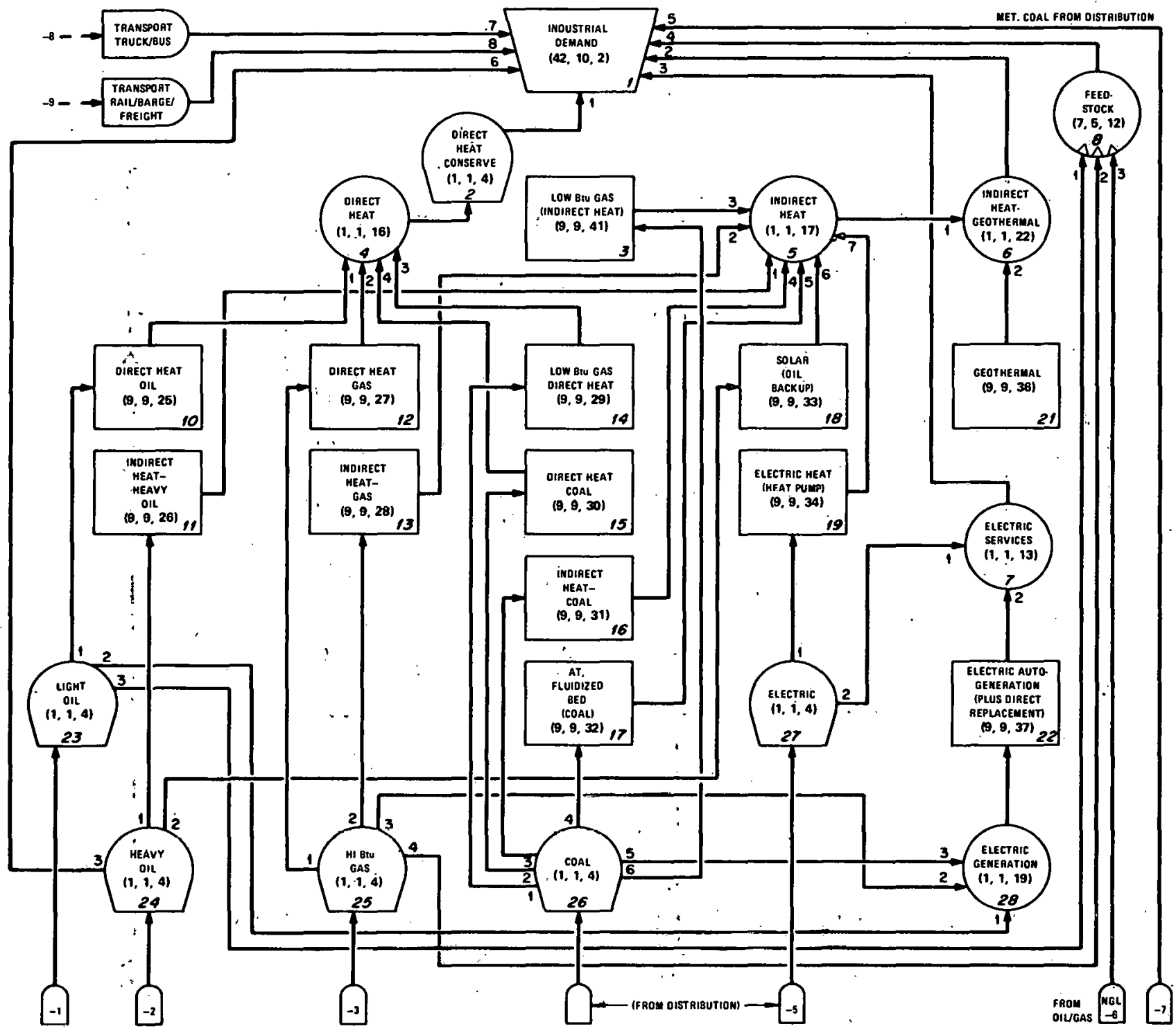

Figure A-2. Network diagram for the indastrial sector of LEAP Mode1. 22 ('see caption of Figure A-1 for basic symbology).

$\therefore$ Node (activity) 22 represents facilities in the industrial sector to generate electricity at industrial

- sites or to replace use of utility electricity. 


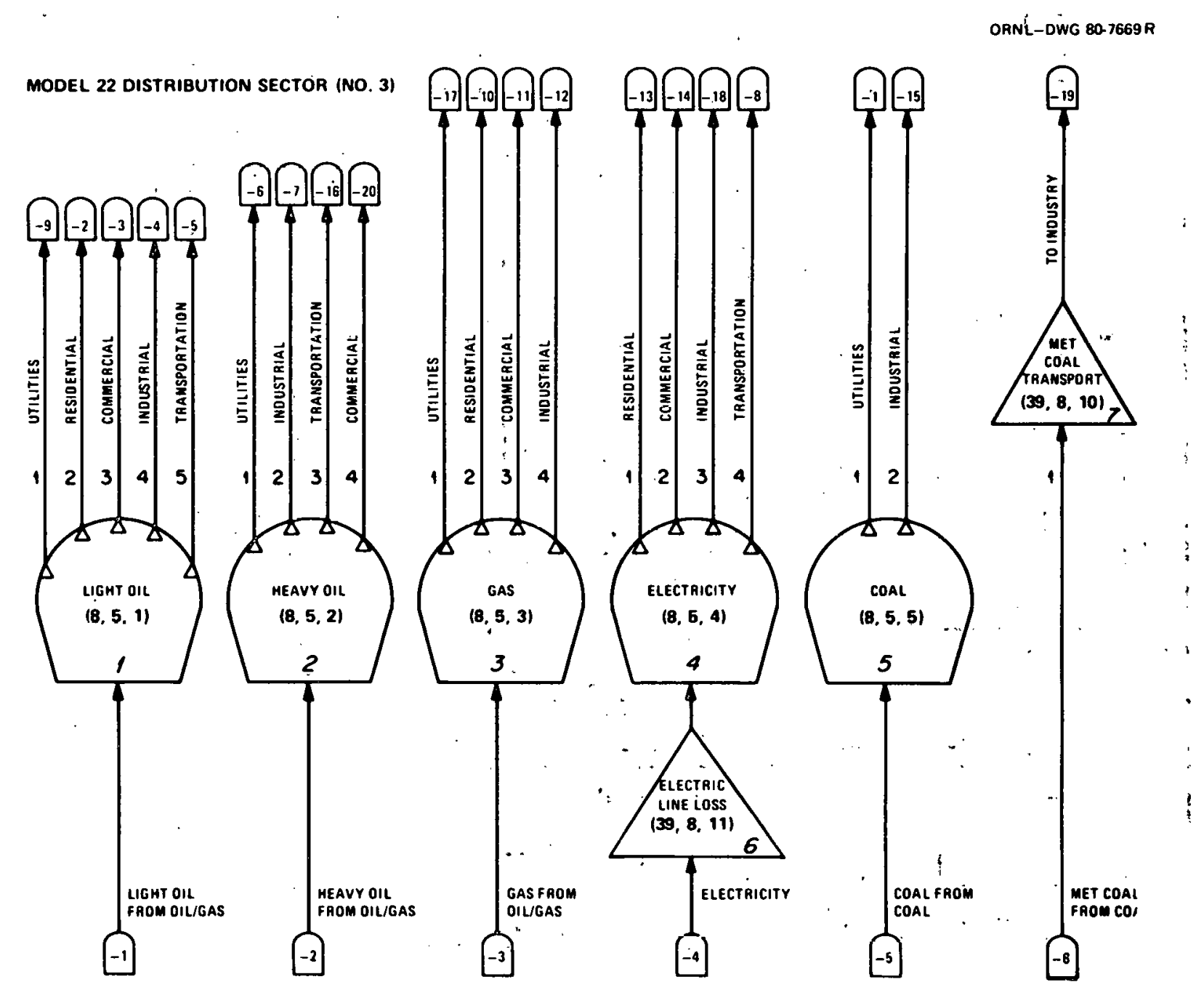

Figure A-3. Network diagram for the distribution, sector of LEAP Hodel 22 (see caption of Figure A-1 for basic symbolugy). The large figures with semicircular tops represent aggregation of demand from different sectors for each. major fuel. The small triangles represent differential price increments to compensate price differences caused, for example, by different distribution costs. 


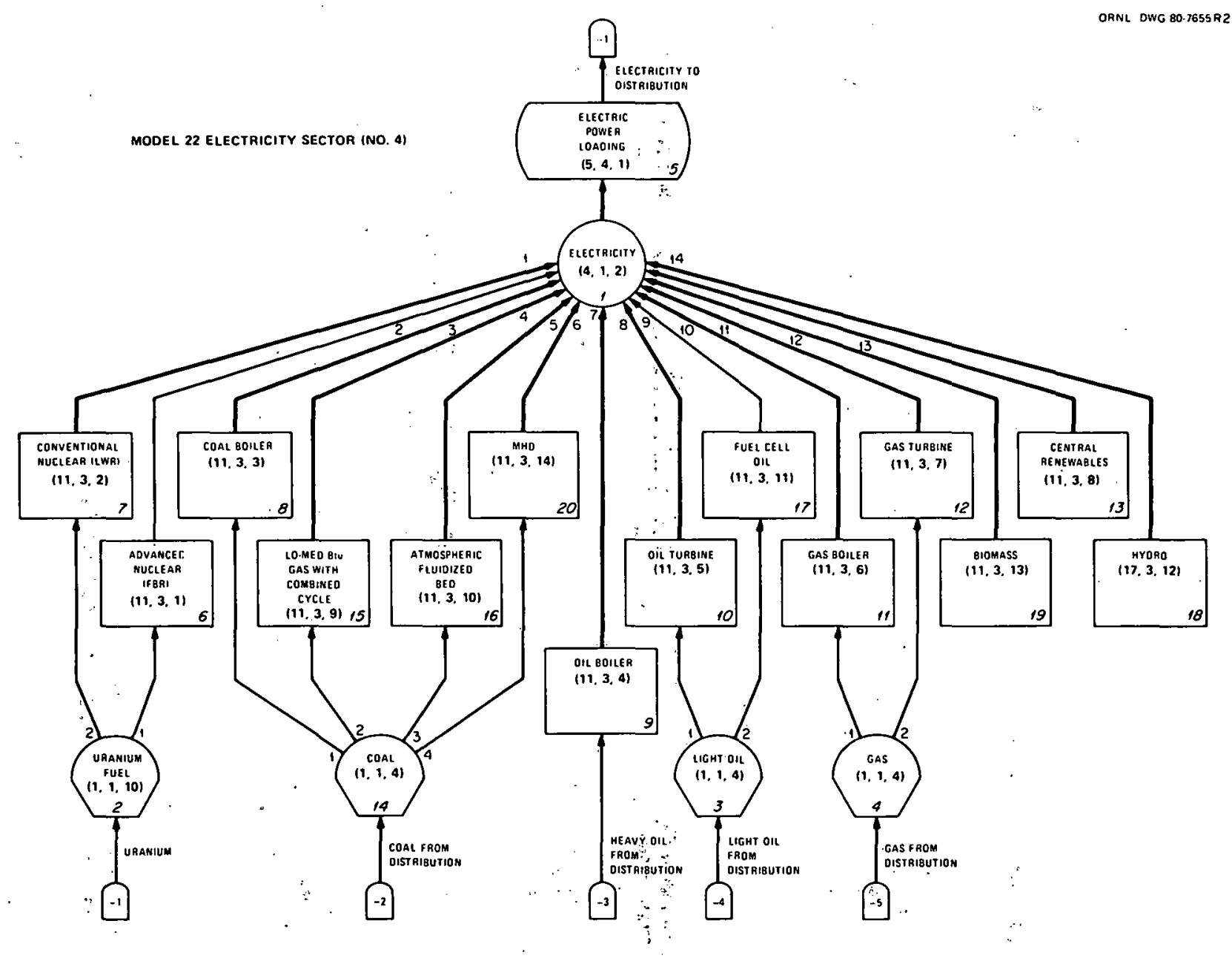

Figure A-4. Network diagram for the electricity sector of LEAP Mode1 22 (see caption of Figure A-1 for basic symbology). In Figure II-1, this sector is called the Utilities sector. Electric generation by central utilities is represented by three load categories; thus, most lines connecting generating activities to the electricity demand allocation node represent three "sublinks" for base, intermediate, and peak loads. 
ORNL-DWG 80-7677

MODEL 22 NUCLEAR SECTOR (NO. 5)

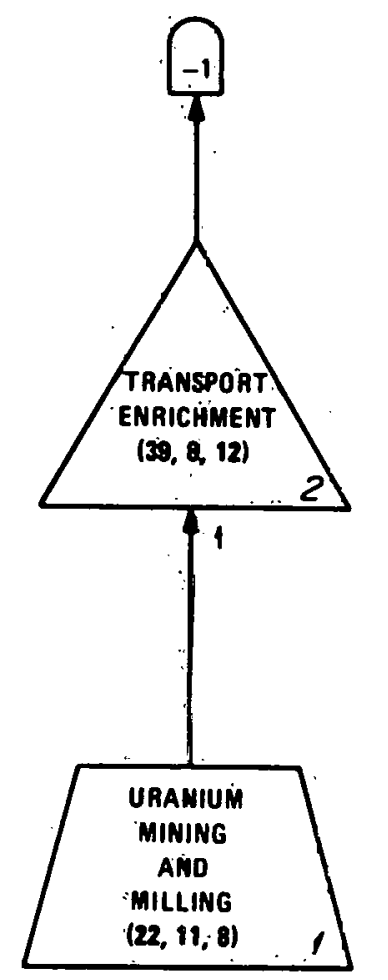

MODEL 22 IMPORTS/EXPORTS SECTOR (NO. 10)
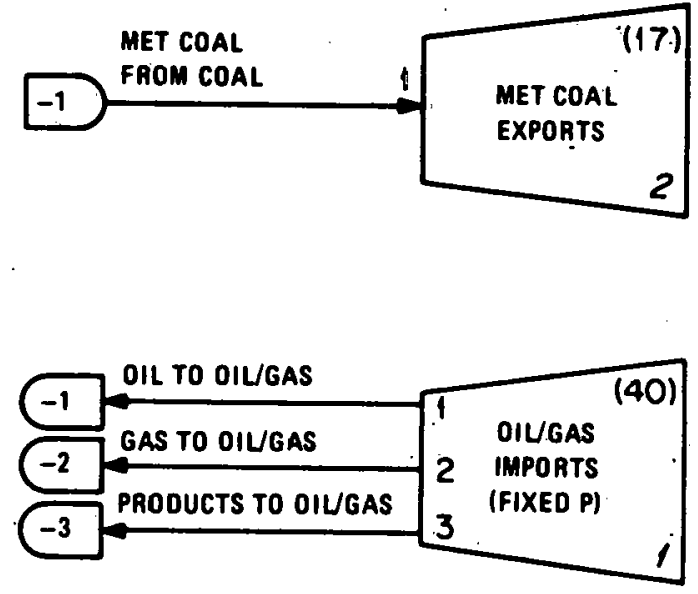

Figure A-5. Network diagrams for the nuclear and imports/exports sectors of LEAP Model 22 (see caption of Figrre A-1 for basic symbology). 


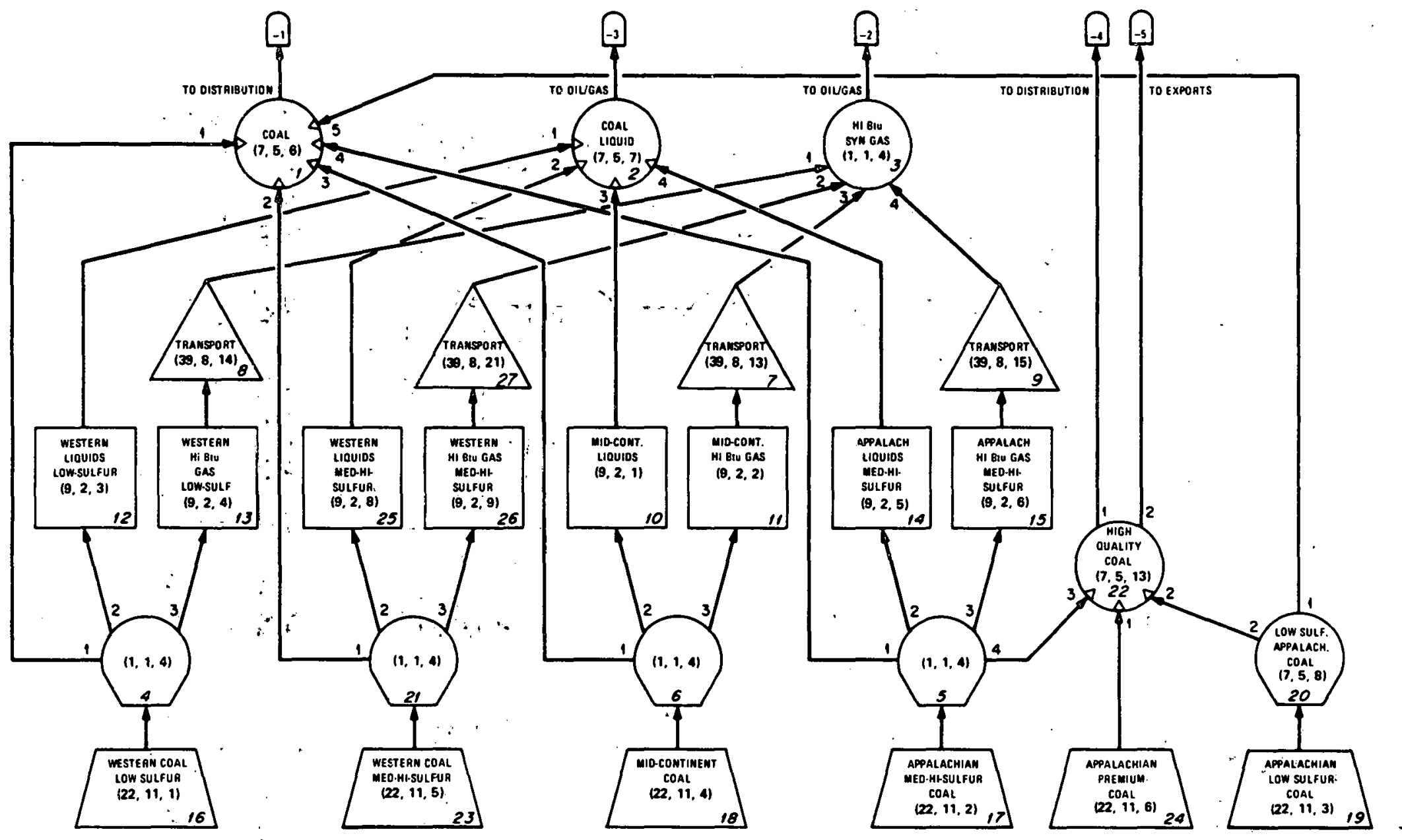

Figure A-6. Network diagram for the cóal sector of LEAP Model 22 (see caption of Figure A-1 for the basic symbology). 
MODEL 22 OIL/GAS SÉcTOR (NO. 7)

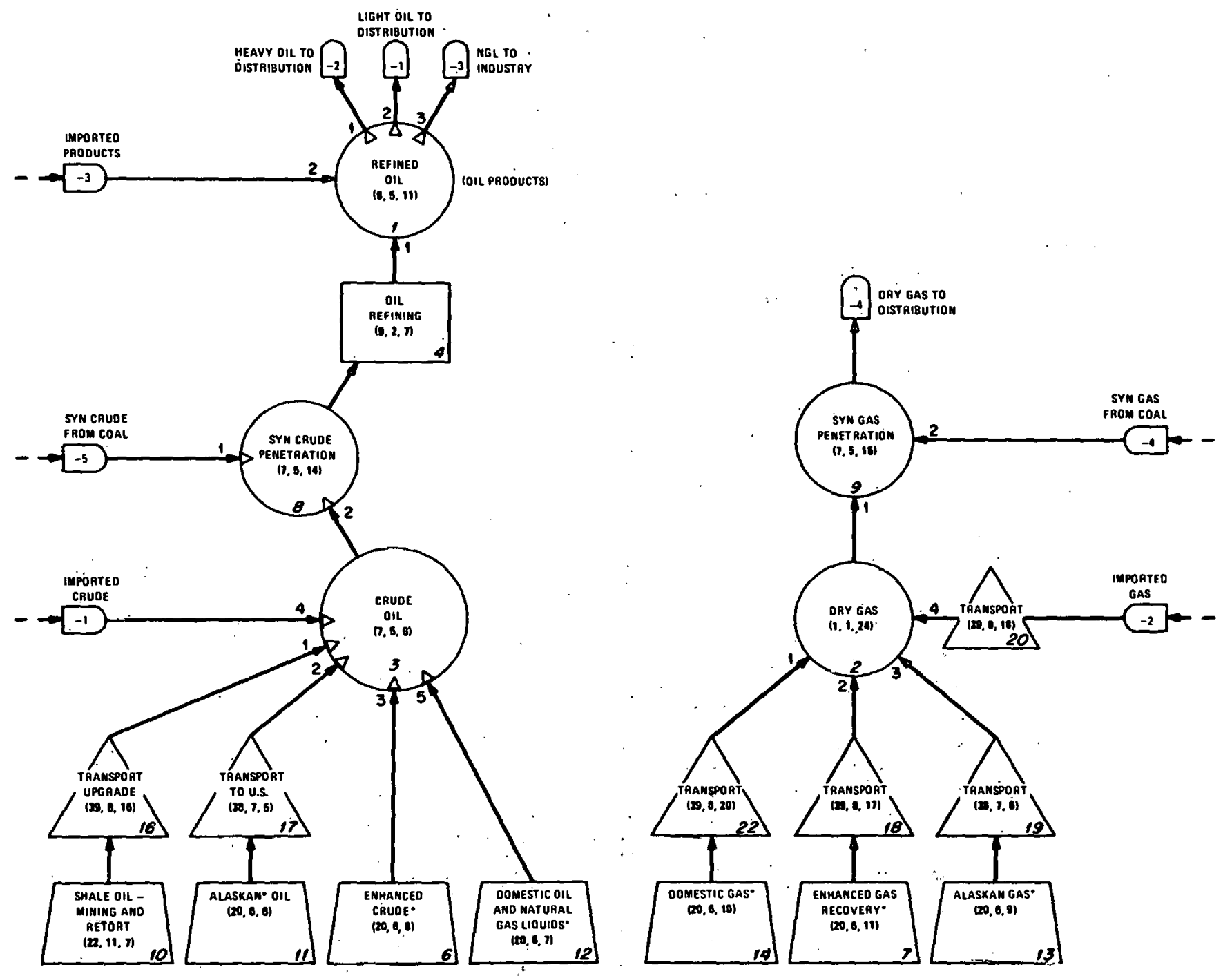

Figure A-7. Network diagram for the 011/gas sector of LEAP Mode1 22 (see caption of Figure A-1 for basic symbology).

-In the model input data tables, node 11 is labeled "North slope 0i1," node 12 is labeled "Domestic $0 i 1$ and Associated Gas,". node 14 is 1 abeled "Non-Associated Gas," and node 19 is labeled "North slope
Gas." 
OANL-OWG 80-7674

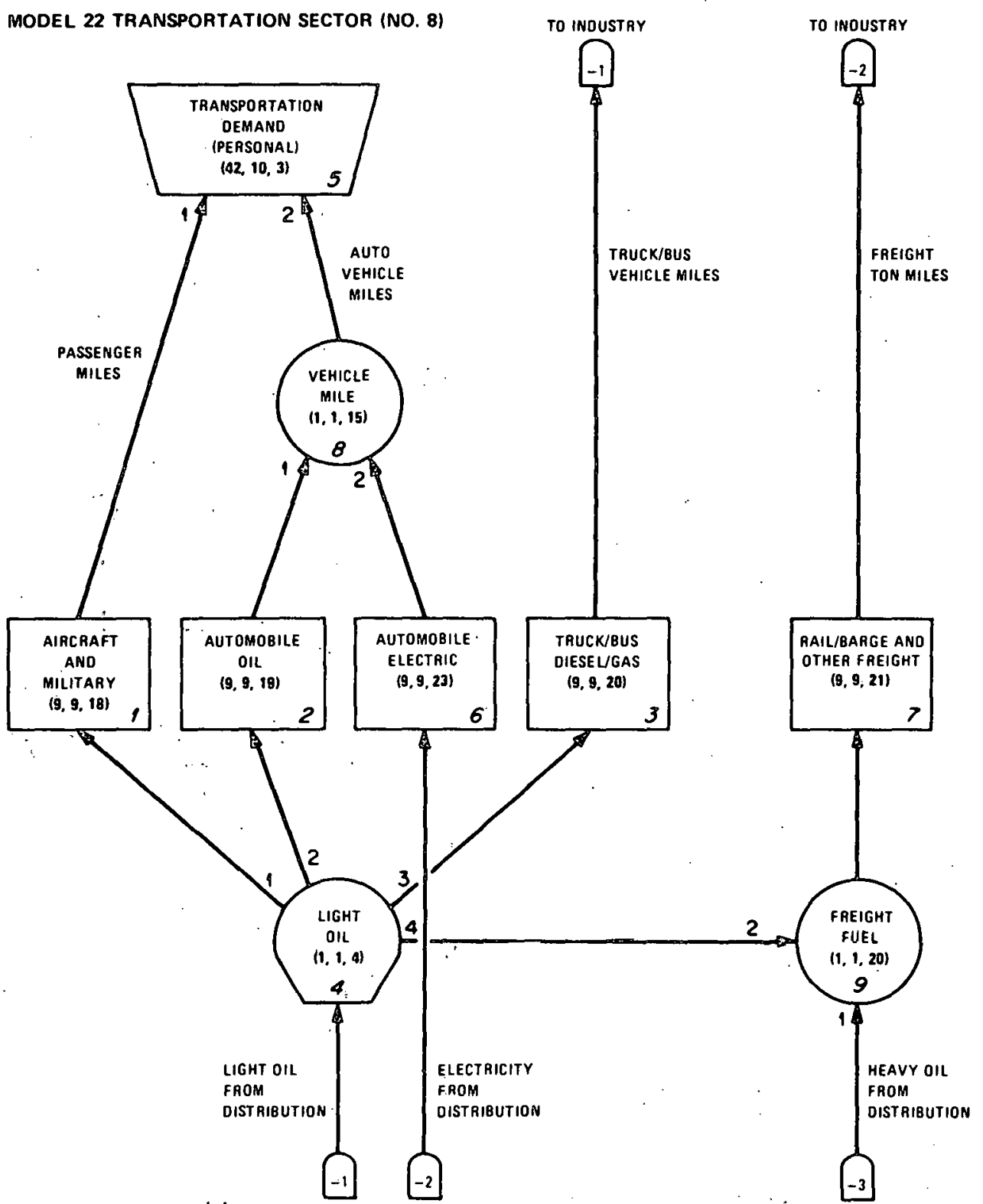

Figrre A-8. Network diagram for the transportation sector of
LEAP Mode1 22 (see caption of Figure A-1 for basic symbology). 
MODEL 22 COMMERCIAL SECTOR (NO. 9)

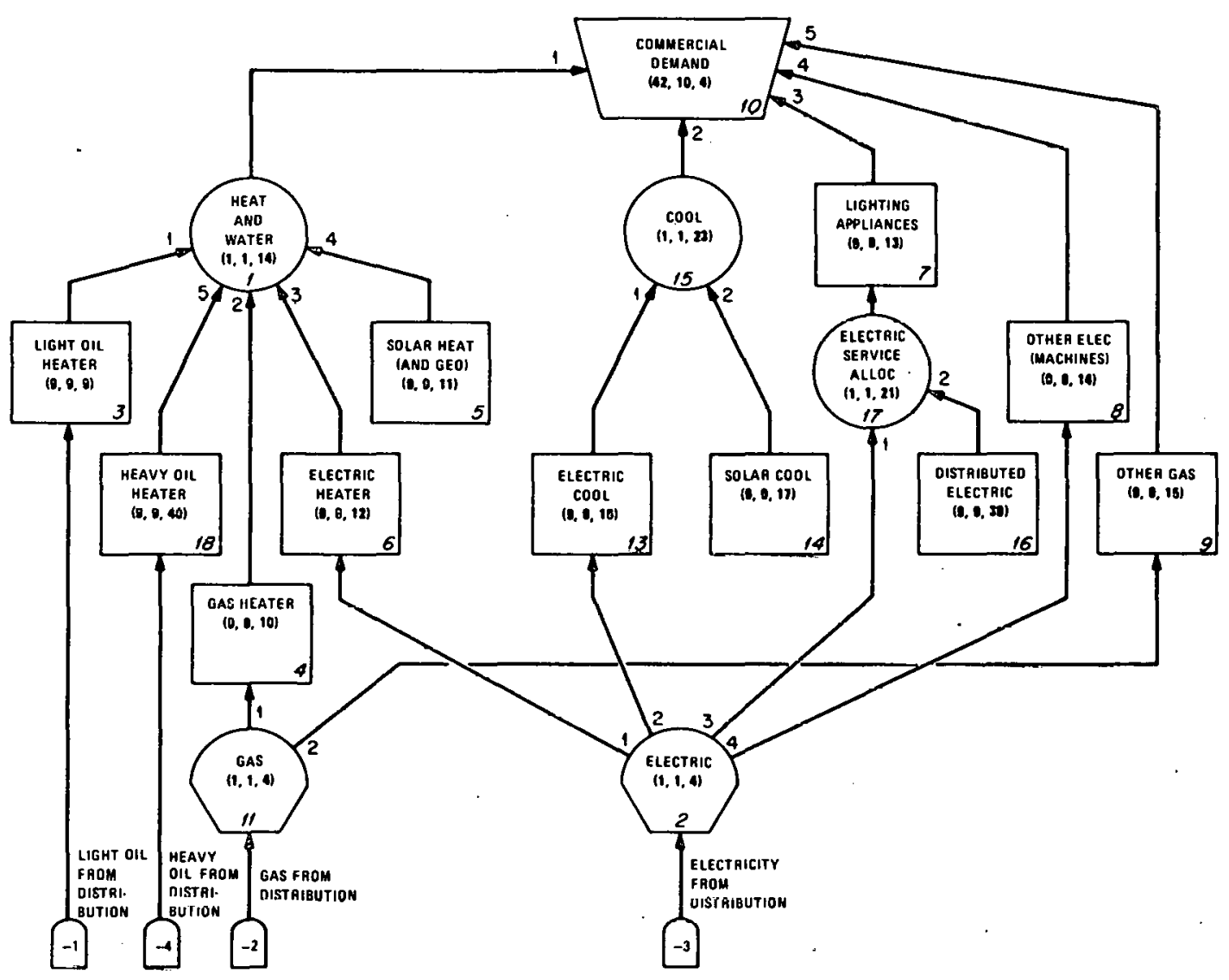

Fignre A-9. Network diagram for the commercial sector of LEAP Model 22 (sec oaption of Figure A-1 for basic (symbology). 


\section{APRPRDIRX $\mathbf{B}$

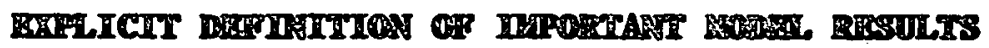

Section III of this report analyzed the uses of the LEAP Mode1 22C projections and defined some important model results or "responses" that focus on those uses. Section IX discussed the sensitivity of these responses to alteration of sets of model inpat parameters. The purpose of this appendix is to make entirely explicit the definition of these responses in terms of the model variables.

Table B.1 lists 24 responses that have been defined, gives the LEAP Mode1 22C numerical values for each response, and in each case indicates the identification of related or component responses. For values that are not dimensionless, units are given for the first and last item on each line. The responses used in Table III.2 have their identification numbers underlined. The "component" responses that are included may help when studying the important responses of Table III. 2 .

Table B.2 identifies the specific energy-quantity and dollar flows to be summed or otherwise combined in each response with reference to the network diagrams given above in Appendix $A$ and in terms of sector ( $\mathrm{SC}$ ), activity ( $\mathrm{AC}$ ), and output link number (OL) indexes. In addition, each referenced model generic activity is identified by the "node number" assigned by the LEAP program when tho particnlar Model 22C network is run. The node number defines the order in which the LEAP-78 program chooses to "visit" the various modeled activities during the itcration process. The node number has significance here because output edits from the operating model are sequenced and labeled by this number. Some model flows do not appear in the responses with unit weight; the values chosen are generally consistent with those values used in the compilation of the ARC-78 report and the available explanations of the model input data 
B-2

(Die79). Note that the defined responses are not independent of each other, and the presence of flows common to more than one response is taken advantage of to shorten the table. 


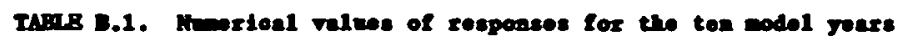

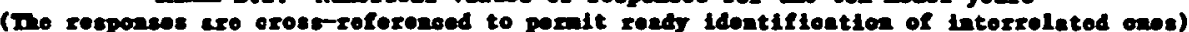

\begin{tabular}{|c|c|c|c|c|c|c|c|c|c|c|c|c|}
\hline \multirow[t]{2}{*}{$\begin{array}{l}\text { Despon } \\
\text { Heber }\end{array}$} & \multirow[t]{2}{*}{ Pee Short Dofinition } & \multicolumn{10}{|c|}{ Munsteal Valeos } & \multirow{2}{*}{$\begin{array}{l}\text { Componont responsess } \\
\text { (rolated sesponsou) }\end{array}$} \\
\hline & & 1975 & 1980 & 1985 & 1990 & 1995 & 2000 & 2005 & 2010 & 2015 & 2020 & \\
\hline 1 & $\begin{array}{l}\text { Total energy-related cost to ond } \\
\text { users per GNP. }\end{array}$ & 0.19 & 0.17 & 0.17 & 0.17 & 0.17 & 0.17 & 0.17 & 0.16 & 0.16 & 0.15 & R16 \\
\hline$\underline{2}$ & Fuel limport cost per GNP. & 0.019 & 0.017 & 0.015 & 0.016 & 0.016 & 0.015 & 0.012 & 0.010 & 0.008 & 0.007 & R16 \\
\hline 3 & $\begin{array}{l}\text { Industrial sector annual onergy } \\
\text { nse (Btu). }\end{array}$ & $17 \times 10^{18}$ & 19 & 24 & 28 & 34 & 40 & 45 & 50 & s5 & $59 \times 1018$ & (See R4, R5) \\
\hline 4 & $\begin{array}{l}\text { Total annual energg ase by the } \\
\text { four demand sectors (Btu). }\end{array}$ & $52 \times 10^{13}$ & .57 & 64 & 70 & 78 & 83 & 89 & 94 & 99 & $103 \times 10^{18}$ & $\begin{array}{l}\text { (See R5, R7, B9, } \\
\text { and R20) }\end{array}$ \\
\hline 5 & $\begin{array}{l}\text { Fractional industrial sector } \\
\text { energy use. }\end{array}$ & 0.33 & 0.34 & 0.37 & 0.40 & 0.44 & 0.48 & 0.51 & 0.53 & 0.56 & 0.57 & $=\mathrm{R} 3 / \mathrm{R} 4$ \\
\hline 6 & $\begin{array}{l}\text { Total annual use of electricity } \\
\text { by demand sectors (Bta). }\end{array}$ & $6.3 \times 10^{28}$ & 7.7 & 10 & 12 & 14 & 16 & 19 & 21 & 23 & $25 \times 10^{23}$ & (See R7) \\
\hline 1 & $\begin{array}{l}\text { Electricity fraction of energy } \\
\text { use in the demand sectors. }\end{array}$ & 0.12 & 0.13 & 0.15 & 0.16 & 0.18 & 0.20 & 0.21 & 0.22 & 0.24 & 0.25 & $=\mathrm{B} 6 / \mathrm{B} 4$ \\
\hline 10 & $\begin{array}{l}\text { Annual domestic primary onergy } \\
\text { supply provided by soal (Bta). }\end{array}$ & $12 \times 1013$ & 16 & 20 & 27 & 35 & 44 & 53 & 62 & 69 & $75 \times 10^{21}$ & (See R11) \\
\hline 11 & $\begin{array}{l}\text { Fraction of ronsenewable domestic } \\
\text { primary energy supplied by coal. }\end{array}$ & 0.19 & 0.21 & 0.24 & 0.28 & 0.33 & 0.37 & 0.42 & 0.45 & 0.46 & 0.47 & R10 \\
\hline$\underline{12}$ & $\begin{array}{l}\text { Anrual domestic natural crade oil } \\
\text { and gas production (Btu). }\end{array}$ & $38 \times 10^{13}$ & 41 & 42 & 44 & 44 & 42 & 39 & 35 & 31 & $27 \times 10^{13}$ & \\
\hline$\underline{13}$ & $\begin{array}{l}\text { Annual imports of oil and oil } \\
\text { products (Btz). }\end{array}$ & $12 \times 10^{1}=$ & 13 & 14 & 13 & 13 & 11 & 10 & 9 & 8 & $7 \times 10^{11}$ & \\
\hline 14 & $\begin{array}{l}\text { Annual tmports of oil, 3as, and } \\
\text { oil products (Bta). }\end{array}$ & $13 \times 1018$ & 14 & 15 & 15 & 14 & 12 & 10 & 9 & 9 & $8 \times 10^{2:}$ & \\
\hline$\underline{15}$ & $\begin{array}{l}\text { Anpal domestic production of } \\
\text { shale oil, cos liquids, and } \\
\text { bigh-Btu sycthetic gas (Bta). }\end{array}$ & $0.00 \times 10^{\prime \prime}$ & 0.00 & 0.00 & 0.4 & 1.8 & 5 & 8 & 12 & 16 & $19 \times 10^{21}$ & \\
\hline 16 & $\begin{array}{l}\text { Annua 1 GNP in bijlions of } 1975 \\
\text { dollars. }\end{array}$ & $1.53 \times 10^{8}$ & 1.9 & 2.3 & 2.6 & 3.0 & 3.4 & 3.9 & 4.3 & 4.9 & $5.5 \times 10^{3}$ & $\begin{array}{l}\text { (See R1, R2, R27, R21 } \\
\text { R22, R23, R24, and } \\
\text { R35) }\end{array}$ \\
\hline 17 & $\begin{array}{l}\text { Total enersy cost to the four } \\
\text { denand sectors per GNP. }\end{array}$ & 0.13 & 0.13 & 0.13 & 0.13 & 0.13 & 0.14 & 0.14 & 0.13 & 0.13 & 0.12 & R16 \\
\hline 18 & $\begin{array}{l}\text { Ansual domestic primary energy } \\
\text { supply (Btal. }\end{array}$ & $69 \times 10^{11}$ & 78 & 87 & 98 & 110 & 121 & 133 & 145 & 156 & $165 \times 10^{2}$ & (See R19) \\
\hline 12 & $\begin{array}{l}\text { Primary onergy inputs to liquids } \\
\text { as a froction of total primary } \\
\text { enorgy. }\end{array}$ & 0.47 & 0.44 & 0.40 & 0.37 & 0.35 & 0.33 & 0.31 & 0.29 & 0.28 & 0.26 & R18 \\
\hline
\end{tabular}




\section{THES 1.1 (contimed)}

\begin{tabular}{|c|c|c|c|c|c|c|c|c|c|c|c|c|}
\hline \multirow[t]{2}{*}{$\begin{array}{l}\text { Tespons } \\
\text { Mepore }\end{array}$} & \multirow[t]{2}{*}{. Dextidofinition } & \multirow[b]{2}{*}{1975} & \multirow[b]{2}{*}{1980} & \multirow[b]{2}{*}{1985} & \multirow[b]{2}{*}{1950} & \multicolumn{3}{|c|}{ Nonertenl Valteos } & $\therefore$ & \multicolumn{2}{|c|}{$\cdot$} & \multirow{2}{*}{$\begin{array}{l}\text { Component rosponeses } \\
\text { (reieted responses) }\end{array}$} \\
\hline & & & & & & 1993 & 2000 & 2005 & 2010 & 2015 & 2020 & \\
\hline 20 & $\begin{array}{l}\text { Liquid fuel consumption in the } \\
\text { demand sectors as a frection } \\
\text { of total energy ase in these } \\
\text { soctors. }\end{array}$ & 0.50 & 0.48 & 0.45 & 0.43 & 0.40 & 0.38 & $0.36 \cdots$ & 0.34 & 0.32 & 0.30 & R4. \\
\hline 21 & $\begin{array}{l}\text { Annuel capital cost por GNP } \\
\text { of new capacity sdded to the } \\
\text { olectric utility sector. }\end{array}$ & $5.2 \times 10^{\circ}$ & 6.5 & 7.7 & 8.2 & 8.3 & $7.2^{\circ}$ & 7.9 & 7.9 & 7.5 & $7.4 \times 10-3$ & $\begin{array}{c}816(\sec 835) \\
\cdots\end{array}$ \\
\hline 22 & $\begin{array}{l}\text { Anoual capital cost por GNP } \\
\text { of nor capactty added to } \\
\text { the industrial, commorcial, and } \\
\text { reaidential domend sectors. }\end{array}$ & 0.026 & 0.023 & 0.018 & 0.022 & 0.020 & 0.017 & 0.015 & $0: 016$ & 0.015 & 0.013 & R16 (see R35) \\
\hline 23 & $\begin{array}{l}\text { Annuai capttal cost por GNP } \\
\text { of now cispecity addod to tho } \\
\text { resonrco sectors. }\end{array}$ & $0.053^{2}$ & $0.030^{\circ}$ & 0.028 & 0.028 & 0.029 & 0.028 & 0.026 & 0.023 & 0.019 . & 0.016 & R16 (see R35). \\
\hline 24 & $\begin{array}{l}\text { Cumulative energy cost to the } \\
\text { demand sectors por cumnlative } \\
\text { GNP. }\end{array}$ & 0.13 & 0.13 & 0.13 & 0.13 & 0.13 & 0.13 & 0.13 & 0.13 & 0.13 & 0.13 & R25, B16 \\
\hline 25 & $\begin{array}{l}\text { Totel energy cost (billions of } \\
1975 \text { dollars) to the demend } \\
\text { sectors. }\end{array}$ & $0.20 \times 10^{\circ}$ & 0.24 & 0.29 & 0.34 & 0.41 & 0.47 & 0.52 & 0.57 & 0.62 & $0.65 \times 10^{2}$ & $=816 \times 817(300 \quad 824)$ \\
\hline 35. & $\begin{array}{l}\text { Total onergp related capital } \\
\text { cost por GNP }\end{array}$ & 0.084 & 0.060 & 0.054 & 0.058 & 0.057 & 0.052 & 0.049 & 0.047 & 0.042 & 0.039 & $=\mathrm{B2} 21+\mathrm{B22}+\mathrm{B23}$ \\
\hline
\end{tabular}

ahis value is unreasonably high becauso the valuo of the historical capacity additions chenge rate (RATLN) for athe domestic oil end ges eotioitlos

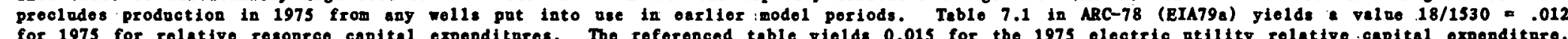
Inconsistent - ith Rosponse 21. Note that dofialtions of "cepital expenditures" diffor sonerhst.

bith the LEAP-78 inpot parameters, the cost of additions in the transportation sector is ostimated to be negiligible relativo to the other contributions. 
Tab10 8.2

Dofleftion of importent model responeos in tome of LRAP Wodol 22 variebles

Rosponse 1:- Total ejeray-related cost to ond psors por GMP Valros aro conind 9 .

\begin{tabular}{|c|c|c|c|c|c|c|}
\hline P100\% & Desoription & Soetor & Motivity & mine & $\begin{array}{c}\text { Ontput } \\
\text { Lint }\end{array}$ & Peotor \\
\hline \multirow{6}{*}{$\begin{array}{l}\mathbf{p q} \\
\mathbf{p q} \\
\mathbf{p q} \\
\mathbf{p q} \\
\mathbf{p q}\end{array}$} & \multirow{6}{*}{$\begin{array}{l}\text { Space and Whiter Heaters } \\
\text { space Cooling } \\
\text { Cooking and.0ther } \\
\text { Lightiag. Freozers. } \\
\text { and Refriberators } \\
\text { oirect Beat Conservation } \\
\text { Allocotion }\end{array}$} & 1 & 1 & 143 & $\mathbf{1}$ & GNP-1 \\
\hline & & 3 & 13 & & $\overline{1}$ & \\
\hline & & 1 & 12 & 134 & 1 & GNP-1 \\
\hline & & 1 & 7 & 144 & 1 & GNP-1 \\
\hline & & & & & & \\
\hline & & 2 & 2 & 137 & 1 & GNP-1 \\
\hline & Indirect Best/Geotherwal & 2 & 6 & 149 & 1 & GNP-1 \\
\hline pq & Electric Sürvices & 2 & 7 & 146 & 1 & NP-1 \\
\hline $\mathbf{p q}$ & Feod stock & 2 & 8 & 115 & 1 & GNP-1 \\
\hline $\mathrm{pq}$ & Mot. Coal from Distribution & 3 & 7 & 58 & 1 & GNP-1 \\
\hline pq & Beavy Oil & 2 & 24 & 107 & 3 & GNP-1 \\
\hline pq & $\begin{array}{l}\text { Transportation Truck/Bus } \\
\text { Transportation Rail/Barge }\end{array}$ & 8 & 3 & 113. & 1 & GNP-1. \\
\hline & & 8 & 7 & 114 & 1 & GNP-1 \\
\hline & Aireraft and Milltary & 8 & $i$ & 111 & 1 & $G \mathbb{N P}-2$ \\
\hline 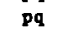 & Auto Vehicio Miles & 0 & 8 . & 124 & 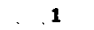 & APP-1 \\
\hline$p$ & - Beat and Woter & 9 & 1 & $140^{\circ}$ & 1 & GNP-i \\
\hline & Cool & 9 & 15 & 129 & 1 & GNP-1 \\
\hline pq & Lighting add Applitances & 9 & $?$ & 141 & 1 & NP2-1 \\
\hline pq & . Other Electric :(Machines) & 9 & 8 & 127 & 1 & GNP-1 \\
\hline & Other Gas & 9 & 9 & 99 & 1 & $\mathrm{GNP}^{-1}$ \\
\hline
\end{tabular}

Responso 2:.., Fuel inport cost per GNP.

$\begin{array}{lllllll}\text { pq } & \text { Imported o11 } & 10 & 1 & 37 & 1 & \text { GNP-1 } \\ \text { pq } & \text { Imported Ge } & 10 & 1 & 37 & 2 & \text { GNP-1 } \\ \text { pq } & \text {.Imported Products } & 10^{\prime \cdots} & 1 & 37 & 3 & \text { GNP-1 }\end{array}$

- NVN - Node Visitation Number

"Flow retrieved frod 1 ink "above" the Indicated act:vity. In this "columin,"

"Flow rotrteved frod 11ak "above" the Indicated act:vity. In this col imin," refors to the price per unit energy. Thus. the "pq" product rofers to the payent floy per your.
TNexB 8.2 (continaed)

Response 3: Industriel bector ennual enorgy.use. Ose is weasured at the Input 1 inks to the sector plas generation within the sector. ${ }^{b}$

\begin{tabular}{|c|c|c|c|c|c|c|}
\hline now & Doscription & soctor & Dotivits & MN & $\begin{array}{l}\text { Oatpest } \\
\text { Lint }\end{array}$ & Peotor \\
\hline $\begin{array}{l}9 \\
9 \\
9 \\
9 \\
9\end{array}$ & $\begin{array}{l}\text { Light 0il to Industry } \\
\text { Heavy Oil to Induetry } \\
\text { Gai to Indastry } \\
\text { Coal. to Indostrg } \\
\text { Electricity to Indastry }\end{array}$ & $\begin{array}{l}\mathbf{3} \\
\mathbf{3} \\
\mathbf{3} \\
\mathbf{3} \\
\mathbf{3}\end{array}$ & $\begin{array}{l}1 \\
2 \\
3 \\
5 \\
4\end{array}$ & $\begin{array}{r}89 \\
90 \\
75 \\
66 \\
122\end{array}$ & $\begin{array}{l}4 \\
2 \\
4 \\
2 \\
3\end{array}$ & $\begin{array}{l}1.00 \\
1.00 \\
1.00 \\
1.00 \\
1.00\end{array}$ \\
\hline 9 & $\begin{array}{l}\text { Met: Coal to Industry } \\
\text { Natural Gos Liquids to }\end{array}$ & $\mathbf{3}$ & 7 & 58 & 1 & 1.00 \\
\hline & Industey & 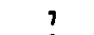 & 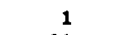 & 80 & 3 & 1.00 \\
\hline $\mathbf{q}$ & Goothermal in Induatry & 2 & 21 & 5 & 1 & 1.00 \\
\hline
\end{tabular}

Responso 4: Total annual energy use by the four dewand sectors. Oze 18

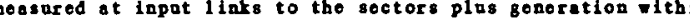
tho sectors. Oas asod to drivo gas pipolinos and olectrio

\begin{tabular}{|c|c|c|c|c|c|}
\hline $\begin{array}{l}\text { Light OH1 co Regidential } \\
\text { Gas to. Residontial } \\
\text { Electricity to Eesidential } \\
\text { Light oil to Commercial } \\
\text { Heary Oil to Commercial }\end{array}$ & $\begin{array}{l}3 \\
3 \\
3 \\
3 \\
3 \\
3\end{array}$ & $\begin{array}{l}1 \\
3 \\
4 \\
1 \\
2\end{array}$ & $\begin{array}{r}89 \\
75 \\
122 \\
89 \\
90\end{array}$ & $\begin{array}{l}2 \\
2 \\
1 \\
3 \\
4\end{array}$ & $\begin{array}{l}1.00 \\
1.00 \\
1.00 \\
1.00 \\
1.00\end{array}$ \\
\hline $\begin{array}{l}\text { Gas to Comercial } \\
\text { Electricity to Commercial } \\
\text { Light Oil to. Transportation } \\
\text { Electricity to Trang- }\end{array}$ & $\begin{array}{r}3 \\
3 \\
3 \\
3\end{array}$ & $\begin{array}{l}3 \\
4 \\
1\end{array}$ & $\begin{array}{r}75 \\
122 \\
89\end{array}$ & $\begin{array}{l}3 \\
2 \\
5\end{array}$ & $\begin{array}{l}1.00 \\
1.00 \\
1.00\end{array}$ \\
\hline $\begin{array}{l}\text { portation } \\
\text { Heavy Oil to Transportation }\end{array}$ & $\begin{array}{l}3 \\
3\end{array}$ & $\begin{array}{l}4 \\
2\end{array}$ & $\begin{array}{r}122 \\
90\end{array}$ & $\begin{array}{l}4 \\
3\end{array}$ & $\begin{array}{l}1.00 \\
1.00\end{array}$ \\
\hline $\begin{array}{l}\text { Distributed Photovoiltaic, } \\
\text { Wind. etc. } \\
\text { Solax Host and Geotherwal }\end{array}$ & 1 & $\begin{array}{r}14 \\
5\end{array}$ & ${ }_{33}^{2}$ & $\begin{array}{l}1 \\
1\end{array}$ & $\begin{array}{l}1.00 \\
1.00\end{array}$ \\
\hline
\end{tabular}
an - Solar hisitat and Geothor

bNote that Toble 5 . in ARC-78 (EIA79A) also inclodes the oce of ot in

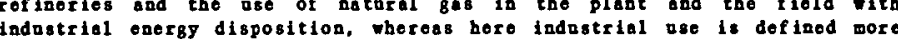
asrouly. For example, in the gear 2000, these oxtro uses sre projeoted to amount to sbout 2.9 and $2.6 \times 1016$ Btu; respoctively.

"Table 5.2 in ARC-7B (BIA79a) does not. inclado pipelino losses por imported ges or olectric 1ine 108s, but doos include the other gas pipoline 108 sos. 
TABLB B.2 (continsod)

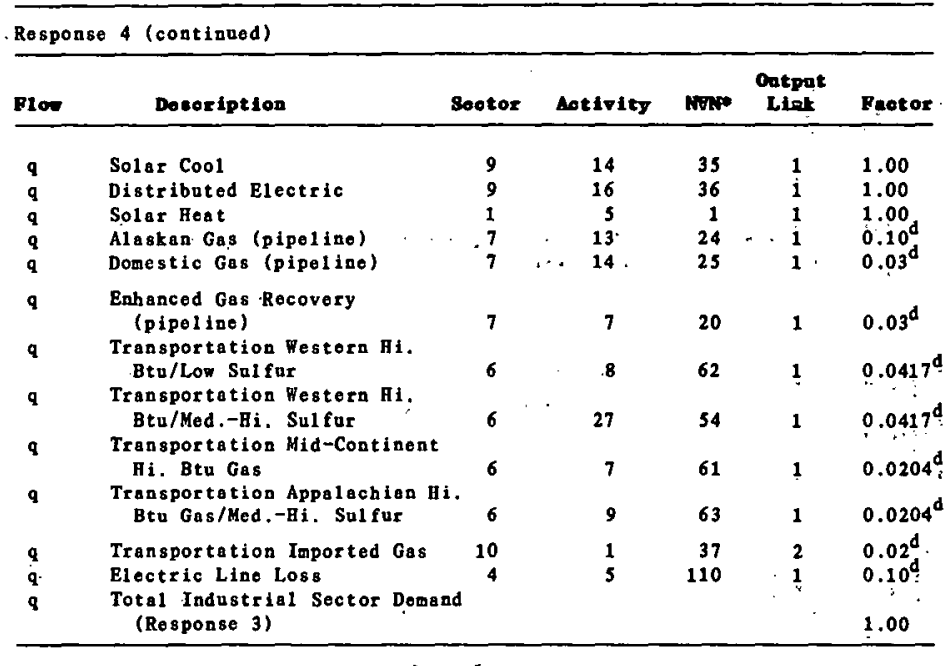

Response 5: Fractional industrial sector enorgy use (Résponse 3/Response 4). Response 6: Total annual use of electricity by demand sectors. This total
includes generation within sectors.

$\begin{array}{ll}\text { q } & \text { Electricity to Residential } \\ \text { q } & \text { Electricity to Commercial } \\ \text { q } & \text { Electricity to Industry } \\ \text { q Electrity to Transportation } \\ \text { q Distributed Photovoltaic, } \\ \text { Vind. etc. } \\ \text { q Distributed Eiectric } \\ \text { q. }\end{array}$

$\begin{array}{rrrr}4 & 122 & 1 & 1.00 \\ 4 & 122 & 2 & 1.00 \\ 4 & 122 & 3 & 1.00 \\ 4 & 122 & 4 & 1.00 \\ 14 & 2 & 1 & 1.00 \\ 16 & 36 & 1 & 1.00 \\ 22 & 119 & 1 & 1.00\end{array}$

dTis factor auliplied by the ontput a from these processes is used to estimate the onorgy lost during gas pipeline transportation and during

'Table 5.6 in ARC-78 (BrA79a) does not include this a ue of electricity generated ot thin the industrial sector, but does lnclude the fuela ased to
TABRB B.2 (contincod)

Response 7: Fractional electricity use (Rosponse 6/Response 4),

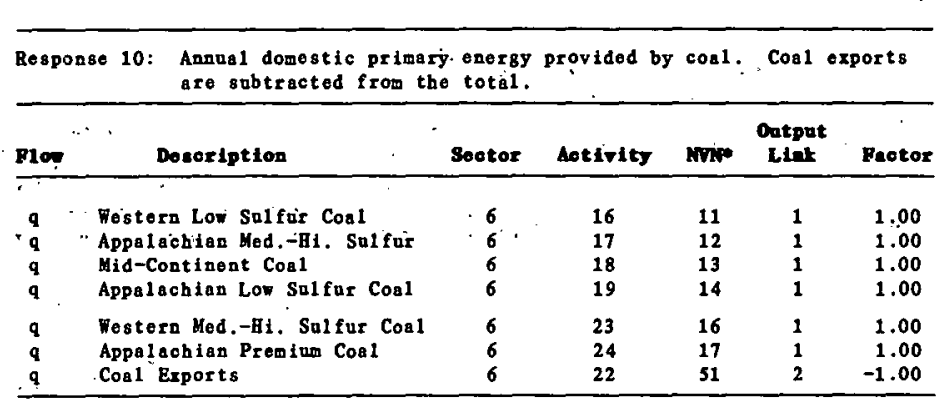

Response'11: Annua 1 noarenowable domostic primary onergy supply other than cos1. f (Goothermal is treated as renewable.)

Uranium Mining and Milling

Eabanced Oil Recovory

Enhanced Gas Recovery

Shale Oil Mining 8

Alaskan 011

Domestic Oil

Alaskan Gas ${ }^{8}$

Domestic Gas
Imported Crude

$\begin{array}{rrrrr}3 & 1 & 9 & 1 & .1 .00 \\ 7 & 6 & 19 & 1 & 1.00 \\ 7 & 7 & 20 & 1 & 1.00 \\ 7 & 10 & 21 & 1 & 1.00 \\ 7 & 11 & 22 & 1 & 1.00 \\ 7 & 12 & 23 & 1 & 1.00 \\ 7 & 13 & 24 & 2 & 1.00 \\ 7 & 14 & 25 & 1 & 1.00 \\ 10 & 1 & 37 & 1 & 1.00 \\ 10 & 1 & 37 & 2 & 1.00 \\ 10 & 1 & 37 & 3 & 1.00\end{array}$

fonstivity studies are not available for this responso. Shown only to simplify presentation of Rosponse 11.

${ }^{8}$ Note that 8.48 of the gas that 18 not imported is stbsequently lost to "plant and fleld use and $108 s e s$." The roported shale oil mast al so be apgraded .ith $95 \%$ of $f$ icioncy. The definttion in this table is the same as in Table 5.1 of
ARC-78 (EIA79a) and doos not place the various sourcos on a comparable basis. 
TABLB B.2 (continnod) Response 11: Praction of nonxenewable domestic primary energy supplied by
cool [Response 11 = Response 10/(Responso 10 + Response 11a)].

Response 12: Annual domestic netural crude oil and gas productior (quantity prior tc any losses to flold use and transportatioz).

\begin{tabular}{|c|c|c|c|c|c|c|}
\hline p1ow & Desoriptica & Sootor & Sotivity & inne & $\begin{array}{c}\text { Ootpat } \\
\text { Link }\end{array}$ & Feotor \\
\hline$q$ & Enhajced Oil Recovery & 7 & 6 & 19 & 1 & 1.00 \\
\hline 9 & Enhanced Gas Recovery & 7 & 7 & 20 & 1 & 1.00 \\
\hline$q$ & Alaszan $0 \mathrm{i} 1$ & 7 & 11 & 22 & 1 & 1.00 \\
\hline 9 & Domestic 0if & 7 & 12 & 23 & 1 & 1.00 \\
\hline $\mathrm{q}$ & Alaskan Gas & 7 & 13 & 24 & $i$ & 1.00 \\
\hline 9 & Domestic Gas ${ }^{1}$ & 7 & 14 & 25 & 1 & 1.00 \\
\hline
\end{tabular}

Response 13: Annual Emported oil and oil products. ${ }^{j}$

\begin{tabular}{lllllll}
$q$ & Imported Crade & 10 & 1 & 37 & 1 & 1.00 \\
$q$ & Ioported Produets & 10 & 1 & 37 & 3 & 1.00 \\
\hline
\end{tabular}

Response 14: Annual :mports of oil, gas, and oil products. j

$\begin{array}{lllllll}\mathbf{q} & \text { Imported Crude } & 10 & 1 & 37 & 1 & 1.00 \\ \mathbf{9} & \text { Imported Gas } & 10 & 1 & 37 & 2 & 1.00 \\ 9 & \text { Imported Produets } & 10 & 1 & 37 & 3 & 1.00\end{array}$

boes not include shäle oil, synthotic gas, or oil frow cosl, bat does inclade Alaskan production.

iNote that $8.4 \%$ of tho gas that 18 not imported is sajsequently lost to "plant and field ase and 128ses." The definition in this table is the same as in Table 5.1 of ARC-78 (EIA79a).

${ }^{j}$ Note that. on an esergy basts, those quantities.-2re not qujte comparable because the refining process in the model has an overall officiency of 0.92 .

\section{$8.2(\cos t \lim x)$}

Rosponse 15: Annual domestic production of shale oil, ooll liquids, and higb

\begin{tabular}{|c|c|c|c|c|c|c|}
\hline Ploo & Dosoription & Sootor & Notivity & $\boldsymbol{m}$ & $\begin{array}{l}\text { Oatyat } \\
\text { Lint }\end{array}$ & Peotor \\
\hline $\begin{array}{l}q \\
q \\
q \\
q\end{array}$ & 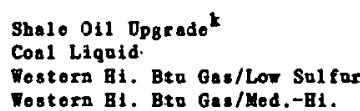 & $\begin{array}{l}7 \\
6 \\
6\end{array}$ & $\begin{array}{r}16 \\
2 \\
13\end{array}$ & $\begin{array}{l}27 \\
60 \\
47\end{array}$ & $\begin{array}{l}1 \\
1 \\
1\end{array}$ & $\begin{array}{l}1.00 \\
1.00 \\
1.00\end{array}$ \\
\hline \multirow[t]{2}{*}{8} & $\begin{array}{l}\text { Sulfor } \\
\text { Hid-Continent HA. Bto Gas } \\
\text { Appaiaohion HA. Btn Gas! }\end{array}$ & $\begin{array}{l}6 \\
6\end{array}$ & $\begin{array}{l}26 \\
11\end{array}$ & $\begin{array}{l}53 \\
45\end{array}$ & $\begin{array}{l}1 \\
1\end{array}$ & $\begin{array}{l}1.00 \\
1.00\end{array}$ \\
\hline & Mod.-Bi. Salfar & 6 & 13 & 49 & 1 & 1.00 \\
\hline
\end{tabular}
Response 16: Annual GNP in billions of 1975 dollars. GNP is calcolated
from the Sectoral Index (SI), which is an input parameter.

$\operatorname{GNP}(1)=1.53 \cdot 10^{3}$

$\operatorname{GNP}(J)=\operatorname{GNP}(J-1) *(1.00+0.01 * \operatorname{SI}(J))^{5} J=2,3, \ldots, 10$ (mode1 year)

Response 17: Total enorgy cout to the four demand sectors per GNP. ${ }^{1}$

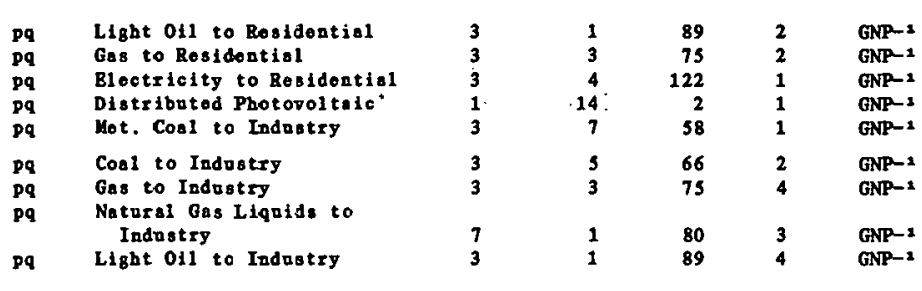

Sha10 oll ${ }^{2}$ figares vore taken ofter apgrading 1038 to make them comparablo to" ornde oll. Table 5.12 of ARC-78 (EIA79a) includes the $5 \%$ higher valu it the input to the apgrading process.

1 Also inoludes the cost of enorgy gonorsted fithin the demand sectors by distribated photovoltaic in residential sector. distributed oloctrio in commoxcial soetor, goothermal in indastrial sector, solar hoat and 801 ax cooling in commercial sector, solar beat in residential soctor, and gas pipol lae and oloctric 1 ino tosses. '(Same 1 ints and factors as for Rosponse 
TABLB B.2 (contined)

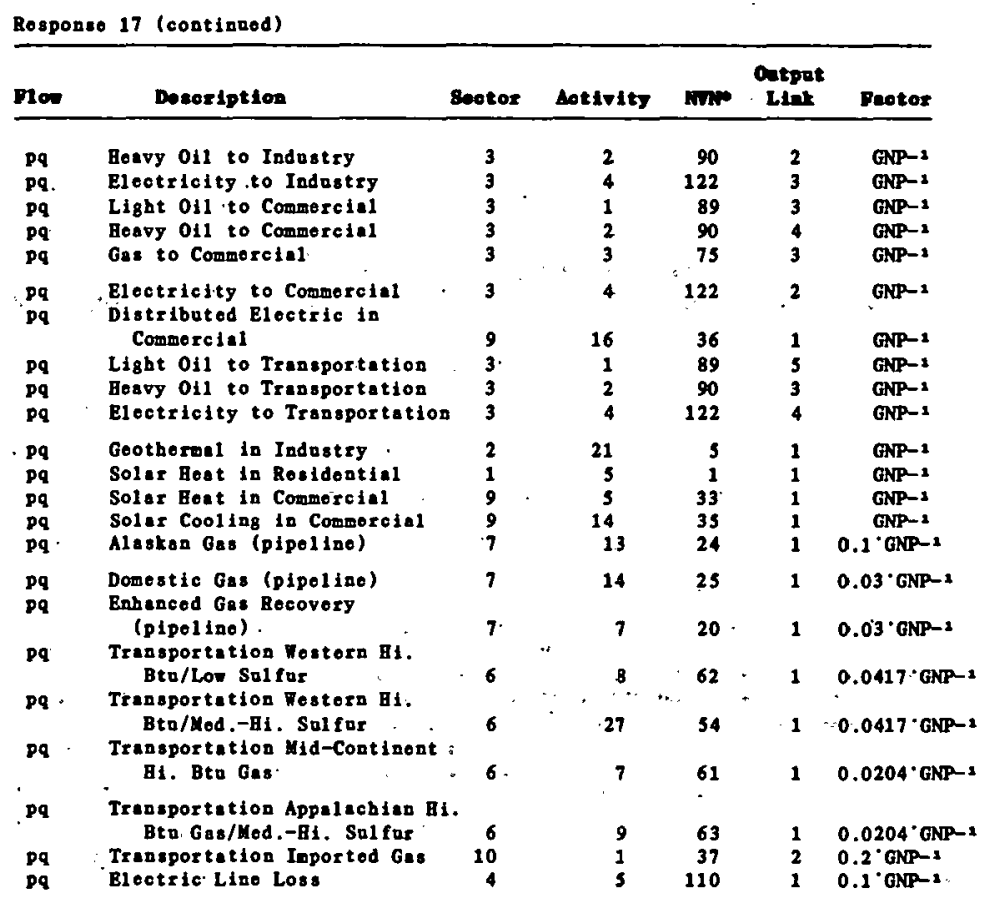

Toprs 8.2 (contimed)

Responso . 18: Annoal domestio primary onergy sopply: ".

\begin{tabular}{|c|c|c|c|c|c|c|}
\hline Plos & Dosoription & Seotox & sotivity & nom & $\begin{array}{c}\text { Output } \\
\text { Lisk }\end{array}$ & Peotor \\
\hline \multirow[t]{2}{*}{$\begin{array}{l}q \\
q\end{array}$} & \multirow{2}{*}{$\begin{array}{l}\text { Testorn Low Solfus Cosl } \\
\text { Appelechien Mod.-Hi. Sulfus } \\
\text { Cosl }\end{array}$} & 6 & 16 & 11 & 1 & 1.00 \\
\hline & & 6 & 17 & 12 & 1 & 1.00 \\
\hline \multirow{3}{*}{ q } & \multirow{3}{*}{ 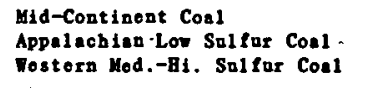 } & 6 & 18 & & & \\
\hline & & 6 & & & & \\
\hline & & 6 & 23 & 16 & 1 & 1.00 \\
\hline & \multirow{5}{*}{ 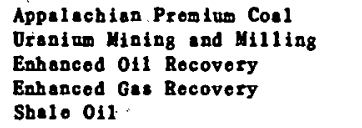 } & 6 & 24 & 17 & 1 & 1.00 \\
\hline & & 3 & 1 & 9 & 1 & \\
\hline & & 7 & 6 & 19 & 1 & 1.00 \\
\hline & & 7 & 7 & 20 & 1 & 1.00 \\
\hline & & 7 & 10 & 21 & 1 & 1.00 \\
\hline \multirow[t]{2}{*}{9} & \multirow{2}{*}{$\begin{array}{l}\text { Alaskan } 011 \\
\text { Domeatic oll and Netoral Gas } \\
\text { Lignids }\end{array}$} & 7 & 11 & 22 & 1 & 1.00 \\
\hline & & 7 & 12 & 23 & 1 & 1.00 \\
\hline \multirow[t]{3}{*}{9} & \multirow{3}{*}{$\begin{array}{l}\text { Alasken Gas } \\
\text { Domestic Gas } \\
\text { Imported Crude }\end{array}$} & 7 & 13 & 24 & 1 & 1.00 \\
\hline & & 7 & 14 & 28 & 1 & 1.00 \\
\hline & & 10 & 1 & 37 & 1 & 1.00 \\
\hline \multirow{4}{*}{$\begin{array}{l}q \\
q \\
q \\
q\end{array}$} & \multirow{4}{*}{$\begin{array}{l}\text { Ioported Gas } \\
\text { Imported Produet: } \\
\text { Exportod Cosl } \\
\text { Contral Ronewablos in Ut1lity } \\
\text { Bydroeloctric in Utility }\end{array}$} & 10 & 1 & 37 & 2 & 1.00 \\
\hline & & 10 & 1 & 37 & 3 & \\
\hline & & .6 & 22 & 51 & & \\
\hline & & 4 & 13 & 6 & $\mathbf{1}^{\mathbf{n}}$ & $\begin{array}{r}3.00^{\circ} \\
3.00^{\circ}\end{array}$ \\
\hline \multirow{6}{*}{$\begin{array}{l}q \\
q \\
q \\
q\end{array}$} & \multirow{6}{*}{ 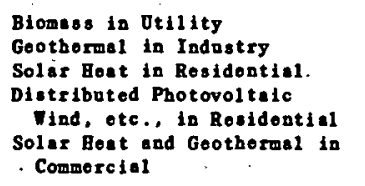 } & & & & $\mathrm{a}$ & \\
\hline & & 2 & $\begin{array}{l}19 \\
21\end{array}$ & 5. & 1 & $\begin{array}{l}3.00^{\circ} \\
1.00\end{array}$ \\
\hline & & 1 & 5 & 1 & 1 & 1.00 \\
\hline & & 1 & 14 & 2 & 1 & $3.00^{\mathrm{p}}$ \\
\hline & & & & & & \\
\hline & & 9 & 5 & 33 & 1 & 1.00 \\
\hline \multirow{2}{*}{9} & \multirow{2}{*}{$\begin{array}{l}\text { Solar cooling in Commercial } \\
\text { Distributed Bl eotric in. } \\
\text { Commerclol }\end{array}$} & 9 & 14 & 35. & 1 & 1.00 \\
\hline & & 9 & 16 & 36 & 1 & $3.00^{\mathrm{P}}$ \\
\hline
\end{tabular}

Note that cosl exports are subtracted from production as was. done in Responso

gquestitios summed over throo soblinks.

${ }^{\circ}$ This factor is usod in LBAP-78 subroutine RPORT and in Table 5.2 in ARC-78 (EIA79n) for oleotric atilitios to ostimate tho quantity of primary enorgy asing. a conventional steem oleotric plent.

PThis fect or is ased to bo consistent with the methodology daed in subroutino RPOBT as described ebovo; however, the fact or anity ras aeod th subrodtino RPORT. (In Model 22C, however, these quantitios aso swaller than 10-1 quad lor 211 mode1 years.) 


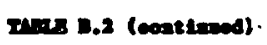

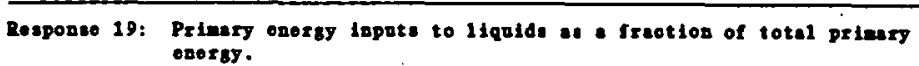

\begin{tabular}{|c|c|c|c|c|c|c|}
\hline now & Decoription & notor & Meivity & mon. & $\begin{array}{l}\text { outyot: } \\
\text { klat. }\end{array}$ & Teotor \\
\hline 9 & $\begin{array}{l}\text { Mestero Low-Sulfax Conl } \\
\text { to Liquids }\end{array}$ & 6 & 4 & 41 & 2 & $8=$ \\
\hline a & $\begin{array}{l}\text { Dostern Conl xed.-Bl. solfux. } \\
\text { to Liquide }\end{array}$ & 6. & 21 & so & 2 & $\mathrm{Bat}_{\mathbf{2}}$ \\
\hline$a$ & Mid-Contineat Cosl to Liquids. & 6 & 6 & 43 & 2 & $8-1$ \\
\hline$?$ & $\begin{array}{l}\text { Appoleoblan Mod.-Bi. Sulfur Cosl } \\
\text { to Liquids }\end{array}$ & 16 & 5 & 42 & 2 & Bit: \\
\hline$q$ & Inoported Crode. & 10 & 1 & 37 & $\mathbf{1}$ & $\mathbf{n}_{\mathbf{2}} \mathbf{2}$ \\
\hline a & Shate 011 & 7 & 10 & 21 & 1 & $R_{\mathbf{1}} \mathbf{z}$ \\
\hline 9 & Alesken 011 & 7 & 11 & 22 & 1 & Eni \\
\hline a & Bnbenced Crade & 7 & 6 & 19 & 1 & nis: \\
\hline$q$ & $\begin{array}{l}\text { Donostide oil ond Netural } \\
\text { Llquide }\end{array}$ & 7 & 12 & 23 & 1 & $B-1$ \\
\hline$q$ & Ingorted Productsq & 10 & 1 & 37 & 3 & B:1 \\
\hline
\end{tabular}

Response 20: Liquid fuel consmption in the denend -eoct ore. As . Ersetion

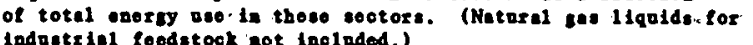

\begin{tabular}{|c|c|c|c|c|c|c|}
\hline q & Ligbt 011 to Bosideatial & $\mathbf{3}$ & 1 & 89 & 2 & $\mathrm{~B}_{\overline{4}}^{2}$ \\
\hline$q$ & Light oil to Comeretel & 3 & 1 & 89 & 3 & $\mathbf{R}_{\mathbf{4}}^{-1}$ \\
\hline 9 & Ligbt o1l to lodoatrtal & 3 & 1 & 89 & 4 & $\mathbf{B}^{\mathbf{2}}$ \\
\hline$q$ & Ligbt 011 to Treneportation & 3 & 1 & 89 & 3 & $\mathbf{R}_{\mathbf{4}} \mathbf{2}$ \\
\hline a & Heavg 011 to lndustriel & 3 & 2 & 90 & 2 & $\mathbf{B}_{\mathbf{4}} \mathbf{2}$ \\
\hline q & Boavy 011 to Tranaportation & 3 & $?$ & 90 & 3. & $\mathbf{B q}_{\mathbf{4}}:$ \\
\hline$q^{9^{-}}$ & 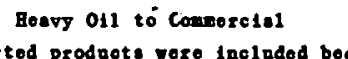 & 3 & 2 & 90 & 4 & $\mathbf{B}_{\mathbf{4}}^{\mathbf{1}}$ \\
\hline
\end{tabular}

TMms B.2 (continen)

Rosponso 21: Annasl capital cost por ONP of not capacity edded to the eleotrio atility eoctor (bydroponer not inoludod). s.e

\begin{tabular}{|c|c|c|c|c|c|c|}
\hline now & Dopostpetion & sootor & Dotivity & Inem & $\begin{array}{l}\text { Ontpot } \\
\text { Lint }\end{array}$ & Puotor \\
\hline $\begin{array}{l}.0 t \\
c 0 \\
c 0 \\
00 \\
c c\end{array}$ & 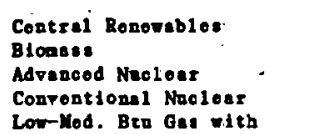 & $\begin{array}{l}4 \\
4 \\
4\end{array}$ & $\begin{array}{r}13 \\
19 \\
6 \\
7\end{array}$ & $\begin{array}{r}6 \\
8 \\
39 \\
40\end{array}$ & $\begin{array}{l}1 \\
1 \\
1 \\
1\end{array}$ & $\begin{array}{l}\mathrm{GNP}-1 \\
\mathrm{GNP}-1 \\
\mathrm{GNP}-2 \\
\mathrm{GNP}-2\end{array}$ \\
\hline & conbined Cycle & 4 & 15 & 68 & 1 & $\mathbb{C N P}^{-1}$ \\
\hline $\begin{array}{l}c 0 \\
c 0 \\
c 0 \\
c e \\
c 0 \\
c o\end{array}$ & 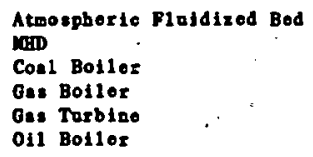 & $\begin{array}{l}4 \\
4 \\
4 \\
4 \\
4 \\
4\end{array}$ & $\begin{array}{r}16 \\
20 \\
8 \\
11 \\
12 \\
9\end{array}$ & $\begin{array}{l}69 \\
70 \\
77 \\
78 \\
79 \\
92\end{array}$ & $\begin{array}{l}1 \\
1 \\
1 \\
1 \\
1 \\
1\end{array}$ & $\begin{array}{l}G N^{-1} \\
G N^{-1} \\
G N^{-1} \\
G N^{-1} \\
G N^{-1} \\
G N^{2-1}\end{array}$ \\
\hline $\begin{array}{l}\text { co } \\
c 0\end{array}$ & $\begin{array}{l}\text { O11 Turbine } \\
\text { Puel Co11 O11 }\end{array}$ & 4 & $\begin{array}{l}10 \\
17\end{array}$ & $\begin{array}{l}93 \\
94\end{array}$ & 1 & $\begin{array}{l}\text { GNP-1 } \\
\text { GNP-1 }\end{array}$ \\
\hline
\end{tabular}

Reaponse 22: Annael capitel cont per GXP of capactity added to the 1ndostriet, commerciel, and residontial sectors. ${ }^{\mathrm{T}}$

\begin{tabular}{|c|c|c|c|c|c|c|}
\hline ce & $\begin{array}{l}\text { Solar Hoat in Rosidontisl } \\
\text { D1stribated Photorol tetic }\end{array}$ & 1 & 5 & 1 & 1 & ANP-1 \\
\hline & in Rosidonticl. & 1 & 14 & 2 & 1 & \\
\hline co & Goothormal in Induetrial & 2 & 21 & 3 & $i$ & \\
\hline & in commercial & 9 & 2 & 30 & 1 & $\mathbb{P}-1$ \\
\hline Ce & Soler Cooling in Commer & 9 & 14 & 35 & 1 & \\
\hline
\end{tabular}

Tho annus1. capten cost of addod capactity for each beste convorsion and oleotrie powor eotivity ls one-flfth the product. capacity additions (N)' these symbols are asod in Eqs. (II.6, II.8, and III.2) in Goldetoinces' rort (Go181). (Tho factor ono-firth is epplied beceuso the modol cont emplates capeoity edditions only in the model years, and these years exo speced at 5-yosr intervals.)

summed over subliats.

'Symbol for capitel cost of addod ospacity. 
TARIB B.2 (oontimed)

\begin{tabular}{|c|c|c|c|c|c|c|}
\hline P1om & Doseription & Sootor & Aotirity & $\mathbf{m} \mathbf{m}$ & $\begin{array}{l}\text { Ontpot } \\
\text { Lille }\end{array}$ & Peotor \\
\hline 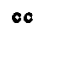 & $\begin{array}{l}\text { Distributed Bloctric in } \\
\text { Commercial }\end{array}$ & 9 & 16 & 36 & 1 & $G \mathbb{N P}^{2}-1$ \\
\hline ce & $\begin{array}{l}\text { Low Btn Gas (Indirect Beat) } \\
\text { in Industrial }\end{array}$ & 2 & 3 & 83 & 1 & GNP-2 \\
\hline cc & $\begin{array}{l}\text { Low Btu Gas (Direct Boat) } \\
\text { in Industria1 }\end{array}$ & 2 & 14 & 84 & 1 & GNP-1 \\
\hline ce & $\begin{array}{l}\text { Direct Heat (Coa1) in } \\
\text { Industria1 }\end{array}$ & 2 & 15 & 85 & 1 & GNP-1 \\
\hline co & $\begin{array}{l}\text { Indirect Beat (Cos1) in } \\
\text { Industrial }\end{array}$ & 2 & 16 & 86 & 1 & GNP-2 \\
\hline$\infty$ & $\begin{array}{l}\text { AT, Finfdized Bod (Cos1) in } \\
\text { industrial }\end{array}$ & 2 & 17 & 87 & 1 & GNP-1 \\
\hline cc & Commorcial & 9 & 3 & 97 & 1 & GNP-1 \\
\hline$\infty$ & Gas Beater in Commereial & 9 & 4 & 98 & 1 & GNP-1 \\
\hline $\mathrm{co}$ & Other Gas in Comwercial & $?$ & 9 & 99 & 1 & GNP-1 \\
\hline ce & Heavy 0il. Heater in Commercial & 9 & 18 & 100 & 1 & GNP-1 \\
\hline $\begin{array}{l}\mathrm{cc} \\
\mathrm{cc}\end{array}$ & $\begin{array}{l}\text { O11 and LPG Heater } \\
\text { Gas Heater }\end{array}$ & $\begin{array}{l}1 \\
1\end{array}$ & $\begin{array}{l}3 \\
4\end{array}$ & $\begin{array}{l}101 \\
102\end{array}$ & $\begin{array}{l}1 \\
1\end{array}$ & $\begin{array}{l}\text { GNP-1 } \\
\text { GNP-1 }\end{array}$ \\
\hline cc & $\begin{array}{l}\text { Gas bieater } \\
\text { Cooking and otbor Gas }\end{array}$ & 1 & 9 & 103 & 1 & GNP:1 \\
\hline ce & Dixoct Heat Gas in Industrial & 2 & 12 & 104 & 1 & $\mathbb{G N P}^{2}-1$ \\
\hline co & Indrect Heat Gas in Industrial & 12 & 13 & $\therefore 105$ & $i$ & ONP-1 \\
\hline $\begin{array}{ll}c o \\
c c\end{array}$ & $\begin{array}{l}\text { Diroet Hoat } 011 \text { in Industrial } \\
\text { Indirect Hoat Heavy O11 in }\end{array}$ & 2 & 10 & 116 & 1 & GNP-1 \\
\hline & Industriel & 2 & 11 & 117 & 1 & ONP-1 \\
\hline cc & $\begin{array}{l}\text { Solar (0il Backap) in } \\
\text { Industrial }\end{array}$ & 2 & 18 & 118 & 1 & GNP-1 \\
\hline cc & $\begin{array}{l}\text { Eleotric Auto Generation in } \\
\text { Indostrial }\end{array}$ & 2 & 22 & 117 & 1 & GNP-2 \\
\hline cc & Blectric Hoater in Comercial & 9 & 6 & 126 & 1 & GNP-1 \\
\hline co & $\begin{array}{l}\text { Othor Blectric (Machines) in } \\
\text { Comborcial }\end{array}$ & 9 & 6 & 127 & 1 & GNP-1 \\
\hline co & Electric Cooking in Commorcial & 9 & 13 & 128 & 1 & GNP-i \\
\hline ce & Electric Hest in Residential & 1 & 6 & 132 & 1 & GNP-1 \\
\hline ce & $\begin{array}{l}\text { Cooking and otber Eloctric in } \\
\text { Rosidential }\end{array}$ & 1 & 8 & 13 & 1 & GN \\
\hline ce & Space Cooling In Residential & 1 & 13 & 135 & 1 & GNP-1 \\
\hline ce & $\begin{array}{l}\text { Lighting Appliances in } \\
\text { Commorcial }\end{array}$ & 9 & 7 & 141 & 1 & GNP-1 \\
\hline 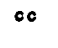 & $\begin{array}{l}\text { Lighting, Freezers, otc., in } \\
\text { Commiercial }\end{array}$ & 1 & 7 & 144 & 1 & GNP \\
\hline co & Electric Bost (Heat Pamps) & 2 & 19 & 147 & 1 & GNP-1 \\
\hline
\end{tabular}

TABuB B.2 (cost inad)

Response 23: Annual capital cost por GNP of new capacity (proved roserves for resource activitios) added to the resource sectors. Inelades

\begin{tabular}{|c|c|c|c|c|c|c|}
\hline Plow & Dosoription & Seotor & Sotivity & Mne & $\begin{array}{l}\text { Outpet } \\
\text { Litit }\end{array}$ & Peotor \\
\hline \multirow{4}{*}{$\begin{array}{l}c c \\
c c \\
c c\end{array}$} & \multirow{4}{*}{$\begin{array}{l}\text { Orani aw Mining and Milling } \\
\text { Western Coal Low Sulfux } \\
\text { Appalachian Med.-Hi. Salfur } \\
\text { Coa1 }\end{array}$} & 5 & 1 & 9 & 1 & GNP-1 \\
\hline & & 6 & 16 & 11 & $i$ & GNP-2 \\
\hline & & & & & & \\
\hline & & 6 & 17 & 12 & 1 & GNP-1 \\
\hline \multirow{2}{*}{$\begin{array}{l}\text { cc } \\
c c\end{array}$} & \multirow{2}{*}{$\begin{array}{l}\text { Mid-Continent Cos1 } \\
\text { Appalaohlan Low Sulfax Cosl }\end{array}$} & & & 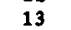 & 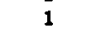 & GNP-1 \\
\hline & & 6 & 19 & 14 & $i$ & GNP-1 \\
\hline \multirow{2}{*}{$\begin{array}{ll}c c \\
c c\end{array}$} & \multirow{2}{*}{$\begin{array}{l}\text { Western Coa1/Med.-Hi. Solfur } \\
\text { Appalaebian Promium Coal }\end{array}$} & 6 & 23 & 16 & 1 & GNP-1 \\
\hline & & 6 & 24 & 17 & 1 & GNP-2 \\
\hline \multirow{3}{*}{$\begin{array}{l}c c \\
c c \\
c c\end{array}$} & Bnhanced Crade 011 Recovery & 7 & 6 & 19 & 1 & GNP-2 \\
\hline & \multirow{2}{*}{$\begin{array}{l}\text { Enhanced Gas Recovery. } \\
\text { Shale Oil Mining. }\end{array}$} & 3 & 7 & 30 & 1 & GNP-1 \\
\hline & & 7 & 10 & 21 & 1 & GNP-1 \\
\hline \multirow{3}{*}{$\begin{array}{l}\text { cc } \\
\text { cc }\end{array}$} & \multirow{3}{*}{$\begin{array}{l}\text { Alaskan O11 } \\
\text { Domestic O11 and Natural Gas } \\
\text { Liquids }\end{array}$} & 7 & 11 & 22 & 1 & GNP-1 \\
\hline & & & & & & GNP-1 \\
\hline & & 7 & $\begin{array}{l}12 \\
13\end{array}$ & 24 & 1 & GNPD-1 \\
\hline \multirow{2}{*}{$\begin{array}{l}\text { cc } \\
\text { cc }\end{array}$} & \multirow{2}{*}{$\begin{array}{l}\text { Alastan Gas } \\
\text { Domestic Gas } \\
\text { Mid-Continont Liquid (Coal) }\end{array}$} & 7 & 14 & 25 & 1 & GNP-1 \\
\hline & & 6 & 10 & 44 & 1 & GNP-1 \\
\hline \multirow{6}{*}{$\begin{array}{l}c c \\
c c \\
c c \\
c c\end{array}$} & \multirow{6}{*}{ 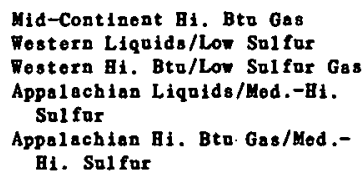 } & 6 & 11 & 45 & 1 & GNP-1 \\
\hline & & 6 & 2 & 46 & 1 & GNP-1 \\
\hline & & 6 & 13 & 47 & 1 & GNP-1 \\
\hline & & 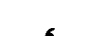 & 4 & & 1 & $\pi$ \\
\hline & & 0 & & & & \\
\hline & & 6 & 15 & 49 & 1 & GNP-1 \\
\hline \multirow{3}{*}{$\begin{array}{l}\text { ce } \\
\text { cc }\end{array}$} & \multirow{4}{*}{$\begin{array}{l}\text { Western Liquida/Mod.-Hi. } \\
\text { Salfar } \\
\text { Westorn Bi. Bto Gas/Med.-Hi. } \\
\text { Salfur } \\
\text { O11 Refining }\end{array}$} & 6 & 25 & 52 & 1 & GRP-1 \\
\hline & & & & & & \\
\hline & & 6 & 26 & $\mathbf{5 3}$ & 1 & GNP-1 \\
\hline cc & & 7 & 4 & 72 & $\mathbf{1}$ & $\mathrm{GNP}^{-1}$ \\
\hline
\end{tabular}

Compated as Indicated in footnoto $x$ for tho basio conversion activitlos

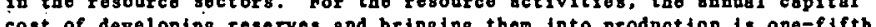

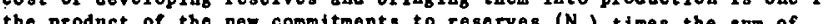
present values of the capital cost of the reservo"eddition (N) and econoole profit associated with the lease payment (II), both por unit of added capacity. 
Twas 8.2 (contimaed)

Rosponse 24: Cumuletivo onergy cost to the dosend seotors por obmaletivo GNP. cost and GNP tor

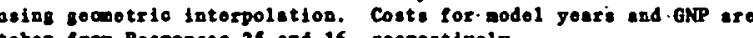

$2024(y)=\frac{\sum_{1975}^{y} C(y)}{\sum_{1975}^{y} \operatorname{GNP}(5)}$

Rasponse 25: Total onoray cost (1975 dollers) to the derend sectoro.

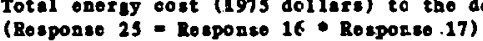

Response 33: Totel osergy-releted capitel costs in the resourco, oleotrito atility, ond dopend sootors per GNP.

Response 35 = Bosponse 21 + Response 22 + Rosponse $23+$ (sinilex quantity for the treasportation (ectex) 


\section{APPaDX C

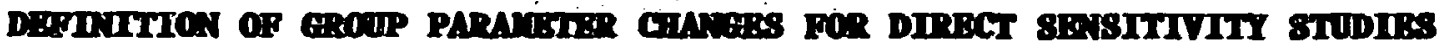

Section IX.A of this report gives sensitivity results for parameter changes of significant ( 10 to $50 \%)$ size, changes typically made at the same time in the corresponding parameters of a number of activities. To avoid any ambiguity, this Appendix contains in Table C.1 an explicit definition of these changes and the activities in which the parameter changes were made.

Note that the parameter (P) for the run with altered input is defined in Table C.1 directly or in terms of the base-case parameter. This format permits clear explanation for a variety of types of input changes. For a given case, the indicated change is made simultaneousiy in the corresponding parameters for all the 1isted. activities.

A complete set of correct definitions of the parameters can be found in the report by Stewart and Goldstein (Ste81); these definitions can most readily be located by the parameter ID numbers given in Table C.1. The sectors are identified by number in Figure II-1, and the activities in each sector are identified on the corresponding sector network diagrams in Appendix A. 
Tab10 C.1

Dotalled defiattions of group paremer ohangeo for sonsitivity stadies

\begin{tabular}{|c|c|c|c|c|c|c|}
\hline \multirow[b]{2}{*}{ 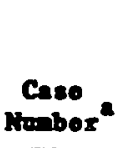 } & \multicolumn{4}{|c|}{ Dofinition of the Farious Paxameters. } & \multirow[b]{2}{*}{ Dofiaftion of Change } & \multirow{2}{*}{$\begin{array}{l}\text { Appliosblo Soetors } \\
\text { Aotivitios. }\end{array}$} \\
\hline & Short Dofinition & $\begin{array}{l}\text { Paremegr } \\
\text { Puabor }\end{array}$ & Po:ArAH & Newer & & \\
\hline 1 & Operating cost aging rate & 23 & VOAGRT & & $0.03^{c}$ & $\begin{array}{l}\text { All basic, electric power, and } \\
\text { resource conversion activities }\end{array}$ \\
\hline 2 & $\begin{array}{l}\text { Price elasticity of final demand; } \\
\text { Behavioral demand } 1 \mathrm{ag}\end{array}$ & A2 & $\begin{array}{l}\text { ELAS } \\
\text { SENS }\end{array}$ & & $\begin{array}{l}=-0.3362^{d} \\
=0.3277\end{array}$ & $\begin{array}{l}1.10,2,1,8.5,9.10^{\circ} \\
\text { (a11 final demand activities) }\end{array}$ \\
\hline 3 & Percent GNP annual growth & A3 & $\mathrm{Y}(\mathrm{JT})$ & & $Y_{0}(J T)+i .5^{f}$ & $\begin{array}{l}1.10,2,1,8,5,9,10 \\
\text { (a11 final demand activities) }\end{array}$ \\
\hline 4 & Percent GNP annual growth & $\mathbf{A} 3$ & $\mathrm{Y}(\mathrm{JT})$ & & $Y_{0}(J T)+0.5$ & (same as Case 3 ) \\
\hline 11 & Percent GNP annual growth & A3. & $\mathrm{Y}(\mathrm{J} T)$ & & $\mathrm{y}_{0}^{\prime}(\mathrm{J} T)-\ddot{1} .5$ & (same as Case 3 ) \\
\hline 12 & Percent GNP annual growth & $\mathrm{A} 3$ & $\mathrm{Y}(\mathrm{JT})$ & & $Y_{0}(J T)-0.5$ & (same as Case 3 ) \\
\hline 13 & $\begin{array}{l}\text { Initial resonrce cost; } \\
\text { Base resonrce price }\end{array}$ & $\begin{array}{l}40 \\
41\end{array}$ & $\begin{array}{l}\text { INRCST } \\
\text { BASEPR }\end{array}$ & & $\begin{array}{l}=\quad{ }^{0}=\text { INRCST }_{0} \times 1.10^{\mathrm{g}} \\
=\quad \text { BASEPR }_{0}^{\circ} \times 1.10\end{array}$ & $\begin{array}{l}7 .(6,7,11,12,13,14)^{e} \\
\text { (domestic oil and gas resource } \\
\text { activities) }\end{array}$ \\
\hline 14 & $\begin{array}{l}\text { Initial resource cost; } \\
\text { Base resource price }\end{array}$ & $\begin{array}{l}40 \\
41 .\end{array}$ & $\begin{array}{l}\text { INRCST } \\
\text { BASEPR }\end{array}$ & & $\begin{array}{l}=\quad \text { INRCST } \times 0.9^{8} \\
=\quad \text { BASEPR }_{0}^{0} \times 0.9\end{array}$ & (same as Case 13) \\
\hline 15 & $\begin{array}{l}\text { Initial resonrce cost: } \\
\text { Base resource price }\end{array}$ & $\begin{array}{l}40 \\
41\end{array}$ & $\begin{array}{l}\text { INRCST } \\
\text { BASEPR }\end{array}$ & & $\begin{array}{l}=\quad \text { INRCST } \times 1.30^{8} \\
=\quad \text { BASEPR }_{0}^{\circ} \times 1.30\end{array}$ & (same as Case 13) \\
\hline 16 & $\begin{array}{l}\text { Initial resource cost: } \\
\text { Base resonrce price }\end{array}$ & $\begin{array}{l}40 \\
41\end{array}$ & $\begin{array}{l}\text { INRCST } \\
\text { BASEPR }\end{array}$ & & $\begin{array}{l}=\quad \text { INRCST }^{\circ} \times 1.50^{8} \\
=\text { BASEPR }_{0}^{\circ} \times 1.50\end{array}$ & $\begin{array}{l}7.10 \\
\text { (shale oil resource activity) }\end{array}$ \\
\hline 17 & $\begin{array}{l}\text { Undiscovered recoverable resources; } \\
\text { New resources at twice base price }\end{array}$ & $\begin{array}{l}42 \\
43\end{array}$ & $\begin{array}{l}\text { UNRCRS } \\
\text { NEWRS2 }\end{array}$ & & $\begin{array}{l}=\quad \text { ONRCRS }^{\circ}=1.10^{h} \\
=\quad \text { NEWRS2 }_{0}^{\circ}=1.10\end{array}$ & $\begin{array}{l}7 .(6,7,11,12,13,14) \\
\text { (natural oil and gas resource } \\
\text { activities) }\end{array}$ \\
\hline 18 & $\begin{array}{l}\text { Ondiscovered recoverable resources; } \\
\text { New resources at twice base price }\end{array}$ & $\begin{array}{l}42 \\
43\end{array}$ & $\begin{array}{l}\text { UNRCRS } \\
\text { NEURS2 }\end{array}$ & & $\begin{array}{l}=\text { UNRCRS } \times 0.90^{\mathrm{h}} \\
=\text { NEWRS2 }_{0}^{\circ} \times 0.90\end{array}$ & (same is Case 17) \\
\hline 19 & $\begin{array}{l}\text { Undiscovered recoverable resources; } \\
\text { New resources at twice base price }\end{array}$ & $\begin{array}{l}42 \\
43\end{array}$ & $\begin{array}{l}\text { UNRCRS } \\
\text { NEWRS2 }\end{array}$ & & $\begin{array}{l}=\text { ONRCRS }^{\circ}=1.30^{h} \\
=\text { NEWRS2 }_{0}^{\mathrm{h}} \times 1.30\end{array}$ & (same as Case 17) \\
\hline 20 & $\begin{array}{l}\text { Ondiscovered recoverable resources; } \\
\text { New resources at twice base price }\end{array}$ & $\begin{array}{l}42 \\
43\end{array}$ & $\begin{array}{l}\text { UNRCRS } \\
\text { NEWRS2 }\end{array}$ & & $\begin{array}{l}=\text { UNRCRS }_{0}=0.70^{\mathrm{h}} \\
=\quad \text { NEWRS2 } \\
0\end{array}$ & ( same as Case 17) \\
\hline 21 & $\begin{array}{l}\text { Undiscovered recoverable resources; } \\
\text { New resources at twice base price }\end{array}$ & $\begin{array}{l}42 \\
43\end{array}$ & $\begin{array}{l}\text { UNRCRS } \\
\text { NEWRS2 }\end{array}$ & & $\begin{array}{l}=\text { ONRCRS }^{\circ} \times 0.70^{h} \\
=\text { NEWRS2 }_{0}^{\mathrm{h}} \times 0.70\end{array}$ & $\begin{array}{l}\text { 7. }(6,11,12) \\
\text { (natural oil gas resource activities) }\end{array}$ \\
\hline 22 & $\begin{array}{l}\text { Depletion sensitivity for resource } \\
\text { cost }\end{array}$ & $(41,43)$ & $C^{i}$ & & $C 2 \times 1.10$ & $\begin{array}{l}\text { 7. }(6,7,11,12,13,14) \text { (natural oil and } \\
\text { gas resource activities) }\end{array}$ \\
\hline 23 & $\begin{array}{l}\text { Depletion sensitivity for resource } \\
\text { cost }\end{array}$ & $(41,43)$ & $\mathrm{c2}^{\mathrm{i}}$ & & $\mathrm{CL}_{\mathrm{i}} \times 0.90$ & (same as Case 22) \\
\hline
\end{tabular}


Income elasticity of demand

Imported crude oil prices:

Imported oil product prices:

Imported natural gas prices

Imported crude oil prices:

Imported oil product prices;

Imported natural gas prices

31 Allocation market share for equal prices

Market share price elasticity

Market share price elasticity

Market share price elasticity

Market share price elasticity

Market share price elasticity

Allocation behavioral 108

Allocation behavioral 108

Allocation behavioral 108

Allocation behavioral 108

41 Market shares for equal prices;

Allocation boheviorel lag

42 Precommercisl pregina/yoar

Capacity factor price sensiejpity
SHSENS

SESENS

SHSENS

BELAG

ROWN

$=$ BASEPR $_{0}^{0} \times 1.50$

ROWN $_{0} \times 0.90$

$\operatorname{GAMMA}(T) 1995)$

POIL ( $T$ >2000) PPROD(T)2000 PGAS (T) 20001

POIL ( $T>2000)$

PPROD ( $T>2000)$

PGAS (T) 2000 )

FREQPR

SHSENS

SHSENS$$
2
$$$$
12.5
$$

$=$ SHSENS $_{\mathrm{0}} \times 1.10$

$=$ SHSENS $_{0} \geq 0.90$

$=$ SHSENS $_{0} \times 1.30$

$=$ BELAG $_{0} \times 0.90$

$=$ BELAG $_{0}$ I 0.90

BELAG

BEAAG

FREQPR

BELAG

$=$ BELAG $_{0} \times 0.70$

$=1 / \mathrm{N}^{1}$

$=$ BELAg $=0.70$

$=0.05^{\mathrm{min}}$

CrSENS $.0 .80^{n}$

CRSENS
$=$ BELAG $_{0} \times 0.70$

$6,(16,17,18,19,23,24)$ and

7.10 (coal and shale oil resource

activities)

6. $(16,17,18,19,23,24)$ and

$7 .(6,7,10,11,12,13,14)$

(all resource activities)

$1.10,2.1,8.5,9.10$

(a11 final demand activities)

10.1 (import activity)

10.1 (import activity)

\section{(a11 allocation activities with}

two or more input 1 inks

$1.12,2,(4,8), 4.1$

$6,(1,2,20,22), 7,9,8,(8,9)$

(all moltiple-supplier allocation activities with SHSENS > 5.0)

$1 .(1,12,15), 2,(4,5,6,7,8), 4.1$

$6,3,7 .(1,2,3,8,9), 8.8,9 .(1,15,17)$

(all multiple supplior allocation activitios $w$ ith SHSENS ( 12.5 )

(all allocation activities with tro or more input links)

(same as Case 34)

(same as Case 34)

$1 .(1,12,15), 2 \cdot(4,5,6,7,8,28), 4,1$, $8,(8,9), 9 .(1,15,17)$

(all demand-sido allocation activitios with two or more input links, including the utility sector)

(same as Case 37)

$6 .(1,2,3,22), 7,(1,2,3,8,9)$

(ail supply-8ido allocation activitios with two or moro input links)

(same as Caso 39)

(the combination of Cases 31 and 40)

(all basic, olectric power, and resonrce conversion activities) 
$4,(6,13,15,16,19,20), 6,(1,0,11,12,13$, $14,15,25,26), 7.10$ (shale oil resource and 11 now-tochnology oloctric otility and egnfuel activitios)

45 Capteal technological chango linit Theral efficiency lialt

46 Roturn on debt

47 Roturn on dobt

48 Retern on equity

49 Retern on debt

so Speciflc capital cost; Spocille oapltal cost
4. $(9,11)$ (o11 and gas-firod boller olectricity genoration)

(ail bastc, olectric powor, and resource conversion ectivitios)

(seme as Caso 46)

(same as Case 46 )

(sime as Caso 46)

$6 .(10,11,12,13,14,15,25,26)$

(alle activttios for eynfuel conversion of conll

"The group sensitivity studies of Sect. IX are keyed to these case numbers.

bs tabulated by Stewart and Goldstein (Ste81). Appendix A.

CThe base case ases a value of 3.0 based on a misinterpretation of the definition (Ste81. Sect. III.B).

dThese values. gield the long-term elasticity of -0.5 and the approximately 4-year 1ag intended by the modeler. The Model 22 values were -0.1 and 0.8 (Ste81).

"The notation "1..10" is to be resd Sector 1, Activity 10. The notation 7,(6,7,...) means Sector 7, Activity 6; Sector 7, Activity $7 ; \ldots .$.

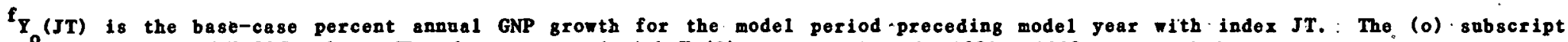
refers to the Hode'l 22C value. The change started with $Y_{0}(3)$ representing the 1981 - 1985 time period.

Bhis chenge scales the resource cost curve by the indicated constent factor for all values of resource depletion.

${ }^{h}$ If the resource cost curve is written as Cost $=$ INRCST[1.00+.(N/N) $]^{C 2}$, where INRCST is the model's initial resource cost parameter and $N$ is the cumalative comitment to reserves for production, $\bar{N}$ is the parameter varied by these changes. It represents the reserve commitment at which the resource cost is doubled, based on present technology.

ithe LEAP model parameter C2, shown in the equation for footnote $h$, is computed from resource data parameters including BASEPR(41) and NEWRS2(43) (Ste81, e. A-65, shows the case UCCF = NCCF $=C_{c}$ ). These two parameters were altered simultaneously to perturb C2 without changing the $N$ of footnote $h$.

J The FORTRAN name GAMA has more than one dse in tho DEMAND submodel. Here GaMaA refers to its first pase.

The energy import price increase continues the trend assumed in earlier years in Model 22C. (The decrease is interesting mostly as a linearity test.)

1 Here $N$ is the number of suppliers' for the allocator. Changes were required only. for activities for which FRePR was not already the same for each input link.

"This relative preming is set at 0,10 in Model $22 \mathrm{C}$.

necanse of a computer program override discessed by Stewart and Goldstein (Ste81; Sect. III.D). the.relative change reaching the basic converstion wodel was only 0.896. The resource extraction models, howerer, accepted the indicated change.

${ }^{\circ}$ For Model 22C, these parameters heve the value CLIM $=2.0,2.0$; ERLIM $=1.21,1.21$, respectively.

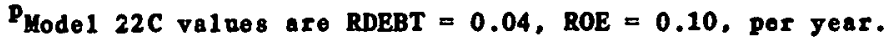


ORNL-574i

INTERNAL DISTRIBUTION

1-2. L. S. Abbott

3. R. G. Alsmiller, Jr.

4. F. S. Alsmiller

5. S. J. Auerbach

6.. J. Barhen

7. J. Barish

8. D. E. Bartine

9. M. A. Bjerke

10. D. Bjornstad

11. D. G. Cacuci

12. S. Cantor

13. G. de Saussure

14. D. J. Downing

15-39. EPIC

40. G. F. Flanagan

41. W. E. Ford, III

42. W. Fulkerson

43. D. A. Gardiner

44. D. Gilal

45. H. Goldstein (Consultant)

46. M. Goldstein

47. D. Greene

48. P. M. Haas

49. E. Halbert

50. M. C. G. Hall

51.: L. Hill

52. E. Hirst

53. J. Horwede1.

54. D. T. Ingersoll

55. J. M. Kallfelz

56-65. A. S. Loeb1

66.: J. L. Lucius

67. B. J. Jacobs

68. F. C. Malenschein

69. J.,. J. Manning

70. J..H. Marable

7i. B. F. Maskewitz

72. B. D. Murphy

73. F. R. Mynatt

74. E.: M. Oblow
75. J. V. Pace

76. S. C. Parikh

77. C. V. Parks

78-87. R. W. Peelle

88. F. G. Perey

89. R. B. Perez

90. R. Pevey

91. Y. Ronen

92. M. W. Rosenthal

93. R. W. Roussin

94. R. T. Santoro

95. D. L. Selby

96. R. Sharma

97. R. B. Shelton

98. L. Stewart

99. C. Thomas

100. B. C. Toney

101. J. Trimble

102. D. K. Trubey

103. D. R. Vondy

104. E. Wacholder

105. J. J. Wagschal

106. C. F. Weber :

107-116. C. R. Weisbin

117. L. W. Weston

118. J. R. White

119. G. E. Whitesides

120. T. J. Hilbanks

121. M. L. Williams

122. R. Q. Wright

123. A. Zucker

124. P. Greebler (Consultant)

125. H. J. C. Kouts (Consultant)

126. W. B. Loewenstein (Consultant)

127. R. Wilson (Consultant)

128-129. Central Research Library

130. ORNL Y-12 Technical Library -

Document Reference Section

131. Laboratory Records

132. ORNL Patent Office

133. Laboratory Records - RC 
EXTERNAL DISTRIBUTION

134. Office of Assistant Manager for Energy Research and Development, DOE-ORO, Oak Ridge, TN 37830

135. R. L. Basmann, Department of Economics, Texas A\&M Uníversity, College Station, Texas 77843

136. M. Becker, Dept. of Nuclear Engineering, Rensselaer Polytechnic Institute, Tibbets Avenue, Troy, NY 12181

137. D. J. Beecy, Office of Foss11 Energy, MS C-125, U. S. Department of Energy, Washington, DC 20545

138. W. G. Bentley, Florida Power and Light Company, P.0. Box 529100, Miami, FL 33152

139. Y. Bishop, Energy Information Administration, U.S. Department of Energy, 12th and Pennsylvania Avenue, NW, Washington, DC 20461

140. J. Blankenship, Forrestal Bullding, MS-7E/088, U.S. Department of Energy, Washington, DC 20585

141. J. Braitsch, Office of Fossil Energy, U.S. Department of Energy, Germantown, Washington, DC 20545

142. T. E. Browne, Energy Supply Studies Program, Electric Power Research Institute, P.0. Box 10412, Palo Alto, CA 94303

143. E. Cazalet, Decision Focus, Incorporated, 5 Palo Alto Square, Sulte 410, Palo Alto, CA 94303

144. R. Gene Clark, Office of Energy Information, U. S. Department of Energy, Federal Bullding, 12th and Pennsylvania Avenue, NW Washington, DC 20461

145. S. Cohen, Energy Information Administration, U, S. Dept. of Energy, 12th and Pennsylvania Ave. NW Washington, DC. 20461

146. C. Cornett, Energy Information Administration, U. S. Depàtment of Energy, 12th and Pennsylvania Ave., NW, Washington, DC 20461

147. C. W. Craven, Science Applications, Inc., 800. Oak Ridge Turnpike, Building C, Suite 100, Oak Ridge, TN 37830

148. Robert Crockett, Energy Information Administration, U. S. Department of Energy, 12th and Pennsylvania Ave., NW, Washington, DC 20461

149. R. Dahlman, Office of Energy Research, U.S. Department of Energy, Germantown, Washington, DC 20545 
150. R. A. Diedrich, Energy Information Administration, U.S. Department of Energy, 12th and Pennsylvania Avenue, NW, Washington, DC 20461

151. R. C. Dieh1, Aerojet Energy Conversion Co., P.0. Box 13222, Sacramento, CA, 95813

152. Energy Systems Library, Brookhaven National Laboratory, Building 475, Upton, Long Island, NY 11973

153. J. Evered; Energy Information Administration, U.S. Department of Energy, 12th and Pennsylvania Avenue, NW, Washington, DC 20461

154. R. T. Eynon, Energy Information Administration, U.S. Department of Energy, Federal Building, 12th and Pennsylvania Avenue, NW, Washington, DC 20461

155. J. Eyster, Energy Information Administration, U.S. Department of Energy, Federal Building, 12th and Pennsylvania Avenue, NW, Washington, DC 20461

156. R. C. Fair, Department of Economics, Yale University, 206 Elm Street, New Haven, Connecticut 06520

157. J. Finucane, Energy Information Administration, U.S. Department of Energy, 12th and Pennsylvania Avenue, NW, Washington, DC 20461

158. A. Ford, Los Alamos Scientific Laboratory, P.0. Box 1663, Los Alamos, NM, 87545

159. D. Freedman, Professor of Statistics, University of California, Berkeley, CA 94708

160. S. I. Gass, College of Business and Management, Un1versity of Maryland, College Park, Maryland 20742

161. Donald Gantzer, U.S. Department of Energy, Federal Building, Room 4447, 12th and Pennsylvania Avenue; Washington, DC 20461

162. J. C. Geidl, Energy Information Administration, U.S. Department of Energy, 12th and Pennsylvania Avenue, NW, Washington, DC 20461

163. 0. Gildersleeve, E]ectric Power Research Institute, 3412 Hillview Ave., Palo Alto, CA 94303

164. C. R. Glassey, University of California Berkeley, 1163 Keeler Avenue, Berkeley, CA 94708

165. Neil Goldman, Energy Laboratory, Massachusetts Institute of Technology, Cambridge, Massachusetts 02139

166. L. Gordon, Energy Information Adminietration, U.S. Department of Energy, Federal Building, 12th and Pennsylvania Avenue, NW, 20461 
167. H. J. Greenberg, U. S. Department of Energy, 12th and Pennsylvanid Avenue, NW, Washington, DC 20461

168. M. Greenberger, Stanford University Graduate School of Business, Room 383, Stanford, CA 94305

169. E. Greenspan, University of Illinois, Nuclear Engineering Program, 214 Nuclear Engineering Laboratory, Urbana, IL 61801

170. James Gruhl, Energy Model Analysis Program, Model Validation Group, MIT Energy Laboratory, Cambridge, Massachusetts 02138

171. N. Gruh1, 142 Plain Road, Wayland, Massachusetts 01778

172. D. E. Hale, Energy Information Administration, U.S. Department of Energy, 12th and Pennsylvania, NW, Washington, DC 20461

173. John Hansen, Charles River Associates, 200 Clarendon Street, Boston, MASS 02116

174. C. Harris, Center for Management \& Policy Research, 1625 "I" Street, NW Washington, DC 20006

175. J. Hausman, Economics Department, E-52, Massachusetts Institute of Technology, Cambridge, MASS 02139

176. W. W. Havens, Columbia University, 520 West 120th Street, New York, NY 10027

177. W. W. Hogan, Harvard University, 79 Boylston Street, Cambridge, MASS 02138

178. Mary Hutzler, Energy Information Administration, 12th and Pennsylvania Avenue, NW, Washington, DC 20461

179. R. H. F. Jackson, Center for Applied Mathematics, U.S. Department of Commerce, National Bureau of Standards, Washington, DC 20234

180. C. W. Kilgore, Energy Information Administration, U.S. Department of Energy, 12th and Pennsylvania Avenue, NW Washington, DC 20461

181. F. A. Koomanoff, Office of Energy Research, U.S. Department of Energy, Germantown, Washington, DC 20545

182. D. Kresge, 53 Church Street, Cambridge, MASS 02138

183. G. M. Lady, Energy Information Administration, U.S. Department of Energy, 12th and Pennsylvania Avenue, NW, Washington, DC 20461

184. Joel Lambert, National Bureau of Standards, Building 101, Washington, DC 20234 
185. C. J. Lee, Department of Economics, Knox College, Galesburg, IL 61401

186. A. Linden, Jr., Energy Information Administration, U.S. Department of Energy, 2000 M Street, Washington, DC. 20545

187. T. V. Long, II, University of Chicago, The Committee on Public Policy Studies, 1050 E. 59th Street, Chicago, IL 60637

188. M. D. McKay, Los Alamos National Laboratory, P.0. Box 1663, Los Alamos, NM 87545

189. D. L. McNicol, Energy Information Administration, U.S. Department of Energy, 12th and Pennsylvania Avenue, NW, Washington, DC 20461

190. R. H. Males, Director, Energy Systems, Environment and Conservation Division, Electric Power Research Institute, 3412 Hillview Avenue, P.0. Box 10412, Palo Alto, CA 94303

191. R. A. Marshalla, Decision Focus, Inc., 5 Palo Alto Square, Suite 410, Palo Alto, CA 94303

192. Lynn Maxwe11, Chief, Power Planning Staff, 300 Chestnut Street Towers, Chat tanooga, TN 37401

193. F. H. Murpliy, Energy Information Administration, U.S. Deparment of Energy, 12th and Pennsylvania Avenue, NW, Washington, DC 20461

194. R. F. Naill, Policy and Evaluation, PE-52, 1000 Independence Avenue, Washington, 'DC- 20585

195. D. M. Nesbitt, Decision Focus, Inc., 5 Palo Alto Square, Suite 410, Palo Alto, CA 94304

196. David Nissen, Chase Manhattan Bank, 1 Chase Manhattan Plaza, New York, NY 10015

197. E. Oatman, Electric Power Research Institute, 3412 Hillview Avenue, P.0. Box 10412, Palo Alto, CA 94303

198. Richard P. O'Neill, Energy Information Administration, U.S. Department of Energy, 12th and Pennsylvania Avenue, NW, Washington, DC 20461

199. John Pearson, Energy Information Administration, U.S. Department of Energy, 12th and Pennsylvania Avcnue, NW, Washlngton, DC 20461

200. Charles Perry, Office of Fossil Energy, U.S. Department of Energy, Germantown, Washington, D.C. 20545

201. J. L. Peterson, Energy Information Administration, U.S. Department of Energy, 12th and Pennsylvania Avenue, NW, Washington, DC 20461 
202. R. Phillips, Decision Focus, Inc., 5 Palo Alto Square, Suite 410, Palo Alto, CA 94303

203. J. Platt, Electric Power Research Institute, 3412 Hillview Avenue, P.0. Box 10412, Palo Alto, CA 94303

204. B. Poole, Energy Information Administration, U.S. Department of Energy, 12th and Pennsylvania Avenue, NW, Washington, DC 20461

205. J. M. Power, Policy and Evaluation, 1000 Independence Avenue, Washington, DC 20585

206. J. Rambo, Lawrence Livermore Laboratory, University of California, Livermore, CA 94550

207. Richard Richels, Electric Power Research Institute, 3412 Hillview Avenue, P.0. Box 10412, Palo Alto, CA 94303

208. M. Riches, Office of Energy Research, U.S. Department of Energy, Germantown, Washington, DC 20545

209. Fred S. Roberts, Rutgers University, Department of Mathematics, New Brunswick, NJ 08903

210. M. E. Rodekohr, Energy Information Administration, U.S. Department of Energy, 12th and Pennsylvania Avenue, NW, Washington, DC 20461

211. D. J. Rose, Dept. of Nuclear Engineering, Massachusetts Institute of Technology, Cambridge, MA 02139

212. L. Rubin, Electric. Power Research Institute, 3412 Hillview Avenue, P.0. Box 10412, Palo Alto, CA 94034

213. Roy Shanker, Resource Planning Associates, 1901 "L" Street, NW, Washington, DC 20036

214. John B. Shewmaker, Energy Information Administration, U.S. Department of Energy, 1000 Independence Avenue, Washington, DC 20461

215. Scott Sitzer, Energy Information Administration, U.S. Department of Energy, 12th and Pennsylvania Avenue, NW, Washington, DC 20461

216. W. Smith, Energy Information Administration, U.S. Department of Energy, 12th and Pennsylvania Avenue, NW, Washington, DC 20461

217. James Sweeney, Energy Modeling Forum, Stanford University, Stanford, CA 94305

218. J. E. Todd, Energy Information Administration, U.S Department of Energy, 12th and Pennsylvania Avenue, NW, Washington, DC 20461

219. J. Weatherly, Institute of Gas Technology, 3424 S. State Street, Chicago, IL 60601 
220. A. M. Weinberg, Institute for Energy Analysis, Oak Ridge Associated Universities, Oak Ridge, TN 37830

221. P. Werbos, Office of Energy Information Validation, U.S. Department of Energy, 12th and Pennsylvania Avenue, NW, Washington, DC $\cdot 20461$

222. D. O. Wood, Energy Laboratory E-38, 418, Massachusetts Institute of Technology, Cambridge, MA 02139

223. J. Zalkind, Energy Information Administration, U.S. Department of Energy, 12th and Pennsylvania Avenue, NW, Washington, DC 20461

224. C. J. Anderson, Lawrence Livermore National Laboratory, MS-L216, P. O. Box 808, Livermore, CA 94550

225. R. B. Be11, Lawrence Livermore National Laboratory, MS-L216, P. 0 . Box 808 , L1vermore, CA 94550

226-252. Technica1 Information Center (TIC)

253. Office of Assistant Manager for Energy Research and Development, Oak Ridge Operations, DOE, Oak Ridge. 